Marlene de Freitas Madeira

\title{
Diagnóstico bioquímico das síndromes de deficiência de creatina
}

Tese apresentada à Faculdade de Medicina da Universidade de São Paulo para obtenção do título de Doutor em Ciências

Área de concentração: Neurologia Orientador: Prof. Dr. Fernando Kok

São Paulo 
Marlene de Freitas Madeira

\section{Diagnóstico bioquímico das síndromes de deficiência de creatina}

Tese apresentada à Faculdade de Medicina da Universidade de São Paulo para obtenção do título de Doutor em Ciências

Área de concentração: Neurologia Orientador: Prof. Dr. Fernando Kok

São Paulo 
Dados Internacionais de Catalogação na Publicação (CIP)

Preparada pela Biblioteca da

Faculdade de Medicina da Universidade de São Paulo

Creprodução autorizada pelo autor

Madeira, Marlene de Freitas

Diagnóstico bioquímico das síndromes de deficiência de creatina / Marlene de Freitas Madeira. -- São Paulo, 2010.

Tese(doutorado)--Faculdade de Medicina da Universidade de São Paulo.

Departamento de Neurologia.

Área de concentração: Neurologia.

Orientador: Fernando Kok.

Descritores: 1.Creatina/deficiência 2.Creatina/genética 3.Guanidinoacetato 4.Espectrometria de massas em tandem 5.Cromatografia líquida 6.Técnicas e procedimentos de laboratório

USP/FM/SBD-039/10 


\section{Dedicatória}

Dedico este trabalho a minha família e aos meus amigos, pelo tempo de nossa convivênia que lhes tomei durante toda a sua elaboração e, de forma especial, a Milene Zakzuk (in memorian) que me fez ver quão felizes nós somos simplesmente por estarmos aqui. 


\section{Agradecimentos}

Agradeço a Deus em primeiro lugar e sempre, por tudo que tenho e sou. Pela Sua bondade e Sua presença na minha vida. Deus é muito nosso amigo: se nos coloca diante de desafios, também nos mune de força e dos meios para transpô-los. E nesta caminhada não poderia ser diferente: diante da oportunidade e do desafio de desenvolver este trabalho contei com a ajuda e a colaboração de muitas pessoas. Então, esta conquista não é apenas minha, mas de todos nós. Tê-los comigo tornou tudo mais fácil, por isso, agradeço a vocês,

Meus pais, Fernanda e Manuel a quem devo tanto! Obrigada pelo apoio, carinho e exemplo que têm me dado sempre;

Minhas irmãs, Nélia, Cristina e Carolina, obrigada por todo o apoio, carinho e incentivo neste e em todos os momentos da minha vida. Obrigada por estarem sempre comigo;

Meus sobrinhos, Ana Beatriz (Bia) Júlia Carolina (Juju), Gabriella (Gabi) e Rafael Lorenzo (Lolo) porque vocês são luz, alegria e motivação na minha vida;

Amigos do Serviço de Laboratório do Hospital Universitário, em particular, Ana Cristina (Cori) e Carolina (Carol) que tornaram esta caminhada mais suave me dando suporte, incentivo e apoio em todos os momentos. A Marilice (Lisinha), Lucilene (Luci), Daniel (Dani boy), Valdir, Elaine, Lilian (Lilinha), Sueli (Sussu), lára (Turini), Maria Claudia (Clau) e Wagner (Nenê) agradeço imensamente pelo apoio e colaboração;

Dra. Marina B. Martinez agradeço por ter feito por mim, e de maneira tão espontânea, muito mais do que eu poderia esperar; 
Minhas amigas de além-mar, Carla Valongo, Ligia Almeida, Célia Nogueira, Sofia Esteves, Mariana e Dra. Laura Vilarinho. Obrigada por sua contribuição na minha formação e pela maneira carinhosa e sem restrições com que me receberam em seu laboratório e em sua casa no Porto;

Dr. Charles Marques Lourenço por seu empenho e colaboração na triagem de pacientes e encaminamento de amostras para a realização deste projeto;

Aos amigos do Fleury, agradeço pela compreensão e apoio;

A Maria Alice Rabello pelas orientações na formatação das referências;

A Giselda Bortoletto pela revisão do texto;

Agradeço às Instituições que apoiaram este projeto: ao Departamento de Neurologia da Faculdade de Medicina da Universidade de São Paulo, ao Grupo Fleury e ao Hospital Universitário da USP;

Agradeço profundamente aos pacientes e seus familiares por terem compreendido a importância de colaborar em um projeto desta natureza mesmo sabendo que poderiam não se beneficiar diretamente dele no sentido de encontrar uma resposta para o problema que os aflige.

E vocês, meus amigos, deixo-os por último porque estiveram comigo desde o início e comigo encerram este ciclo:

Obrigada, Dr. Fernando Kok, meu orientador e amigo pelo presente que me deu ao me oferecer a oportunidade de realizar este trabalho sobre um tema que me encantou. Obrigada pela confiança, por todo apoio e por essa convivência tão serena e carinhosa;

Dra. Karina H. Cardozo, agradeço não só por toda a sua inestimável 
colaboração, mas por todo apoio, incentivo e pelo carinho da sua amizade;

E a você, Dr. Valdemir Melechco Carvalho, meu amigo Val, o que posso dizer? Se não foi meu co-orientador de direito, o foi de fato, o que torna ainda mais especial tudo o que você fez e faz por mim. Obrigada pela generosidade e disposição com que você compartilha o seu conhecimento. Sem a sua ajuda, certamente não teríamos chegado até aqui.

Então, amigos, vocês me deram a oportunidade e os meios e isso, não tem preço. Obrigada por tudo. 
Esta dissertação está de acordo com as seguintes normas, em vigor no momento desta publicação:

Referências: adaptado de International Committee of Medical Journals Editors (Vancouver).

Universidade de São Paulo. Faculdade de Medicina. Serviço de Biblioteca e Documentação. Guia de apresentação de dissertações, teses e monografias. Elaborado por Annelise Carneiro da Cunha, Maria Júlia A. L. Freddi, Maria F. Crestana, Marinalva de Souza Aragão, Suely Campos Cardoso, Valéria Vilhena. 2a ed. São Paulo: Serviço de Biblioteca e Documentação; 2005.

Abreviaturas dos títulos de periódicos de acordo com List of Journals Indexed in Index Medicus.

Reforma ortográfica da língua portuguesa de 29/09/2008. 


\section{SUMÁRIO}

Lista de figuras

Lista de tabelas

Lista de abreviaturas e siglas

Resumo

Summary

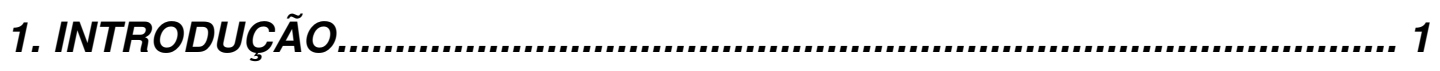

1.1. Creatina: Biossíntese e função...................................................... 1

1.2. Doenças associadas à deficiência na síntese ou transporte de

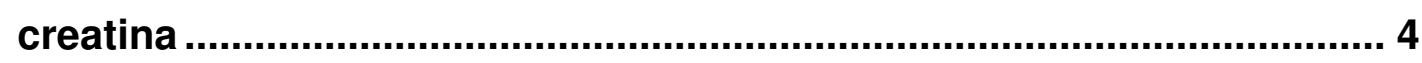

1.3. Diagnóstico das síndromes de deficiência de creatina.................... 6

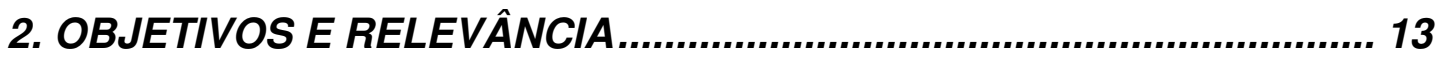

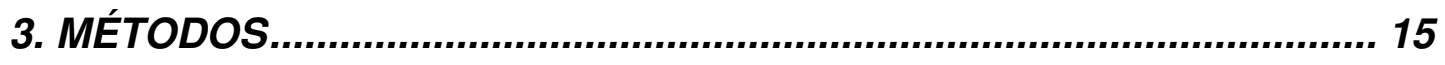

3.1. Reagentes e materiais ..............................................................15

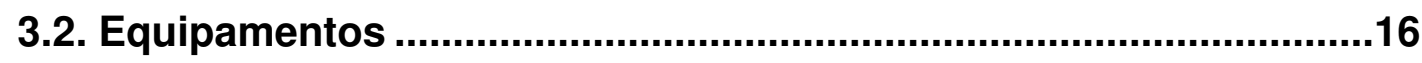

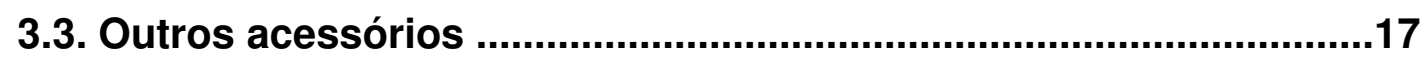

3.4. Preparo das soluções padrão e curva de calibração........................18

3.4.1. Soluções-padrão primárias ……………………………......18

3.4.2. Soluções-padrão secundárias ................................................18

3.4.3. Outras soluções- padrão.....................................................19

3.4.4. Amostras para lineridade e curva de calibração em água.........20

3.4.5. Curva de calibração em $\mathrm{NaCl} 0,15 \mathrm{~mol} / \mathrm{L}$.................................20

3.4.6. Amostras adicionadas de padrões ..........................................20

3.5. Análises por espectrometria de massas em tandem.......................24

3.6. Desenvolvimento do método cromatográfico ................................25 
3.6.1. Separação cromatográfica .25

3.6.2. Avaliação do efeito elutrópico 27

3.6.3. Acoplamento da cromatografia líquida a espectrometria de massas em tandem.

3.7. Desenvolvimento do método de extração .28

3.7.1. Avaliação inicial do protocolo de extração e definição do sistema de drenagem dos eluatos.... 29

3.7.2. Avaliação das soluções para eluição de interferentes ácidos e alcalinos 30

3.7.3. Avaliação do meio de preparo da amostra. 31

3.7.4. Avaliação do volume e concentração de base para eluição......31

3.7.5. Avaliação preliminar da sensibilidade de detecção sem extração em fase sólida. 32

3.7.6. Avaliação da inserção de uma etapa de concentração da amostra 33

3.7.7. Avaliação da linearidade em padrões aquosos. .33

3.8. Extração em fase sólida com matriz urinária 34

3.8.1. Definição do volume da amostra para extração em resina SCX34 3.8.2 Avaliação preliminar de limite de quantificação em matriz urinária. 35

3.8.3. Avaliação preliminar da recuperação do ensaio em matriz urinária 36

3.8.4. Comparação das extrações de urina em resina SCX (sílica) e

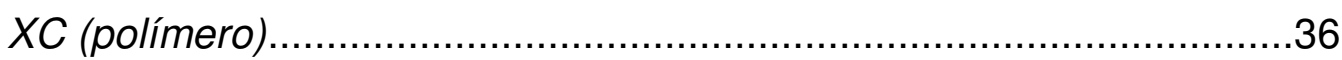

3.8.5. Definição dos volumes de extração em resina XC....................37

3.9. Extração em fase sólida com matriz de soro ou plasma.................37

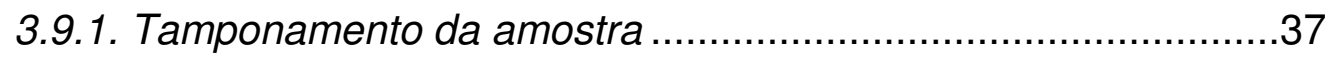

3.9.2. Contribuição da extração em SPE no sinal dos analitos em soro/plasma

3.9.3. Avaliação da eficiência da remoção de proteínas pela extração39 


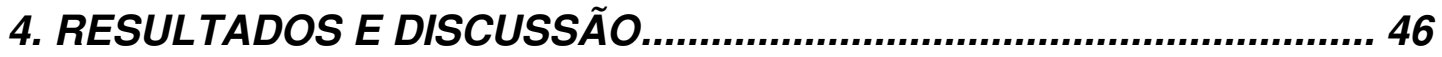

4.1. Análises por espectrometria de massas em tandem.......................46

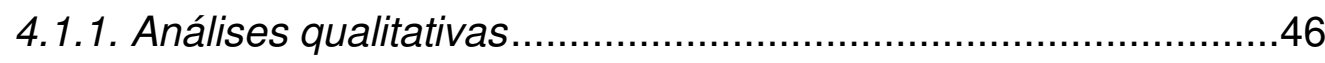

4.1.2. Adequação das condições de detecção por espectrometria de

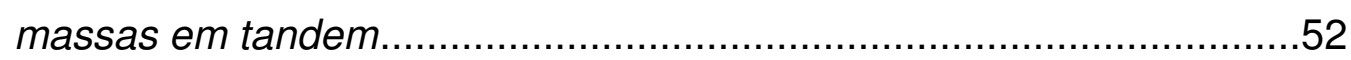

4.2. Desenvolvimento do método cromatográfico .................................54

4.2.1. Avaliação da separação cromatográfica .................................55

4.2.2. Acoplamento da cromatografia líquida à espectrometria de

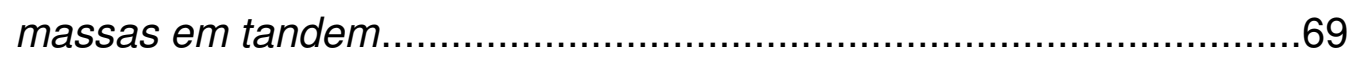

4.3. Desenvolvimento do método de extração da amostra .....................74 4.3.1. Avaliação inicial do protocolo de extração e definição do sistema de drenagem dos eluatos ...................................................76

4.3.2. Avaliação das soluções para eluição de interferentes ácidos e

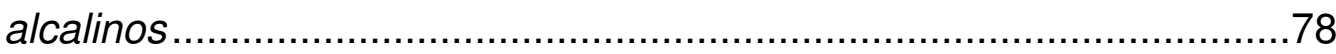

4.3.3. Avaliação do meio de preparo da amostra...............................80

4.3.4. Avaliação do volume e concentração da base para eluição.......80

4.3.5. Avaliação da inserção de uma etapa de concentração da

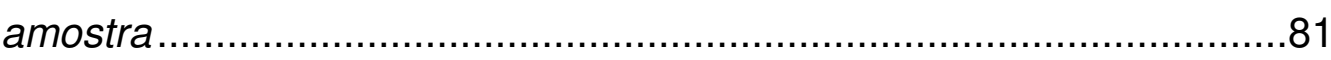

4.3.6. Avaliação preliminar da linearidade em padrões aquosos .........82

4.4. Extração em fase sólida com matriz urinária ...................................83

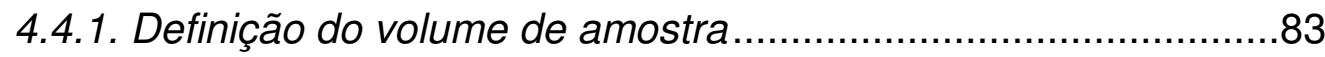

4.4.2. Avaliação preliminar de limite de quantificação em matriz

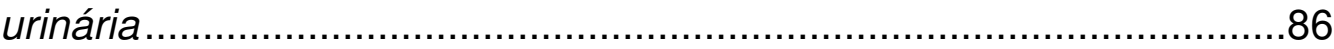

4.4.3. Avaliação preliminar da recuperação do ensaio em matriz

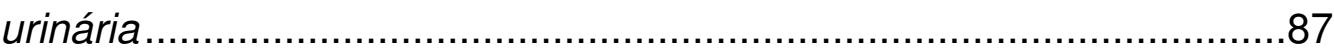

4.4.4. Comparação do desempenho das extrações de urina em resina SCX (sílica) e XC (polímero)............................................................... 89

4.5. Extração em fase sólida com matriz de soro ou plasma................92

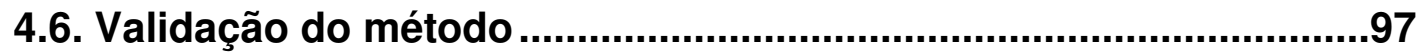


4.7. Avaliação das amostras dos participantes do estudo..

5. CONCLUSÕES E CONSIDERAÇÕES FINAIS

6. ANEXOS

7. REFERÊNCIAS 


\section{LISTA DE FIGURAS}

Figura 1. Fosforilação reversível da creatina por ATP e formação de

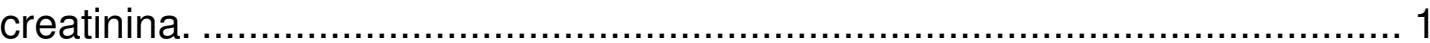

Figura 2. Via de biossíntese de creatina............................................... 3

Figura 3. Espectroscopia por ressonância magnética de prótons do encéfalo de um indivíduo normal. Mio: mioinositol; Co: colina; CRE: creatina e NAA: $\mathrm{N}$-acetil-aspartato

Figura 4. Algoritmo de diagnóstico laboratorial dos defeitos da biossíntese ou transporte de creatina (adaptado de Verhoeven e colaboradores) ${ }^{2}$. 10 Figura 5 - Mecanismo de fragmentação proposto para a creatina $(\mathrm{m} / \mathrm{z} 132)$ e guanidinoacetato $(\mathrm{m} / \mathrm{z} 118)$.

Figura 6 - Espectros de dissociação da creatinina $(\mathrm{m} / z$ 114) obtidos com diferentes energias de colisão: $5 \mathrm{eV}, 10 \mathrm{eV}, 15 \mathrm{eV}, 20 \mathrm{eV}, 25 \mathrm{eV}$ e $30 \mathrm{eV}$....50 Figura 7 - Espectros de dissociação da GAA- $d_{2}$ protonado $(m / z 120)$ obtidos com diferentes energias de colisão: $5 \mathrm{eV}, 10 \mathrm{eV}, 15 \mathrm{eV}, 20 \mathrm{eV}, 25 \mathrm{eV}$ e 30 eV.

Figura 8. Espectros de dissociação da creatina- $d_{3}$ protonada $(\mathrm{m} / \mathrm{z} 135)$ obtidos com diferentes energias de colisão: $5 \mathrm{eV}, 10 \mathrm{eV}, 15 \mathrm{eV}, 20 \mathrm{eV}, 25 \mathrm{eV}$ e $30 \mathrm{eV}$.

Figura 9. Espectros de dissociação da creatinina- $d_{3}$ protonada $(\mathrm{m} / \mathrm{z} 117)$ obtidos com diferentes energias de colisão: $5 \mathrm{eV}, 10 \mathrm{eV}, 15 \mathrm{eV}, 20 \mathrm{eV}, 25 \mathrm{eV}$ e $30 \mathrm{eV}$.

Figura 10. Cromatograma obtido pelo método A (Tabela 4). A: guanidinoacetato e B: creatina

Figura 11. Cromatograma obtido pelo método B (Tabela 4 de Materiais e Métodos). A: guanidinoacetato e B: creatina.

Figura 12. Perfil cromatográfico obtido pela injeção do padrão a $0,1 \mu \mathrm{g} / \mathrm{mL}$ diluído em água de A: guanidinoacetato e B: creatina. .58

Figura 13. Perfil cromatográfico obtido pela injeção de padrão a $0,1 \mu \mathrm{g} / \mathrm{mL}$

diluído em ACN de A: guanidinoacetato e B: creatina. 58

Figura 14. Gráfico da resposta em área e largura à meia altura $\left(\mathrm{W}_{0,5}\right)$ da 
creatina em função da concentração de formiato de amônio utilizado na fase móvel.

Figura 15. Gráfico da resposta em área e largura a meia altura $\left(\mathrm{W}_{0,5}\right)$ do GAA em função da concentração de formiato de amônio utilizado na fase móvel. 60

Figura 16. Cromatograma obtido com método $D$ (Tabela 4 de Materiais e Métodos). A: guanidinoacetato e B:creatina.

Figura 17. Cromatograma obtido com método E (Tabela 4 de Materiais e Métodos). A: guanidinoacetato e B: creatina. 62

Figura 18. Cromatograma obtido com método $F$ (Tabela 4 de Matériais e Métodos). A: guanidinoacetato e B: creatina. 62

Figura 19. Cromatograma obtido com método $C$ (Tabela 4 de Materiais e Métodos). A: guanidinoacetato e B: creatina. 64

Figura 20. Cromatograma obtido com método $\mathrm{F}$ (Tabela 4 de Materiais e Métodos). A: guanidinoacetato e B: creatina.

Figura 21. Cromatogramas obtidos com diferentes colunas empregando 0 método $\mathrm{F}$ (Tabela 4 de Materiais e Métodos). A: guanidinoacetato e B: creatina.

Figura 22. Áreas obtidas com as diferentes colunas avaliadas. .68 Figura 23. Larguras a meia altura obtidas com as diferentes colunas avaliadas

Figura 24. Dados de resposta dos compostos creatina e guanidinoacetato em função da temperatura da fonte. .70 Figura 25. Dados de resposta dos compostos creatina e guanidinoacetato em função da temperatura da coluna. .71 Figura 26. Dados de resposta dos compostos creatina e guanidinoacetato em função da temperatura de dessolvatação. .72

Figura 27. Dados de resposta dos compostos creatina e guanidinoacetato em função do fluxo do gás de dessolvatação. .73 Figura 28. Sequência de preparação das placas de 96 poços com a utilização do sistema Multiscreen ${ }^{\circledR}$ Column loader $100 \mu \mathrm{L}$ da Millipore ${ }^{\circledR}$.......76 Figura 29. Gráfico relacionando resposta em área em função da 
concentração e volume de $\mathrm{NH}_{4} \mathrm{OH}$. Detalhes de cada extração estão

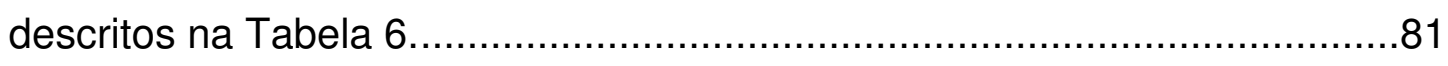

Figura 30. Comparação das respostas para creatina após extração em

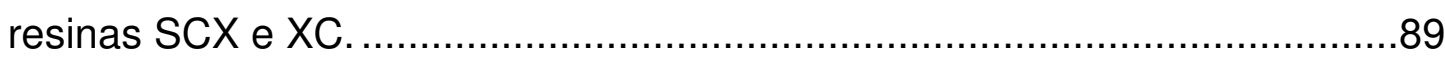

Figura 31. Comparação das respostas para GAA após extração em resinas

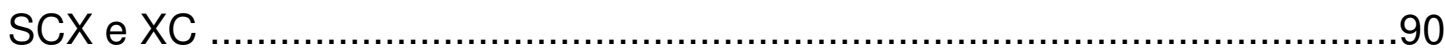

Figura 32. Comparação das respostas para creatina obtidas após extração de volumes de 5, 10 e $50 \mu \mathrm{L}$ de amostra em resina XC..............................91 Figura 33. Comparação das respostas para GAA obtidas após extração de volumes de 5,10 e $50 \mu \mathrm{L}$ de amostra em resina XC.................................92

Figura 34. Áreas obtidas para creatina com e sem extração por SPE...........94 Figura 35. Áreas obtidas para GAA com e sem extração por SPE................95 


\section{LISTA DE TABELAS}

Tabela 1. Alterações bioquímicas observadas nas síndromes de deficiência

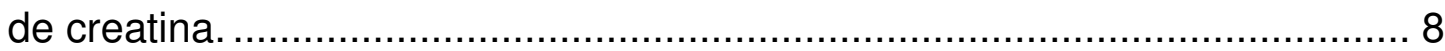

Tabela 2. Preparo das amostras para validação em soro............................22

Tabela 3. Preparo das amostras para validação em urina............................23 Tabela 4. Métodos avaliados por HPLC para as análises de creatina e guanidinoacetato

Tabela 5. Protocolos de avaliação das condições de lavagens de interferentes ácidos e alcalinos. (Amostra: solução de creatina, GAA e deuterados a $10 \mu \mathrm{g} / \mathrm{mL}$ em ácido fórmico a $25 \mathrm{mmol} / \mathrm{L}$ ).

Tabela 6. Avaliação do volume e concentração da base para a eluição dos analitos (Amostra: solução de creatina, GAA e deuterados a $100 \mu \mathrm{g} / \mathrm{mL}$ em tampão fosfato $25 \mathrm{mmol} / \mathrm{L} \mathrm{pH} \mathrm{1,9)....}$

Tabela 7. Descrição dos pacientes incluídos no estudo quanto a idade, sexo, consanguinidade parental e quadro clínico.

Tabela 8. Transições de massas selecionadas como quantificadoras e qualificadoras para creatina, guanidinoacetato, creatinina, creatina- $d_{3}$, guanidinoacetato- $d_{2}$ e creatinina- $d_{3}$.

Tabela 9. Condições de aquisição e transições selecionadas para cada um dos analitos

Tabela 10. Larguras a meia altura dos picos $\left(\mathrm{W}_{0,5}\right)$ de creatina e guanidinoacetato e fator de retenção ou capacidade $(k)$ obtidos nos três exemplos de gradientes descritos na Tabela 4 de Materiais e Métodos.

Tabela 11. Larguras a meia altura dos picos $\left(\mathrm{W}_{0,5}\right)$ de creatina e guanidinoacetato obtidos nas condições isocrática (método C, Tabela 4) e gradiente (método F, Tabela 4 de Materiais e Métodos).

Tabela 12. Condições de acoplamento da cromatografia líquida com espectrometria de massas.

Tabela 13. Valores de guanidinoacetato esperados e obtidos em extrações de diluições de amostra de urina (U) com urina sintética (US), volume:volume. 
Tabela 14. Resultados esperados e obtidos para creatina em extrações de diluições de amostra de urina (U) com $\mathrm{NaCl}$ 0,15 M (volume:volume).

Tabela 15. Resultados dos testes preliminares de recuperação em urina pura e adicionada de padrões de creatina e guanidinoacetato .88

Tabela 16. Extremos de valores de referência para creatina e guanidinoacetato encontrados na literatura expressos em $\mu \mathrm{g} / \mathrm{mL}$ e $\mu \mathrm{mol} / \mathrm{L}{ }^{41}$, 51-55 .93

Tabela 17. Dados de validação nas matrizes de urina e soro. .98

Tabela 18. Dados de desempenho de métodos descritos na literatura. 99

Tabela 19. Valores de referência para creatina e GAA adotados no IGMJM ${ }^{51}$ e na Mayo Clinic $^{55}$ 101

Tabela 20. Valores de creatina e GAA obtidos no IGMJM e pelo método proposto (unidade: $\mu \mathrm{mol} / \mathrm{L}$ ). 102

Tabela 21. Valores de creatina e GAA obtidos na Mayo Clinic e pelo método proposto (unidade: $\mu \mathrm{mol} / \mathrm{L}$ ). 103

Tabela 22. Valores de referência em urina definidos para o novo método $($ Crtnn $=$ creatinina $)$. 105

Tabela 23. Valores de referência em soro definidos para o novo método...105 Tabela 24. Diagnóstico referido para pacientes das amostras E1 a E20. Interpretação das relações creatina/creatinina e GAA/creatinina segundo valores de referência do IGMJM; Interpretação dos dados obtidos pela nova metodologia segundo a referência estabelecida. 106 Tabela 25. Resultados obtidos na Mayo Clinic e pelo novo método com a interpretação em relação aos respectivos valores de referência. 108 Tabela 26. Resultados de creatina e guanidinoacetato obtidos pelo novo método. 110

Tabela 27. Resultados de creatina e GAA em urina expressos em função da creatinina e indicação de alterações tendo em vista os valores de referência estabelecidos. 


\section{LISTA DE ABREVIATURAS E SIGLAS}

ACN: acetonitrila

ADP: difosfato de adenosina

AGAT: arginina:glicina amidinotransferase

ATP: trifosfato de adenosina

CID: dissociação induzida por colisão (Collision Induced Dissociation)

CK: creatina-quinase

CLSI: Clinical and Laboratory Standards Institute

Creatina- $d_{3}$ : creatina deuterada

Creatinina- $d_{3}$ : creatinina deuterada

DNPM: desenvolvimento neuropsicomotor

EIM: erros inatos do metabolismo

ERM: espectroscopia por ressonância magnética

GAA: guanidinoacetato

GAA- $d_{2}$ : guanidinoacetato deuterado

GAMT: S-adenosil-L-metionina:N-guanidinoacetato metiltransferase

GC-MS: cromatografia a gás acoplada a espectrometria de massas (Gas Chromatography-Mass Spectrometry)

HILIC: cromatografia de interação hidrofílica (Hydrophilic Interaction Chromatography)

HPLC: cromatografia líquida de alta eficiência (High Performance Liquid Chromatography)

IRM: imagem por ressonância magnética

LC-MS/MS: cromatografia líquida associada a espectrometria de massas em tandem (Liquid Chromatography-Mass Spectrometry/Mass spectrometry) $m / z$ : razão massa/carga

$\mathrm{MeOH}:$ metanol

PI: padrão interno

RM: ressonância magnética

SNC: sistema nervoso central

SPE: extração em fase sólida (Solid Phase Extraction) 
TOF: tempo de vôo (Time-Of-Flight)

$\mathrm{W}_{0,5}$ : largura à meia altura 


\section{RESUMO}

Madeira MF. Diagnóstico bioquímico das Síndromes de Deficiência de Creatina [tese]. São Paulo: Faculdade de Medicina, Universidade de São Paulo; 2010. 156 p.

Recentemente, foi descrito um grupo de alterações no metabolismo da creatina denominado "Síndromes de Deficiência de Creatina". Há três formas da doença geneticamente determinadas que cursam com deficiência de creatina, seja por comprometimento de sua síntese ou por defeito na proteína transportadora. O espectro de apresentação clínica dessa condição é inespecífico e inclui atraso ou estagnação do desenvolvimento neuromotor, hipotonia muscular, movimentos involuntários do tipo coreoatetose, retardo ou ausência do desenvolvimento da fala, retardo mental de grau variável, comportamento autista e epilepsia. Neste trabalho, foi desenvolvida e validada uma alternativa metodológica àquelas disponíveis na literatura, com a utilização de extração por troca catiônica forte e separação e detecção por cromatografia líquida de interação hidrofílica acoplada a espectrometria de massas em tandem em que foram exploradas as características químicas das moléculas de creatina e guanidinoacetato, metabólito intermediário da síntese de creatina. Os valores de referência para o método foram definidos pela sua aplicação a 150 amostras de urina e 197 amostras de soro de indivíduos de ambos os sexos e idades entre 0 e 16 anos. Foram também analisadas amostras de urina, soro e plasma de 54 pacientes com clínica compatível com a síndrome de deficiência de creatina sendo que 3 deles apresentaram perfil bioquímico característico de uma das formas dessa 
condição.

Descritores: Creatina/deficiência, Creatina/genética, Guanidinoacetato, Espectrometria de massas em tandem, Cromatografia líquida, Técnicas e procedimentos de laboratório. 


\section{SUMMARY}

Madeira MF. Biochemical diagnosis of Creatine Deficiency Syndromes [thesis]. São Paulo: "Faculdade de Medicina, Universidade de São Paulo"; 2010. $156 \mathrm{p}$.

Recently, a new group of inborn errors of metabolism, collectively named as creatine deficiency syndrome, was identified. Three genetically determined presentations are currently known, affecting both creatine synthesis and transport. Clinical presentation spectrum is non-specific and includes developmental delay, hypotonia, involuntary movements as choreoathetosis, delay or lack of speech acquisition, mental retardation of variable severity, autistic behavior, and epilepsy. Herein, we developed and validated an innovative method for determination of creatine and of its metabolic intermediate, guanidinoacetate, based on cation-exchange solid-phase extraction and hydrophilic interaction liquid chromatography coupled to tandem mass spectrometry. Reference values for the method were defined testing 150 urine and 197 serum samples in males and females with age ranging from 0 to 16 years. Urine and serum samples from 54 patients with some clinical features that might be attributable to creatine deficiency were also evaluated, and in three, biochemical profile characteristic of one of the disorders was detected.

Descriptors: Creatine/deficiency, Creatine/genetics, Guanidinoacetate, Tandem mass spectrometry, Liquid chromatography, Laboratory techniques and procedures. 


\section{INTRODUÇÃO}

\subsection{Creatina: Biossíntese e função}

A creatina exerce um importante papel na homeostase do metabolismo energético celular. Tecidos que exigem grande demanda de energia como músculos esquelético e cardíaco, cérebro, entre outros, são ricos na enzima creatina-quinase (CK), que catalisa a fosforilação reversível da creatina pela adenosina trifosfato (ATP) gerando adenosina difosfato (ADP) e fosfocreatina. Quando ocorrem demandas energéticas, a CK catalisa a transferência do grupo fosfato da fosfocreatina para o ADP restaurando as reservas de ATP e creatina ${ }^{1,2}$ (Figura 1).

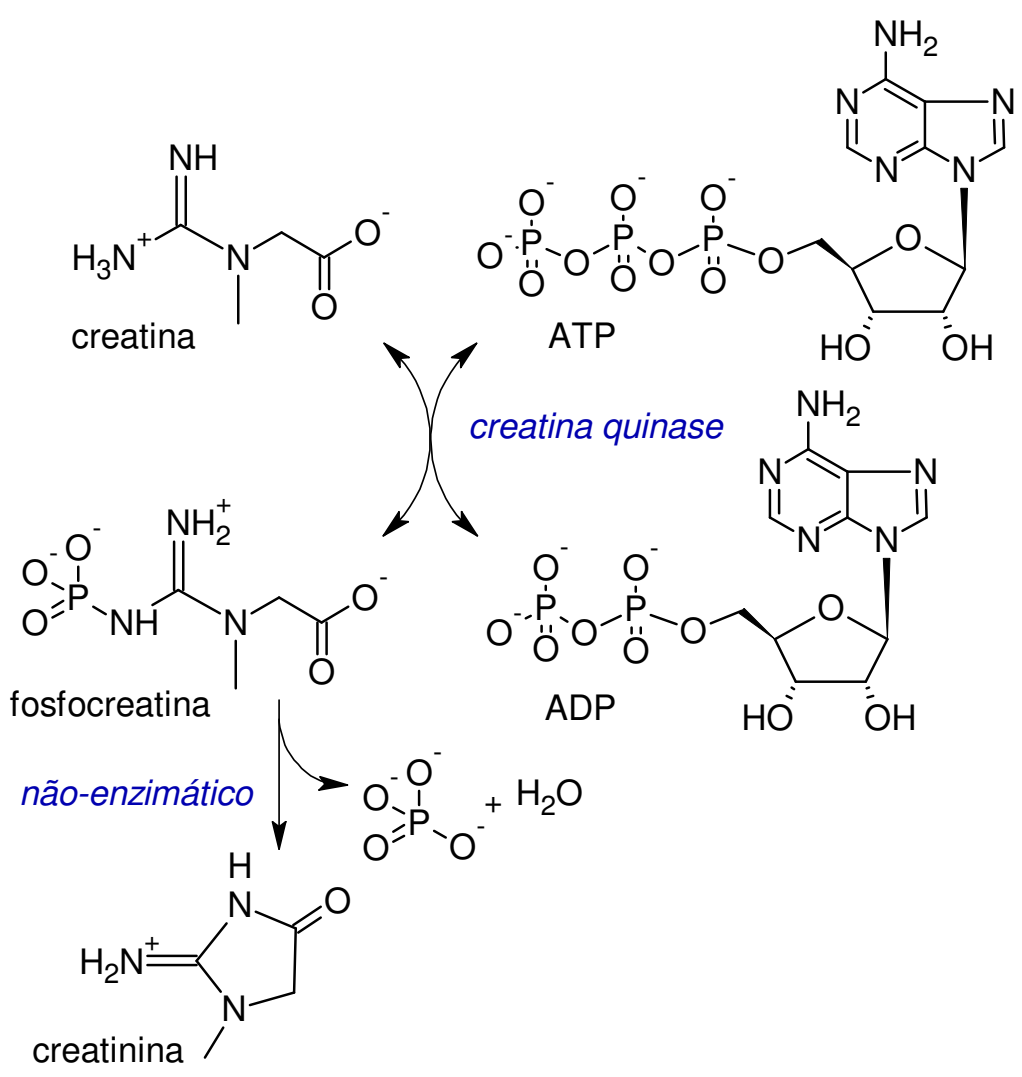

Figura 1. Fosforilação reversível da creatina por ATP e formação de creatinina. 
No sistema nervoso central, a creatina atua de maneira diferenciada e está envolvida na atividade de $\mathrm{Na}^{+} / \mathrm{K}^{+}$-ATPase, liberação de neurotransmissores ${ }^{3}$, homeostase de $\mathrm{Ca}^{++}$e manutenção dos potenciais de membrana ${ }^{4}$. Estudos têm indicado que exerce uma função essencial no processo de alongamento dendrítico e axonal e no crescimento do cone de migração do neurônio ${ }^{5,6}$. Desempenha ainda um papel fundamental na proteção do SNC em processos neurodegenerativos como nas doenças de Parkingson e Huntington, na esclerose lateral amiotrófica e na isquemia cerebral $^{7-10}$.

Os níveis de creatina são mantidos por meio da ingestão de produtos de origem animal (especialmente a carne) e da síntese endógena que ocorre primariamente nos rins, pâncreas e fígado ${ }^{11}$.

Sua biossíntese envolve a ação de duas enzimas: a $L$-arginina:glicina amidinotransferase (AGAT, EC 2.1.4.1) e a S-adenosil-L-metionina:Nguanidinoacetato metiltransferase (GAMT. EC 2.1.1.2) ${ }^{2}$. A AGAT catalisa a transferência do grupo amidino da arginina para a glicina formando ornitina e guanidinoacetato (GAA). A GAMT promove a transferência reversível do grupo metil da S-adenosil-L-metionina para o GAA originando creatina e Sadenosil-L-homocisteína ${ }^{11,12}$ (Figura 2). 


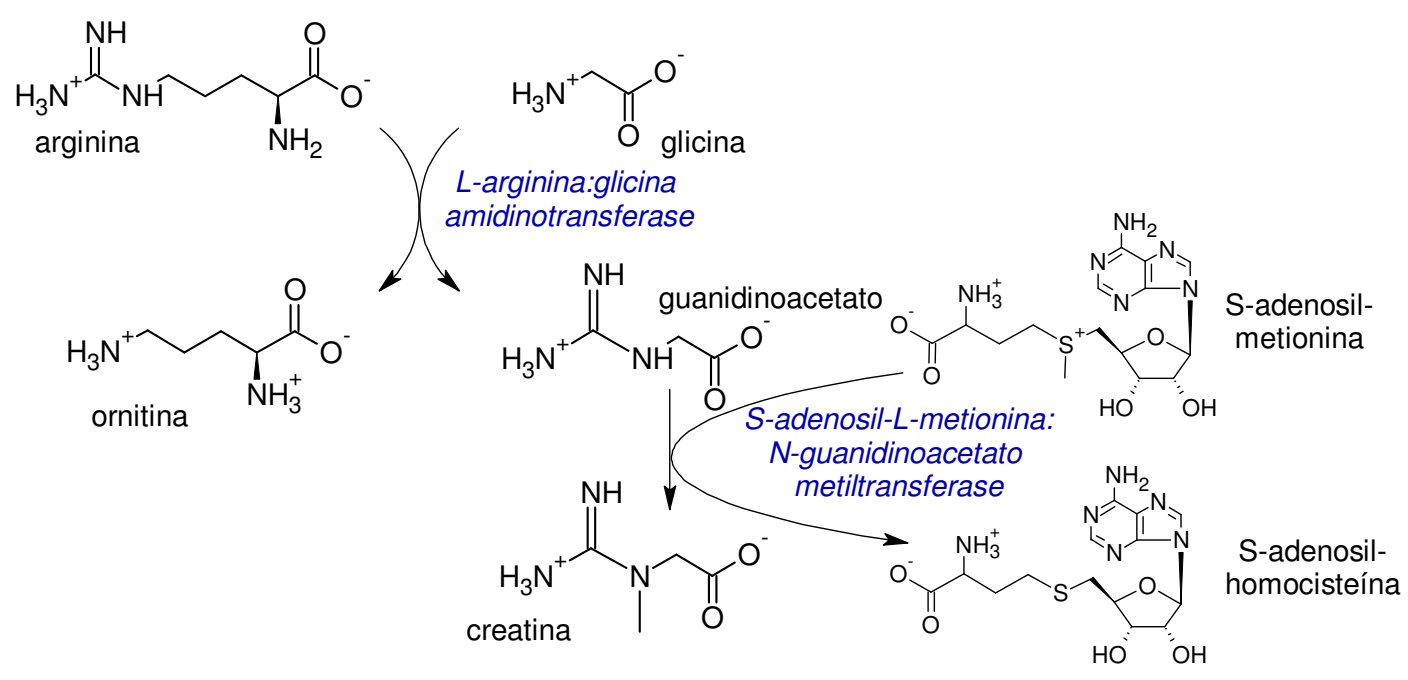

Figura 2. Via de biossíntese de creatina.

Os mecanismos de transporte e distribuição do GAA e da creatina entre os tecidos permanecem ainda pouco esclarecidos ${ }^{2}$. Vários tecidos contêm o transportador de creatina SLC6A8 dependente de sódio e cloro, que transfere a creatina através da membrana plasmática contra um gradiente de concentração de aproximadamente $50 \mu \mathrm{mol} / \mathrm{L}$ no plasma para mais de $40 \mathrm{mmol} / \mathrm{L}$ no meio intracelular ${ }^{11}$. Desta forma, tecidos com pouca ou nenhuma síntese de creatina têm suas necessidades dessa substância supridas pela ação desse transportador ${ }^{2}$. A creatina e a fosfocreatina são convertidas enzimaticamente a uma taxa relativamente constante (aproximadamente 1,5 a $1,7 \%$ por dia) em creatinina ${ }^{13}$, que se difunde passivamente através da membrana celular para fora da célula e é excretada pelos rins por meio da urina ${ }^{2,4}$. 


\subsection{Doenças associadas à deficiência na síntese ou transporte de creatina}

Recentemente, foram identificados erros inatos do metabolismo decorrentes do comprometimento da função das enzimas envolvidas na biossíntese de creatina, a AGAT (codificada na subregião q11.2 do cromossomo 15$)^{11,} 14$ e a GAMT (codificada na subregião p13.3 do cromossomo 19$)^{11}$ e com a proteína responsável por seu transporte, a SLC6A8 (localizada em Xq28) ${ }^{11}$ que coletivamente constituem as síndromes de deficiência de creatina. A primeira dessas condições a ser descrita foi a deficiência de GAMT (OMIM \# 601240), em 1994 ${ }^{15}$. Em 2001, foram descritas a deficiência de SLC6A8 (OMIM \# 300036) ${ }^{16}$ e a deficiência de AGAT (OMIM \# 602360) ${ }^{17}$.

As deficiências de AGAT e de GAMT têm caráter autossômico recessivo e a de SLC6A8, de herança recessiva ligada ao cromossomo $X^{11}$, ${ }^{14}$ e são decorrentes de mutações nos genes que as codificam ${ }^{18,19}$.

As manifestações clínicas da deficiência de creatina são bastante variáveis e comprometem de forma intensa a função do sistema nervoso central (SNC) $)^{2,14,20}$. Os sintomas são pouco específicos e incluem atraso ou estagnação do desenvolvimento neuromotor, hipotonia muscular, movimentos involuntários do tipo coreoatetose, retardo ou ausência do desenvolvimento da fala, retardo mental de grau variável, comportamento autista $^{2,11,14}$ e, particularmente nos portadores de deficiência de GAMT, epilepsia.

Estudos recentes demonstram que os sintomas motores, assim como 
os quadros de epilepsia, comuns em pacientes com deficiência de GAMT, podem ser atribuídos a atuação do guanidinoacetato como agonista parcial dos receptores neuronais $\mathrm{GABA}_{A}{ }^{21,22}$.

Essa falta de especificidade na apresentação clínica indica a relevância da inclusão da investigação das síndromes de deficiência de creatina no diagnóstico diferencial de condições neurológicas.

Embora a creatina seja muito abundante nos músculos esquelético e cardíaco, a sua deficiência nesses tecidos não leva a manifestações clínicas. Estudos demonstram que pacientes portadores de deficiência de GAMT apresentam redução da creatina muscular ${ }^{11}$.

Nos portadores de deficiência de GAMT e AGAT, a suplementação oral de creatina em concentrações acima de vinte vezes das necessidades diárias (de 350 miligramas a 2 gramas por $\mathrm{Kg}$ de peso corporal por dia ${ }^{11}$ ) leva a significativa melhora dos sintomas clínicos e, especialmente quando iniciada precocemente, tem grande impacto no desenvolvimento cognitivo e no controle dos sintomas neurológicos associados ${ }^{14,23-25}$. Nos pacientes portadores de deficiência de GAMT, a combinação entre restrição de arginina e suplementação de ornitina leva a diminuição dos níveis de GAA e supressão dos efeitos neurotóxicos provocados pelo acúmulo dessa substância ${ }^{14,26,27}$. Estudos de imagem por ressonância magnética com espectroscopia de próton sugerem que a redução do GAA circulante favorece a restauração dos níveis cerebrais de creatina e fosfocreatina particularmente em pacientes com deficiência de $\mathrm{GAMT}^{28}$. Para a deficiência de SLC6A8, não há tratamento definido e a reposição oral de creatina não 
mostrou benefícios clínicos ${ }^{14,15,24}$.

Independentemente da resposta terapêutica, todos os pacientes e suas famílias podem se beneficiar de um diagnóstico e de um apropriado aconselhamento genético.

A prevalência das síndromes de deficiência de creatina na população geral ainda não está estabelecida. Há estudos indicando a ocorrência de deficiência de SLC6A8 em até $2 \%$ dos deficientes mentais do sexo masculino $^{19,29,30}$. Recentemente foram realizados estudos populacionais em Portugal que sugeriram uma prevalência de deficiência de GAMT de 1:40.000 nascimentos ${ }^{31}$. Dada a proximidade genética entre Brasil e Portugal, é possível que esses achados se apliquem também à nossa população.

\subsection{Diagnóstico das síndromes de deficiência de creatina}

As concentrações cerebrais de creatina e fosfocreatina podem ser estimadas in vivo por meio da espectroscopia por ressonância magnética (ERM) obtida durante estudos de imagem por ressonância magnética (RM) (Figura 3). A realização de estudos com o uso de RM, habitualmente sob anestesia, é parte da rotina clínica comumente indicada na investigação de pacientes que apresentam distúrbios neurológicos. No entanto, a utilização de ERM é infrequente devido a limitações instrumentais (nem todos os equipamentos de RM possuem o recurso da ERM) e ao fato de que a obtenção dos espectros prolonga o tempo de exame e, portanto, de anestesia. 


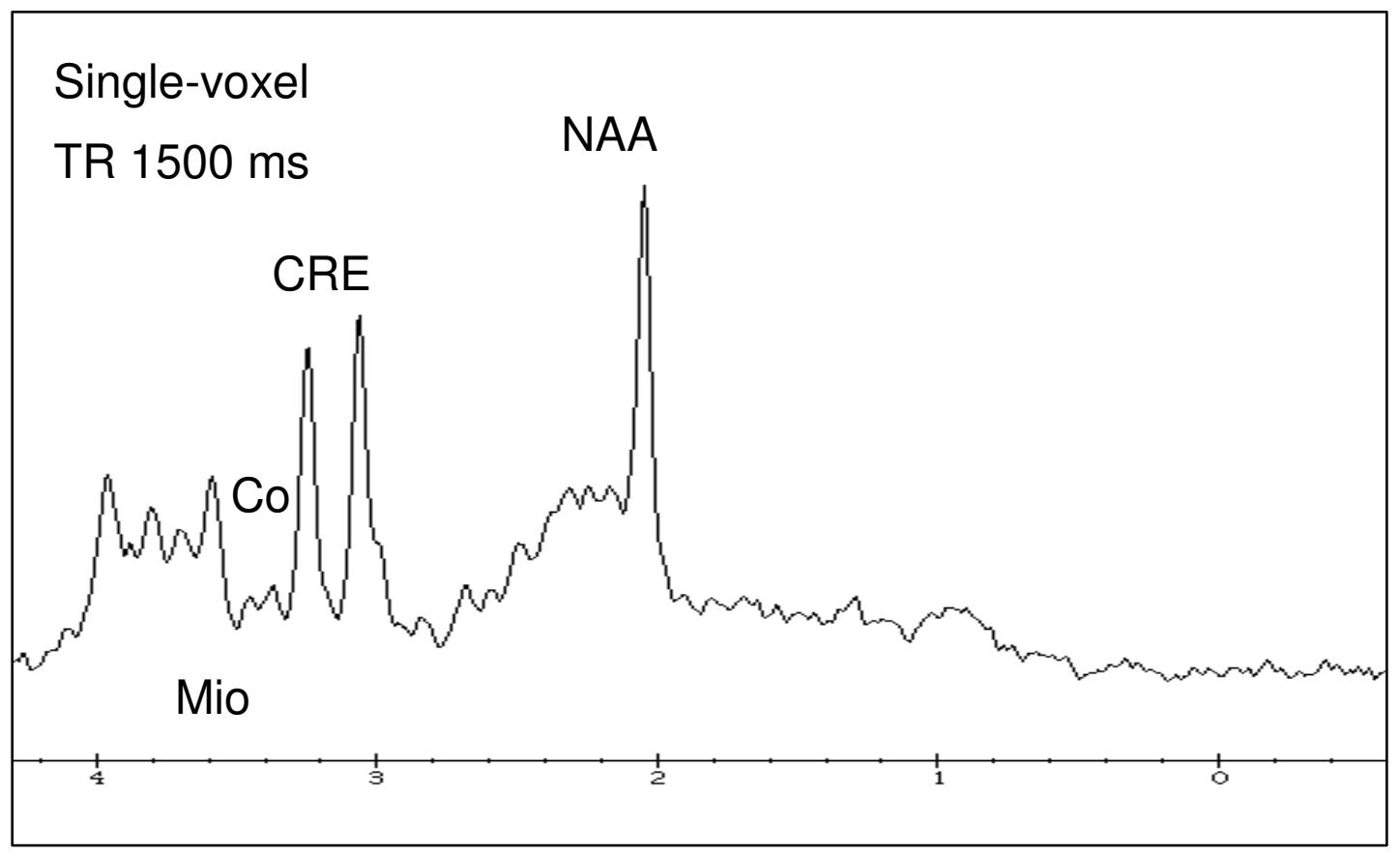

Figura 3. Espectroscopia por ressonância magnética de prótons do encéfalo de um indivíduo normal. Mio: mioinositol; Co: colina; CRE: creatina e NAA: N-acetilaspartato.

Embora a ERM seja de grande importância na identificação da presença da síndrome de deficiência de creatina, o padrão observado é comum a todas as suas formas: acentuada redução dos picos de creatina e fosfocreatina. No entanto, a fim de direcionar o tratamento e o acompanhamento dos pacientes acometidos por essas doenças é necessária a identificação do erro metabólico envolvido. Essa diferenciação é possível com a quantificação do GAA e creatina em amostras de sangue (soro ou plasma) e urina.

Os níveis de creatinina podem ou não se apresentar diminuídos nas síndromes de deficiência de creatina já que são decorrentes da sua conversão espontânea e a uma taxa diária constante, refletindo, portanto, de maneira indireta, seu status no organismo. 
A Tabela 1 apresenta o padrão dos achados bioquímicos observados nas síndromes de deficiência de creatina.

Tabela 1. Alterações bioquímicas observadas nas síndromes de deficiência de creatina.

\begin{tabular}{cccc}
\hline Deficiência & $\begin{array}{c}\text { Guanidinoacetato } \\
\text { (sangue e urina) }\end{array}$ & $\begin{array}{c}\text { Creatina } \\
\text { (sangue e urina) }\end{array}$ & $\begin{array}{c}\text { Creatinina } \\
\text { (sangue e urina) }\end{array}$ \\
\hline GAMT & Elevado & Baixa & Normal ou Baixa \\
AGAT & Baixo & Baixa & Baixa \\
SLC6A8 & Normal & Elevada & Normal ou Baixa \\
\hline
\end{tabular}

A avaliação dos níveis de creatina e GAA e outras matrizes também pode ser de grande utilidade na prática clínica. Estudos indicam que o aumento dos níveis de GAA em líquido amniótico é patognomônico de deficiência de GAMT, podendo contribuir para o diagnóstico pré-natal dessa condição $0^{32}$.

Alterações da síntese e/ou transporte da creatina podem ocorrer secundariamente a outras condições decorrentes da diminução dos substratos da sua via metabólica como na deficiência de vitamina B12 (que cursa com a diminuição de S-adenosilmetionina) ou em decorrência de dietas hipoproteicas impostas por outras doenças (como na acidúria 3hidroxi-metilglutárica, na fenilcetonúria e na leucinose, por exemplo). Há indícios de que nos estados de hiperamonemia haja diminuição dos níveis de creatina, o que poderia justificar a interrupção do crescimento axonal observado nessa condição ${ }^{8}$.

Portanto, uma vez identificadas alterações bioquímicas nos níveis 
desses metabólitos, exames complementares, podem ser associados contribuindo para a caracterização das deficiências primárias da síntese e transporte de creatina ${ }^{2}$. Com essa finalidade, podem ser utilizadas a análise da atividade enzimática realizada inicialmente em amostras de biópsias de fígado $^{23}$ e mais recentemente em cultura de fibroblastos ${ }^{33-35}$, atestando a deficiência funcional das enzimas envolvidas na biossíntese da creatina, e estudos mutacionais dos genes que codificam essas enzimas e a proteína transportadora. A Tabela 4 apresenta o algoritmo de diagnóstico laboratorial dos erros inatos da biossíntese ou transporte de creatina ${ }^{2}$ e ilustra a importância da abordagem bioquímica no diagnóstico desse grupo de doenças, consolidando-se como o ponto de partida para a sua investigação. 


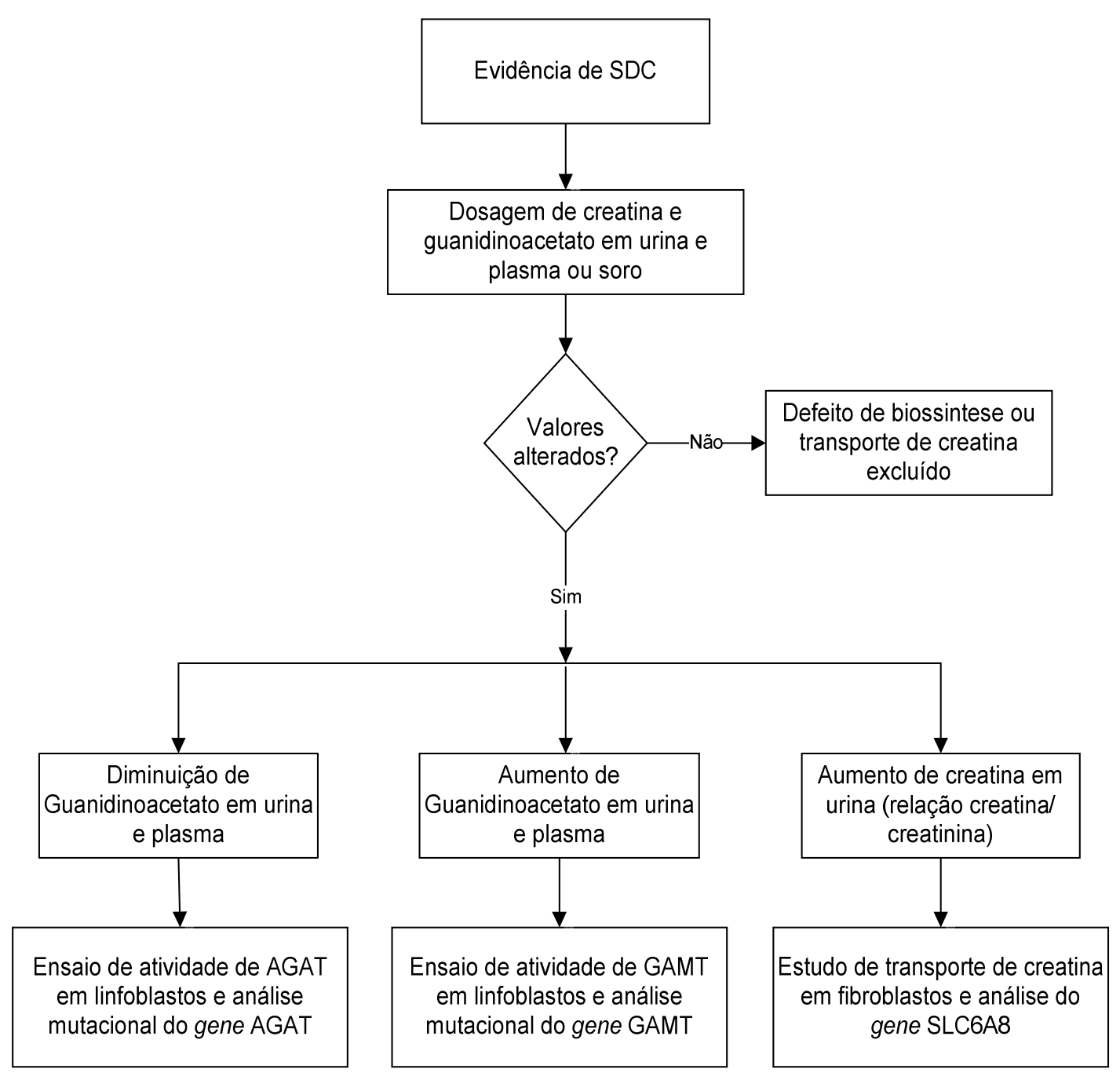

Figura 4. Algoritmo de diagnóstico laboratorial dos defeitos da biossíntese ou transporte de creatina (adaptado de Verhoeven e colaboradores) ${ }^{2}$.

Nos últimos anos, vários grupos têm se dedicado ao desenvolvimento de metodologias para o diagnóstico bioquímico das síndromes de deficiência de creatina. Schulze e colaboradores ${ }^{36}$ aplicaram um princípio de detecção colorimétrica conhecido há décadas, a reação de Sakaguchi, na triagem de guanidino-compostos após separação dos componentes da urina por cromatografia em camada delgada.

Hunneman e Hanefeld ${ }^{37}$ usaram a técnica de cromatografia a gás acoplada à espectrometria de massas (GC-MS) para a análise quantitativa 
de GAA em urina e plasma. O método envolve um longo processo de derivatização do grupo cianoamido da porção guanidino da molécula por hexafluoroacetilacetona e esterificação do grupo carboxila com trimetilsilil. Outro método utilizando GC-MS foi descrito por Struys e colaboradores ${ }^{38}$ combinando a derivatização do grupo cianoamido por hexafluoroacetilacetona com uma alquilação da extremidade carboxila por brometo de pentafluorobenzila. Tal estratégia resultou em redução no tempo de derivatização e ganho de seletividade pela deteç̧ão por ionização química no modo negativo. Apesar da aplicabilidade de GC-MS no diagnóstico de várias doenças metabólicas, a técnica apresenta diversos inconvenientes, sobretudo quanto à etapa de extração e derivatização da amostra, limitando seu uso na maioria dos laboratórios clínicos e hospitais.

Carducci e colaboradores desenvolveram um método baseado em derivatização com benzoína seguido por cromatografia líquida de alta eficiência (HPLC) com detecção fluorimétrica que permitiu a quantificação conjunta de GAA e creatina/creatinina em sangue em papel de filtro ${ }^{39} \mathrm{e}$ urina $^{40}$. Apesar de o preparo da amostra ser parcialmente automatizado, o tempo de análise cromatográfica é longo e não há separação de creatina e creatinina.

Devido a sua alta especificidade e sensibilidade, a cromatografia líquida associada a espectrometria de massas em tandem (LC-MS/MS) vem se estabelecendo como o padrão-ouro para esse tipo de análise. Recentemente, foram descritos três métodos baseados nesta técnica para a quantificação de GAA e creatina. Dois deles utilizaram a estratégia de 
esterificação com butanol para aumentar os pesos moleculares dos analitos e seus respectivos tempos de retenção cromatográfica em fase reversa ${ }^{41,42}$. Um terceiro ${ }^{43}$, refere a utilização de fase reversa sem derivatização. Entretanto, observando-se as figuras apresentadas, verifica-se que quase não há retenção dos compostos na coluna analítica, o que é previsível, dada a sua natureza hidrofílica. 


\section{OBJETIVOS E RELEVÂNCIA}

Ainda não há, no Brasil, relatos da ocorrência das síndromes de deficiência de creatina. Em Portugal, país com o qual compartilha muito de seu patrimônio genético, a deficiência de GAMT tem uma frequência estimada de 1:40.000 nascimentos ${ }^{31}$. Há também dados na literatura mundial indicando que a deficiência de SLC6A8 possa ser uma importante causa de deficiência mental com herança ligada ao $\mathrm{X}$, sendo responsável por até $2 \%$ dos casos de deficiência mental em indivíduos do sexo masculino $^{19,29}$

Esses dados reforçam a hipótese de que a prevalência dessas condições possa justificar a inclusão, no futuro, da pesquisa de defeitos de síntese e transporte de creatina no painel de triagem de erros inatos de metabolismo por meio da utilização de um teste laboratorial que permita a diferenciação entre elas contribuindo para o seu correto diagnóstico e tratamento.

Assim, os objetivos deste projeto foram:

1. O desenvolvimento e validação de uma metodologia para a análise e quantificação de GAA e creatina por meio de LC-MS/MS;

2. A definição de valores de referência aplicáveis à metodologia proposta em matrizes urinária e sérica para indivíduos de ambos os sexos com idades compreendidas entre 0 e 16 anos;

3. A avaliação dos níveis de creatina e guanidinoacetato em pacientes que apresentassem clínica compatível com alguma das 
formas de síndrome de deficiência de creatina. 


\section{MÉTODOS}

\subsection{Reagentes e materiais}

Foram utilizados os solventes de grau cromatográfico acetonitrila (Vetec Química Fina, Rio de Janeiro, Brasil) e metanol (Tedia Company Inc, Fairfield, EUA).

Foram usados formiato de amônio e fosfato de sódio da SigmaAldrich (St. Louis, EUA), sulfato de zinco da Nuclear (São Paulo, Brasil), hidróxido de sódio da Merck KGaA (Darmstadt, Alemanha), ácidos clorídrico a 37\%, acético e fosfórico a $85 \%$ da Merck KGaA (Darmstadt, Alemanha) e fórmico a $96 \%$ da Tedia (Fairfield, EUA).

A água utilizada para preparo de reagentes e soluções foi obtida no sistema de purificação Milli-Q da Millipore (Billerica, EUA).

Como solução eluidora foi usada, inicialmente, diluição da solução de $\mathrm{NH}_{4} \mathrm{OH}$ a $25 \%$ da Merck KGaA (Darmstadt, Alemanha) e, posteriormente, diluição da solução de amônia a 7N em metanol da Sigma-Aldrich (St. Louis, EUA).

Os padrões de creatina e GAA foram adquiridos da Fluka, SigmaAldrich (St.Louis, EUA) e o de creatinina, da VETEC (Rio de Janeiro, Brasil). Seus análogos deuterados (creatina- $d_{3}$, GAA- $d_{2}$ e creatinina- $d_{2}$ ), da CDN Isotopes (Pointe-Claire, Canadá).

Análises de proteínas e de creatinina foram realizadas no sistema analítico Advia ${ }^{\circledR} 1200$ Chemistry System da Siemens Healthcare Diagnostics 
Inc (Deerfield, EUA) com os reagentes vermelho de pirogalol e CREA ADVIA Chemistry (método de Jaffé modificado) respectivamente, ambos da marca Siemens Healthcare Diagnostics Inc (Deerfield, EUA).

Para as separações cromatográficas foram empregadas as colunas Luna Sílica (2) (Phenomenex ${ }^{\circledR}, 100 \AA$, $3 \mu \mathrm{m}, 50 \times 2,0 \mathrm{~mm}$ ), Luna Ciano (Phenomenex ${ }^{\circledR}, 100 \AA$, $3 \mu \mathrm{m}, 50 \times 2,0$ mm), Luna Amino (Phenomenex ${ }^{\circledR}, 100$ $\AA ̊ \AA, 3 \mu \mathrm{m}, 50 \times 2,0 \mathrm{~mm}$ ) e Luna HILIC (Phenomenex ${ }^{\circledR}, 200 \AA$, $3 \mu \mathrm{m}, 50 \times 2,0$ $\mathrm{mm})$.

Para a extração das amostras foram avaliadas as resinas de troca catiônica forte SCX (SEPRA SCX, $65 \AA$ A $50 \mu \mathrm{m}$, Phenomenex ${ }^{\circledR}$ ) e XC (SEPRA XC, $33 \mu \mathrm{m}$, Phenomenex ${ }^{\circledR}$ ) disponíveis comercialmente em "bulk" e placas de 96 poços das marcas Millipore ${ }^{\circledR}$ (Solvinert Multiscreen MDRL NP4 e MDRL NO4) e Axygen Biosciences (AxyPrep ${ }^{\circledR}$ Fritted 1,5 mL).

Para a coleta dos eluatos foram utilizadas placas com capacidade de $0,8 \mathrm{~mL}\left(\right.$ Thermo Scientific $\left.{ }^{\circledR}\right)$.

Foram utilizadas fitas indicadoras de $\mathrm{pH}$ nas faixas de 0-6 $\left(\right.$ Acilit $\left.^{\circledR}\right)$ e 014 (Universal indicator) da Merck KGaA (Darmstardt, Alemanha).

\subsection{Equipamentos}

Foram utilizados os seguintes equipamentos:

- Sistema analítico composto por espectrômetro de massas em tandem Quattro Micro (Waters) equipado com probe de eletrospray, bombas binárias Shimadzu LC-10ATvp e 
amostrador 2777 Waters equipado com seringa Hamilton de $100 \mu \mathrm{L}$ e loop de $20 \mu \mathrm{L}$;

- Espectrômetro de massas Q-TOF Synapt Mass Spectrometry ${ }^{\top \mathrm{M}}$ (Waters), operado em modo nanoelectrospray positivo;

- Forno para colunas Thermasphere ${ }^{\mathrm{TM}} \mathrm{TS}^{-130}$ da Phenomenex ${ }^{\circledR}$;

- Sistema analítico automatizado Advia ${ }^{\circledR} 1200$ Chemistry System (Siemens);

- Sistema de drenagem a vácuo da Waters acoplado a bomba de vácuo da Gast Manufacturing (modelo: DOA-P704-AA);

- Sistema de liofilização ou concentração a vácuo modelo Speed Vac SC 200 da ThermoSavant;

- Centrífuga marca Abbott modelo 3531;

- Centrífuga de placas marca Eppendorf modelo 5804;

- Balança analítica marca Sartorius modelo BP 211 D;

- Sistema de purificação de água por osmose reversa e deionização Milli-Q da Millipore ${ }^{\circledR}$;

- Sistema de preparo de placas Multiscreen ${ }^{\circledR}$ Column loader 100 $\mu \mathrm{L}$ da Millipore ${ }^{\circledR}$.

\subsection{Outros acessórios}

- Pipetas automáticas e ponteiras descartáveis;

- Tubos eppendorf;

- Pipetas plásticas de bulbo; 
- Vidraria;

- Conexões de peek;

- Tubulações de sílica fundida;

- Seringa Hamilton de $100 \mu \mathrm{L}$ para infusão contínua.

\subsection{Preparo das soluções padrão e curva de calibração}

\subsubsection{Soluções-padrão primárias}

Foram preparadas soluções-estoque independentes de creatina, GAA, creatinina, creatina- $d_{3}$, GAA- $d_{2}$ e creatinina- $d_{3}$ a $1 \mathrm{mg} / \mathrm{mL}$ e a $5 \mathrm{mg} / \mathrm{mL}$ em água.

\subsubsection{Soluções-padrão secundárias}

A partir das soluções primárias adequadas foram preparadas as seguintes soluções:

a) Soluções independentes de cada padrão em água a $50 \mu \mathrm{g} / \mathrm{mL}$;

b) Solução única de creatina e GAA a $50 \mu \mathrm{g} / \mathrm{mL}$ em água;

c) Solução única de creatina e GAA a 100 g/mL em água;

d) Solução única de creatina, GAA, creatina- $d_{3}$ e GAA- $d_{2}$ a $10 \mu \mathrm{g} / \mathrm{mL}$ em ácido fórmico a $25 \mathrm{mmol} / \mathrm{L}$;

e) Solução única de creatina, GAA, creatina- $d_{3}$ e GAA- $d_{2}$ a $10 \mu \mathrm{g} / \mathrm{mL}$ em tampão fosfato a $25 \mathrm{mmol} / \mathrm{L} \mathrm{pH} \mathrm{1,9;}$

f) Solução única de creatina, GAA, creatina- $d_{3}$ e GAA- $d_{2}$ a $100 \mu \mathrm{g} / \mathrm{mL}$ em tampão fosfato a $25 \mathrm{mmol} / \mathrm{L} \mathrm{pH} \mathrm{1,9;}$ 
g) Solução única de creatina- $d_{3}$, creatinina- $d_{3}$ e GAA- $d_{2}$ a $500 \mu \mathrm{g} / \mathrm{mL}$ em água;

h) Solução única de creatina, creatinina e GAA a $2500 \mu \mathrm{g} / \mathrm{mL}$ em água;

i) Solução única de creatina, creatinina e GAA a 1000 mg/mL em água;

j) Solução única de creatina e GAA a $10 \mu \mathrm{g} / \mathrm{mL}$ em água;

k) Solução única de creatinina- $d_{3}$ a $1000 \mu \mathrm{g} / \mathrm{mL}$ em água.

\subsubsection{Outras soluções- padrão}

Foram preparadas as seguintes soluções:

a) Solução única de Creatina e GAA a $0,1 \mu \mathrm{g} / \mathrm{mL}$ em água a partir da solução descrita no item 3.4.2 b;

b) Solução única de creatina e GAA a $0,5 \mu \mathrm{g} / \mathrm{mL}$ em água a partir da solução descrita no item 3.4 .2 b;

c) Solução única de creatina e GAA a $0,1 \mu \mathrm{g} / \mathrm{mL}$ em $\mathrm{ACN}$ a partir da solução descrita no item 3.4.2 b;

d) Solução de creatina e GAA a $10 \mu \mathrm{g} / \mathrm{mL}$ em $\mathrm{ACN}$ a partir da solução descrita no item $3.4 .2 \mathrm{c}$;

e) Solução de creatina- $d_{3}$ e GAA- $d_{2}$ a $10 \mu \mathrm{g} / \mathrm{mL}$ em água a partir da solução descrita no item $3.4 .2 \mathrm{~g}$;

f) Solução de creatina- $d_{3}$, creatininaa- $d_{3}$ e GAA- $d_{2}$ a $100 \mu \mathrm{g} / \mathrm{mL}$ em água a partir das soluções descritas nos itens $3.4 .2 \mathrm{~g}$ e $3.4 .2 \mathrm{k}$;

g) Solução de creatina e GAA a $0,05 \mu \mathrm{g} / \mathrm{mL}$ em ACN a partir da solução descrita no item 3.4.3 d; 
h) Solução de creatina e GAA a $1 \mu \mathrm{g} / \mathrm{mL}$ em $\mathrm{ACN}$ a partir da solução descrita no item 3.4.3 d;

i) Soluções independentes de creatina e GAA a $0,05 \mu \mathrm{g} / \mathrm{mL}$ em solução ACN $50 \%$ em água com $0,1 \%$ de ácido fórmico, a partir da solução descrita no item 3.4.3 d.

3.4.4. Amostras para lineridade e curva de calibração em água

Foram preparados padrões aquosos de creatina e GAA nas concentrações 0,$05 ; 0,1 ; 1,0 ; 10 ; 100 ; 500$ e $1000 \mu \mathrm{g} / \mathrm{mL}$ partindo de diluições adequadas das soluções-estoque primárias e secundárias.

\subsubsection{Curva de calibração em NaCl 0,15 mol/L}

A curva de calibração em $\mathrm{NaCl} 0,15 \mathrm{~mol} / \mathrm{L}$ para creatina, creatinina e GAA foi preparada nas concentrações de 0,$1 ; 0,5 ; 1 ; 5 ; 10 ; 25 ; 50 ; 100 ; 250$; 500 e $1000 \mu \mathrm{g} / \mathrm{mL}$ partindo de diluições adequadas das soluções-estoque primárias e secundárias. Para a análise em soro e plasma foram utilizadas as concentrações de 0,$1 ; 0,5 ; 1 ; 5 ; 10 ; 25$ e $50 \mu \mathrm{g} / \mathrm{mL}$. Para a análise em urina foram utilizadas as concentrações de $1 ; 5 ; 10 ; 50 ; 100 ; 250 ; 500$ e $1000 \mu \mathrm{g} / \mathrm{mL}$.

\subsubsection{Amostras adicionadas de padrões}

Foram preparados pools de urina e de soro dialisado e a partir deles:

a) Pool de urina adicionado dos padrões de creatina e GAA representando um acréscimo de $50 \mu \mathrm{g} / \mathrm{mL}$; 
b) Pool de urina adicionado de padrões de creatina e GAA representando um acréscimo de $1 \mu \mathrm{g} / \mathrm{mL}$;

c) Pool de urina adicionado de padrões de creatina e GAA representando um acréscimo de $100 \mu \mathrm{g} / \mathrm{mL}$;

d) Pool de urina adicionado de padrões de creatina e GAA representando um acréscimo de $500 \mu \mathrm{g} / \mathrm{mL}$;

e) Pool de urina adicionado de padrões de creatina e GAA representando um acréscimo de $1000 \mu \mathrm{g} / \mathrm{mL}$;

f) Pool de soro dialisado adicionado de padrões para as concentrações de $0,04 \mu \mathrm{g} / \mathrm{mL}$ de $\mathrm{GAA}$ e $0,5 \mu \mathrm{g} / \mathrm{mL}$ de creatina;

g) Pool de soro dialisado adicionado de padrões para as concentrações de $0,42 \mu \mathrm{g} / \mathrm{mL}$ de GAA e $15 \mu \mathrm{g} / \mathrm{mL}$ de creatina.

\subsubsection{Amostras de soro para validação}

As amostras para validação do método em soro foram preparadas em pool de soros dialisados e sem dialisação segundo descrito na Tabela 2. 
Tabela 2. Preparo das amostras para validação em soro.

\begin{tabular}{|c|c|c|}
\hline Experimento & Preparo & Denominação \\
\hline \multirow{10}{*}{ Linearidade } & $\begin{array}{c}100 \mu \mathrm{L} \text { de solução } 3.4 .2 \mathrm{i}+900 \mu \mathrm{L} \text { de pool de soro } \\
\text { dialisado }\end{array}$ & $\begin{array}{l}\operatorname{Lin} 10(100 \\
\mu \mathrm{g} / \mathrm{mL})\end{array}$ \\
\hline & $\begin{array}{c}75 \mu \mathrm{L} \text { de solução } 3.4 .2 \mathrm{i}+925 \mu \mathrm{L} \text { de pool de soro } \\
\text { dialisado }\end{array}$ & Lin $9(75 \mu \mathrm{g} / \mathrm{mL})$ \\
\hline & $\begin{array}{c}50 \mu \mathrm{L} \text { de solução } 3.4 .2 \mathrm{i}+950 \mu \mathrm{L} \text { de pool de soro } \\
\text { dialisado }\end{array}$ & Lin $8(50 \mu \mathrm{g} / \mathrm{mL})$ \\
\hline & $\begin{array}{c}25 \mu \mathrm{L} \text { de solução } 3.4 .2 \mathrm{i}+975 \mu \mathrm{L} \text { de pool de soro } \\
\text { dialisado }\end{array}$ & Lin $7(25 \mu \mathrm{g} / \mathrm{mL})$ \\
\hline & $\begin{array}{c}10 \mu \mathrm{L} \text { de solução } 3.4 .2 \mathrm{i}+990 \mu \mathrm{L} \text { de pool de soro } \\
\text { dialisado }\end{array}$ & Lin $6(10 \mu \mathrm{g} / \mathrm{mL})$ \\
\hline & $\begin{array}{c}5 \mu \mathrm{L} \text { de solução } 3.4 .2 \mathrm{i}+995 \mu \mathrm{L} \text { de pool de soro } \\
\text { dialisado }\end{array}$ & Lin $5(5 \mu \mathrm{g} / \mathrm{mL})$ \\
\hline & $\begin{array}{c}10 \mu \mathrm{L} \text { de solução } 3.4 .2 \mathrm{c}+990 \mu \mathrm{L} \text { de pool de soro } \\
\text { dialisado }\end{array}$ & Lin $4(1 \mu \mathrm{g} / \mathrm{mL})$ \\
\hline & $\begin{array}{c}5 \mu \mathrm{L} \text { de solução } 3.4 .2 \mathrm{c}+995 \mu \mathrm{L} \text { de pool de soro } \\
\text { dialisado }\end{array}$ & Lin $3(0,5 \mu \mathrm{g} / \mathrm{mL})$ \\
\hline & $\begin{array}{c}2 \mu \mathrm{L} \text { de solução } 3.4 .2 \mathrm{~b}+998 \mu \mathrm{L} \text { de pool de soro } \\
\text { dialisado }\end{array}$ & $\operatorname{Lin} 2(0,1 \mu \mathrm{g} / \mathrm{mL})$ \\
\hline & $\begin{array}{c}5 \mu \mathrm{L} \text { de solução } 3.4 .2 \mathrm{j}+995 \mu \mathrm{L} \text { de pool de soro } \\
\text { dialisado }\end{array}$ & Lin $1(0,05 \mu \mathrm{g} / \mathrm{mL})$ \\
\hline \multirow[t]{4}{*}{$\begin{array}{l}\text { Limite de } \\
\text { Quantificação }\end{array}$} & $\begin{array}{l}\text { Diluição do pool de soros puro com } \mathrm{NaCl} \text { 0,15 mol/L } \\
\text { nas razões de } 1: 2,1: 5,1: 10 \text { e } 1: 20\end{array}$ & LQ1 a LQ4 \\
\hline & Pool de soros puro & $\mathrm{LI}$ \\
\hline & $\begin{array}{l}\text { A partir dos padrões primários independentes de } \\
\text { creatina, GAA e creatinina de } 1000 \mu \mathrm{g} / \mathrm{mL} \text { cada: } 100\end{array}$ & \\
\hline & $\begin{array}{c}\mu \mathrm{L} \text { de padrão de creatina }+5 \mu \mathrm{L} \text { do padrão de GAA + } \\
50 \mu \mathrm{L} \text { de padrão de creatinina }+9845 \mu \mathrm{L} \text { de pool de } \\
\text { soros }\end{array}$ & LII \\
\hline \multirow{2}{*}{ Precisão } & $\begin{array}{l}\text { A partir dos padrões primários independentes de } \\
\text { creatina, GAA e creatinina de } 1000 \mu \mathrm{g} / \mathrm{mL} \text { cada: } 200\end{array}$ & \\
\hline & $\begin{array}{c}\mu \mathrm{L} \text { de padrão de creatina }+50 \mu \mathrm{L} \text { do padrão de GAA } \\
+100 \mu \mathrm{L} \text { de padrão de creatinina }+9650 \mu \mathrm{L} \text { de pool } \\
\text { de soros }\end{array}$ & LIII \\
\hline Arraste & $\begin{array}{l}\text { Amostra Lin } 2 \text { do experimento de linearidade } \\
\text { Amostra Lin } 8 \text { do experimento de linearidade }\end{array}$ & $\begin{array}{l}\text { Amostra Baixa (B) } \\
\text { Amostra alta }(A)\end{array}$ \\
\hline
\end{tabular}




\subsubsection{Amostras de urina para validação}

As amostras para validação do método para urina foram preparadas em pool de urinas segundo descrito na Tabela 3.

Tabela 3. Preparo das amostras para validação em urina.

\begin{tabular}{|c|c|c|}
\hline Experimento & Preparo & Denominação \\
\hline \multirow{9}{*}{ Linearidade } & $\begin{array}{l}\text { Pool adicionado com } 1500 \mu \mathrm{g} / \mathrm{mL} \text { de creatina e GAA } \\
\text { a partir das soluções primárias de } 5 \mathrm{mg} / \mathrm{mL} \text { do item } \\
\text { 3.4.1 }\end{array}$ & Lin 9 \\
\hline & $\begin{array}{l}\text { Pool adicionado com } 1000 \mu \mathrm{g} / \mathrm{mL} \text { de creatina e GAA } \\
\text { a partir da solução descrita no item } 3.4 .2 \mathrm{~h}\end{array}$ & Lin 8 \\
\hline & $\begin{array}{l}\text { Pool adicionado com } 750 \mu \mathrm{g} / \mathrm{mL} \text { de creatina e GAA a } \\
\text { partir da solução descrita no item } 3.4 .2 \mathrm{~h}\end{array}$ & Lin 7 \\
\hline & $\begin{array}{l}\text { Pool adicionado com } 500 \mu \mathrm{g} / \mathrm{mL} \text { de creatina e GAA a } \\
\text { partir da solução descrita no item 3.4.2 } h\end{array}$ & Lin 6 \\
\hline & $\begin{array}{l}\text { Pool adicionado com } 250 \mu \mathrm{g} / \mathrm{mL} \text { de creatina e GAA a } \\
\text { partir da solução descrita no item 3.4.2 } h\end{array}$ & Lin 5 \\
\hline & $\begin{array}{l}\text { Pool adicionado com } 100 \mu \mathrm{g} / \mathrm{mL} \text { de creatina e GAA a } \\
\text { partir da solução descrita no item } 3.4 .2 i\end{array}$ & Lin 4 \\
\hline & $\begin{array}{l}\text { Pool adicionado com } 50 \mu \mathrm{g} / \mathrm{mL} \text { de creatina e GAA a } \\
\text { partir da solução descrita no item } 3.4 .2 i\end{array}$ & Lin 3 \\
\hline & $\begin{array}{l}\text { Pool adicionado com } 25 \mu \mathrm{g} / \mathrm{mL} \text { de creatina e GAA a } \\
\text { partir da solução descrita no item } 3.4 .2 i\end{array}$ & Lin 2 \\
\hline & $\begin{array}{l}\text { Pool adicionado com } 10 \mu \mathrm{g} / \mathrm{mL} \text { de creatina e GAA a } \\
\text { partir da solução descrita no item } 3.4 .2 i\end{array}$ & Lin 1 \\
\hline \multirow[t]{2}{*}{$\begin{array}{l}\text { Limite de } \\
\text { Quantificação }\end{array}$} & $\begin{array}{l}\text { Pool de urinas foi diluído } 1: 2,1: 5,1: 10 \text { e } 1: 20 \text { em } \\
\text { solução de } \mathrm{NaCl} \text { a } 0,15 \mathrm{~mol} / \mathrm{L}\end{array}$ & LQ1 a LQ4 \\
\hline & Pool de urinas puro & $\mathrm{LI}$ \\
\hline \multirow[t]{3}{*}{ Precisão } & $\begin{array}{l}\text { Pool de urinas adicionado para uma concentração de } \\
230 \mu \mathrm{g} / \mathrm{mL} \text { de cada composto }\end{array}$ & LII \\
\hline & $\begin{array}{l}\text { Pool de urinas adicionado para a concentração de } \\
625 \mu \mathrm{g} / \mathrm{mL} \text { de cada composto }\end{array}$ & LIII \\
\hline & Pool de urinas puro & Amostra Baixa (B) \\
\hline Arraste & Amostra Lin 8 do experimento de linearidade & Amostra alta $(A)$ \\
\hline
\end{tabular}




\subsection{Análises por espectrometria de massas em tandem}

A otimização das condições de detecção das massas de interesse foi realizada por infusão direta de cada um dos padrões na concentração de 50 $\mu \mathrm{g} / \mathrm{mL}$ (item 3.4 .2 a) por meio de uma bomba de seringa integrada ao espectrômetro Quattro Micro a um fluxo contínuo de $5 \mu \mathrm{L} / \mathrm{min}$. O capilar proveniente da seringa foi conectado a uma junção em "T" onde confluía com um make-up flow de solução aquosa de formiato de amônio a $5 \mathrm{mmol} / \mathrm{L}$ pH 3 em $60 \%$ de ACN com vazão de $0,3 \mathrm{~mL} / \mathrm{min}$. O fluxo resultante foi introduzido diretamente no espectrômetro equipado com uma probe de electrospray operando em modo positivo. O monitoramento dos íons de interesse foi compreendido entre $\mathrm{m} / \mathrm{z}$ 40-150.

Os espectros de dissociação dos íons precursores foram adquiridos utilizando argônio como gás de colisão (aproximadamente $4 \times 10^{-3} \mathrm{mbar}$ ) com energias de colisão de 5, 10, 15, 20, 25 e 30 eV. A análise dos perfis de fragmentação permitiu a definição das transições de massas que seriam monitoradas para cada composto.

Foi realizado um experimento em alta resolução no equipamento QTOF Synapt operado no modo nanoelectrospray positivo com a infusão de padrões de creatina e GAA nas concentrações de $0,01 \mu \mathrm{g} / \mathrm{mL}$ (item 3.4.3 i) a fim de verificar seus padrões de fragmentação.

Após a seleção das transições de massas a serem utilizadas, as soluções-padrão de cada um dos analitos a $50 \mu \mathrm{g} / \mathrm{mL}$ (item 3.4.2 a) foram infundidas no espectrômetro e os diversos parâmetros de análise (energia 
de colisão, potencial capilar, voltagens do cone, do extrator e das lentes RF) foram ajustados de forma a maximizar a intensidade dos íons mais abundantes.

Foi realizado um experimento para avaliação do impacto da variação do tempo de aquisição (dwell time) na sensibilidade para cada analito alterando-se o padrão único de 0,10 segundos para 0,05 segundos para creatina e creatina- $d_{3}$ e 0,15 segundos para GAA e GAA- $d_{2}$ com o objetivo de verificar a possibilidade de aumento da sensibilidade para GAA e seu deuterado, cujos sinais são menos intensos.

\subsection{Desenvolvimento do método cromatográfico}

\subsubsection{Separação cromatográfica}

Diversos gradientes, fases móveis e colunas foram avaliados. A Tabela 4 apresenta os parâmetros aplicados em cada método de análise por HPLC avaliado. As fases móveis foram preparadas em água deionizada e o volume de injeção foi de $20 \mu \mathrm{L}$ (exceto para o método B em que foram injetados $10 \mu \mathrm{L})$. A coluna utilizada inicialmente foi a Luna Sílica $50 \times 2 \mathrm{~mm}$ e o fluxo utilizado variou de 0,2 a $0,3 \mathrm{~mL} / \mathrm{min}$. As amostras injetadas foram as soluções descritas nos itens $3.4 .2 \mathrm{a}, 3.4 .3 \mathrm{~b}$ e $3.4 .3 \mathrm{~d}$. 
Tabela 4. Métodos avaliados por HPLC para as análises de creatina e guanidinoacetato.

\begin{tabular}{|c|c|c|c|c|}
\hline \multirow{2}{*}{ Método } & \multicolumn{2}{|c|}{ Fase móvel } & \multirow{2}{*}{ Modo de Eluição } & \multirow{2}{*}{ Conc. Padrão } \\
\hline & A & B & & \\
\hline$A$ & ------- & ACN $80 \%$ & $0-20 \min -100 \% B$ & $50 \mu \mathrm{g} / \mathrm{mL}$ em água \\
\hline B & ------- & ACN $75 \%$ & $0-9 \min -100 \% \mathrm{~B}$ & 0,5 $\mu \mathrm{g} / \mathrm{mL}$ em água \\
\hline C & $\begin{array}{c}\mathrm{FA} 25 \mathrm{mmol} / \mathrm{L} \\
(\mathrm{pH} 3,0)\end{array}$ & $\mathrm{ACN}$ & $0-4 \min -35 \% A: 65 \% B$ & $10 \mu \mathrm{g} / \mathrm{mL}$ em ACN \\
\hline $\mathrm{D}$ & $\begin{array}{c}\mathrm{FA} 25 \mathrm{mmol} / \mathrm{L} \\
(\mathrm{pH} 3,0)\end{array}$ & $\mathrm{ACN}$ & $\begin{array}{cc}0-2 \min & 88-70 \% \text { B } \\
2-4 \min & 70-65 \% \text { B } \\
4-5 \min & 65 \% \text { B } \\
5-6 \text { min } & 65-88 \% \text { B }\end{array}$ & $10 \mu \mathrm{g} / \mathrm{mL}$ em $\mathrm{ACN}$ \\
\hline E & $\begin{array}{c}\text { FA } 25 \mathrm{mmol} / \mathrm{L} \\
(\mathrm{pH} \mathrm{3,0)}\end{array}$ & $\mathrm{ACN}$ & $\begin{array}{c}0-2 \min \quad 88-65 \% \text { B } \\
2-4 \min \quad 65 \% \text { B } \\
4-5 \text { min } \quad 65-88 \% \text { B } \\
5-5,5 \text { min } \quad 88 \% \text { B }\end{array}$ & $10 \mu \mathrm{g} / \mathrm{mL}$ em ACN \\
\hline $\mathrm{F}$ & $\begin{array}{c}\text { FA } 25 \mathrm{mmol} / \mathrm{L} \\
(\mathrm{pH} \mathrm{3,0)}\end{array}$ & $\mathrm{ACN}$ & $\begin{array}{cc}0-1 \mathrm{~min} & 88-65 \% \mathrm{~B} \\
1-3 \mathrm{~min} & 65 \% \mathrm{~B} \\
3-3,01 \mathrm{~min} & 65-88 \% \mathrm{~B} \\
3,01-4 \mathrm{~min} & 88 \% \mathrm{~B}\end{array}$ & $10 \mu \mathrm{g} / \mathrm{mL}$ em $A C N$ \\
\hline
\end{tabular}

Legenda: FA: formiato de amônio; ACN: acetonitrila.

O efeito tamponante da fase móvel foi avaliado com a utilização de soluções de formiato de amônio (pH 3) nas concentrações de 0,5; 5; 10; 15; 20; 25 e $50 \mathrm{mmol} / \mathrm{L}$. Para isso, foram realizadas injeções em triplicata de 20 $\mu \mathrm{L}$ da solução padrão de creatina e GAA a $0,1 \mu \mathrm{g} / \mathrm{mL}$ em ACN (item $3.4 .3 \mathrm{c}$ ) 
aplicando o método $\mathrm{F}$ da Tabela 4 para cada concentração de formiato de amônio adicionado à fase móvel $A$.

Foram analisadas diferentes fases estacionárias. Três colunas adaptáveis a cromatografia de interação hidrofílica (HILIC) foram testadas como possíveis candidatas: Sílica (Luna Sílica $2100 \AA$ Å, $3 \mu \mathrm{m}, 50$ × 2,0mm), Ciano (Luna CN $100 \AA$, $3 \mu \mathrm{m}, 50 \times 2,0$ mm), Amino (Luna $\mathrm{NH}_{2} 100 \AA$, $3 \mu \mathrm{m}$, 50 x 2,0 mm). Foi também avaliada uma coluna de ligação cruzada de diol especialmente concebida para aplicação em HILIC (Luna HILIC $200 \AA$ A, 3 m, $50 \times 2,0 \mathrm{~mm}$ ). Para essas análises, $10 \mu \mathrm{L}$ de soluções-padrão contendo creatina e GAA a $10 \mu \mathrm{g} / \mathrm{mL}$ em ACN (item 3.4.3 d) foram injetadas utilizando o gradiente descrito no método $\mathrm{F}$ da Tabela 4.

\subsubsection{Avaliação do efeito elutrópico}

Para verificar a ocorrência ou não do efeito elutrópico, $20 \mu \mathrm{L}$ das soluções-padrão na concentração de $0,1 \mu \mathrm{g} / \mathrm{mL}$ preparadas em água (item 3.4.3 c) e em ACN (item 3.4.3 a) foram injetados utilizando o método $F$ da Tabela 4.

3.6.3. Acoplamento da cromatografia líquida a espectrometria de massas em tandem

Nestas análises foram realizados ajustes em quatro variáveis que podem impactar significativamente a sensibilidade do método analítico:

- Temperatura da fonte: foram testadas as temperaturas de $60^{\circ} \mathrm{C}, 80^{\circ} \mathrm{C}, 100^{\circ} \mathrm{C}$ e $120^{\circ} \mathrm{C}$; 
- Temperatura da coluna: foram testadas as temperaturas de $30^{\circ} \mathrm{C}, 35^{\circ} \mathrm{C}, 40^{\circ} \mathrm{C}$ e $45^{\circ} \mathrm{C}$;

- Temperatura de dessolvatação: foram testadas as temperaturas de $300^{\circ} \mathrm{C}, 350^{\circ} \mathrm{C}, 400^{\circ} \mathrm{C}$ e $450^{\circ} \mathrm{C}$;

- Fluxo do gás de dessolvatação: foram testados os fluxos para o gás de dessolvatação $\left(\mathrm{N}_{2}\right)$ de 500, 600, 700 e $800 \mathrm{~L} / \mathrm{h}$.

Cada parâmetro descrito acima foi avaliado com injeções em triplicata de $20 \mu \mathrm{L}$ da solução-padrão de creatina e GAA a $10 \mu \mathrm{g} / \mathrm{mL}$ em ACN (item 3.4.3 d) sob o método F da Tabela 4.

\subsection{Desenvolvimento do método de extração}

A estratégia adotada para a purificação das amostras foi baseada na extração em fase sólida (SPE) de troca iônica. Foram avaliados os desempenhos de dois tipos de resinas de troca catiônica forte: uma baseada em sílica ligada a grupamentos iônicos $\left(\mathrm{SCX}\right.$ da Phenomenex $\left.{ }^{\circledR}\right)$ e outra em partículas poliméricas (poliestireno divinilbenzeno) ligadas ao mesmo tipo de grupamentos (XC da Phenomenex ${ }^{\circledR}$ ). As placas de 96 poços foram preparadas in house com a utilização do sistema Multiscreen ${ }^{\circledR}$ da Millipore ${ }^{\circledR}$. Diferentes placas foram avaliadas:

- Multiscreen ${ }^{\circledR}$ Solvinert da Millipore ${ }^{\circledR}$ MDRL NP4;

- Multiscreen ${ }^{\circledR}$ Solvinert da Millipore ${ }^{\circledR}$ MDRL NO4;

- AxyPrep ${ }^{\circledR}$ Fritted 1,5 mL da Axygen Biosciences. 
3.7.1. Avaliação inicial do protocolo de extração e definição do sistema de drenagem dos eluatos

Nos testes iniciais foi aplicado um protocolo padrão de extração em fase sólida de troca catiônica forte com a aplicação sequencial das seguintes soluções:

1. $1 \mathrm{~mL}$ de $\mathrm{MeOH}$;

2. $1 \mathrm{~mL}$ de $\mathrm{H}_{2} \mathrm{O}$;

3. $1 \mathrm{~mL}$ da solução padrão única de creatina, GAA e deuterados a $10 \mu \mathrm{g} / \mathrm{mL}$ em ácido fórmico a $25 \mathrm{mmol} / \mathrm{L}$ (item $3.4 .2 \mathrm{~d}$ ) (Eluato $1)$

4. $1 \mathrm{~mL}$ de $\mathrm{HCl} 0,1 \mathrm{M}$ (Eluato 2);

5. $1 \mathrm{~mL}$ de $\mathrm{MeOH}$ (Eluato 3);

6. $1 \mathrm{~mL}$ de $\mathrm{NH}_{4} \mathrm{OH}$ a $5 \%$ em MeOH (Eluato 4).

Para a coleta de cada eluato, foram avaliadas as estratégias de utilização de centrifugação da placa entre as aplicações com diferentes relações rotação/tempo e de um sistema de drenagem por aplicação de vácuo da marca Waters.

Os eluatos 1 a 4 diluídos em ácido fórmico e ACN $(100 \mu \mathrm{L}$ de eluato + $100 \mu \mathrm{L}$ de ácido fórmico a $25 \mathrm{mmol} / \mathrm{L}+800 \mu \mathrm{L}$ de $\mathrm{ACN}$ ) foram analisados por LC-MS/MS com injeção de $20 \mu \mathrm{L}$ de cada. 
3.7.2. Avaliação das soluções para eluição de interferentes ácidos e alcalinos

A Tabela 5 apresenta os diversos protocolos de SPE testados para avaliar a eluição de interferentes ácidos e alcalinos. Para estes testes foi utilizada uma solução-padrão de creatina, GAA e deuterados a $10 \mu \mathrm{g} / \mathrm{mL}$ em ácido fórmico a $25 \mathrm{mmol} / \mathrm{L}$ (item 3.4.2 d).

Tabela 5. Protocolos de avaliação das condições de lavagens de interferentes ácidos e alcalinos. (Amostra: solução de creatina, GAA e deuterados a $10 \mu \mathrm{g} / \mathrm{mL}$ em ácido fórmico a $25 \mathrm{mmol} / \mathrm{L})$.

Protocolos

\begin{tabular}{|c|c|c|c|c|c|c|c|c|}
\hline Controle & 1 & 2 & 3 & 4 & 5 & 6 & 7 & Eluatos \\
\hline $\mathrm{MeOH}$ & $\mathrm{MeOH}$ & $\mathrm{MeOH}$ & $\mathrm{MeOH}$ & $\mathrm{MeOH}$ & $\mathrm{MeOH}$ & $\mathrm{MeOH}$ & $\mathrm{MeOH}$ & Cond. \\
\hline Água & Água & Água & Água & Água & Água & Água & Água & coluna \\
\hline Amostra & Amostra & Amostra & Amostra & Amostra & Amostra & Amostra & Amostra & Eluato 1 \\
\hline Água & $\begin{array}{c}\mathrm{HCl} 10 \\
\mathrm{mM}\end{array}$ & $\begin{array}{c}\text { Ácido } \\
\text { Fórmico } \\
50 \mathrm{mM}\end{array}$ & $\begin{array}{l}\text { Ácido } \\
\text { Acético } \\
50 \mathrm{mM}\end{array}$ & Água & Água & Água & Água & Eluato 2 \\
\hline $\mathrm{MeOH}$ & $\mathrm{MeOH}$ & $\mathrm{MeOH}$ & $\mathrm{MeOH}$ & $\mathrm{MeOH}$ & $\mathrm{MeOH}$ & $\mathrm{MeOH}$ & $\mathrm{MeOH}$ & Eluato 3 \\
\hline & & & & $\begin{array}{c}0,02 \% \\
\mathrm{NH}_{4} \mathrm{OH} \\
e m \\
\mathrm{MeOH}\end{array}$ & $\begin{array}{c}0,12 \% \\
\mathrm{NH}_{4} \mathrm{OH} \\
\mathrm{em} \\
\mathrm{MeOH}\end{array}$ & $\begin{array}{c}0,25 \% \\
\mathrm{NH}_{4} \mathrm{OH} \\
e m \\
\mathrm{MeOH}\end{array}$ & $\begin{array}{c}0,5 \% \\
\mathrm{NH}_{4} \mathrm{OH} \\
e m \\
\mathrm{MeOH}\end{array}$ & Eluato 4 \\
\hline $\begin{array}{c}5 \% \\
\mathrm{NH}_{4} \mathrm{OH} \\
\mathrm{em} \mathrm{MeOH}\end{array}$ & $\begin{array}{c}5 \% \\
\mathrm{NH}_{4} \mathrm{OH} \\
\mathrm{em} \\
\mathrm{MeOH}\end{array}$ & $\begin{array}{c}5 \% \% \\
\mathrm{NH}_{4} \mathrm{OH} \\
\mathrm{em} \\
\mathrm{MeOH}\end{array}$ & $\begin{array}{c}5 \% \\
\mathrm{NH}_{4} \mathrm{OH} \\
\mathrm{em} \\
\mathrm{MeOH}\end{array}$ & $\begin{array}{c}5 \% \\
\mathrm{NH}_{4} \mathrm{OH} \\
\mathrm{em} \\
\mathrm{MeOH}\end{array}$ & $\begin{array}{c}5 \% \\
\mathrm{NH}_{4} \mathrm{OH} \\
\mathrm{em} \\
\mathrm{MeOH}\end{array}$ & $\begin{array}{c}5 \% \\
\mathrm{NH}_{4} \mathrm{OH} \\
\mathrm{em} \\
\mathrm{MeOH}\end{array}$ & $\begin{array}{c}5 \% \\
\mathrm{NH}_{4} \mathrm{OH} \\
\mathrm{em} \\
\mathrm{MeOH}\end{array}$ & Eluato 5 \\
\hline
\end{tabular}

Legenda: Cond. Coluna, condicionamento da coluna.

Todas as frações coletadas (Eluatos 1 a 5 ) foram analisadas por LCMS/MS.

As amostras foram preparadas com a diluição de $100 \mu \mathrm{L}$ do eluato em 
$100 \mu \mathrm{L}$ de ácido fórmico a $25 \mathrm{mmol} / \mathrm{L}$ e $800 \mu \mathrm{L}$ de $\mathrm{ACN}$. O volume injetado foi de $20 \mu \mathrm{L}$.

\subsubsection{Avaliação do meio de preparo da amostra}

Foram realizadas extrações das soluções-padrão contendo creatina, GAA e deuterados a $10 \mu \mathrm{g} / \mathrm{mL}$ em ácido fórmico a $25 \mathrm{mmol} / \mathrm{L}$ (item 3.4 .2 d) e em tampão fosfato a $25 \mathrm{mmol} / \mathrm{L} \mathrm{pH} 1,9$ (item $3.4 .2 \mathrm{e}$ ). O protocolo empregado foi o mesmo descrito para o controle (Tabela 5). As etapas de lavagens ácida e alcalina foram excluídas de maneira a isolar a variável em estudo. As frações coletadas foram analisadas por LC-MS/MS, sendo que 20 $\mu \mathrm{L}$ dos eluatos diluídos em formiato de amônio 25 mmol/L e ACN (100 $\mu \mathrm{L}$ de eluato $+100 \mu \mathrm{L}$ de formiato de amônio $25 \mathrm{mmol} / \mathrm{L}+800 \mu \mathrm{L}$ de $\mathrm{ACN}$ ) foram injetados no sistema.

\subsubsection{Avaliação do volume e concentração de base para eluição}

$\mathrm{O}$ volume e concentração de $\mathrm{NH}_{4} \mathrm{OH}$ necessários para a eluição dos compostos foram avaliados com a extração da solução padrão de creatina, GAA e deuterados a $100 \mu \mathrm{g} / \mathrm{mL}$ em tampão fosfato $25 \mathrm{mmol} / \mathrm{L} \mathrm{pH} \mathrm{1,9} \mathrm{(item}$ 3.4.2 f). O protocolo utilizado está descrito na Tabela 6. As colunas foram condicionadas com $1 \mathrm{~mL}$ de $\mathrm{MeOH}$ e $1 \mathrm{~mL}$ de tampão fosfato $25 \mathrm{mmol} / \mathrm{L} \mathrm{pH}$ 1,9. Todas as etapas de lavagens foram excluídas. 
Tabela 6. Avaliação do volume e concentração da base para a eluição dos analitos (Amostra: solução de creatina, GAA e deuterados a $100 \mu \mathrm{g} / \mathrm{mL}$ em tampão fosfato $25 \mathrm{mmol} / \mathrm{L} \mathrm{pH} \mathrm{1,9).}$

\begin{tabular}{|c|c|c|c|c|c|c|c|c|}
\hline \multicolumn{9}{|c|}{ Protocolos } \\
\hline 1 & 2 & 3 & 4 & 5 & 6 & 7 & 8 & 9 \\
\hline $\mathrm{MeOH}$ & $\mathrm{MeOH}$ & $\mathrm{MeOH}$ & $\mathrm{MeOH}$ & $\mathrm{MeOH}$ & $\mathrm{MeOH}$ & $\mathrm{MeOH}$ & $\mathrm{MeOH}$ & $\mathrm{MeOH}$ \\
\hline Tampão & Tampão & Tampão & Tampão & Tampão & Tampão & Tampão & Tampão & Tampão \\
\hline fosfato & fosfato & fosfato & fosfato & fosfato & fosfato & fosfato & fosfato & fosfato \\
\hline $25 \mathrm{mM}$ & $25 \mathrm{mM}$ & $25 \mathrm{mM}$ & $25 \mathrm{mM}$ & $25 \mathrm{mM}$ & $25 \mathrm{mM}$ & $25 \mathrm{mM}$ & $25 \mathrm{mM}$ & $25 \mathrm{mM}$ \\
\hline $\mathrm{pH} 1,9$ & $\mathrm{pH} 1,9$ & $\mathrm{pH} 1,9$ & $\mathrm{pH} 1,9$ & $\mathrm{pH} 1,9$ & $\mathrm{pH} 1,9$ & $\mathrm{pH} 1,9$ & pH 1,9 & $\mathrm{pH} 1,9$ \\
\hline Amostra & Amostra & Amostra & Amostra & Amostra & Amostra & Amostra & Amostra & Amostra \\
\hline $1 \mathrm{~mL}$ & $0,5 \mathrm{~mL}$ & $0,1 \mathrm{~mL}$ & $1 \mathrm{~mL}$ & $0,5 \mathrm{~mL}$ & $0,1 \mathrm{~mL}$ & $1 \mathrm{~mL}$ & $0,5 \mathrm{~mL}$ & $0,1 \mathrm{~mL}$ \\
\hline $\mathrm{NH}_{4} \mathrm{OH}$ & $\mathrm{NH}_{4} \mathrm{OH}$ & $\mathrm{NH}_{4} \mathrm{OH}$ & $\mathrm{NH}_{4} \mathrm{OH}$ & $\mathrm{NH}_{4} \mathrm{OH}$ & $\mathrm{NH}_{4} \mathrm{OH}$ & $\mathrm{NH}_{4} \mathrm{OH}$ & $\mathrm{NH}_{4} \mathrm{OH}$ & $\mathrm{NH}_{4} \mathrm{OH}$ \\
\hline $5 \% \mathrm{em}$ & $5 \%$ em & $5 \%$ em & $10 \%$ em & $10 \%$ em & $10 \% \mathrm{em}$ & $20 \%$ em & $20 \%$ em & $20 \%$ em \\
\hline $\mathrm{MeOH}$ & $\mathrm{MeOH}$ & $\mathrm{MeOH}$ & $\mathrm{MeOH}$ & $\mathrm{MeOH}$ & $\mathrm{MeOH}$ & $\mathrm{MeOH}$ & $\mathrm{MeOH}$ & $\mathrm{MeOH}$ \\
\hline
\end{tabular}

Legenda: $\mathrm{MeOH}$, metanol.

Os eluatos das extrações de 1 a 9 foram coletados e analisados por LC-MS/MS. Foram injetados $5 \mu \mathrm{L}$ dos eluatos puros (sem neutralização nem diluição em ACN).

3.7.5. Avaliação preliminar da sensibilidade de detecção sem extração em fase sólida

Para verificar a sensibilidade do método analítico independentemente da extração, amostras contendo creatina e GAA nas concentrações de 0,05; 0,1 e $1 \mu \mathrm{g} / \mathrm{mL}$ em ACN (itens $3.4 .3 \mathrm{~g}, 3.4 .3 \mathrm{c}$ e $3.4 .3 \mathrm{~h}$ ) foram analisadas sem extração prévia. O volume injetado de cada uma destas soluções foi de $20 \mu \mathrm{L}$. 
3.7.6. Avaliação da inserção de uma etapa de concentração da amostra

Nesse teste foi avaliada a inserção de uma etapa de secagem dos eluatos obtidos por SPE em um sistema de liofilização ou concentração a vácuo (speed vac). Foram realizadas extrações de padrões de creatina, GAA e seus deuterados nas concentrações de $10 \mu \mathrm{g} / \mathrm{mL}$ (item 3.4.2 e) e 100 $\mu \mathrm{g} / \mathrm{mL}$ (item 3.4.2 f) com aplicação sequencial das seguintes soluções:

1. $1 \mathrm{~mL}$ de $\mathrm{MeOH}$;

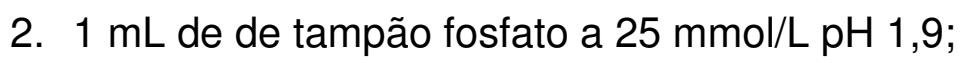

3. $1 \mathrm{~mL}$ de solução padrão creatina e GAA adicionado de $25 \mu \mathrm{L}$ de tampão fosfato $2 \mathrm{M} \mathrm{pH} \mathrm{1,9} \mathrm{(eluato} \mathrm{1);}$

4. $1 \mathrm{~mL}$ de ácido fórmico a $50 \mathrm{mmol} / \mathrm{L}$ (eluato 2);

5. $1 \mathrm{~mL}$ de $\mathrm{NH}_{4} \mathrm{OH} 0,02 \%$ em MeOH (eluato 3);

6. $0,5 \mathrm{~mL}$ de $\mathrm{NH}_{4} \mathrm{OH}$ a $5 \%$ em MeOH (Eluato 4).

Os eluatos de 1 a 4 foram secos em speed vac, ressuspendidos com $12 \mu \mathrm{L}$ de água e $88 \mu \mathrm{L}$ de $\mathrm{ACN}$ e $20 \mu \mathrm{L}$ injetados no sistema.

\subsubsection{Avaliação da linearidade em padrões aquosos}

Neste teste foi realizada a avaliação preliminar de linearidade em padrões aquosos com a adição de padrões internos à amostra.

Foram utilizadas as soluções-padrão aquosas de 0,$05 ; 0,1 ; 1 ; 10 ; 100 \mathrm{e}$ $500 \mu \mathrm{g} / \mathrm{mL}$ de creatina e GAA (item 3.4.4) e a solução única de creatina- $d_{3}$ e GAA- $d_{2}$ na concentração de $500 \mu \mathrm{g} / \mathrm{mL}$ em água (item $3.4 .2 \mathrm{~g}$ ).

As amostras foram preparadas adicionando-se a $1 \mathrm{~mL}$ de soluções de 
creatina e GAA nas diferentes concentrações, $25 \mu \mathrm{L}$ de tampão fosfato 2 $\mathrm{mol} / \mathrm{L} \mathrm{pH} \mathrm{1,9} \mathrm{e} 50 \mu \mathrm{L}$ da solução dos padrões internos (PI).

A extração foi realizada segundo o protocolo descrito no item 3.7.6. As amostras foram analisadas por LC-MS/MS e os resultados obtidos com a utilização de um método de quantificação que utiliza a relação das áreas dos compostos de interesse pela área dos respectivos análogos deuterados (creatina/ creatina- $d_{3}$ e GAA/ GAA- $d_{2}$ ).

\subsection{Extração em fase sólida com matriz urinária}

3.8.1. Definição do volume da amostra para extração em resina SCX

Foi realizado um teste preliminar com extração de volumes de 100 e $500 \mu \mathrm{L}$ de urina pura e de urina adicionada de solução-padrão de creatina e GAA representando um acréscimo de $50 \mu \mathrm{g} / \mathrm{mL}$ ao valor basal (item 3.4.6 a). A preparação da amostra para aplicação na placa pré-condicionada com 1 $\mathrm{mL} \mathrm{MeOH}$ e $1 \mathrm{~mL}$ de tampão fosfato $25 \mathrm{mmol} / \mathrm{L} \mathrm{pH} 1,9$ foi realizada da seguinte maneira:

- $500 \mu \mathrm{L}$ de urina $+12,5 \mu \mathrm{L}$ de tampão fosfato $2 \mathrm{~mol} / \mathrm{L}+50 \mu \mathrm{L}$ da solução de PI a $10 \mu \mathrm{g} / \mathrm{mL}$ (item 3.4.3 e);

- $100 \mu \mathrm{L}$ de urina $+400 \mu \mathrm{L}$ de água $+12,5 \mu \mathrm{L}$ de tampão fosfato 2 $\mathrm{mol} / \mathrm{L}+50 \mu \mathrm{L}$ da solução de PI a10 $\mu \mathrm{g} / \mathrm{mL}$.

Os eluatos secos em speed vac foram ressuspendidos com $12 \mu \mathrm{L}$ de água e $88 \mu \mathrm{L}$ de $\mathrm{ACN}$ e $20 \mu \mathrm{L}$ injetados no sistema. Para a quantificação das amostras foi construída uma curva de calibração por meio da extração de $500 \mu \mathrm{L}$ dos padrões aquosos nas concentrações de 0,$05 ; 0,1 ; 1 ; 10 ; 100$ e 
$500 \mu \mathrm{g} / \mathrm{mL}$ (item 3.4.4).

Esse experimento foi expandido extraindo-se 10, 50 e $100 \mu \mathrm{L}$ de urina pura e urina adicionada de 1, 100, 500 e $1000 \mu \mathrm{g} / \mathrm{mL}$ de creatina e GAA (itens 3.4.6b a 3.4.6 e). Paralelamente foram extraídos $100 \mu \mathrm{L}$ dos padrões aquosos nas concentrações de 0,$5 ; 1 ; 10 ; 25 ; 50 ; 100 ; 500$ e $1000 \mu \mathrm{g} / \mathrm{mL}$ (item 3.4.4). Tendo em vista a diminuição de volume de amostra, foram também reduzidos os volumes das soluções de condicionamento da coluna e de lavagem de $1 \mathrm{~mL}$ para $500 \mu \mathrm{L}$.

As amostras com e sem adição de padrões foram preparadas para SPE como descrito a seguir:

- $10 \mu \mathrm{L}$ de amostra $+12,5 \mu \mathrm{L}$ de tampão fosfato $2 \mathrm{~mol} / \mathrm{L}+50 \mu \mathrm{L}$ de PI a $10 \mu \mathrm{g} / \mathrm{mL}$ (item 3.4.3 e) + $490 \mu \mathrm{L}$ de água;

- $50 \mu \mathrm{L}$ de amostra $+12,5 \mu \mathrm{L}$ de tampão fosfato $2 \mathrm{~mol} / \mathrm{L}+50 \mu \mathrm{L}$ de $\mathrm{PI}(10 \mu \mathrm{g} / \mathrm{mL})+450 \mu \mathrm{L}$ de água;

- $100 \mu \mathrm{L}$ de amostra $+12,5 \mu \mathrm{L}$ de tampão fosfato $2 \mathrm{~mol} / \mathrm{L}+50 \mu \mathrm{L}$ de PI $(10 \mu \mathrm{g} / \mathrm{mL})+400 \mu \mathrm{L}$ de água.

Os extratos secos foram ressuspendidos em $24 \mu \mathrm{L}$ de água e $176 \mu \mathrm{L}$ de ACN. Foram injetados os volumes de 5, 10, 20 e $40 \mu \mathrm{L}$.

3.8.2 Avaliação preliminar de limite de quantificação em matriz urinária

O estudo preliminar de limite de quantificação para urina foi realizado com a extração de diluições de urina em urina sintética para GAA e em solução fisiológica ( $\mathrm{NaCl}$ 0,15 mmol/L) para creatina. As extrações foram 
realizadas segundo o protocolo descrito no item 3.7.6 com os volumes das soluções de condicionamento de coluna e lavagem reduzidos conforme descrito no item 3.8.1. A amostra foi preparada com a adição de $50 \mu \mathrm{L}$ de amostra, $12,5 \mu \mathrm{L}$ de tampão fosfato $2 \mathrm{~mol} / \mathrm{L}, 50 \mu \mathrm{L}$ de Pl a $10 \mu \mathrm{g} / \mathrm{mL}$ (item de 3.4.3 e) e $450 \mu \mathrm{L}$ de água. O eluato seco em speed vac foi ressuspendido com $24 \mu \mathrm{L}$ de água e $176 \mu \mathrm{L}$ de ACN. Foram injetados $5 \mu \mathrm{L}$.

3.8.3. Avaliação preliminar da recuperação do ensaio em matriz urinária

Foi conduzido um estudo preliminar da recuperação com amostra de urina pela extração de $50 \mu \mathrm{L}$ de preparações de urina pura e adicionada com 1, 100, 500 e $1000 \mu \mathrm{g} / \mathrm{mL}$ de padrão de creatina e GAA (itens $3.4 .6 \mathrm{~b}$ a 3.4.6 e). Os extratos secos foram ressuspendidos com $24 \mu \mathrm{L}$ de água e 176 $\mu \mathrm{L}$ de $\mathrm{ACN}$ e $5 \mu \mathrm{L}$ injetados. Os cálculos foram realizados utilizando-se a curva de calibração aquosa com concentrações de 0,5 a $500 \mu \mathrm{g} / \mathrm{mL}$ (item 3.4.4).

3.8.4. Comparação das extrações de urina em resina SCX (sílica) e XC (polímero)

Foram realizadas extrações das amostras preparadas para o teste de linearidade em urina (item 3.4.6.2) em placa preparada com resina SCX e em placa preparada com resina XC. 
3.8.5. Definição dos volumes de extração em resina $X C$

Foram realizadas extrações em resina XC dos volumes de 5, 10 e 50 $\mu \mathrm{L}$ de amostras preparadas para o teste de linearidade em urina (item 3.4.6.2).

A preparação das amostras foi reajustada em função do volume de extração:

- $5 \mu \mathrm{L}$ de amostra $+12,5 \mu \mathrm{L}$ de tampão fosfato a $2 \mathrm{~mol} / \mathrm{L}+50 \mu \mathrm{L}$ de PI a $10 \mu \mathrm{g} / \mathrm{mL}$ (item 3.4.3 e) + $495 \mu \mathrm{L}$ de água;

- $10 \mu \mathrm{L}$ de amostra $+2,5 \mu \mathrm{L}$ de tampão fosfato a $2 \mathrm{~mol} / \mathrm{L}+50 \mu \mathrm{L}$ de PI $(10 \mu \mathrm{g} / \mathrm{mL})+490 \mu \mathrm{L}$ de água;

- $50 \mu \mathrm{L}$ de amostra $+12,5 \mu \mathrm{L}$ de tampão fosfato a $2 \mathrm{~mol} / \mathrm{L}+50 \mu \mathrm{L}$ de PI $(10 \mu \mathrm{g} / \mathrm{mL})+450 \mu \mathrm{L}$ de água.

Os extratos secos foram ressuspendidos com $24 \mu \mathrm{L}$ de água e $176 \mu \mathrm{L}$ de ACN. Foram injetados $10 \mu \mathrm{L}$.

\subsection{Extração em fase sólida com matriz de soro ou plasma}

\subsubsection{Tamponamento da amostra}

Foi avaliada a relação soro/ácido ortofosfórico adequada para o tamponamento da amostra em um pH em torno de 1,5.

Para isso foram utilizados $100 \mu \mathrm{L}$ de pool de soros adicionados de diferentes volumes de ácido ortofosfórico e os pHs resultantes foram medidos com fita indicadora de $\mathrm{pH}$ da Merck. 
3.9.2. Contribuição da extração em SPE no sinal dos analitos em soro/plasma

Foram preparados dois grupos de amostras sendo que um deles foi submetido a extração por SPE (grupo 1) e o outro foi apenas desproteinizado e centrifugado (grupo 2). A preparação das amostras foi realizada como descrito a seguir:

Grupo 1 (amostras a serem extraídas em SPE):

- $25 \mu \mathrm{L}$ de soro dialisado $+0,5 \mu \mathrm{L}$ de ácido ortofosfórico $+10 \mu \mathrm{L}$ de PI a $100 \mu \mathrm{g} / \mathrm{mL}$ (item 3.4.3 f) + $930 \mu \mathrm{L}$ de água;

- $50 \mu \mathrm{L}$ de soro dialisado $+1 \mu \mathrm{L}$ de ácido ortofosfórico $+10 \mu \mathrm{L}$ de PI a $100 \mu \mathrm{g} / \mathrm{mL}+900 \mu \mathrm{L}$ de água;

- $100 \mu \mathrm{L}$ de soro dialisado $+2 \mu \mathrm{L}$ de ácido ortofosfórico $+10 \mu \mathrm{L}$ de PI a $100 \mu \mathrm{g} / \mathrm{mL}+850 \mu \mathrm{L}$ de água;

- $200 \mu \mathrm{L}$ de soro dialisado $+4 \mu \mathrm{L}$ de ácido ortofosfórico $+10 \mu \mathrm{L}$ de PI a $100 \mu \mathrm{g} / \mathrm{mL}+750 \mu \mathrm{L}$ de água.

Cada uma das amostras foi aplicada na placa de extração preparada com a resina de troca catiônica Sepra XC précondicionda com $0,5 \mathrm{~mL}$ de $\mathrm{MeOH}$ e $0,5 \mathrm{~mL}$ de tampão fosfato a $25 \mathrm{mmol} / \mathrm{L}$. Foram realizadas lavagens seqüenciais com $0,5 \mathrm{~mL}$ de ácido fórmico a $50 \mathrm{mmol} / \mathrm{L}$ e $0,5 \mathrm{~mL}$ de $\mathrm{NH}_{4} \mathrm{OH}$ a $0,02 \%$ em metanol. Os analitos foram eluídos da placa com a aplicação de $0,5 \mathrm{~mL}$ de $\mathrm{NH}_{4} \mathrm{OH}$ a $5 \%$ em metanol e secos em speed vac. Os extratos secos foram ressuspendidos com $24 \mu \mathrm{L}$ de água e $176 \mu \mathrm{L}$ de ACN. 
Grupo 2 (amostras sem extração, apenas desproteinizadas):

- $25 \mu \mathrm{L}$ de soro dialisado $+10 \mu \mathrm{L}$ de PI a $100 \mu \mathrm{g} / \mathrm{mL}$ (item 3.4 .3 f) $+125 \mu \mathrm{L}$ de ACN;

- $50 \mu \mathrm{L}$ de soro dialisado $+10 \mu \mathrm{L}$ de PI a $100 \mu \mathrm{g} / \mathrm{mL}+250 \mu \mathrm{L}$ de $\mathrm{ACN}$;

- $100 \mu \mathrm{L}$ de soro dialisado $+10 \mu \mathrm{L}$ de PI a $100 \mu \mathrm{g} / \mathrm{mL}+500 \mu \mathrm{L}$ de ACN;

- $200 \mu \mathrm{L}$ de soro dialisado $+10 \mu \mathrm{L}$ de PI a $100 \mu \mathrm{g} / \mathrm{mL}+1000 \mu \mathrm{L}$ de ACN.

As amostras foram homogeneizadas e centrifugadas a 13000 RPM (14170 g) por 10 minutos. Os sobrenadantes foram secos em speed vac e os extratos secos ressuspendidos com $24 \mu \mathrm{L}$ de água e $176 \mu \mathrm{L}$ de ACN.

Foram injetados no espectrômetro $10 \mu \mathrm{L}$ de cada amostra.

\subsubsection{Avaliação da eficiência da remoção de proteínas pela extração}

Para verificar se as proteínas presentes na amostra eram removidas pela extração foi coletado o eluato resultante da aplicação da amostra de $100 \mu \mathrm{L}$ de soro dialisado na placa de extração e foi preparada uma diluição correspondente de soro dialisado em água $(100 \mu \mathrm{L}$ de soro dialisado +762 $\mu \mathrm{L}$ de água).

As duas amostras foram analisadas quanto ao conteúdo proteico por vermelho de pirogalol no equipamento ADVIA ${ }^{\circledR} 1200$. 


\subsection{Validação do método}

Os seguintes parâmetros de validação foram analisados: linearidade ${ }^{44}$, recuperação ${ }^{44}$, precisão ${ }^{45}$, limite de quantificação ${ }^{46}$, exatidão ${ }^{47}$ e arraste (carryover $)^{48}$. Foram seguidos os procedimentos recomendados pelo CLSI. Os dados foram analisados com o uso do software EP Evaluator versão $4^{48}$.

A extração das amostras foi realizada segundo os protocolos definidos em função da natureza do material (urina ou soro), conforme descrito abaixo:

- Linearidade: toda a sequência foi extraída três vezes e analisadas no mesmo dia.

- Precisão: foram realizadas extrações em duplicata de cada um dos três níveis avaliados durante 20 dias perfazendo um total de 40 extrações por nível.

- Limite de quantificação: foram realizadas duas extrações de cada diluição por dia durante 10 dias resultando em um total de 20 extrações de cada diluição.

- Arraste: as amostras foram extraídas e analisadas na seguinte sequência: $B, B, B, A, A, B, A, A, B, B, B, B, A, A, B, A, A, B, A$, A, B

Os dados obtidos foram analisados no software EP Evaluator versão $4^{48}$. 
A exatidão em soro foi avalida apenas na acepção de recuperação e em matriz urinária foram utilizadas vinte amostras de pacientes portadores de alguma das formas de Síndrome de Deficiência de Creatina cedidas pelo Instituto de Genética Médica Jacinto de Magalhães (IGMJM), sediado na cidade do Porto, Portugal, e doze amostras provenientes de pacientes com suspeita dessa condição, encaminhadas à Mayo Clinic, Rochester, Estados Unidos.

\subsection{Casuística}

Este estudo foi avaliado e aprovado pela Comissão de ética para análise de Projetos de Pesquisa (CAPPESQ) da Diretoria Clínica do Hospital das Clínicas e da Faculdade de Medicina da Universidade de São Paulo, avaliado e aprovado em 16/06/2006, protocolo 244/06 (Anexo A), pelo Instituto Fleury (Anexo B) e pelo Comitê de Ética em Pesquisa do Hospital Universitário da Universidade de São Paulo (Anexo C).

Os experimentos para o desenvolvimento e validação do método e 0 processamento das amostras foram realizados no setor de Cromatografia do Setor de Análises Clínicas do Grupo Fleury em colaboração com sua área de Inovação, Pesquisa e Desenvolvimento.

As amostras para determinação dos valores de referência foram obtidas após aplicação de termo de consentimento livre esclarecido apropriado (Anexo D) a indivíduos de ambos os sexos com idades entre 0 a 16 anos atendidos em regime ambulatorial no setor de coleta do Serviço de Laboratório Clínico do Hospital Universitário da Universidade de São Paulo. 
Tais indivíduos compareceram àquele serviço por terem solicitação médica para coleta de urina e/ou sangue para a realização de exames rotineiros. Quando possível, foi aproveitado o excedente daquele material.

Amostras de indivíduos portadores de manifestações clínicas compatíveis com a síndrome de deficiência de creatina foram obtidas após aplicação de termo de consentimento livre e esclarecido apropriado a seus responsáveis (Anexo $\mathrm{E}$ ) e mantidas $\mathrm{a}-70^{\circ} \mathrm{C}$ até o momento das análises.

Os critérios de inclusão neste estudo foram essencialmente clínicos sendo definidos com possíveis participantes indivíduos que apresentassem:

- Deficiência mental isolada;

- Deficiência mental com padrão sugestivo de herança recessiva (mais de um irmão afetado ou presença de consanguinidade), ou associação com epilepsia e distúrbio de movimento tipo coreotetose;

- Deficiência mental com padrão sugestivo de herança ligada ao $\mathrm{X}$, nos quais tivesse sido excluída a síndrome do X frágil;

- Comportamento autista.

Esses pacientes foram provenientes do Hospital das Clínicas de Ribeirão Preto $(n=17)$, Hospital das Clínicas de Ribeirão Preto em colaboração com a APAE de Limeira $(n=22)$, Hospital das Clínicas de Porto Alegre $(n=2)$, Centro de Estudo do Genoma Humano $(n=2)$, Hospital das Clínicas da Faculdade de Medicina da Universidade de São Paulo $(n=10)$ e encaminhamento por interesse de colaboração de médico particular $(n=1)$, totalizando 54 amostras. 
Tabela 7. Descrição dos pacientes incluídos no estudo quanto a idade, sexo, consanguinidade parental e quadro clínico.

\begin{tabular}{|c|c|c|c|c|}
\hline Pac. & $\begin{array}{l}\text { Idade } \\
\text { (anos) }\end{array}$ & Sexo & $\begin{array}{l}\text { Consangüinida } \\
\text { de parental }\end{array}$ & Quadro clínico \\
\hline 1 & 3 & M & P1 & Retardo mental \\
\hline 2 & 6 & $\mathrm{~F}$ & Não & Atraso no desenvolvimento \\
\hline 3 & 10 & M & $\mathrm{P} 1$ & Retardo mental, Microcefalia, distonia \\
\hline 4 & 11 & M & Não & Retardo mental, distonia \\
\hline 5 & 12 & $\mathrm{~F}$ & P3 & Retardo mental \\
\hline 6 & 8 & $\mathrm{~F}$ & P1 & Retardo mental, coreoatetose \\
\hline 7 & 6 & M & P3 & Retardo mental, Epilepsia grave \\
\hline 8 & 7 & M & Não & Espectro autista \\
\hline 9 & 14 & M & Não & Clínica compatível com SDC \\
\hline 10 & 14 & $M$ & Não & $\begin{array}{c}\text { Retardo DNPM ligado ao X com alteração } \\
\text { comportamental e epilepsia }\end{array}$ \\
\hline 11 & 9 & $M$ & Não & $\begin{array}{c}\text { Retardo do desenvolvimento neuromotor } \\
\text { ligado ao X, alteração comportamental e } \\
\text { epilepsia }\end{array}$ \\
\hline 12 & 15 & $M$ & Não & $\begin{array}{l}\text { Retardo do desenvolvimento neuromotor } \\
\text { ligado ao X, alteração comportamental e } \\
\text { epilepsia }\end{array}$ \\
\hline 13 & 13 & $M$ & Não & $\begin{array}{c}\text { Deficiência mental ligada ao X e alteração } \\
\text { comportamental }\end{array}$ \\
\hline 14 & 13 & $M$ & Não & $\begin{array}{c}\text { Deficiência mental ligada ao X e alteração } \\
\text { comportamental }\end{array}$ \\
\hline 15 & 19 & $M$ & Não & $\begin{array}{l}\text { Retardo do DNPM, epilepsia e alterações } \\
\text { comportamentais }\end{array}$ \\
\hline 16 & 2 & $M$ & Não & $\begin{array}{l}\text { Deficiência mental, distúrbios da fala e crises } \\
\text { convulsivas }\end{array}$ \\
\hline 17 & 8 & $M$ & Não & $\begin{array}{l}\text { Deficiência mental, distúrbio comportamental e } \\
\text { epilepsia }\end{array}$ \\
\hline 18 & 2 & $M$ & Não & $\begin{array}{c}\text { Deficiência mental ligada ao X e alteração } \\
\text { comportamental }\end{array}$ \\
\hline 19 & 10 & $M$ & Não & $\begin{array}{c}\text { Deficiência mental e atraso importante do } \\
\text { desenvolvimento da fala }\end{array}$ \\
\hline
\end{tabular}




\begin{tabular}{|c|c|c|c|c|}
\hline Pac. & $\begin{array}{l}\text { Idade } \\
\text { (anos) }\end{array}$ & Sexo & $\begin{array}{c}\text { Consangüinida } \\
\text { de parental }\end{array}$ & Quadro clínico \\
\hline 20 & 17 & $M$ & Não & $\begin{array}{c}\text { Deficiência mental ligada ao X e alteração } \\
\text { comportamental }\end{array}$ \\
\hline 21 & $\mathrm{NI}$ & M & Não & $\begin{array}{l}\text { Deficiência mental ligada ao X, alteração } \\
\text { comportamental e epilepsia }\end{array}$ \\
\hline 22 & 12 & M & Não & $\begin{array}{c}\text { Deficiência mental possivelmente ligada ao } \mathrm{X} \\
\text { e epilepsia }\end{array}$ \\
\hline 23 & 12 & $M$ & Não & $\begin{array}{c}\text { Deficiência mental possivelmente ligada ao X, } \\
\text { alteração comportamental e epilepsia }\end{array}$ \\
\hline 24 & 12 & $M$ & Não & $\begin{array}{c}\text { Deficiência mental e alteração } \\
\text { comportamental }\end{array}$ \\
\hline 25 & 15 & $M$ & Não & $\begin{array}{c}\text { Deficiência mental, atraso importante do } \\
\text { desenvolvimento da fala e alteração } \\
\text { comportamental }\end{array}$ \\
\hline 26 & 4 & $M$ & Não & $\begin{array}{c}\text { Atraso no DNPM, movimentos involuntários e } \\
\text { epilepsia }\end{array}$ \\
\hline 27 & 9 & $\mathrm{~F}$ & $\mathrm{NI}$ & $\mathrm{NI}$ \\
\hline 28 & 6 & $M$ & Não & $\begin{array}{c}\text { Involução do DNPM após o } 6^{\circ} \text { mês, síndrome } \\
\text { extrapiramidal }\end{array}$ \\
\hline 29 & $\mathrm{NI}$ & $M$ & Não & $\begin{array}{l}\text { Deficiência mental, atraso importante do } \\
\text { desenvolvimento da fala e alteração } \\
\text { comportamental }\end{array}$ \\
\hline 30 & 19 & $M$ & Não & $\begin{array}{c}\text { Deficiência mental ligada ao X, alteração } \\
\text { comportamental e epilepsia }\end{array}$ \\
\hline 31 & 15 & M & Não & $\begin{array}{c}\text { Deficiência mental possivelmente ligada ao X } \\
\text { e alteração comportamental }\end{array}$ \\
\hline 32 & 40 & $M$ & Não & $\begin{array}{l}\text { Deficiência mental moderada, alterações } \\
\text { comportamentais graves e atraso da fala }\end{array}$ \\
\hline 33 & 4 & $M$ & Não & $\begin{array}{c}\text { Deficiência mental, atraso importante do } \\
\text { desenvolvimento da fala e alteração } \\
\text { comportamental }\end{array}$ \\
\hline 34 & 9 & $\mathrm{~F}$ & Não & $\begin{array}{l}\text { Deficiência mental e alteração } \\
\text { comportamental }\end{array}$ \\
\hline 35 & 19 & $\mathrm{~F}$ & Não & Deficiência mental e epilepsia \\
\hline 36 & 7 & M & Não & Deficiência mental e distúrbio de fala \\
\hline 37 & 14 & M & Não & $\begin{array}{c}\text { Deficiência mental moderada, atraso } \\
\text { importante do desenvolvimento da fala e } \\
\text { alteração comportamental }\end{array}$ \\
\hline
\end{tabular}




\begin{tabular}{|c|c|c|c|c|}
\hline Pac. & $\begin{array}{l}\text { Idade } \\
\text { (anos) }\end{array}$ & Sexo & $\begin{array}{c}\text { Consangüinida } \\
\text { de parental }\end{array}$ & Quadro clínico \\
\hline 38 & 9 & $\mathrm{~F}$ & Não & Deficiência mental e epilepsia \\
\hline 39 & 17 & M & Não & $\begin{array}{l}\text { Deficiência mental ligada ao } \mathrm{X} \text {, crises } \\
\text { convulsivas e comportamento autista }\end{array}$ \\
\hline 40 & 7 & M & Não & $\begin{array}{l}\text { Deficiência mental, distúrbio comportamental e } \\
\text { epilepsia }\end{array}$ \\
\hline & & & & Deficiência mental moderada, atraso \\
\hline 41 & 37 & M & Não & $\begin{array}{l}\text { importante do desenvolvimento da fala e } \\
\text { alteração comportamental }\end{array}$ \\
\hline 42 & 19 & M & Não & $\begin{array}{c}\text { Deficiência mental, atraso importante do } \\
\text { desenvolvimento da fala e crises convulsivas }\end{array}$ \\
\hline 43 & $\mathrm{NI}$ & M & $\mathrm{NI}$ & $\mathrm{NI}$ \\
\hline 44 & 6 & M & P1 & $\begin{array}{l}\text { Atraso do desenvolvimento neuromotor e da } \\
\text { fala, retardo mental moderado, leve atetose e } \\
\text { epilepsia }\end{array}$ \\
\hline 45 & 5 & M & Não & $\begin{array}{c}\text { Distonia após os } 4 \text { meses com regressão } \\
\text { neurológica, síndromes extrapiramidal e } \\
\text { piramidal }\end{array}$ \\
\hline 46 & 10 & M & Não & $\begin{array}{l}\text { Deficiência menatal ligada ao } X \text {, atraso de fala } \\
\text { moderado }\end{array}$ \\
\hline 47 & 20 & $\mathrm{~F}$ & $\mathrm{P} 1$ & $\begin{array}{l}\text { Deficiência mental e alteração } \\
\text { comportamental }\end{array}$ \\
\hline 48 & 15 & M & Não & $\begin{array}{l}\text { Deficiência mental e alteração } \\
\text { comportamental }\end{array}$ \\
\hline 49 & 14 & M & Não & $\begin{array}{c}\text { Deficiência mental ligada ao } \mathrm{X} \text { e atraso de fala } \\
\text { importante }\end{array}$ \\
\hline 50 & 6 & $\mathrm{~F}$ & Não & $\begin{array}{l}\text { Deficiência mental, alteração comportamental } \\
\text { e epilepsia }\end{array}$ \\
\hline 51 & 5 & M & Não & $\begin{array}{c}\text { Deficiência mental ligada ao } \mathrm{X} \text { e atraso de fala } \\
\text { importante }\end{array}$ \\
\hline 52 & 17 & M & P2 & Deficiência mental e atraso de fala importante \\
\hline 53 & 16 & M & Não & $\begin{array}{l}\text { Deficiência mental ligada ao } X \text {, atraso de fala } \\
\text { e crises convulsivas }\end{array}$ \\
\hline 54 & 5 & M & $\mathrm{NI}$ & $\begin{array}{l}\text { Deficiência mental, atraso da fala e } \\
\text { comportamento autista }\end{array}$ \\
\hline
\end{tabular}

Legenda: Pac., paciente; DNPM, desenvolvimento neuropsicomotor; NI, não informado; P1, primos em $1^{\circ}$ grau; P2, primos em $2^{\circ}$ grau; P3, primos em $3^{\circ}$ grau. 


\section{RESULTADOS E DISCUSSÃO}

\subsection{Análises por espectrometria de massas em tandem}

\subsubsection{Análises qualitativas}

Para que a detecção por espectrometria de massas seja possível, é necessário que as moléculas estejam carregadas positiva ou negativamente, já que apenas espécies iônicas podem ser analisadas e separadas em função de sua relação massa/carga $(\mathrm{m} / \mathrm{z})$. Com base nas estruturas das moléculas de creatina, guanidinoacetato e creatinina, foi selecionado o modo positivo para esses analitos.

As amostras, preparadas e analisadas segundo descrito nos itens 3.4 e 3.5 de Materiais e Métodos, foram infundidas no espectrômetro utilizando uma fase móvel composta de $40 \%$ de formiato de amônio a $5 \mathrm{mmol} / \mathrm{L} \mathrm{com}$ $60 \%$ de acetonitrila para favorecer o processo de ionização dos analitos.

A varredura dos padrões de creatina, GAA, creatinina e seus análogos deuterados creatina- $d_{3}$, GAA- $d_{2}$ e creatinina- $d_{3}$ realizada de $m / z 40$ a 150 (full scan ou varredura) revelou a presença dos íons de $m / z 132,118$, 114, 135, 120, 117 respectivamente.

Uma vez verificada a presença em grande abundância das moléculas protonadas dos analitos, os seus padrões de fragmentação foram avaliados com a finalidade de identificar as melhores transições de massas a serem monitoradas para a quantificação.

Esse estudo foi realizado para cada composto em espectrômetro de resolução unitária (Quattro Micro) com a infusão contínua a um fluxo de 5 
$\mu \mathrm{L} / \mathrm{min}$ de soluções-padrão a $50 \mu \mathrm{g} / \mathrm{mL}$ em água e aplicação de diferentes energias de colisão de forma a obter-se os espectros de dissociação dos íons precursores.

Uma das maiores dificuldades na aplicação de detecção por espectrometria de massas em tandem a moléculas pequenas é a obtenção de transições de massas específicas e informativas, uma vez que seu perfil de fragmentação é dominado por íons inespecíficos correspondentes a perdas comuns como $\mathrm{H}_{2} \mathrm{O}, \mathrm{CO}_{2}$ and $\mathrm{NH}_{3}{ }^{49}$. Apesar disso, a análise dos íons produzidos pela dissociação induzida por colisão (CID) e ionização por electrospray no modo positivo da creatina e guanidinoacetato protonados revelou vários fragmentos que poderiam ser utilizados para a sua quantificação. Embora um espectrômetro de massas em tandem de baixa resolução tenha sido utilizado para esse estudo, adicionalmente foi realizada uma análise em um equipamento de alta resolução no sentido de esclarecer as identidades das transições de massas e contribuir para a proposição dos mecanismos de fragmentação envolvidos. Para isso foi utilizado o analisador Q-TOF Synapt operando no modo nanoelectrospray positivo e soluções de padrões a $0,05 \mu \mathrm{g} / \mathrm{mL}$ (item $3 \cdot 4 \cdot 3 \mathrm{i}$ ).

Os fragmentos mais intensos resultantes dissociação da creatina protonada poderiam ser atribuídos a perdas sequenciais de uma metanodiimina da porção guanidino e uma molécula de ácido fórmico, resultando em íons de $m / z$ de 90 e 44 , respectivamente.

A dissociação do guanidinoacetato resultou em três intensos fragmentos de $m / z 101,76$ e 74 . O primeiro deles adveio da perda de $\mathrm{NH}_{3}$, 
uma perda comum e por isso desconsiderada. O fragmento de $\mathrm{m} / \mathrm{z} 76$ poderia ser resultante da eliminação de uma molécula de metanodiimina a exemplo do que ocorreu para creatina protonada. É importante notar que a eliminação desse grupo é característica de moléculas que contêm grupamentos guanidino, o que a torna bastante específica. A transição de m/z de 72 foi obtida pela perda não sequencial de uma molécula de ácido fórmico (Figura 5). 


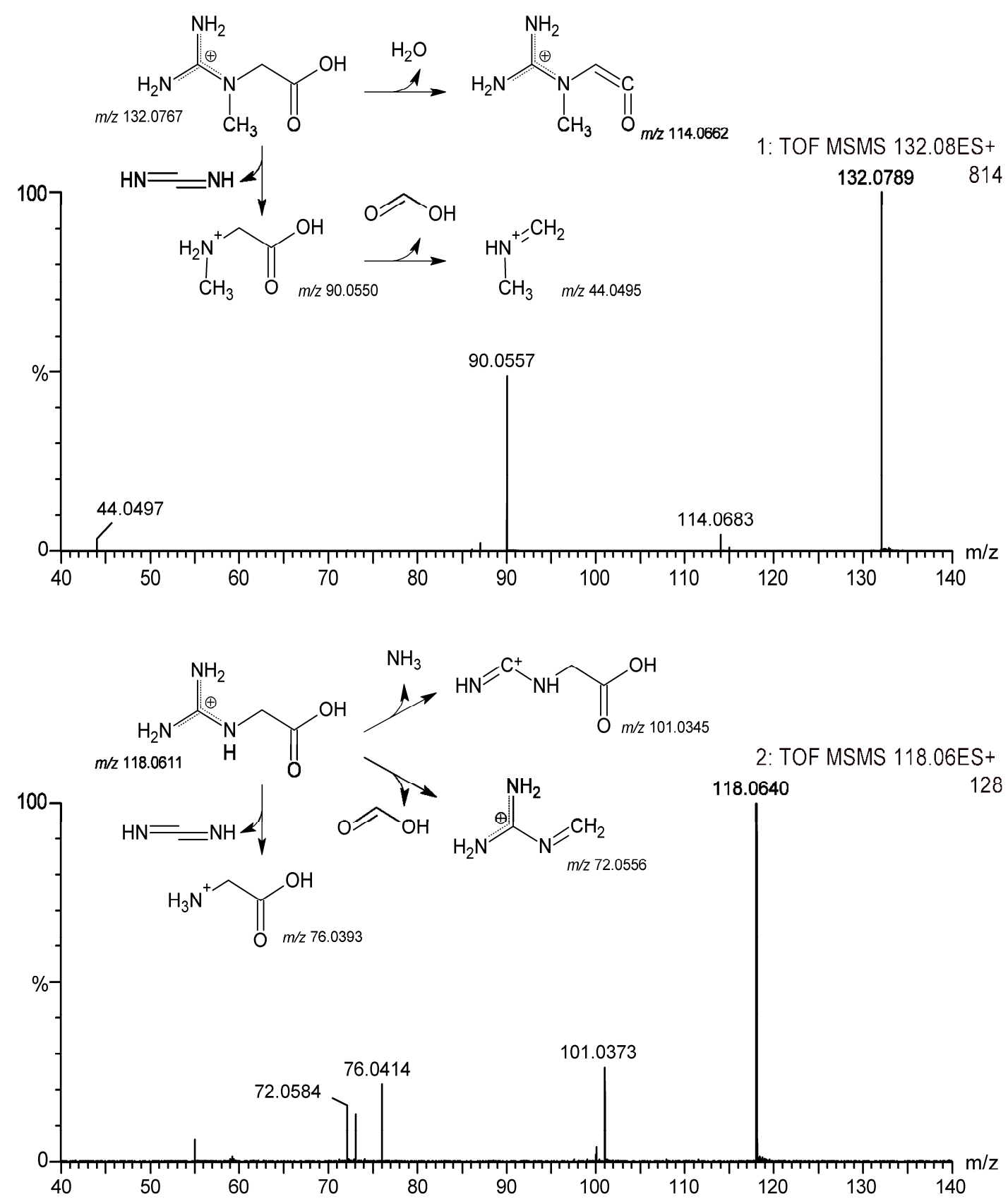

Figura 5 - Mecanismo de fragmentação proposto para a creatina $(\mathrm{m} / \mathrm{z} 132)$ e guanidinoacetato $(\mathrm{m} / \mathrm{z} 118)$.

Da mesma forma, foi realizado o estudo do perfil de fragmentação das moléculas protonadas de creatinina e dos análogos deuterados GAA- $d_{2}$, creatina- $d_{3}$, e creatinina- $d_{3}$ em baixa resolução com a aplicação de diferentes energias de colisão (figuras 6 a 9). 


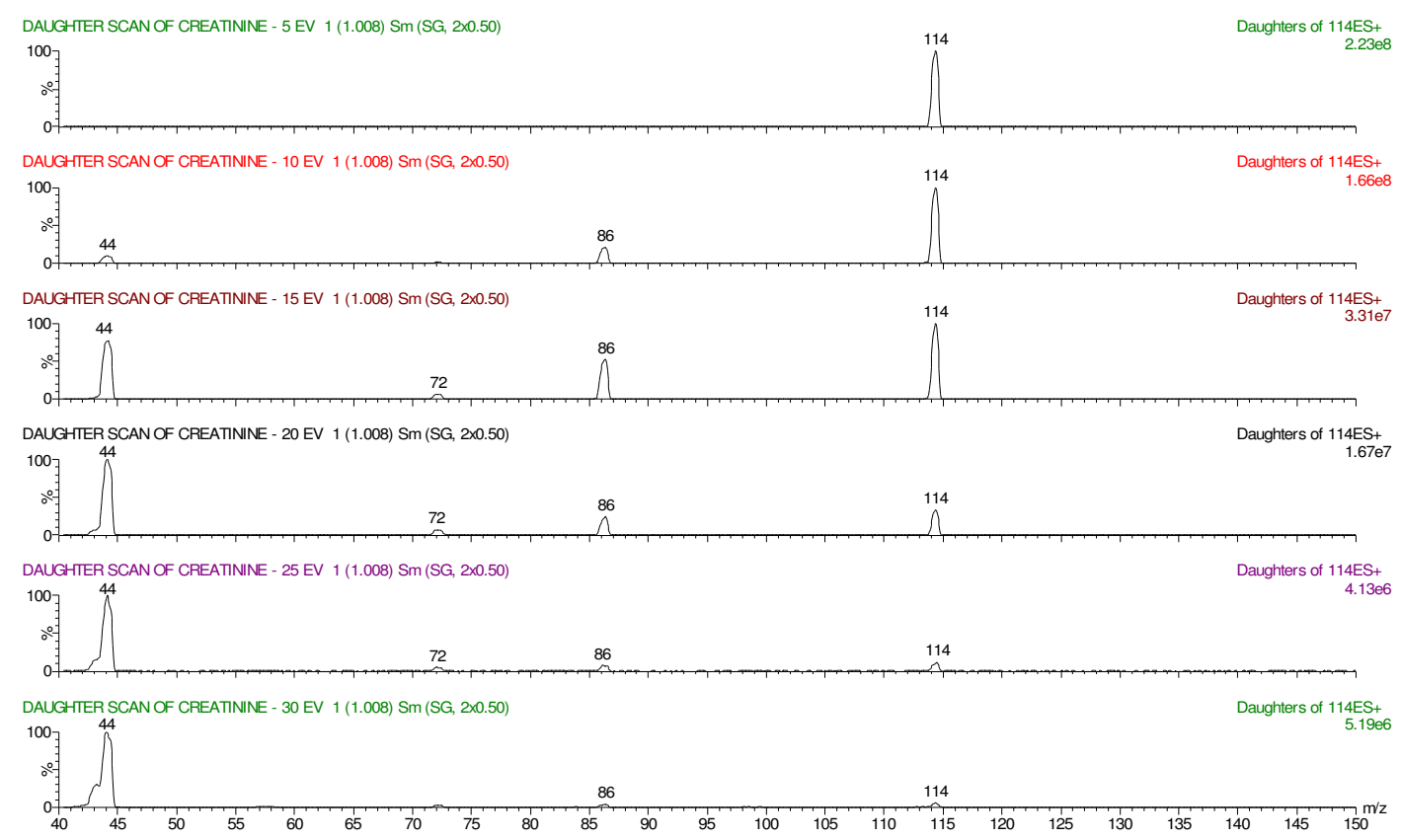

Figura 6 - Espectros de dissociação da creatinina $(\mathrm{m} / \mathrm{z} 114)$ obtidos com diferentes energias de colisão: 5 eV, 10 eV, 15 eV, 20eV, 25 eV e 30 eV

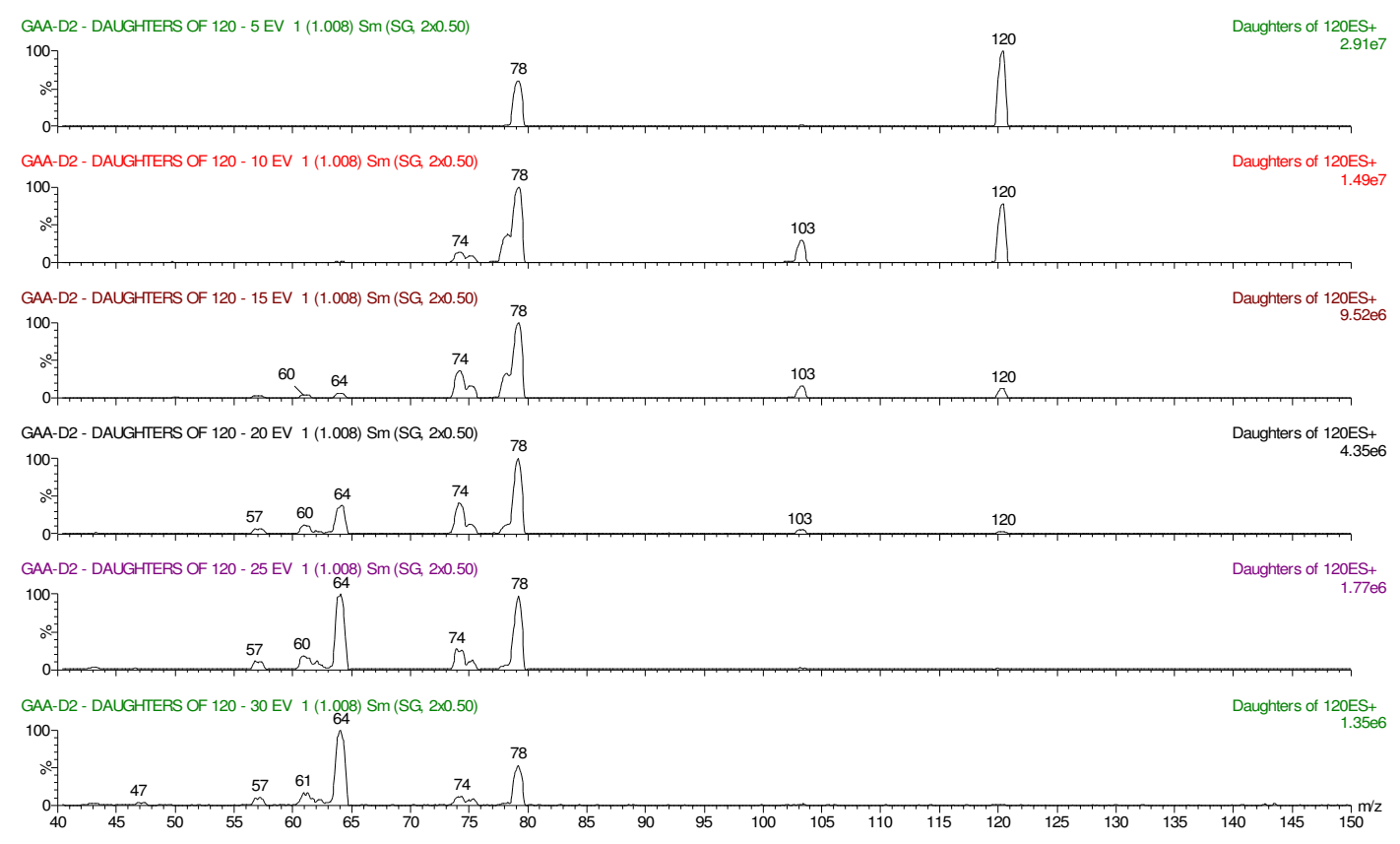

Figura 7 - Espectros de dissociação da GAA- $d_{2}$ protonado $(\mathrm{m} / \mathrm{z} 120)$ obtidos com diferentes energias de colisão: $5 \mathrm{eV}, 10 \mathrm{eV}, 15 \mathrm{eV}, 20 \mathrm{eV}, 25 \mathrm{eV}$ e $30 \mathrm{eV}$. 


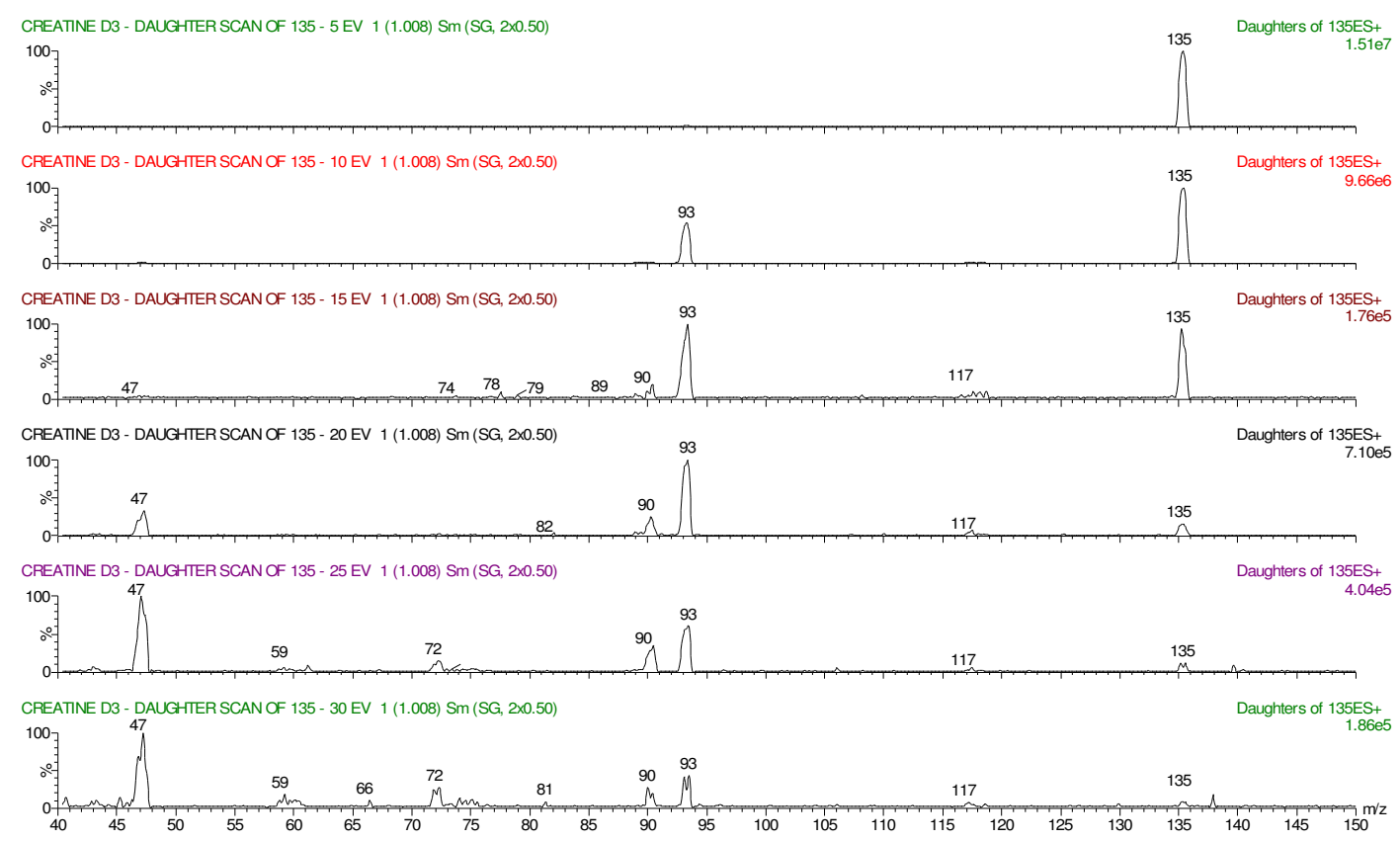

Figura 8. Espectros de dissociação da creatina- $d_{3}$ protonada $(\mathrm{m} / \mathrm{z} 135)$ obtidos com diferentes energias de colisão: 5 eV, 10 eV, 15 eV, $20 \mathrm{eV}, 25 \mathrm{eV}$ e $30 \mathrm{eV}$.

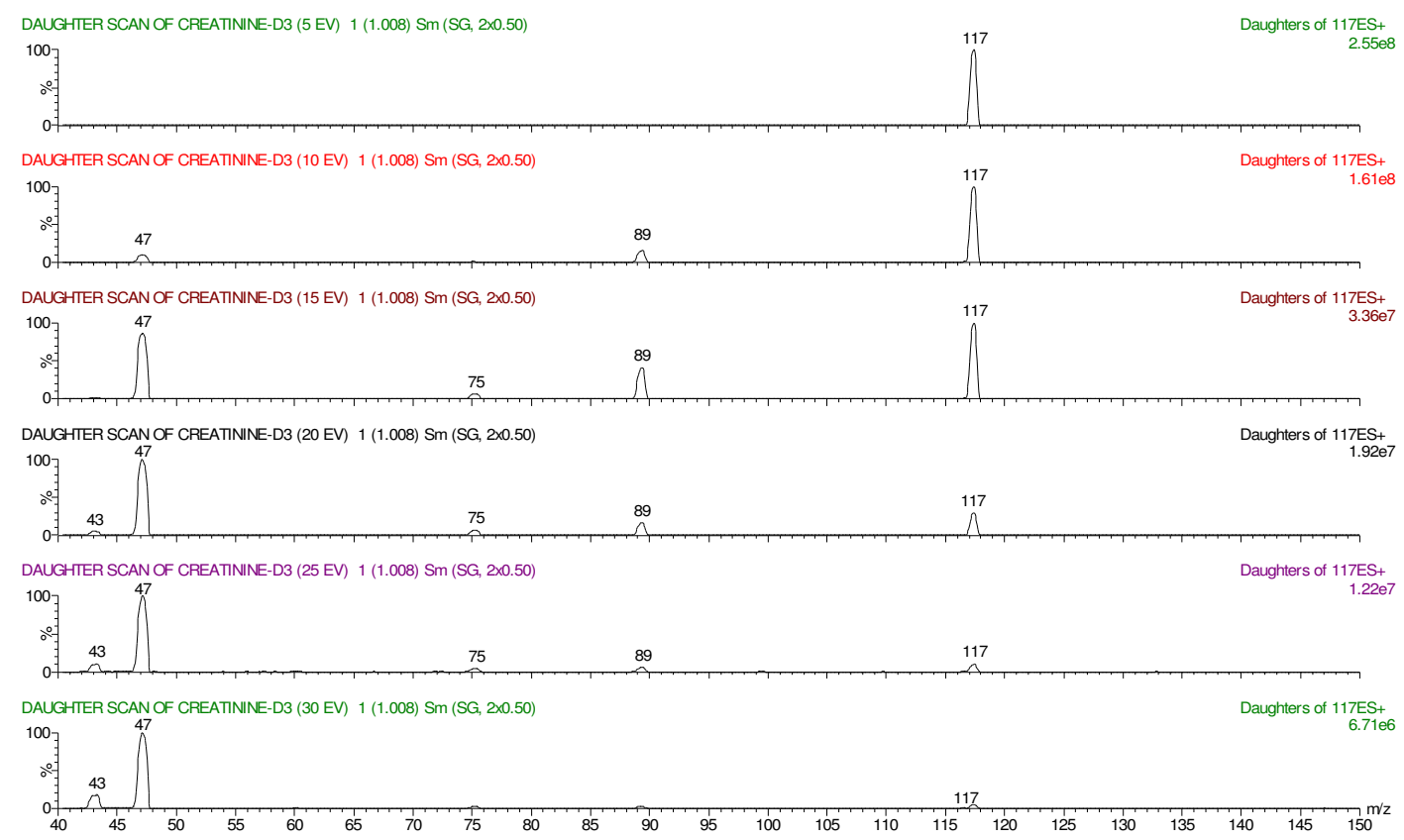

Figura 9. Espectros de dissociação da creatinina- $d_{3}$ protonada $(m / z 117)$ obtidos com diferentes energias de colisão: $5 \mathrm{eV}, 10 \mathrm{eV}, 15 \mathrm{eV}, 20 \mathrm{eV}, 25 \mathrm{eV}$ e $30 \mathrm{eV}$.

Os perfis de fragmentação dos compostos deuterados foram semelhantes aos dos compostos não-deuterados. Esse foi um achado 
importante no sentido de confirmá-los como padrões internos adequados já os fragmentos resultantes conservaram os deutérios e, portanto, a marcação permaneceu na porção carregada das moléculas.

4.1.2. Adequação das condições de detecção por espectrometria de massas em tandem

Conforme discutido acima, as transições de massas monitoradas para a quantificação foram selecionadas com base na análise dos íons produtos resultantes da fragmentação das moléculas protonadas quanto à sua intensidade e à singularidade das perdas. Assim, fragmentos intensos e resultantes de quebras menos comuns foram os escolhidos.

Para o monitoramento de cada analito foram selecionadas duas transições sendo uma quantificadora (mais abundante) e outra qualificadora (Tabela 8). A estratégia de associação de duas transições tem por finalidade aumentar o grau de certeza sobre a identidade da molécula sob investigação. 
Tabela 8. Transições de massas selecionadas como quantificadoras e qualificadoras para creatina, guanidinoacetato, creatinina, creatina- $d_{3}$, guanidinoacetato- $d_{2}$ e creatinina- $d_{3}$.

\begin{tabular}{ccc}
\hline Analito & $\begin{array}{c}\text { Transição } \\
\text { quantificadora }\end{array}$ & $\begin{array}{c}\text { Transição } \\
\text { qualificadora }\end{array}$ \\
\hline Creatina & $132>90$ & $132>44$ \\
Guanidinoacetato & $118>76$ & $118>72$ \\
Creatinina & $114>86$ & $114>72$ \\
Creatina- $d_{3}$ & $135>93$ & $135>47$ \\
Guanidinoacetato- $d_{2}$ & $120>78$ & $120>74$ \\
Creatinina- $d_{3}$ & $117>89$ & $117>75$ \\
\hline
\end{tabular}

A seguir, foi realizado o ajuste fino das condições de detecção com relação a energia de cone, capilar, energia de colisão e das lentes RF para cada fragmento selecionado.

Com essas informações, as condições de detecção por espectrometria de massas foram definidas para os quatro analitos. Esses dados, bem como as transições monitoradas, estão apresentados na Tabela 9. 
Tabela 9. Condições de aquisição e transições selecionadas para cada um dos analitos.

\begin{tabular}{ccccc}
\hline Analito & $\begin{array}{c}\text { Ion } \\
\text { precursor }\end{array}$ & $\begin{array}{c}\text { Transições } \\
\text { selecionadas }\end{array}$ & Cone $(\mathbf{V})$ & $\begin{array}{c}\text { Colisão } \\
(\mathbf{e V})\end{array}$ \\
\hline $\begin{array}{c}\text { Creatina } \\
(131,1 \mathrm{Da})\end{array}$ & 132 & 90 & 24 & 12 \\
$\begin{array}{c}\text { Guanidinoacetato } \\
(117,1 \mathrm{Da})\end{array}$ & 118 & 44 & 25 & 18 \\
& & 76 & 25 & 11 \\
$\begin{array}{c}\text { Creatinina } \\
(113,1 \mathrm{Da})\end{array}$ & 114 & 86 & 24 & 13 \\
$\begin{array}{c}\text { Creatina- } d_{3} \\
(134,1 \mathrm{Da})\end{array}$ & 135 & 72 & 27 & 10 \\
& & 93 & 24 & 14 \\
Guanidinoacetato- $d_{2}$ & 120 & 47 & 27 & 12 \\
$(119,1 \mathrm{Da})$ & & 78 & 28 & 18 \\
Creatinina- $d_{3}$ & 117 & 74 & 22 & 11 \\
$(116,1 \mathrm{Da})$ & 89 & 23 & 13 \\
\hline
\end{tabular}

\subsection{Desenvolvimento do método cromatográfico}

Dadas as características de alta polaridade dos compostos em estudo, foi definida a aplicação de uma modalidade de cromatografia líquida denominada HILIC (Hydrophilic Interaction Chromatography ou cromatografia de interação hidrofílica) em que a fase estacionária é muito polar (retendo, portanto, compostos polares) e a fase móvel é relativamente mais apolar, porém com uma porcentagem de solvente aquoso ${ }^{50}$. Portanto, neste caso, contrariamente ao que ocorre em fase reversa, o solvente forte é a água. A retenção do analito é, desta forma, condicionada a sua partição 
entre a fase móvel e a camada de solvatação aquosa da fase estacionária.

\subsubsection{Avaliação da separação cromatográfica}

Inicialmente, foi testada a coluna de sílica, a mais polar de todas e, portanto, potencialmente a de maior retenção, com a aplicação de uma condição isocrática descrita no método A (Tabela 4) de Materiais e Métodos.

Como pode ser verificado na Figura 10, foram observados dois picos muito intensos com tempos de retenção entre 4 e 6 minutos de bases muito largas e larguras a meia altura de 0,56 minutos para guanidinoacetato e de 0,76 min para creatina (Figura $10 \mathrm{~A}$ e B, respectivamente).

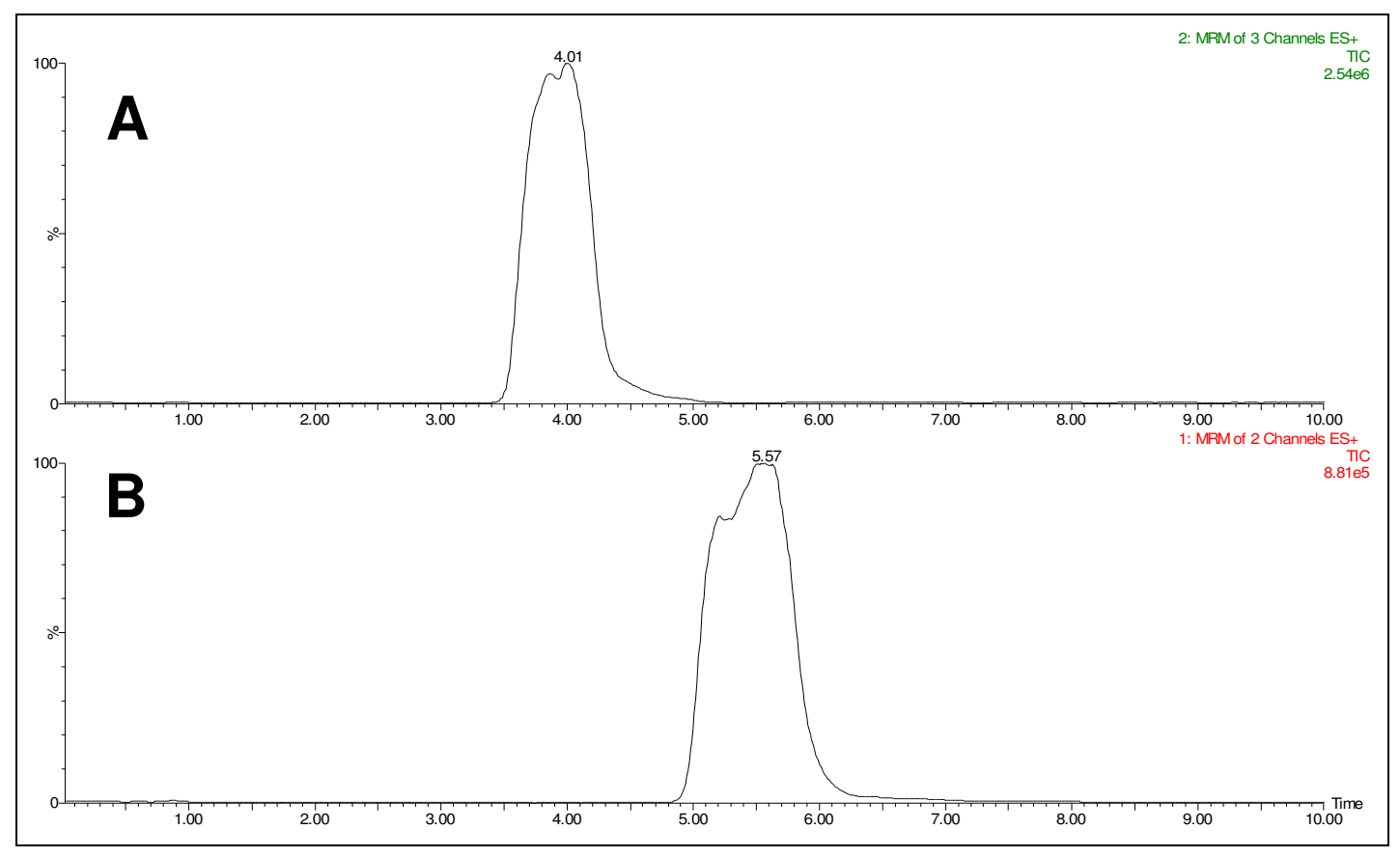

Figura 10. Cromatograma obtido pelo método A (Tabela 4). A: guanidinoacetato e B: creatina.

A seguir foi utilizada uma diluição maior da mistura de padrões, o volume de injeção foi reduzido e a força do solvente aumentada na tentativa 
de diminuir a retenção dos compostos (método $B$, Tabela 4 de Materiais e Métodos). Como previsto, os tempos de retenção diminuíram situando-se entre 2,50 e 3,27 min. Porém, os picos permaneceram alargados com largura a meia altura para GAA de 0,44 min e para creatina de 0,49 min (Figura 11 A e B, respectivamente).

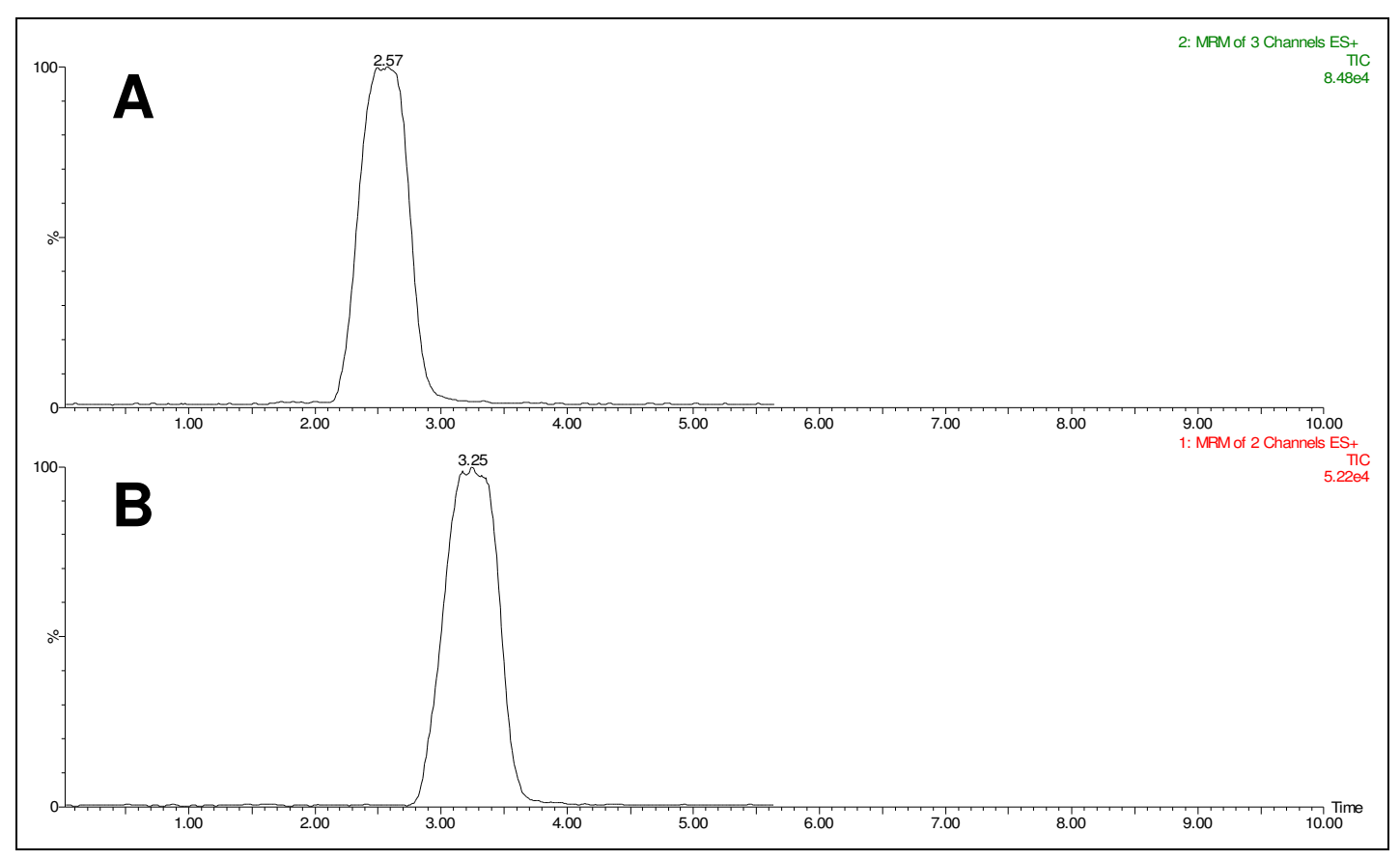

Figura 11. Cromatograma obtido pelo método B (Tabela 4 de Materiais e Métodos). A: guanidinoacetato e B: creatina.

Os resultados obtidos até então sugeriram a possibilidade de melhora do perfil e largura dos picos com a utilização de um gradiente cujo objetivo seria o de promover uma concentração dos analitos no início da coluna durante o período de rampa e sua eluição em "plug", resultando em picos mais simétricos e finos.

Neste sentido, diferentes gradientes foram avaliados com o objetivo de alcançar uma condição em que os picos apresentassem largura 
adequada, formato gaussiano, e um perfil de retenção que permitisse um tempo de corrida total, entre a saída dos picos e o período de reequilibração da coluna relativamente curto.

No decorrer desses experimentos, foi observado, em algumas injeções, o desdobramento dos picos e alguma irregularidade nos perfis dos cromatogramas obtidos sob as mesmas condições, particularmente com relação a tempo de retenção e abundância de sinal. Foi necessário corrigir essa situação antes de prosseguir com os testes de gradiente. Esses achados poderiam ser decorrentes da sobreposição de dois fatores:

1) Ocorrência do "efeito elutrópico" da água (solvente usado para o preparo da solução de padrões) no volume de injeção. Em princípio, o solvente da amostra (e padrões) deve ser mais fraco do que a fase móvel para que, ao serem introduzidos na coluna, os compostos de interesse fiquem retidos em bandas coesas, de forma que sejam eluídos também de maneira coesa, resultando em picos finos e de formato gaussiano. Quando, ao contrário, o solvente da amostra é forte em relação à fase móvel, a retenção na coluna ocorre em uma banda menos compactada, o que pode causar espalhamento durante a eluição. Mesmo com a injeção de volumes pequenos de amostras em meio aquoso (da ordem de 10 a $20 \mu \mathrm{L}$ ), esse efeito poderia ocorrer, particularmente quando uma coluna de dimensões reduzidas é utilizada. Para verificar a ocorrência ou não desse fenômeno foram preparadas duas soluções a $0,1 \mu \mathrm{g} / \mathrm{mL}$ : uma em água e outra em ACN e $20 \mu \mathrm{L}$ de cada foram injetadas nas mesmas condições. As figuras 12 e 13 apresentam os cromatogramas obtidos. 


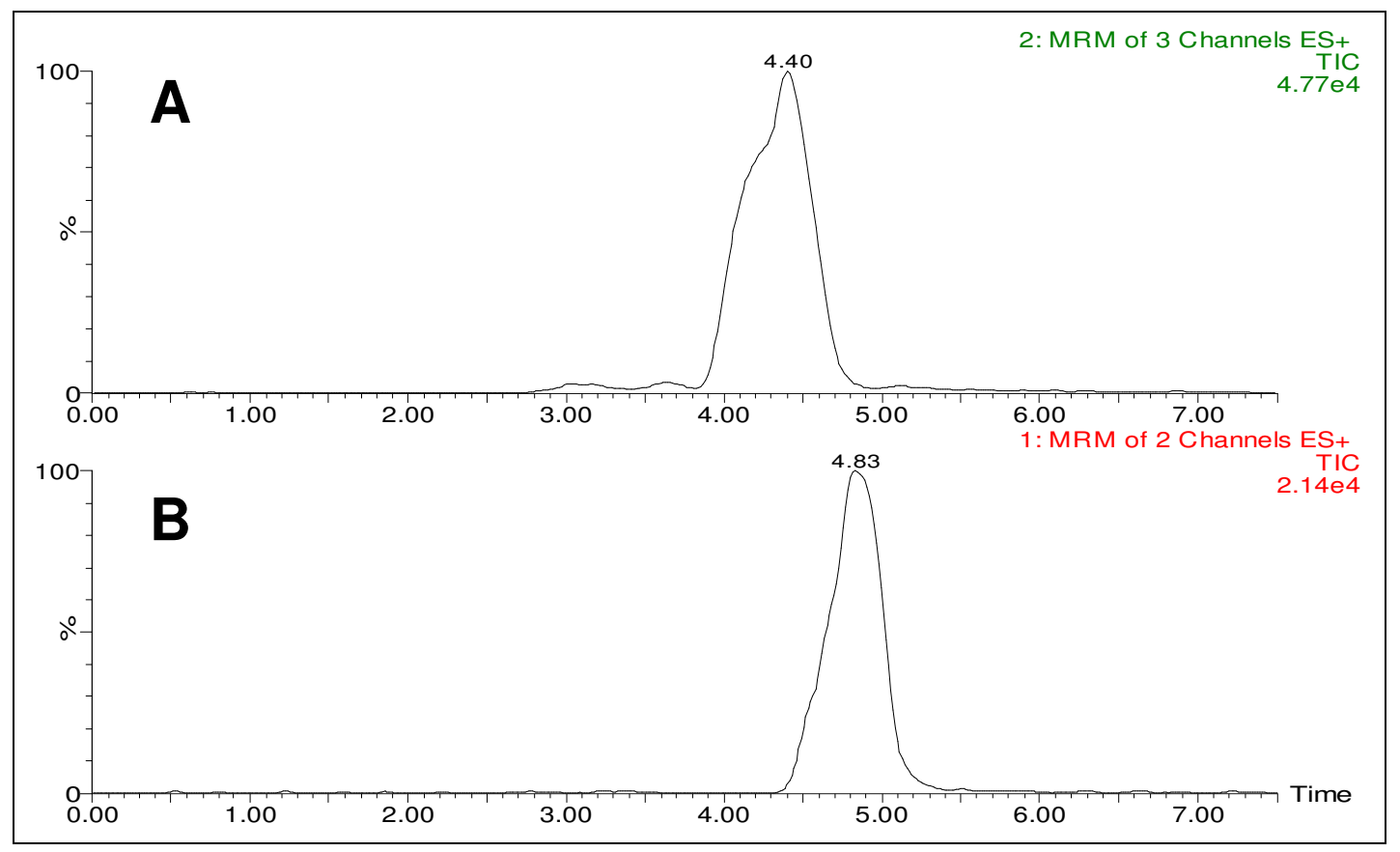

Figura 12. Perfil cromatográfico obtido pela injeção do padrão a $0,1 \mu \mathrm{g} / \mathrm{mL}$ diluído em água de A: guanidinoacetato e B: creatina.

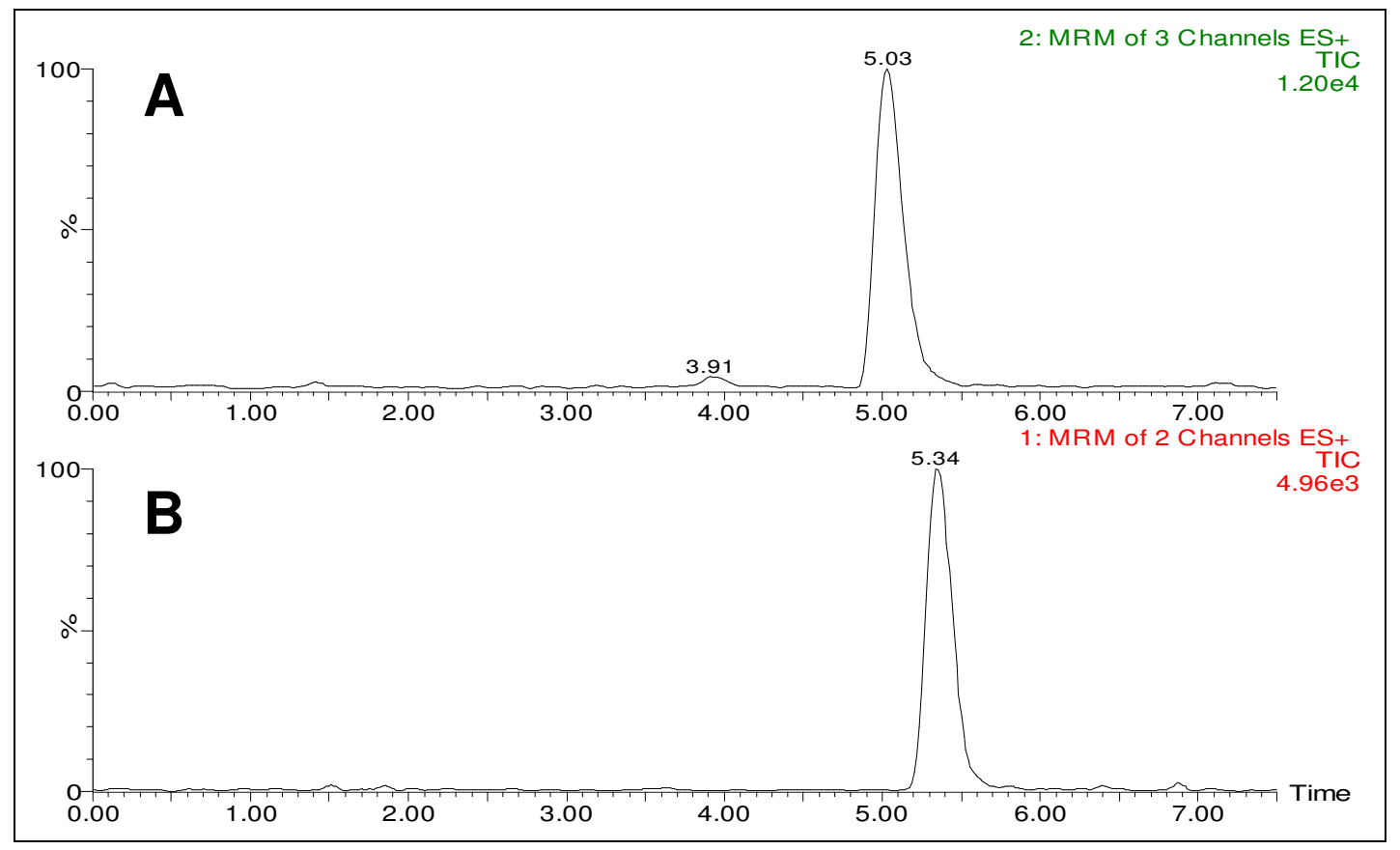

Figura 13. Perfil cromatográfico obtido pela injeção de padrão a $0,1 \mu \mathrm{g} / \mathrm{mL}$ diluído em ACN de A: guanidinoacetato e B: creatina. 
No intuito de eliminar a possível contribuição desse artefato nos picos resultantes, optou-se por manter a amostra em uma condição de polaridade próxima à da fase móvel e, deste ponto em diante, as soluções injetadas passaram a ser preparadas em ACN a $88 \%$.

2) Falta de tamponamento do meio, o que propiciaria a ocorrência de dois estados de carga com a apresentação do composto nos estados protonado e desprotonado, resultando em recuperação irregular. Assim, com o tamponamento da fase móvel, haveria um ambiente de cargas mais homogêneo e um comportamento cromatográfico mais previsível. Portanto, foi testada, em seguida, a adição do aditivo tamponado $(\mathrm{pH}$ aproximado de 3,5) de formiato de amônio nas concentrações de 0,5; 5; 10; 15; $20 ; 25$ e 50 $\mathrm{mmol} / \mathrm{L}$ com injeção em triplicata da solução de padrões de concentração de $0,1 \mu \mathrm{g} / \mathrm{mL}$ em ACN.

As figuras 14 e 15 apresentam as respostas e as larguras à meia altura em função das concentrações de formiato de amônio para a creatina e GAA, respectivamente. 


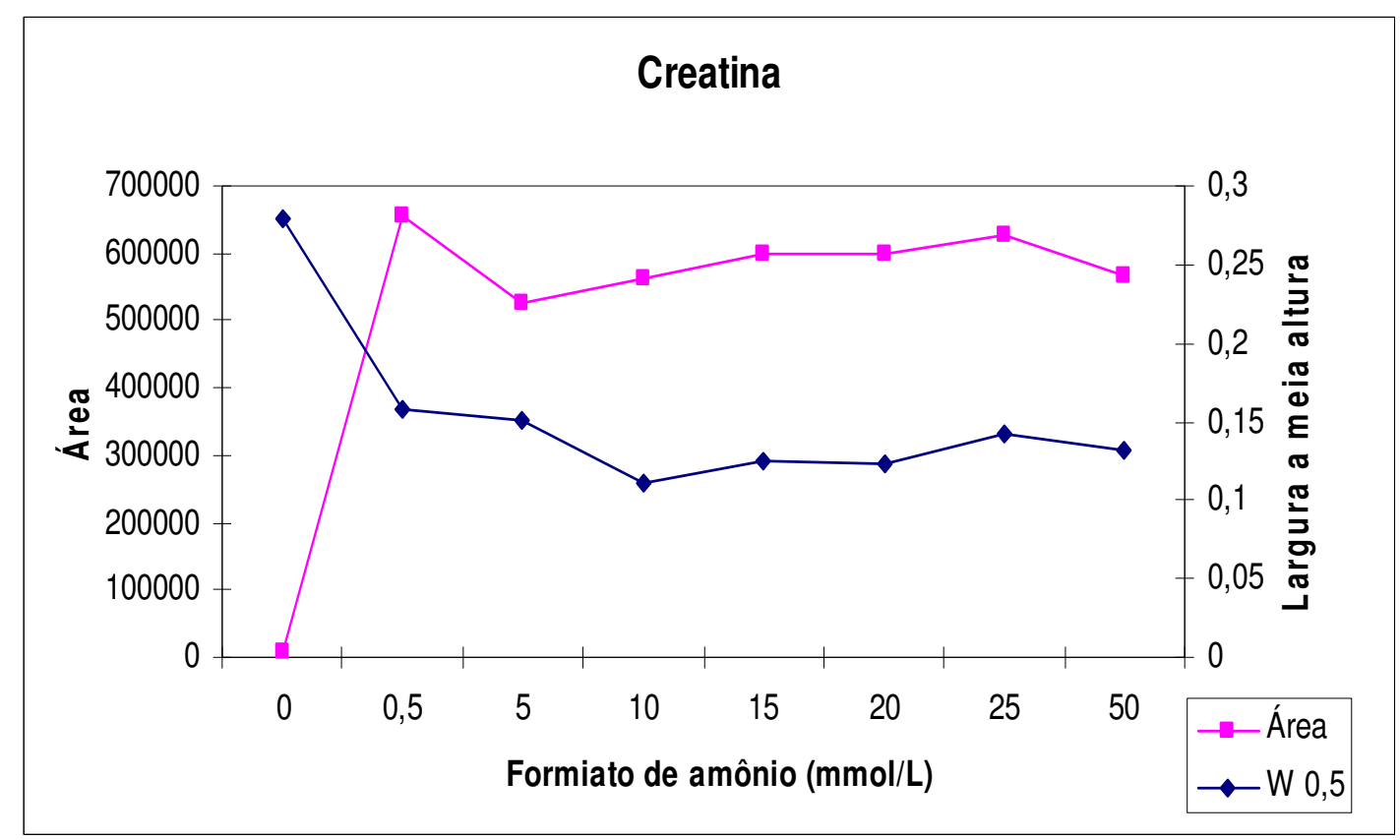

Figura 14. Gráfico da resposta em área e largura à meia altura $\left(\mathrm{W}_{0,5}\right)$ da creatina em função da concentração de formiato de amônio utilizado na fase móvel.

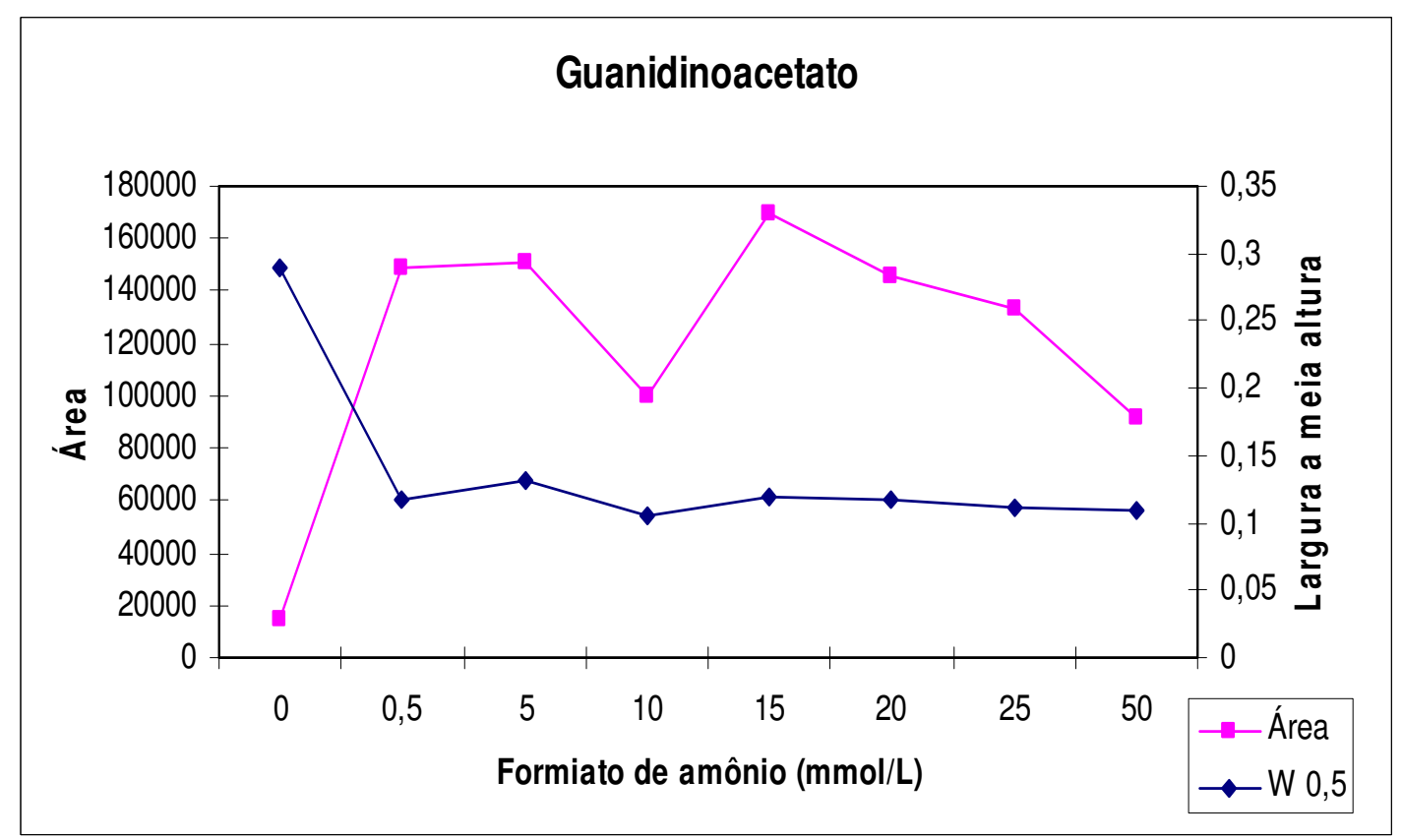

Figura 15. Gráfico da resposta em área e largura a meia altura $\left(W_{0,5}\right)$ do GAA em função da concentração de formiato de amônio utilizado na fase móvel. 
Os dados apresentados revelam que a condição, dentre as avaliadas, que oferece melhor resposta em termos de área, largura a meia altura e formato dos picos, em particular para o GAA, analito de menor sensibilidade, foi a adição de $15 \mathrm{mmol} / \mathrm{L}$ de formiato de amônio à fase móvel, sendo essa a padronizada para os métodos testados posteriormente.

Após a padronização do tamponamento da fase móvel, os experimentos para avaliação da separação em modo gradiente foram retomados com o objetivo de reduzir o tempo de aquisição cromatográfica.

Com esse intuito, uma série de gradientes com diferentes tempos e extensões de rampa foi avaliada. Em todos os casos, foi fixada a condição de injeção de $20 \mu \mathrm{L}$ da solução de padrões a $10 \mu \mathrm{g} / \mathrm{mL}$ em ACN.

Os perfis cromatográficos obtidos empregando os métodos D, E e F (Tabela 4 de Materiais e Métodos) estão apresentados nas figuras 16 a 18.

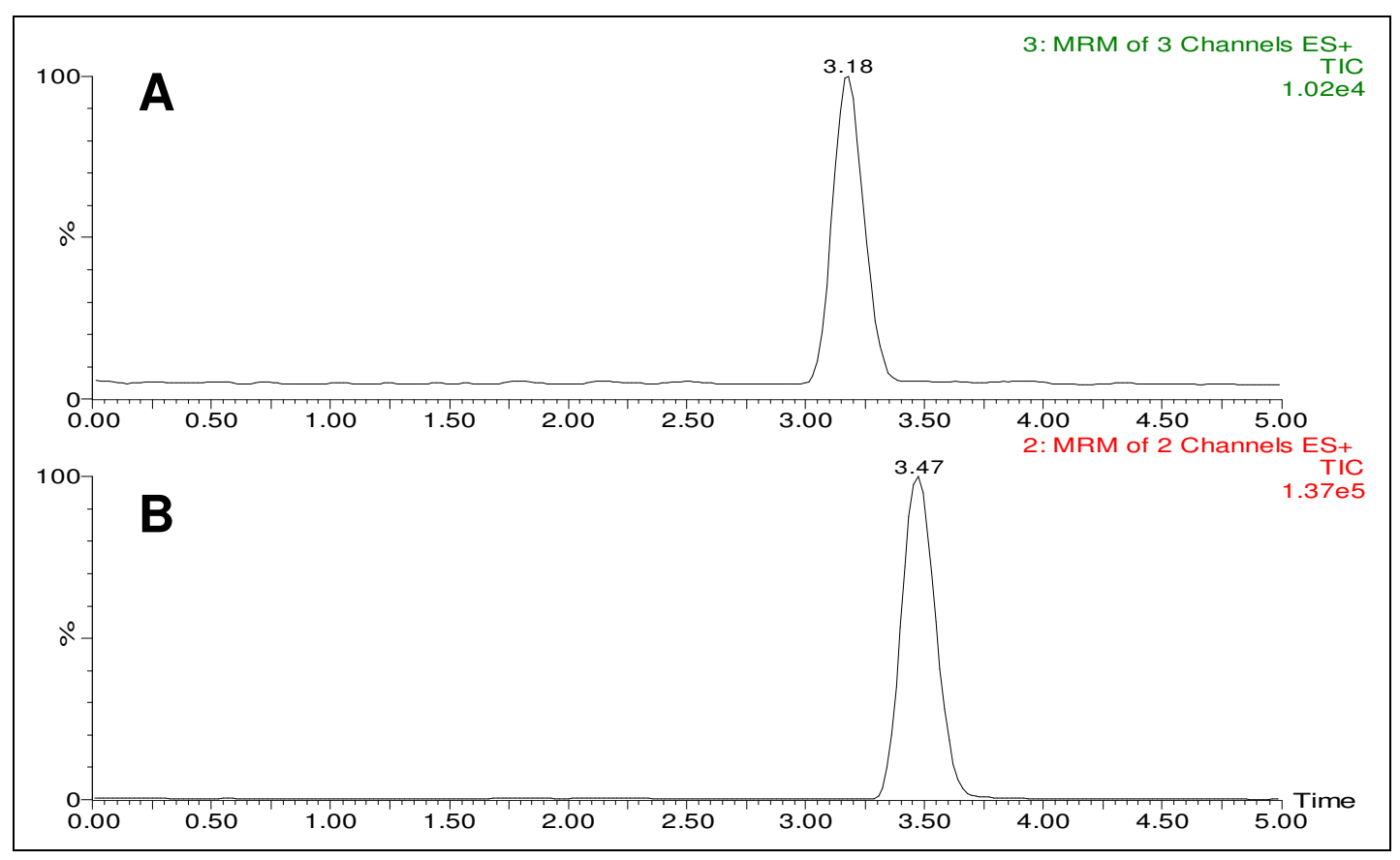

Figura 16. Cromatograma obtido com método D (Tabela 4 de Materiais e Métodos). A: guanidinoacetato e B:creatina. 


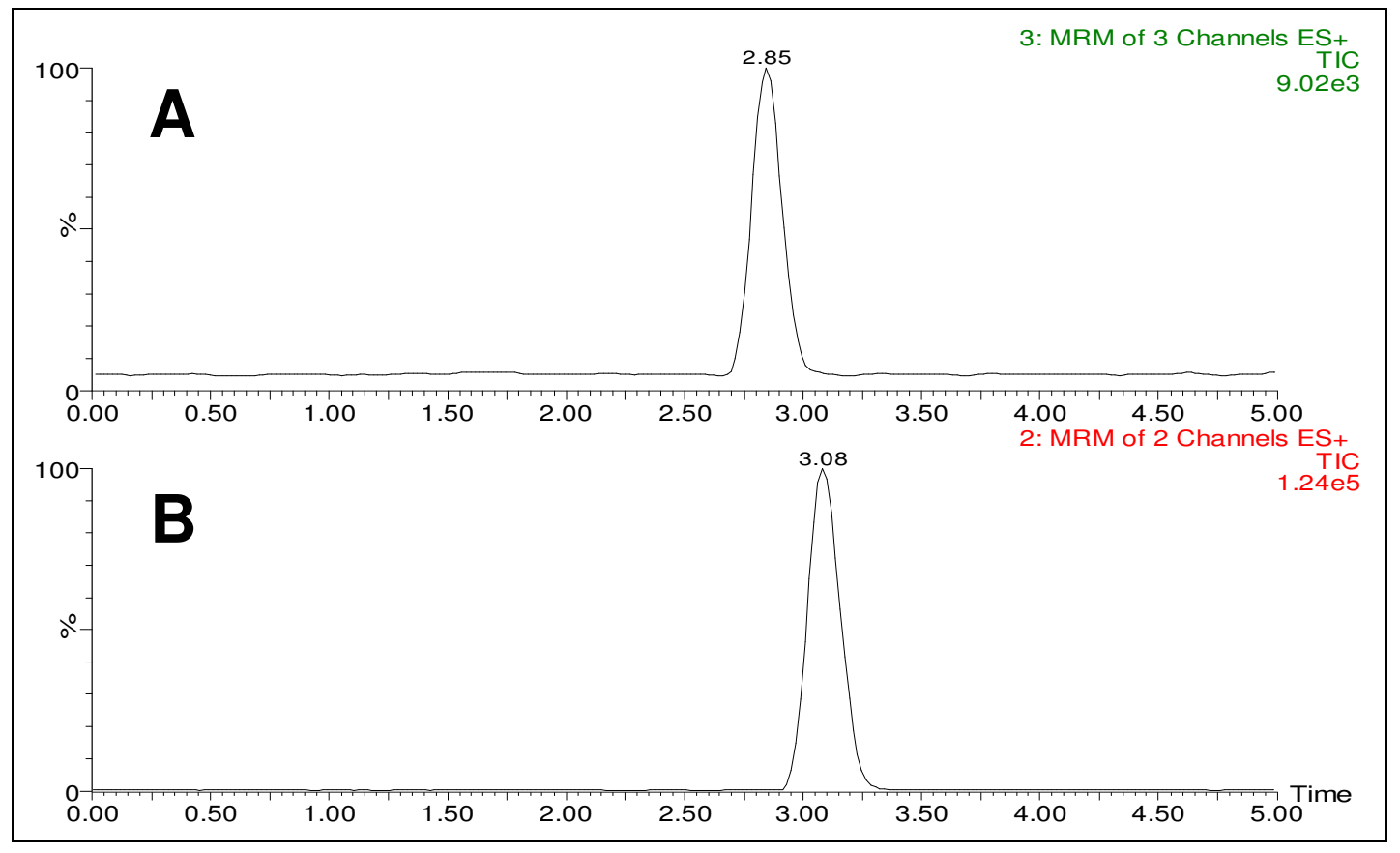

Figura 17. Cromatograma obtido com método $E$ (Tabela 4 de Materiais e Métodos). A: guanidinoacetato e B: creatina.

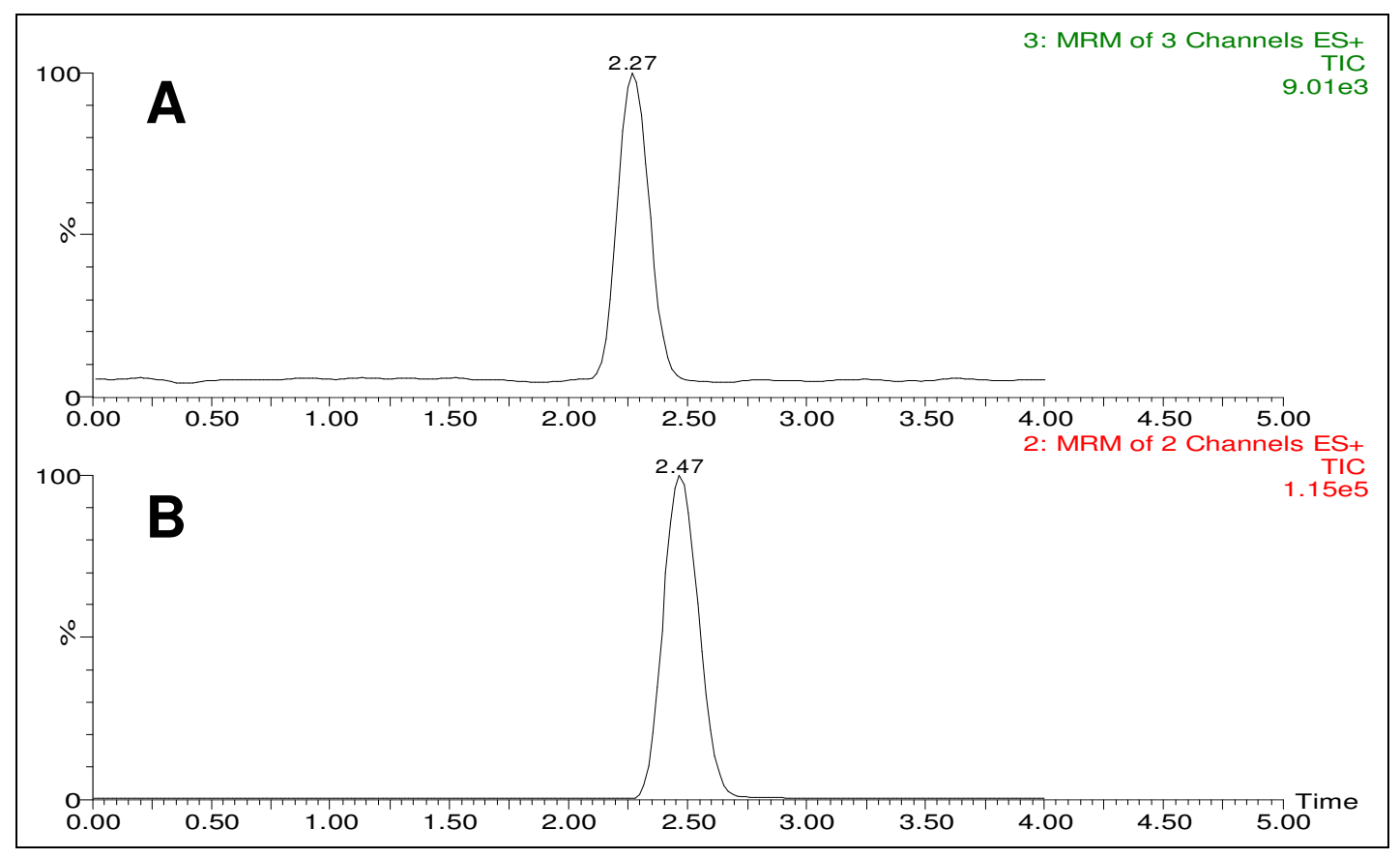

Figura 18. Cromatograma obtido com método $\mathrm{F}$ (Tabela 4 de Matériais e Métodos). A: guanidinoacetato e B: creatina. 
As larguras a meia altura obtidas estão expressas na Tabela 10.

Tabela 10. Larguras a meia altura dos picos $\left(\mathrm{W}_{0,5}\right)$ de creatina e guanidinoacetato e fator de retenção ou capacidade $(k)$ obtidos nos três exemplos de gradientes descritos na Tabela 4 de Materiais e Métodos.

\begin{tabular}{ccccc}
\hline Método & \multicolumn{2}{c}{ Creatina } & \multicolumn{2}{c}{ Guanidinoacetato } \\
& $\mathbf{W}_{0,5}$ & $\mathbf{k}$ & $\mathbf{W}_{\mathbf{0 , 5}}$ & $\mathbf{k}$ \\
\hline $\mathrm{D}$ & 0,1449 & 9,52 & 0,1449 & 8,64 \\
$\mathrm{E}$ & 0,1610 & 8,33 & 0,1449 & 7,73 \\
$\mathrm{~F}$ & 0,1610 & 6,48 & 0,1449 & 5,88 \\
\hline
\end{tabular}

A última condição de gradiente foi selecionada como padrão por apresentar um bom compromisso entre largura dos picos, tempo de retenção, tempo de reequilíbrio da coluna e, portanto, tempo total de corrida.

Observando-se os tempos de retenção com relação ao gradiente verifica-se que os compostos são eluídos bem após o término da rampa na condição de $35 \%$ de A (fase aquosa) e $65 \%$ de B (fase orgânica). Possivelmente, se a porcentagem de fase aquosa fosse aumentada, a eluição ocorreria mais rapidamente. No entanto, definiu-se não ultrapassar esse patamar com o intuito de poupar a coluna analítica em que a fase é de sílica não ligada, uma vez que uma fase móvel muito polar poderia reduzir drasticamente sua vida útil.

Com base nos resultados obtidos até então, outra abordagem que poderia reduzir o tempo de análise seria a realização da corrida em modo isocrático. Assim, foram realizados novos testes com o objetivo de verificar sua aplicabilidade.

Utilizando a mesma força de eluição ( $35 \%$ de $\mathrm{A}$ e $65 \%$ de $\mathrm{B}$ ), foram 
realizadas corridas no modo isocrático (método C, Tabela 4 de Materiais e Métodos). A Figura 19 apresenta o perfil cromatográfico obtido nessas análises.

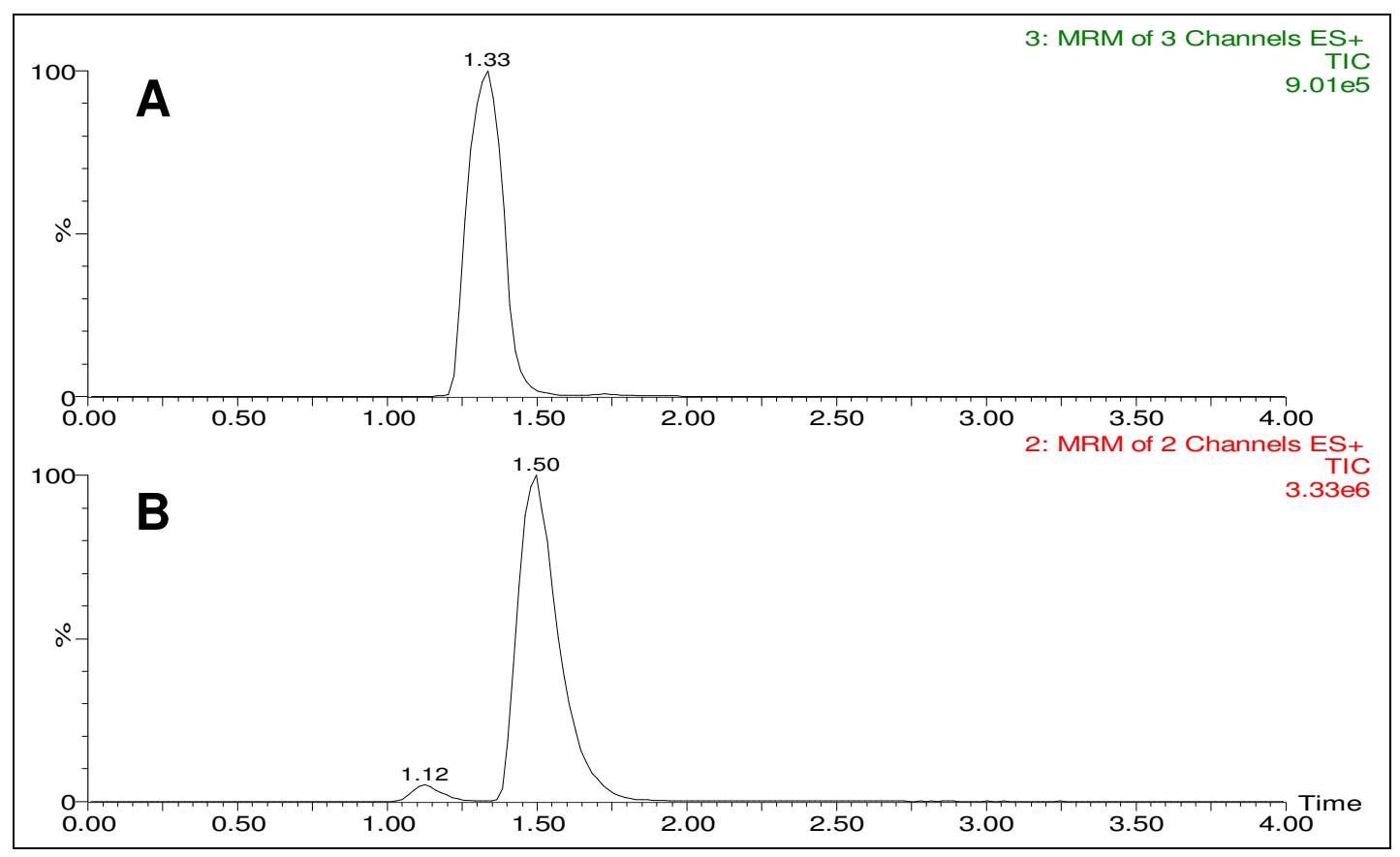

Figura 19. Cromatograma obtido com método $C$ (Tabela 4 de Materiais e Métodos). A: guanidinoacetato e B: creatina.

Paralelamente, foi também injetado o mesmo padrão na condição do gradiente descrito no método $\mathrm{F}$ (Tabela 4 de Materiais e Métodos). $\mathrm{O}$ cromatograma está apresentado na Figura 20. 


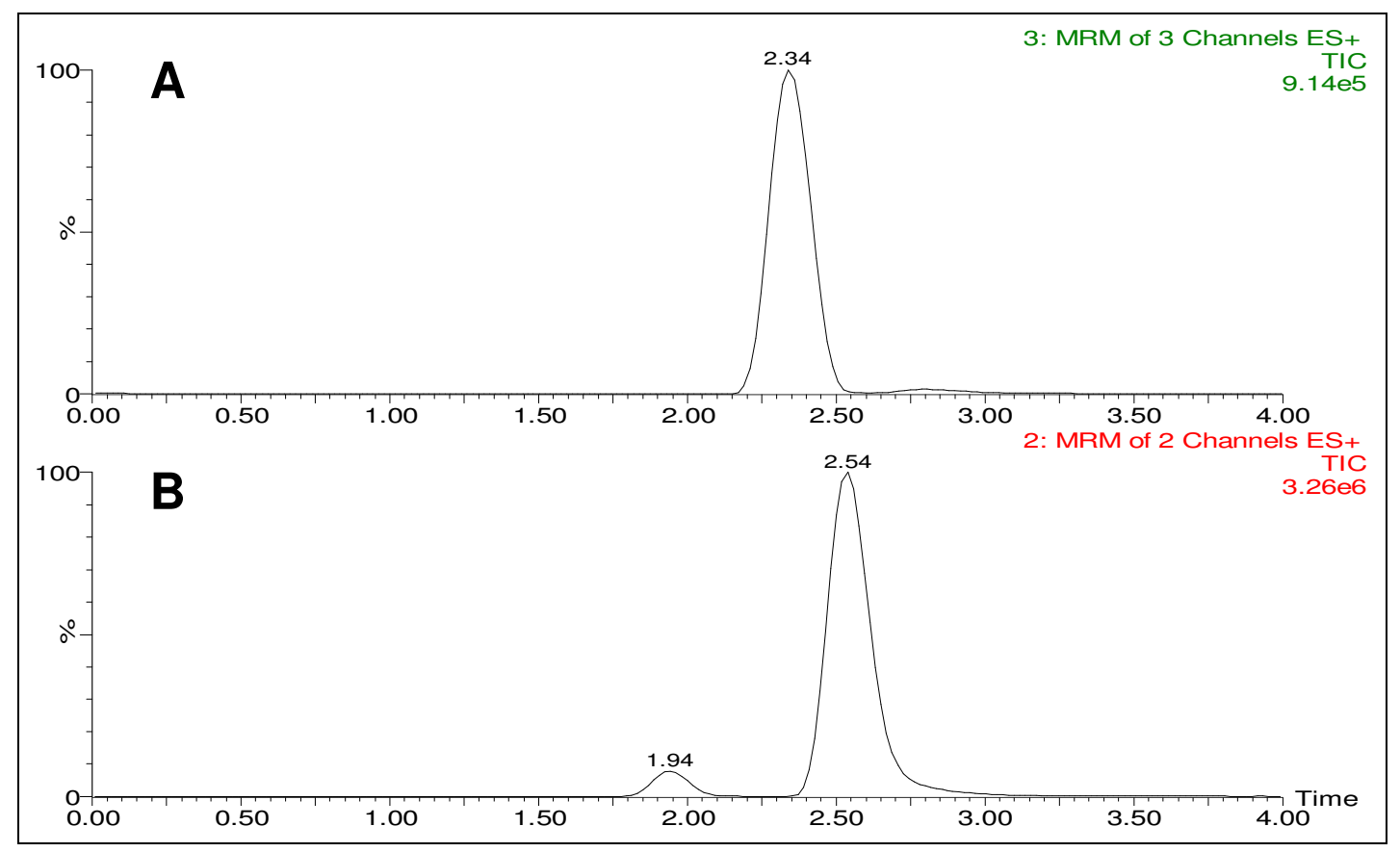

Figura 20. Cromatograma obtido com método $\mathrm{F}$ (Tabela 4 de Materiais e Métodos). A: guanidinoacetato e B: creatina.

As larguras a meia altura dos picos obtidos nos cromatogramas das figuras 19 e 20 estão apresentadas na Tabela 11.

Tabela 11. Larguras a meia altura dos picos $\left(\mathrm{W}_{0,5}\right)$ de creatina e guanidinoacetato obtidos nas condições isocrática (método $\mathrm{C}$, Tabela 4) e gradiente (método $\mathrm{F}$, Tabela 4 de Materiais e Métodos).

\begin{tabular}{ccc}
\hline Condição & Creatina $\left(\mathrm{W}_{0,5}\right)$ & Guanidinoacetato $\left(\mathrm{W}_{0,5}\right)$ \\
\hline Isocrático & 0,1771 & 0,1610 \\
Gradiente & 0,1500 & 0,1554 \\
\hline
\end{tabular}

Conforme demonstrado nas figuras 19 e 20 e Tabela 11, com a aplicação do modo isocrático, os picos apresentaram um discreto alargamento em relação à largura observada com o modo gradiente definido como padrão.

Nesse momento, foi necessário arbitrar sobre a característica do 
método a ser privilegiada: se por um lado, a eluição em regime isocrático poderia oferecer uma condição em que o tempo de corrida seria consideravelmente reduzido, por outro, a eluição em modo gradiente resultaria em picos discretamente mais finos, já que uma condição mais branda de solvente, no princípio da corrida, concentraria os analitos no início da coluna, favorecendo uma eluição mais coesa, resultando em picos mais finos e resposta ligeiramente superior (vide escala nos cromatogramas). No entanto, o tempo total de corrida seria consideravelmente superior.

Embora o ganho em termos de eficiência de coluna com o modo gradiente não seja grande e a perda em termos de tempo de corrida seja algo considerável, optou-se por manter a condição gradiente no sentido de preservar a coluna analítica, já que a condição ininterrupta de $35 \%$ de ambiente aquoso poderia reduzir sua vida útil.

Outro aspecto avaliado na separação cromatográfica relacionou-se à fase estacionária. Foram selecionadas três diferentes fases estacionárias adaptáveis ao regime cromatográfico HILIC: baseadas em sílica não ligada, ligada a grupamentos ciano e a grupamentos amino. Foi também avaliada uma coluna concebida especificamente para aplicação em HILIC, a Luna HILIC, que é baseada em fase de ligação cruzada de diol.

Para cada fase, foram realizadas três injeções de $10 \mu \mathrm{L}$ da solução de padrões de $10 \mu \mathrm{g} / \mathrm{mL}$ em ACN sob o último gradiente descrito. A Figura 21 apresenta os cromatogramas obtidos nas diferentes colunas testadas. 


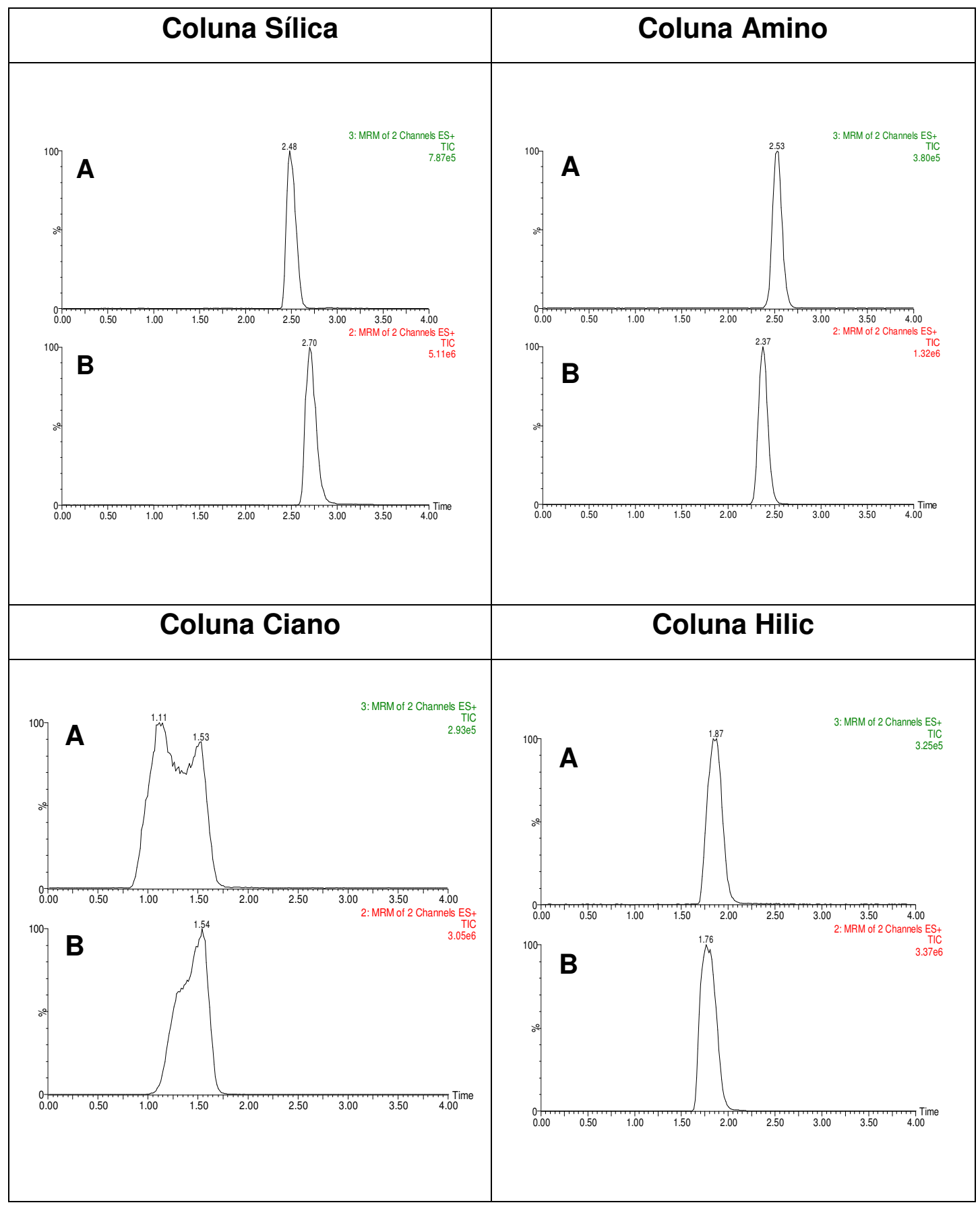

Figura 21. Cromatogramas obtidos com diferentes colunas empregando o método $F$ (Tabela 4 de Materiais e Métodos). A: guanidinoacetato e B: creatina.

A Figura 21 mostra que as duas melhores fases para a condição de eluição aplicada foram a sílica e a amino e dentre as duas, a que apresentou melhor área foi a de sílica tendo sido essa a selecionada para o método.

As áreas e larguras a meia altura estão apresentadas nas Figuras 22 
e 23.

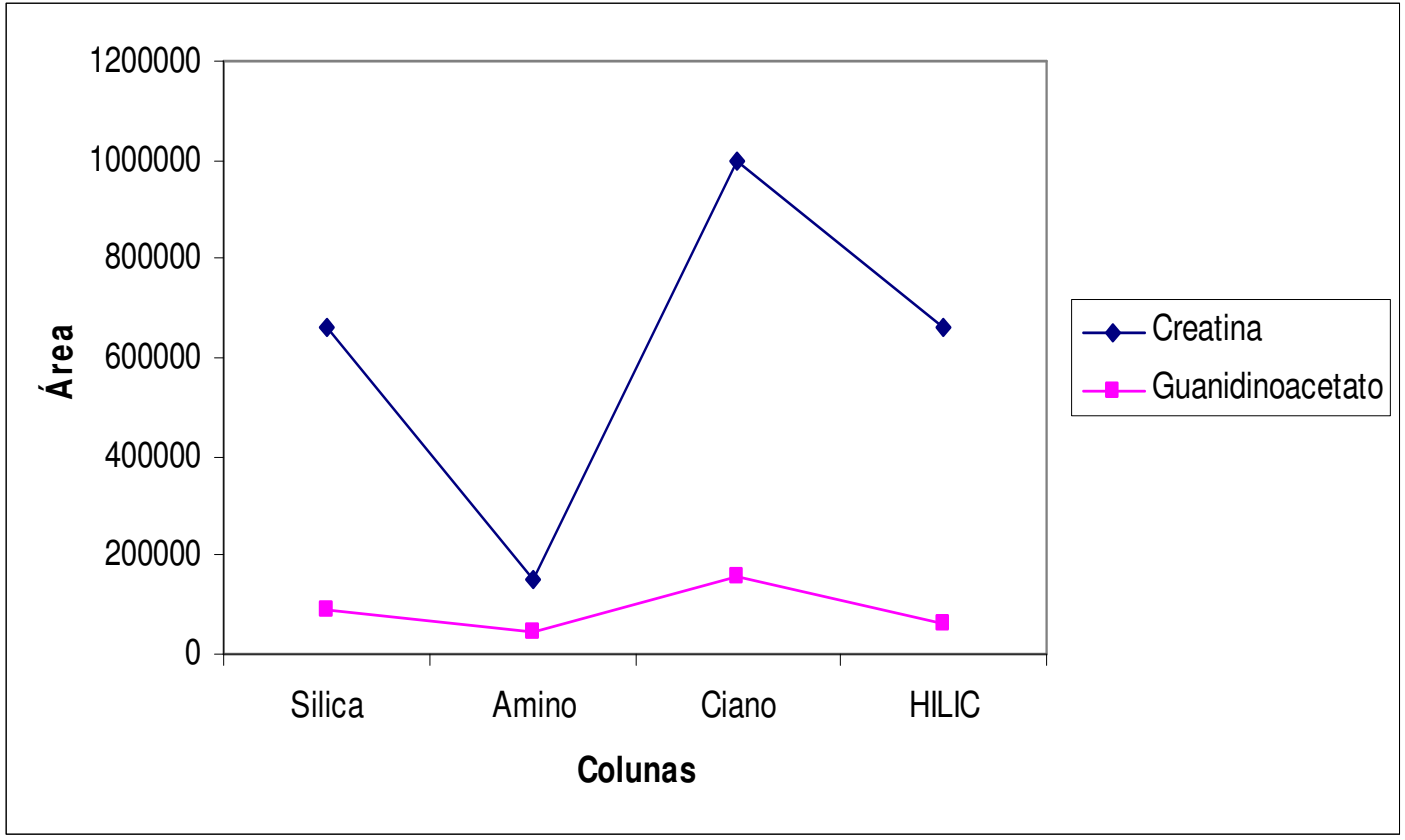

Figura 22. Áreas obtidas com as diferentes colunas avaliadas.

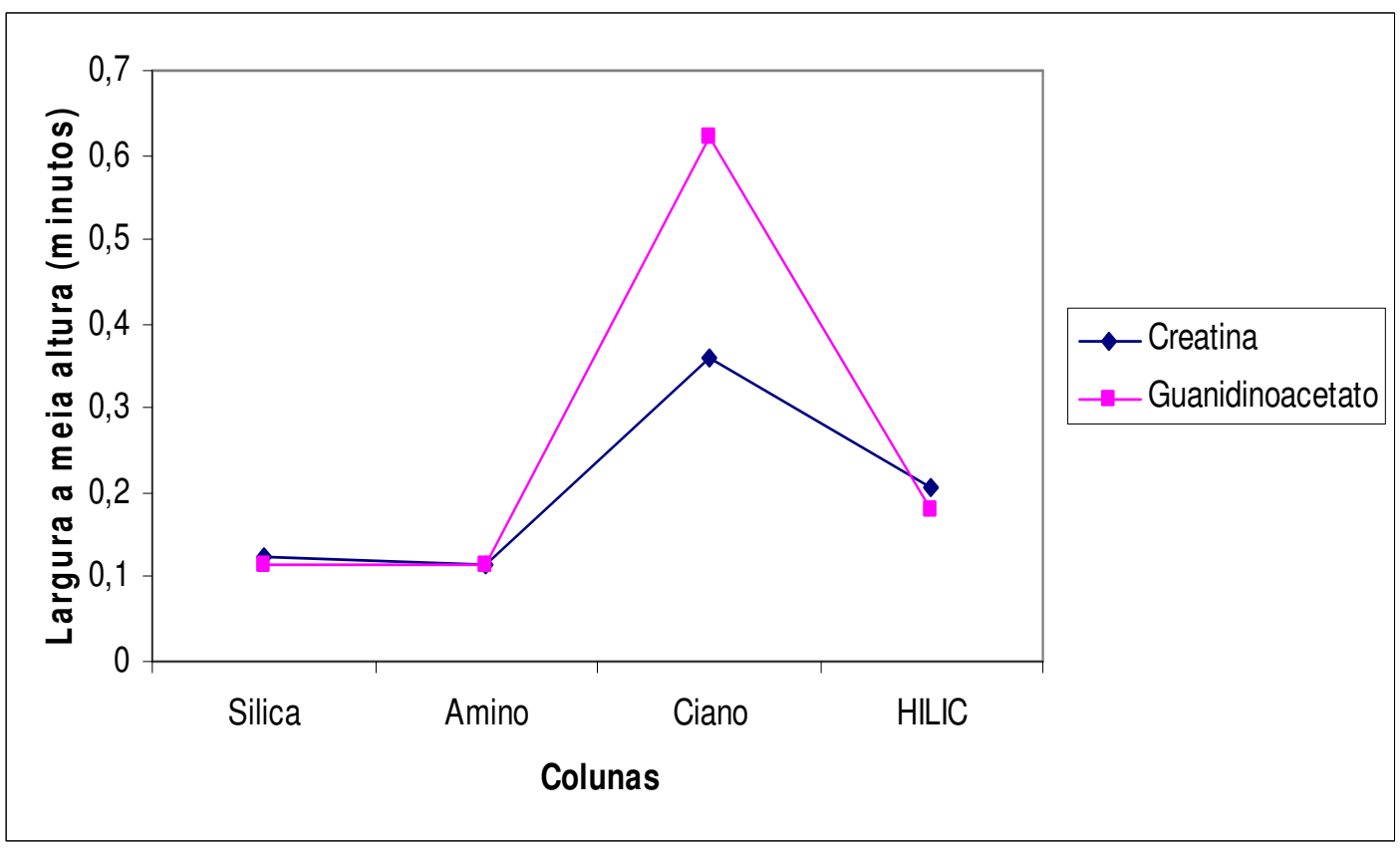

Figura 23. Larguras a meia altura obtidas com as diferentes colunas avaliadas. 
4.2.2. Acoplamento da cromatografia líquida à espectrometria de massas em tandem

Após a obtenção das melhores condições de separação cromatográfica e de deteç̧ão, foi necessário aperfeiçoar o "acoplamento" destes dois elementos do método. Assim, foi estudado o impacto na resposta de detecção dos compostos de interesse mediante a variação das condições de outros importantes fatores envolvidos na aquisição dos sinais: temperatura da fonte, da coluna, de dessolvatação e o fluxo do gás de dessolvatação.

- Temperatura da fonte:

A temperatura da fonte foi avaliada no intervalo de $60^{\circ} \mathrm{C}$ a $120^{\circ} \mathrm{C}$ com variações de $20^{\circ} \mathrm{C}$ em três injeções de $20 \mu \mathrm{L}$ da solução dos padrões a 10 $\mu \mathrm{g} / \mathrm{mL}$ em ACN para cada condição. Os resultados obtidos foram relacionados em função de resposta/temperatura conforme demonstrado na Figura 24. 


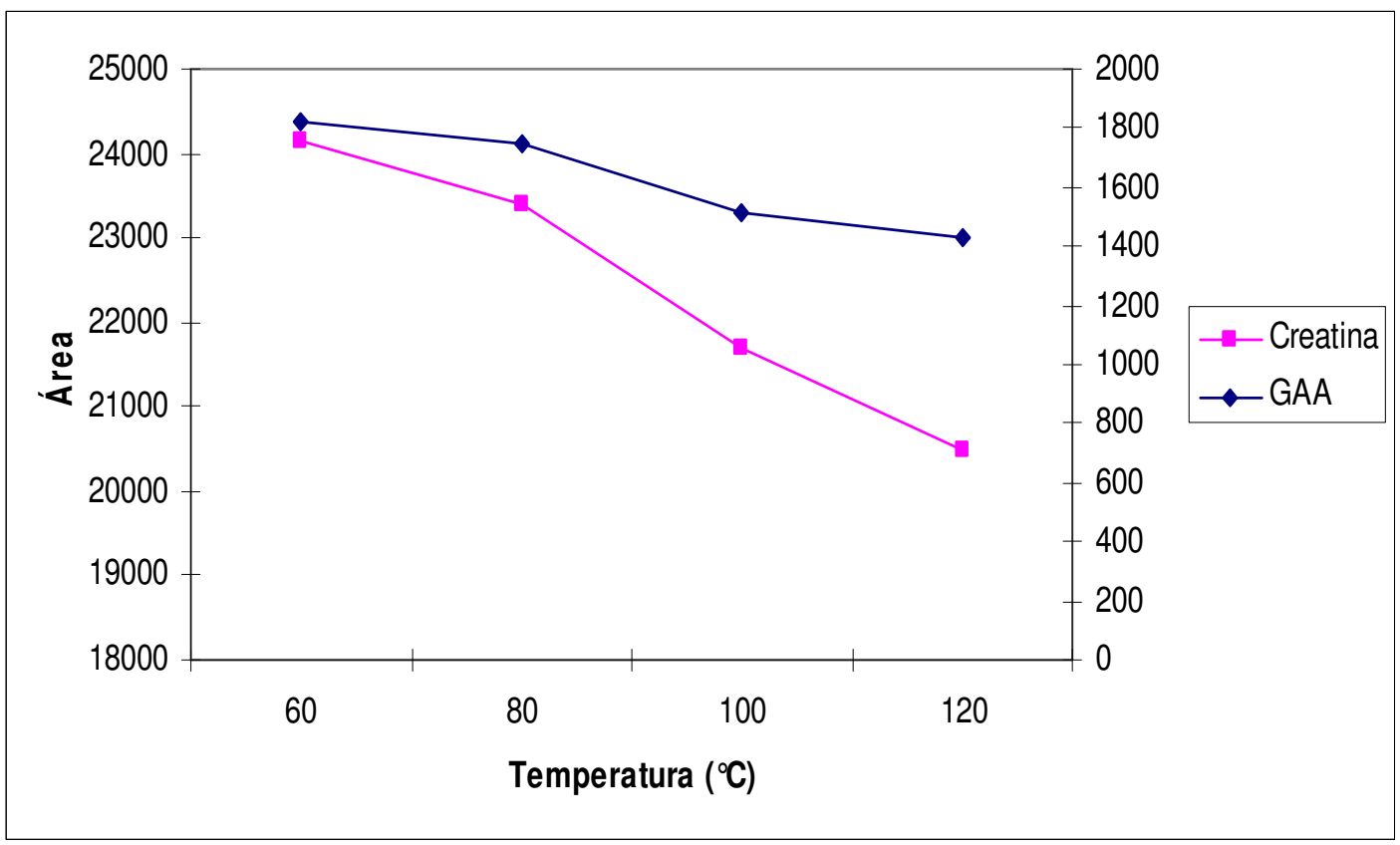

Figura 24. Dados de resposta dos compostos creatina e guanidinoacetato em função da temperatura da fonte.

As respostas para todos os compostos foram mais intensas à temperatura da fonte de $60^{\circ} \mathrm{C}$. Porém, nessa condição foi observada uma variação maior do que a verificada a $80^{\circ} \mathrm{C}$, temperatura em que os sinais são também bastante intensos. Assim, foi definido um valor intermediário de $70^{\circ} \mathrm{C}$.

- Temperatura da coluna:

A temperatura da coluna analítica foi avaliada com variações a cada $5^{\circ} \mathrm{C}$ no intervalo de $30^{\circ} \mathrm{C}$ a $45^{\circ} \mathrm{C}$ com três injeções de $20 \mu \mathrm{L}$ da solução dos padrões a $10 \mu \mathrm{g} / \mathrm{mL}$ em ACN para cada condição. Os resultados obtidos estão apresentados na Figura 25. 


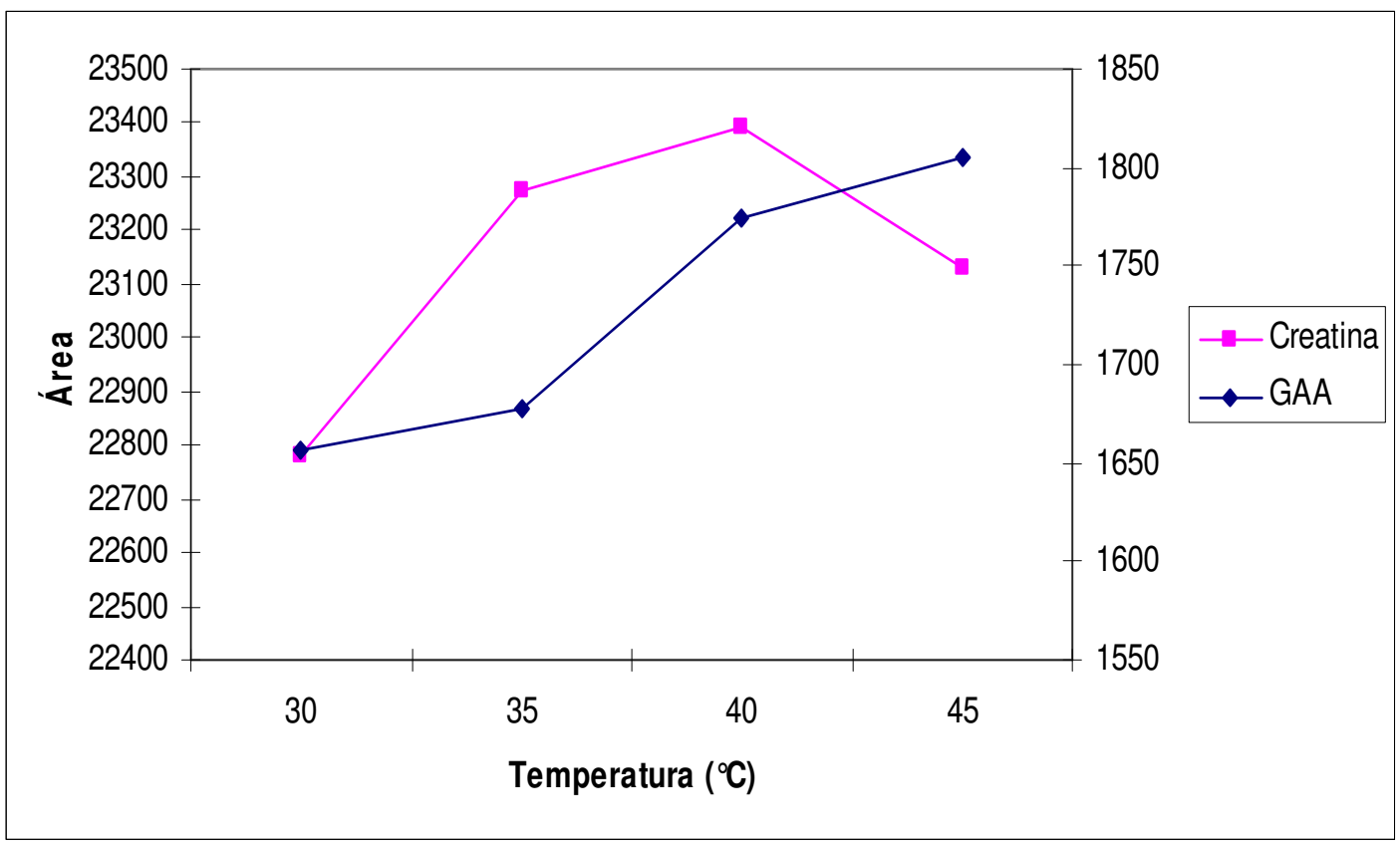

Figura 25. Dados de resposta dos compostos creatina e guanidinoacetato em função da temperatura da coluna.

Houve variação nas temperaturas "ótimas" de coluna para cada composto. Foi definido um valor médio de $40^{\circ} \mathrm{C}$ com o objetivo de favorecer a detecção dos compostos de menor sinal, GAA e GAA- $d_{2}$. Um valor maior causaria uma perda de sinal muito pronunciada para creatina, conforme observado na Figura 25.

- Temperatura de dessolvatação:

Foram testadas temperaturas de dessolvatação a cada $50^{\circ} \mathrm{C}$ no intervalo de $300^{\circ} \mathrm{C}$ a $450^{\circ} \mathrm{C}$, com três injeções de $20 \mu \mathrm{L}$ da solução dos padrões a $10 \mu \mathrm{g} / \mathrm{mL}$ em ACN para cada condição. Os resultados obtidos em função de resposta versus temperatura estão apresentados na Figura 26. 


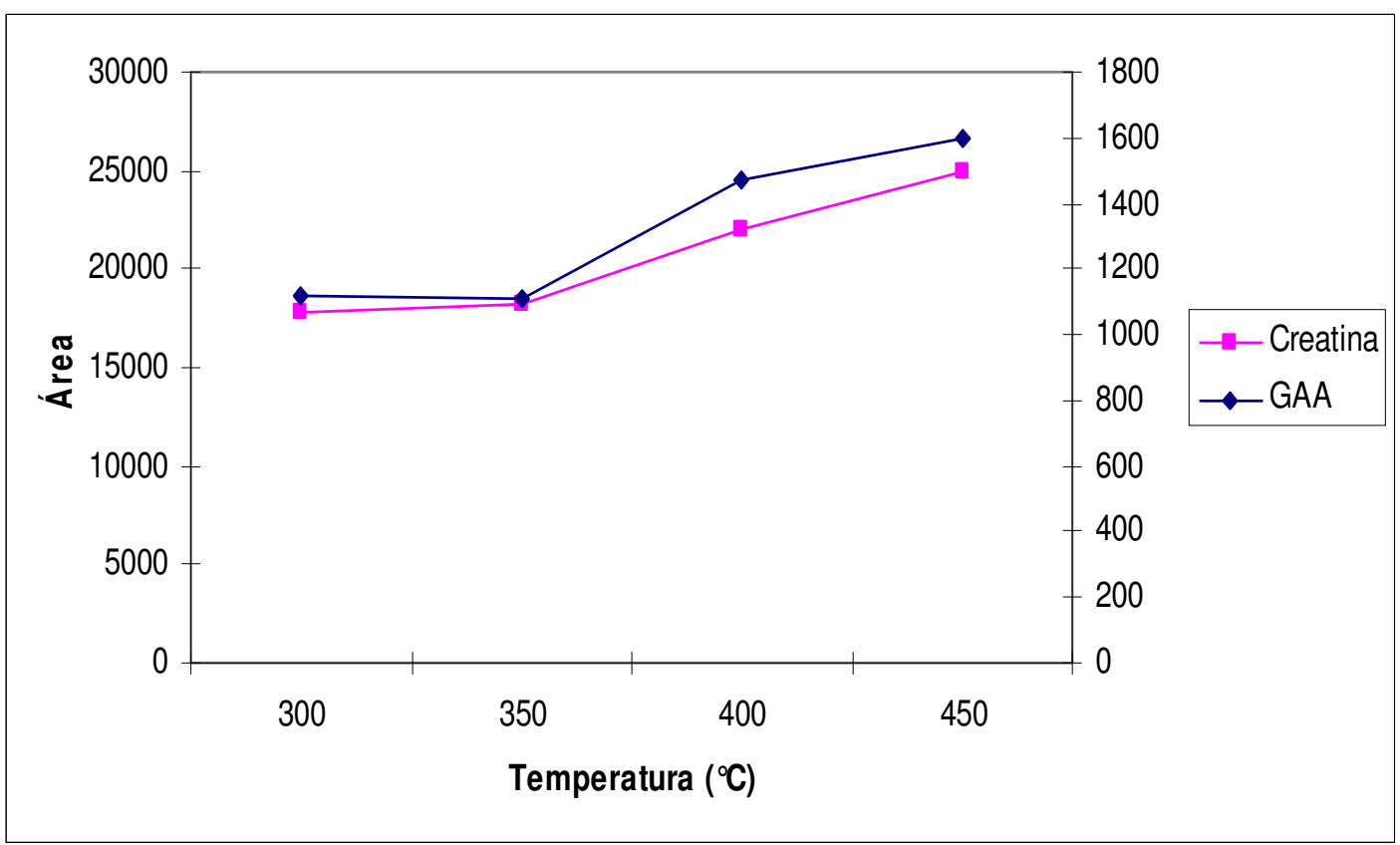

Figura 26. Dados de resposta dos compostos creatina e guanidinoacetato em função da temperatura de dessolvatação.

Embora tenha sido observada uma variação pronunciada nas respostas dos compostos com a temperatura de dessolvatação de $450^{\circ} \mathrm{C}$, nessa condição houve um considerável aumento de resposta para todos os compostos, justificando sua escolha.

- Fluxo do gás de dessolvatação:

O fluxo do gás de dessolvatação $\left(\mathrm{N}_{2}\right)$ foi avaliado com variações de $100 \mathrm{~L} / \mathrm{h}$ no intervalo de $500 \mathrm{~L} / \mathrm{h}$ a $800 \mathrm{~L} / \mathrm{h}$ com três injeções de $20 \mu \mathrm{L}$ da solução dos padrões a $10 \mu \mathrm{g} / \mathrm{mL}$ em ACN em cada condição. Os resultados obtidos foram apresentados em função de resposta/vazão de gás na Figura 27. 


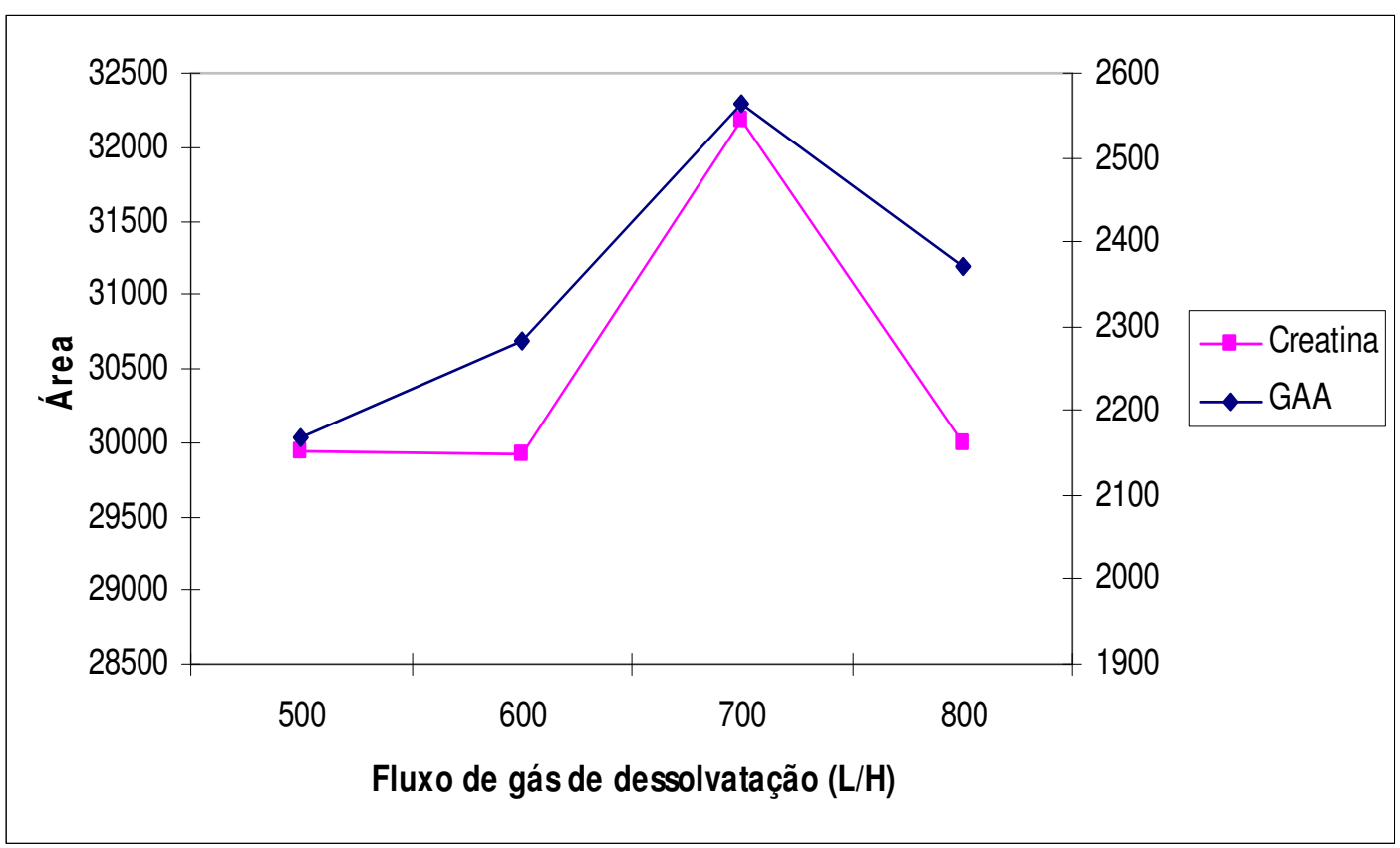

Figura 27. Dados de resposta dos compostos creatina e guanidinoacetato em função do fluxo do gás de dessolvatação.

Para todos os compostos, a vazão do gás de dessolvatação de 700 L/h apresentou uma relação satisfatória entre intensidade e regularidade de resposta, sendo essa a selecionada.

A Tabela 12 mostra as condições ajustadas para o acoplamento da cromatografia líquida com espectrometria de massas.

Tabela 12. Condições de acoplamento da cromatografia líquida com espectrometria de massas.

\section{Parâmetro}

Temperatura da fonte

Temperatura da coluna

Temperatura de dessolvatação

Fluxo do gás de dessolvatação

\section{Condição definida}

$70^{\circ} \mathrm{C}$

$40^{\circ} \mathrm{C}$

$450^{\circ} \mathrm{C}$

$700 \mathrm{~L} / \mathrm{h}$ 


\subsection{Desenvolvimento do método de extração da amostra}

Os compostos creatina e GAA, assim como seus análogos deuterados, possuem um grupo amino, podendo permanecer protonados sob o pH adequado (abaixo do seu valor de pKa).

A estratégia adotada para a purificação das amostras se baseou na troca iônica em fase sólida. Para esse fim foram avaliadas duas resinas de troca catiônica forte, a SCX (SEPRA SCX $50 \mu \mathrm{m}$ com poro de $65 \AA$ da marca Phenomenex ${ }^{\circledR}$ ) e a XC (SEPRA XC $33 \mu \mathrm{m}$ da marca Phenomenex ${ }^{\circledR}$ ). Ambas são constituídas de partículas ligadas a grupos sulfonatos que em baixos valores de $\mathrm{pH}$ se mantêm negativamente carregados. No caso da SCX as partículas são de sílica e na XC, de polímero. Embora por definição, a resina polimérica apresente vantagens em relação à de sílica (maior resistência a variações de $\mathrm{pH}$ e de polaridades dos solventes, partículas de dimensões menores, o que aumenta a superfície de contato e o número de grupamentos disponíveis e, portanto, de oportunidades de ligações resultando em maior eficiência de extração), durante grande parte do desenvolvimento do método trabalhou-se com a resina de sílica pela indisponibilidade comercial que a primeira apresenta.

Assim, foi estudado o impacto do $\mathrm{pH}$ do meio na recuperação do ensaio, buscando-se uma condição em que fosse assegurada a completa protonação dos compostos e o estado de cargas negativas dos grupos sulfonato da resina de purificação, favorecendo a troca catiônica. Foram avaliados os tamponamentos com ácido fórmico a $25 \mathrm{mmol} / \mathrm{L}$ (pKa 3,75) e tampão fosfato a $25 \mathrm{mmol} / \mathrm{L} \mathrm{pH} \mathrm{1,9} \mathrm{(vide} \mathrm{discussão} \mathrm{adiante).}$ 
A fase sólida utilizada foi adquirida como bulk, ou seja, apenas a resina, sem o suporte (placa ou coluna) para contê-la. O objetivo foi preparar in house as placas com a resina, de maneira a minimizar seu custo.

A próxima etapa relacionou-se a seleção do tipo de placa que seria utilizada como suporte. Inicialmente, foi avaliada a placa Multiscreen Solvinert da Millipore ${ }^{\circledR}$, composta por uma membrana hidrofílica (MDRL NP4) e um pré-filtro. Essa placa é resistente ao ataque por solventes. Devido à dificuldade de aquisição (a comercialização desse produto foi descontinuada pelo fornecedor) foram também avaliadas duas outras alternativas: Multiscreen Solvinert da Millipore ${ }^{\circledR}$, código MDRL NO4, também hidrofílica, porém sem pré-filtro e AxyPrep ${ }^{\circledR}$ Fritted $1,5 \mathrm{~mL} 96$ da Axygen Biosciences, uma placa mais simples, sem membrana e sem pré-filtro, apenas um frit para contenção da fase estacionária. Ambas apresentaram bons resultados e a selecionada como padrão foi esta última, por ter um custo menor.

As placas foram preparadas com a utilização do sistema Multiscreen da Millipore ${ }^{\circledR}$ próprio para esse fim (Figura 28), em que a resina é depositada em uma plataforma constituída de 96 orifícios ou poços, de dimensões regulares e controladas, de maneira a preenchê-los completamente. $\mathrm{O}$ excesso de resina é removido e uma placa vazia de 96 poços é posicionada sobre a plataforma com a face vazada de encontro a ela. O conjunto é invertido de forma que as porções de resina que preenchiam cada poço sejam transferidas para os respectivos orifícios da placa. A placa é selada a seguir com um filme plástico. No momento da utilização, a porção do lacre que recobre o número de poços necessários é removida. 

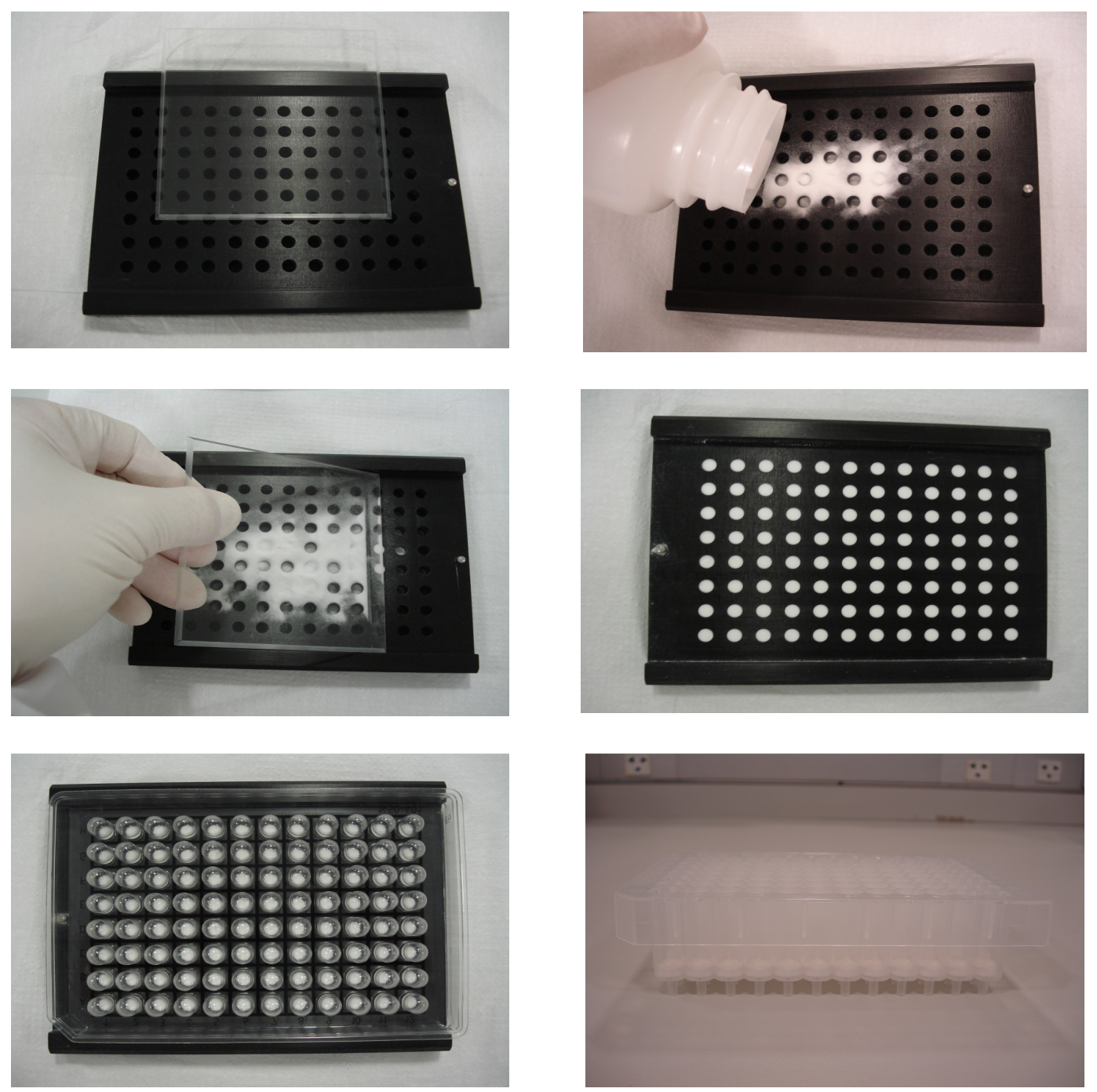

Figura 28. Sequência de preparação das placas de 96 poços com a utilização do sistema Multiscreen ${ }^{\circledR}$ Column loader $100 \mu \mathrm{L}$ da Millipore ${ }^{\circledR}$.

4.3.1. Avaliação inicial do protocolo de extração e definição do sistema de drenagem dos eluatos

Para os testes de extração foi inicialmente utilizada uma soluçãopadrão única de $10 \mu \mathrm{g} / \mathrm{mL}$ de cada composto em ácido fórmico a 25 mmol/L.

Como ponto de partida, foi utilizado um protocolo-padrão de extração em fase sólida com troca catiônica (item 3.7.1 de Materiais e Métodos) que constou da aplicação sequencial das seguintes soluções: 
- Condicionamento da "coluna":

$-1 \mathrm{~mL}$ de $\mathrm{MeOH}$;

$-1 \mathrm{~mL}$ de $\mathrm{H}_{2} \mathrm{O}$.

- Aplicação da amostra:

- $1 \mathrm{~mL}$ da solução de padrões (Eluato 1).

- Remoção de interferentes ácidos:

- $1 \mathrm{~mL}$ de $\mathrm{HCl} 0,1 \mathrm{~N}$ (Eluato 2).

- Remoção de interferentes neutros e hidrofóbicos:

- $1 \mathrm{~mL}$ de $\mathrm{MeOH}$ (Eluato 3).

- Eluição:

- $1 \mathrm{~mL}$ de $\mathrm{NH}_{4} \mathrm{OH}$ a $5 \%$ em MeOH (Eluato 4).

Para forçar a passagem das soluções pela resina foi utilizada, inicialmente, a centrifugação da placa entre as aplicações com avaliação de várias relações rotação/tempo. Com esse modo de escoamento, chegou-se a uma condição adequada com o uso de 1500 rpm (370 g) por 2 minutos. Em um segundo momento, passou-se a utilizar o sistema de drenagem pela formação de vácuo obtido por bomba com resultados igualmente satisfatórios. Este último foi definido como padrão devido a sua simplicidade e rapidez.

Nessa etapa inicial foram coletados todos os eluatos obtidos a partir do passo de aplicação da amostra para verificar se os compostos eram completamente retidos até a etapa de eluição com $\mathrm{NH}_{4} \mathrm{OH}$ a $5 \%$ em $\mathrm{MeOH}$.

Cada um dos quatro eluatos obtidos nesse experimento foi diluído na 
proporção de 1:1:8 (v:v:v) com ácido fórmico $25 \mathrm{mmol} / \mathrm{L}$ e ACN (1 parte de eluato + 1 parte de ácido fórmico $25 \mathrm{mmol} / \mathrm{L}+8$ partes de $\mathrm{ACN}$ ) para injeção no sistema.

As análises por LC-MS/MS revelaram que os analitos eluíram também na lavagem ácida (eluato 2), contrariamente ao esperado, que seria a presença dos analitos apenas no eluato 4. Possivelmente ocorreu uma competição entre os prótons dos compostos e os do meio ácido pelos grupos sulfonatos da fase sólida.

Com o intuito de verificar se de fato havia ocorrido esse tipo de interação, ou algo como a saturação da fase sólida e, portanto, arraste pela solução ácida, foi realizada uma extração (protocolo controle, Tabela 5 de Materiais e Métodos) em que a etapa de lavagem com $\mathrm{HCl} 0,1 \mathrm{~N}$ foi substituída por uma lavagem com água. Os resultados mostraram a presença dos analitos apenas no eluato 4 , ou seja, com a aplicação da solução de $\mathrm{NH}_{4} \mathrm{OH}$ a $5 \%$ em $\mathrm{MeOH}$.

4.3.2. Avaliação das soluções para eluição de interferentes ácidos e alcalinos

No experimento subsequente foram realizados testes de lavagem com os ácidos clorídrico em menor concentração (10 mmol/L), fórmico (50 $\mathrm{mmol} / \mathrm{L})$ e acético $(50 \mathrm{mmol} / \mathrm{L})$ (protocolos 1,2 e 3 Tabela 5 de Materiais e Métodos, respectivamente). Adicionalmente, foi inserida uma etapa de lavagem alcalina subsequente à lavagem ácida com soluções de $\mathrm{NH}_{4} \mathrm{OH}$ a $0,02 \%, 0,12 \%, 0,25 \%$ e $0,5 \%$ em $\mathrm{MeOH}$ (protocolos 4 a 7 , Tabela 5 de 
Materiais e Métodos). O objetivo foi determinar qual o ácido mais apropriado para a remoção de interferentes ácidos e qual a maior proporção de $\mathrm{NH}_{4} \mathrm{OH}$ que poderia ser utilizada de maneira a retirar possíveis interferentes alcalinos sem eluir os compostos de interesse.

Nesse experimento, verificou-se que a aplicação de $\mathrm{HCl}$ para a realização da lavagem ácida não é recomendável mesmo em uma concentração menor já que foi observado sinal nesse eluato. Em seu lugar, poderiam ser utilizados ácidos fórmico ou acético. Foi definido o uso do ácido fórmico cujo pka é mais baixo $(3,75)$ do que o do ácido acético $(4,76)$.

Foi ainda evidenciado que a condição de lavagem alcalina mais adequada era a de $\mathrm{NH}_{4} \mathrm{OH} 0,02 \%$ em MeOH (protocolo 4, Tabela 5), pois não foi observada a presença dos analitos neste eluato. Uma vez que o $\mathrm{NH}_{4} \mathrm{OH}$ utilizado nessa lavagem é preparado em $\mathrm{MeOH}$, a etapa anterior de lavagem com $\mathrm{MeOH}$ puro foi suprimida.

Os cromatogramas obtidos foram avaliados quanto à intensidade das respostas de todos os compostos monitorados. Observou-se que os sinais para creatina e cretina- $d_{3}$ nas condições de extração e deteç̧ão estavam amplamente satisfatórios. Porém, para GAA e GAA- $d_{2}$ estavam pouco intensos. Foram discutidas algumas possibilidades para contornar essa situação:

1) Modificação do $\mathrm{pH}$ de tamponamento da amostra de maneira a garantir a total protonação dos compostos de interesse, o que, em princípio, melhoraria a sensibilidade do ensaio. Para esse fim foi realizada a comparação da preparação da amostra em solução de ácido fórmico a 25 
$\mathrm{mmol} / \mathrm{L}$ e em tampão fosfato a $25 \mathrm{mmol} / \mathrm{L} \mathrm{pH} \mathrm{1,9;}$

2) Aumento da força da solução de eluição (o que possivelmente implicaria na necessidade de posterior neutralização do eluato a fim de evitar danos à coluna analítica, cuja estabilidade em altos valores de $\mathrm{pH}$ pode ser comprometida) e/ou

3) Diminuição do volume da solução de eluição.

Nesse momento, arbitrou-se pela alteração da sequência de condicionamento da coluna de extração com a utilização de uma solução ácida (tampão fosfato $25 \mathrm{mmol} / \mathrm{L}$ ) no lugar de água pura, com o objetivo de maximizar o estado de cargas negativas dos grupamentos ligados às suas partículas de sílica (grupos sulfonato) na tentativa de favorecer as oportunidades de ligação dos compostos de interesse.

\subsubsection{Avaliação do meio de preparo da amostra}

As amostras analisadas nesse experimento foram preparadas segundo o item 3.7.3. Foi observada uma maior recuperação dos dois compostos em termos de área obtida na condição de preparo da amostra em tampão fosfato $25 \mathrm{mmol} / \mathrm{L} \mathrm{pH}$ 1,9 mantendo-se dessa forma a amostra tamponada em pH menor que o pKa dos analitos.

\subsubsection{Avaliação do volume e concentração da base para eluição}

Para esses ensaios, as amostras foram preparadas segundo o item 3.7.4. Considerando que concentrações maiores de $\mathrm{NH}_{4} \mathrm{OH}$ possivelmente necessitariam de uma etapa de neutralização do eluato, pois, de outra 
maneira poderia haver danos à coluna analítica, optou-se pela eluição com $0,5 \mathrm{~mL}$ de $\mathrm{NH}_{4} \mathrm{OH} 5 \%$ em MeOH (Protocolo 2, Tabela 5). Essa redução do volume de eluição de 1 para $0,5 \mathrm{~mL}$ contribuiria também para a melhora da sensibilidade por representar uma concentração duas vezes maior em comparação à concentração anteriormente obtida e uma redução de custo de reagentes. Os resultados obtidos com a eluição em volume de $0,5 \mathrm{~mL}$ estão apresentados na Figura 29.

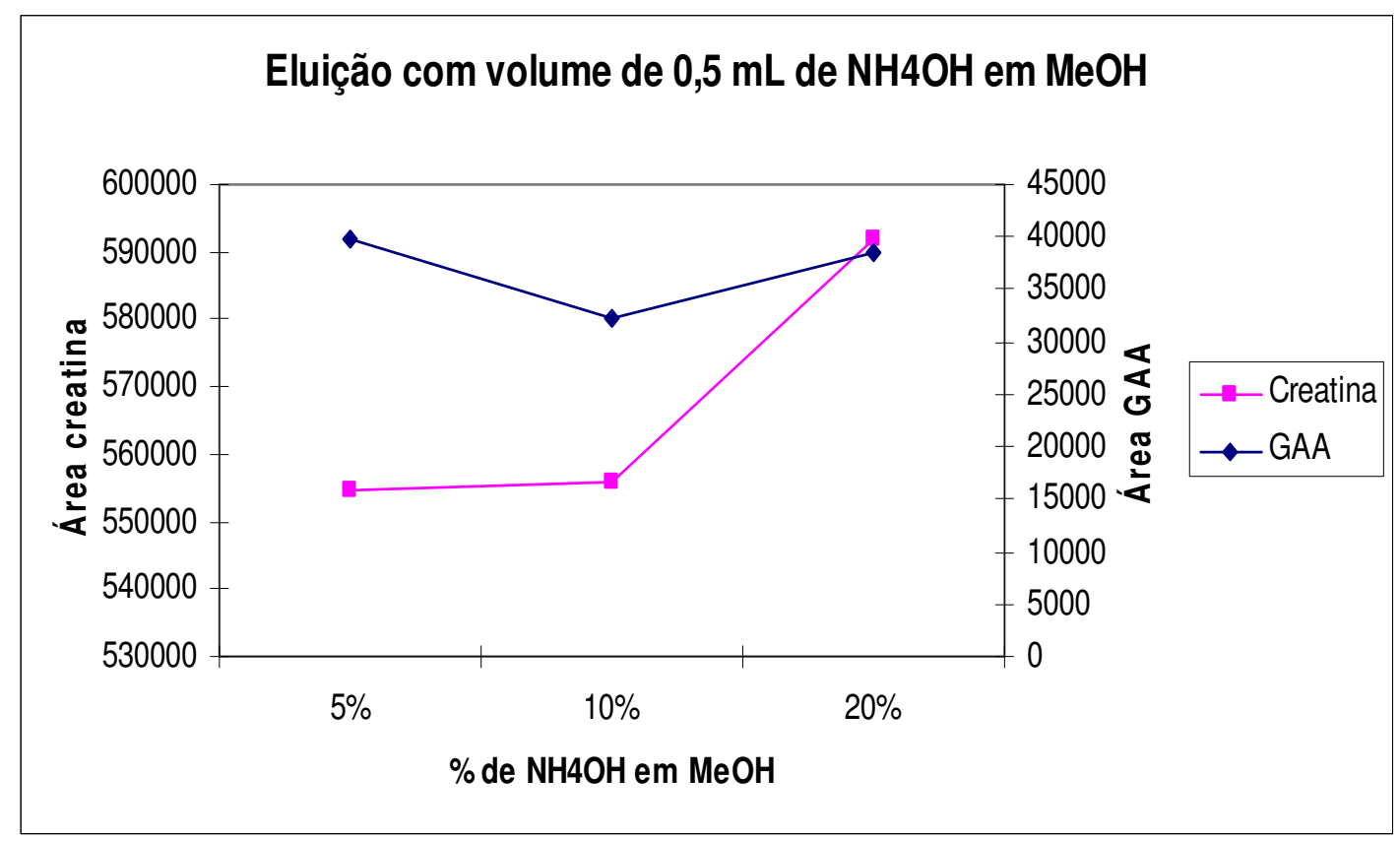

Figura 29. Gráfico relacionando resposta em área em função da concentração e volume de $\mathrm{NH}_{4} \mathrm{OH}$. Detalhes de cada extração estão descritos na Tabela 6 .

4.3.5. Avaliação da inserção de uma etapa de concentração da amostra

Foi realizado um teste de sensibilidade sem extração por SPE a fim de verificar se a baixa sensibilidade observada para GAA era decorrente de 
recuperação insuficiente da extração ou a uma limitação de detecção.

As amostras nas concentrações de 0,05; 0,1 e 1,0 $\mu \mathrm{g} / \mathrm{mL}$ em ACN foram preparadas e analisadas segundo descrito no item 3.7.5. Nesse experimento foi observado que a sensibilidade de detecção para GAA não passava de $1 \mu \mathrm{g} / \mathrm{mL}$ (não houve boa resposta para 0,05 e $0,1 \mu \mathrm{g} / \mathrm{mL}$ ). No entanto, esse limite é insuficiente já que os valores de referência apontados na literatura ${ }^{51,52}$ partem de valores baixos como $0,05 \mu \mathrm{g} / \mathrm{mL}$ para soro. Diante desses resultados, a estratégia adotada foi a da inserção de uma etapa de secagem dos eluatos em speed vac ao final da extração e ressuspensão do extrato seco com ACN 88\%. Essa abordagem permitiu a adequação do volume de ressuspensão do extrato seco em função da sensibilidade requerida para o ensaio.

Tal estratégia foi testada aplicando-se o protocolo descrito no item 3.7.6 com a adição de uma etapa final de secagem dos eluatos em um sistema de liofilização, speed vac, antes da injeção por LC-MS/MS. Os resultados mostraram que nos dois casos (extração dos analitos nas concentrações de 10 e $100 \mu \mathrm{g} / \mathrm{mL}$ ) os sinais obtidos para todos os canais foram mais intensos, confirmando a contribuição da inclusão da etapa de secagem em speed vac no protocolo de extração independentemente da concentração inicial dos analitos.

\subsubsection{Avaliação preliminar da linearidade em padrões aquosos}

A seguir foi realizado um teste para avaliação preliminar de linearidade com a utilização de padrões aquosos e a adição de solução de 
padrões internos à amostra. As amostras foram preparadas, extraídas e quantificadas segundo o item 3.7.7.

O resultado de linearidade revelou que, no estado atual do método, a faixa linear para ambos os compostos situava-se entre 0,05 e $100 \mu \mathrm{g} / \mathrm{mL}$. Foi observado arraste após a injeção da concentração de $500 \mu \mathrm{g} / \mathrm{mL}$. Nessa avaliação verificou-se ainda que a concentração dos compostos deuterados utilizados como padrão interno estava muito alta, resultando em áreas de $\mathrm{PI}$ muito grandes em relação às dos compostos de interesse. Definiu-se diluir os padrões internos para uma concentração de $100 \mu \mathrm{g} / \mathrm{mL}$ e utilização de 10 $\mu \mathrm{L}$.

\subsection{Extração em fase sólida com matriz urinária}

\subsubsection{Definição do volume de amostra}

Os resultados da incorporação da etapa de secagem em speed vac, discutidos no item 4.3.5, sugeriram que seria possível utilizar volumes menores de amostra, já que essa estratégia permitiria dimensionar a sensibilidade necessária ao ensaio pela manipulação do volume de ressuspensão do extrato seco.

Assim, foi realizado um teste preliminar com extração de volumes de 100 e $500 \mu \mathrm{L}$ de urina pura e adicionada de solução de padrões de creatina e GAA, cujo objetivo foi avaliar a possibilidade de redução do volume de urina e estimar preliminarmente a recuperação na extração dessa matriz. As amostras foram extraídas e quantificadas como descrito no item 3.8.1.

Nesse experimento foi observado novamente algum arraste 
(identificado em injeções de brancos intercaladas às injeções das amostras). Foi então necessário isolar as duas possíveis fontes desse arraste: contaminação da coluna (efeito de "memória" devido a sua saturação) ou contaminação do sistema de injeção.

Para isso, foram realizadas várias injeções de branco (ACN a 80\%), que revelaram a presença de picos para os analitos em estudo e a seguir, uma "injeção branca", ou seja, foi dado o disparo para a aquisição sem amostra e sem a seringa. Nesta última "injeção", não foram observados picos, embora o gradiente tenha sido aplicado. Esse procedimento simples demonstrou que a contaminação tinha origem no sistema de injeção (seringa, agulha e/ou porta de injeção). Para contornar esse problema, as programações de lavagem pré e pós-injeção do amostrador foram alteradas.

A utilização de curva aquosa resultou em uma quantificação adequada com resultados das extrações de 100 e $500 \mu \mathrm{L}$ de amostra comparáveis e com sinais abundantes.

Com base nesses resultados, e considerando que a linearidade do ensaio deveria ser ampliada já que até então estava em torno de $100 \mu \mathrm{g} / \mathrm{mL}$, definiu-se testar a extração de volume menor de amostra (50 $\mu \mathrm{L})$. Essa diminuição seria desejável por uma série de razões, dentre as quais se destaca o fato de que a competição de interferentes catiônicos da amostra pelos grupos de ligação da coluna de extração seria reduzida, resultando em uma recuperação e linearidade potencialmente maiores e com menor arraste entre as injeções. Além disto, a utilização de volumes menores em todas as etapas de lavagem intermediárias representaria uma economia de recursos. 
Poder-se-ia ainda associar a essa estratégia o aumento do volume de ressuspensão do extrato seco ou ainda a diminuição do volume injetado.

Foi então conduzido um experimento com a extração de volumes de 10,50 e $100 \mu \mathrm{L}$ de urina pura e da mesma urina adicionada de 1, 100, 500 e $1000 \mu \mathrm{g} / \mathrm{mL}$ de creatina e GAA e utilização de volumes reduzidos de $1 \mathrm{~mL}$ para 0,5 mL de todas as soluções de lavagem (item 3.8.1).

A extração de $50 \mu \mathrm{L}$ de amostra resultou em resposta satisfatória tendo sido essa a condição fixada para extração de amostras de urina extraídas com a resina até então disponível, a SCX. Com relação ao volume de injeção, ficou definida a utilização de $5 \mu \mathrm{L}$ de eluato uma vez que a injeção de volumes maiores ainda resultava em arraste nas amostras de concentrações altas dos padrões. Entretanto, embora o sinal para creatina tenha sido satisfatório nessa condição, a resposta para valores de GAA entre 0,5 e $1 \mu \mathrm{g} / \mathrm{mL}$ da curva aquosa ainda permaneceu muito baixa.

$\mathrm{Na}$ tentativa de obter melhor sinal para valores baixos de GAA e GAA$d_{2}$, essa mesma extração foi reinjetada em uma condição de detecção em que o tempo de monitoramento dos canais ( $d$ well time) de GAA e GAA- $d_{2}$ foi aumentado em relação aos da creatina e creatina- $d_{3}(0,15$ segundos e 0,05 segundos, respectivamente). No entanto essa estratégia não resultou em ganho de sinal significativo e a condição anterior de 0,10 segundos para cada analito foi mantida. 
4.4.2. Avaliação preliminar de limite de quantificação em matriz urinária

A partir dos resultados obtidos até então, foi conduzido um estudo para avaliação preliminar de limite de quantificação em matriz urinária com a extração de diluições de urina em urina sintética para GAA e em solução fisiológica ( $\mathrm{NaCl}$ 0,15 mmol/L) para creatina, preparadas segundo item 3.8.2. Foi necessária essa diferenciação pelo fato de ter sido verificado sinal para creatina na extração de urina sintética pura. A fim de manter um ambiente de íons comparável com o da amostra, foi preservada a condição de diluição em urina sintética para GAA.

Os resultados obtidos estão expressos na Tabela 13 para GAA e Tabela 14 para creatina.

Tabela 13. Valores de guanidinoacetato esperados e obtidos em extrações de diluições de amostra de urina (U) com urina sintética (US), volume:volume.

\begin{tabular}{ccc}
\hline Matriz & GAA $(\mu \mathrm{g} / \mathrm{mL})$ & Valor esperado $(\mu \mathrm{g} / \mathrm{mL})$ \\
\hline Urina pura & 40,3 & ---- \\
Urina sintética & 0 & $-\cdots--$ \\
U + US (1:1) & 20,13 & 20,15 \\
U + US (1:5) & 7,11 & 6,72 \\
U + US (1:10) & 4,06 & 3,66 \\
U + US (1:20) & 1,83 & 1,92 \\
U + US (1:30) & 1,48 & 1,3 \\
U + US (1:40) & 1,09 & 0,98 \\
\hline
\end{tabular}


Tabela 14. Resultados esperados e obtidos para creatina em extrações de diluições de amostra de urina $(\mathrm{U})$ com $\mathrm{NaCl}$ 0,15 M (volume:volume).

\begin{tabular}{ccc}
\hline Matriz & Creatina $(\mu \mathrm{g} / \mathrm{mL})$ & Valor esperado $(\mu \mathrm{g} / \mathrm{mL})$ \\
\hline Urina pura & 3,05 & --- \\
$\mathrm{NaCl} 0,15 \mathrm{M}$ & 0,12 & --- \\
$\mathrm{U}+\mathrm{NaCl}(1: 1)$ & 1,39 & 1,52 \\
$\mathrm{U}+\mathrm{NaCl}(1: 4)$ & 0,68 & 0,61 \\
$\mathrm{U}+\mathrm{NaCl}(1: 9)$ & 0,39 & 0,31 \\
$\mathrm{U}+\mathrm{NaCl}(1: 14)$ & 0,37 & 0,20 \\
$U+\mathrm{NaCl}(1: 19)$ & 0,28 & 0,15 \\
$U+\mathrm{NaCl}(1: 49)$ & 0,31 & 0,06 \\
$U+\mathrm{NaCl}(1: 99)$ & 0,19 & 0,03 \\
\hline
\end{tabular}

Os dados apresentados demonstram que os limites de quantificação em urina para creatina estão na faixa de 0,3 a $0,4 \mu \mathrm{g} / \mathrm{mL}$ e para $\mathrm{GAA}$ possivelmente abaixo de $1 \mu \mathrm{g} / \mathrm{mL}$. Esses resultados estão consistentes com os extremos de valores de referência utilizados em métodos baseados em CG-MS e LC-MS/MS descritos na literatura ${ }^{41,51-55}$. É importante destacar que não há consenso entre os vários autores com relação a esses valores, mas que, de maneira geral, a maioria deles aponta faixas muito amplas de referência dentro de cada grupo etário, em particular em relação a urina.

\subsubsection{Avaliação preliminar da recuperação do ensaio em matriz urinária}

Em sequência, foi realizado um estudo preliminar da recuperação com amostra de urina segundo procedimento descrito no item 3.8.3. Os valores 
obtidos, expressos em $\mu \mathrm{g} / \mathrm{mL}$, estão apresentados na Tabela 15.

Tabela 15. Resultados dos testes preliminares de recuperação em urina pura e adicionada de padrões de creatina e guanidinoacetato.

\begin{tabular}{|c|c|c|c|c|}
\hline \multirow[b]{2}{*}{ Matriz } & \multicolumn{2}{|c|}{ Creatina } & \multicolumn{2}{|c|}{ Guanidinoacetato } \\
\hline & $\begin{array}{l}\text { Valor obtido } \\
(\mu \mathrm{g} / \mathrm{mL})\end{array}$ & $\begin{array}{l}\text { Valor esperado } \\
\qquad(\mu \mathrm{g} / \mathrm{mL})\end{array}$ & $\begin{array}{l}\text { Valor obtido } \\
(\mu \mathrm{g} / \mathrm{mL})\end{array}$ & $\begin{array}{c}\text { Valor } \\
\text { esperado } \\
\text { ( } \mu \mathrm{g} / \mathrm{mL})\end{array}$ \\
\hline Urina pura & 2,38 & --------- & 39,4 & -----------. \\
\hline Urina + 1 ug/mL & 2,93 & 3,38 & 40,54 & 40,4 \\
\hline $\begin{array}{l}\text { Urina }+100 \\
\text { ug } / \mathrm{mL}\end{array}$ & 121,25 & 102,38 & 156,15 & 139,4 \\
\hline $\begin{array}{l}\text { Urina }+500 \\
\text { ug } / \mathrm{mL}\end{array}$ & 673,90 & 502,38 & 541,70 & 539,4 \\
\hline $\begin{array}{c}\text { Urina }+1000 \\
\text { ug } / \mathrm{mL}\end{array}$ & 1611,10 & 1002,38 & 1039,39 & 1039,4 \\
\hline
\end{tabular}

Os resultados demonstram uma boa relação entre os valores esperados e os observados para GAA (correlação: 0,999) e creatina (correlação: 0,996).

Os dados preliminares de recuperação e de limites de quantificação indicaram que o método estava suficientemente ajustado em relação à extração dessa matriz.

Nessa etapa foi possível realizar a avaliação do desempenho da extração com a utilização da resina de troca catiônica forte baseada em polímero, a XC, diante daquela disponível e utilizada até o momento, a SCX. 
4.4.4. Comparação do desempenho das extrações de urina em resina SCX (sílica) e XC (polímero)

As respostas em termos de áreas de creatina e GAA obtidas pela extração das mesmas amostras (item 3.8.4) nas duas resinas estão apresentadas nas Figuras 30 e 31.

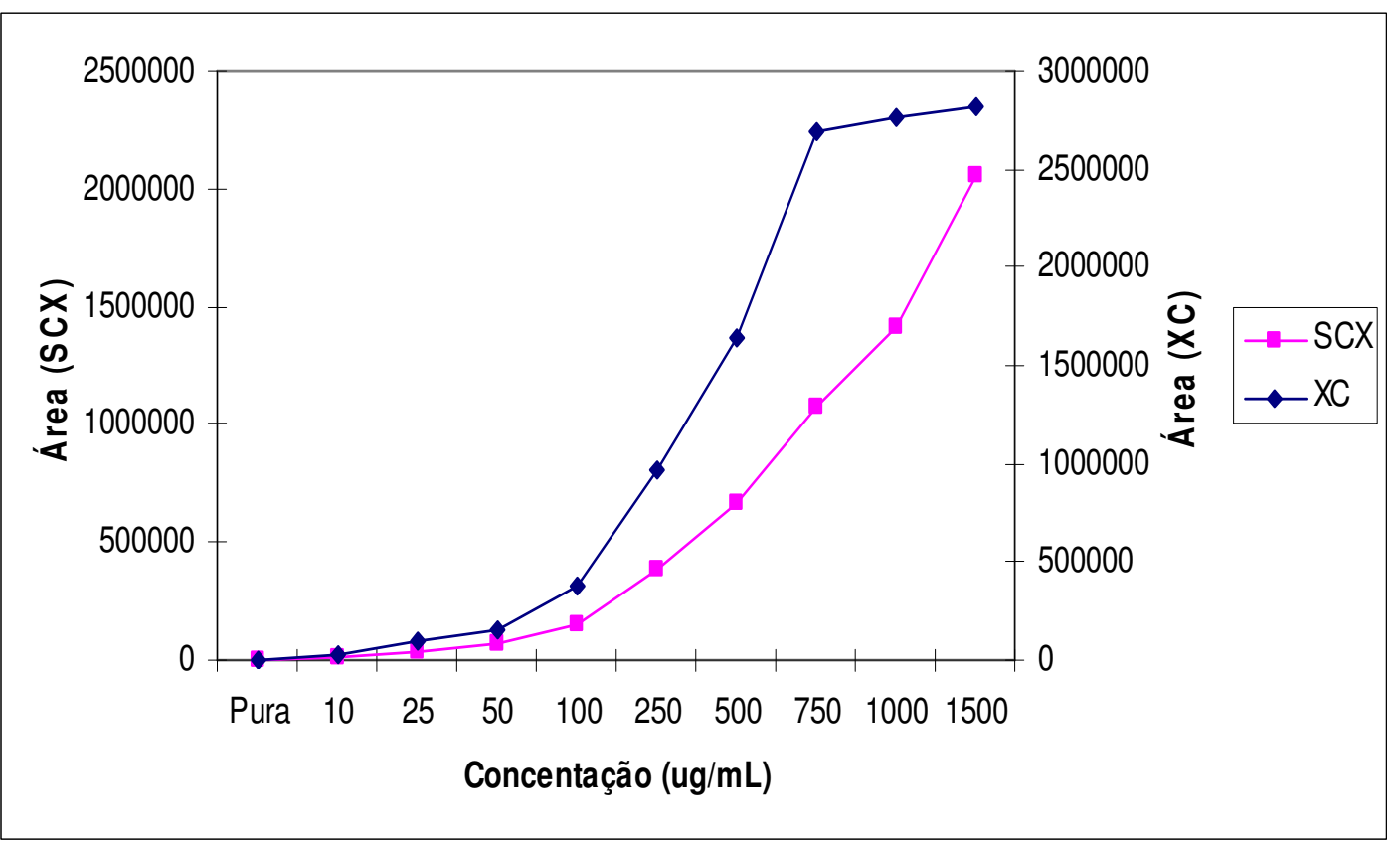

Figura 30. Comparação das respostas para creatina após extração em resinas SCX e XC. 


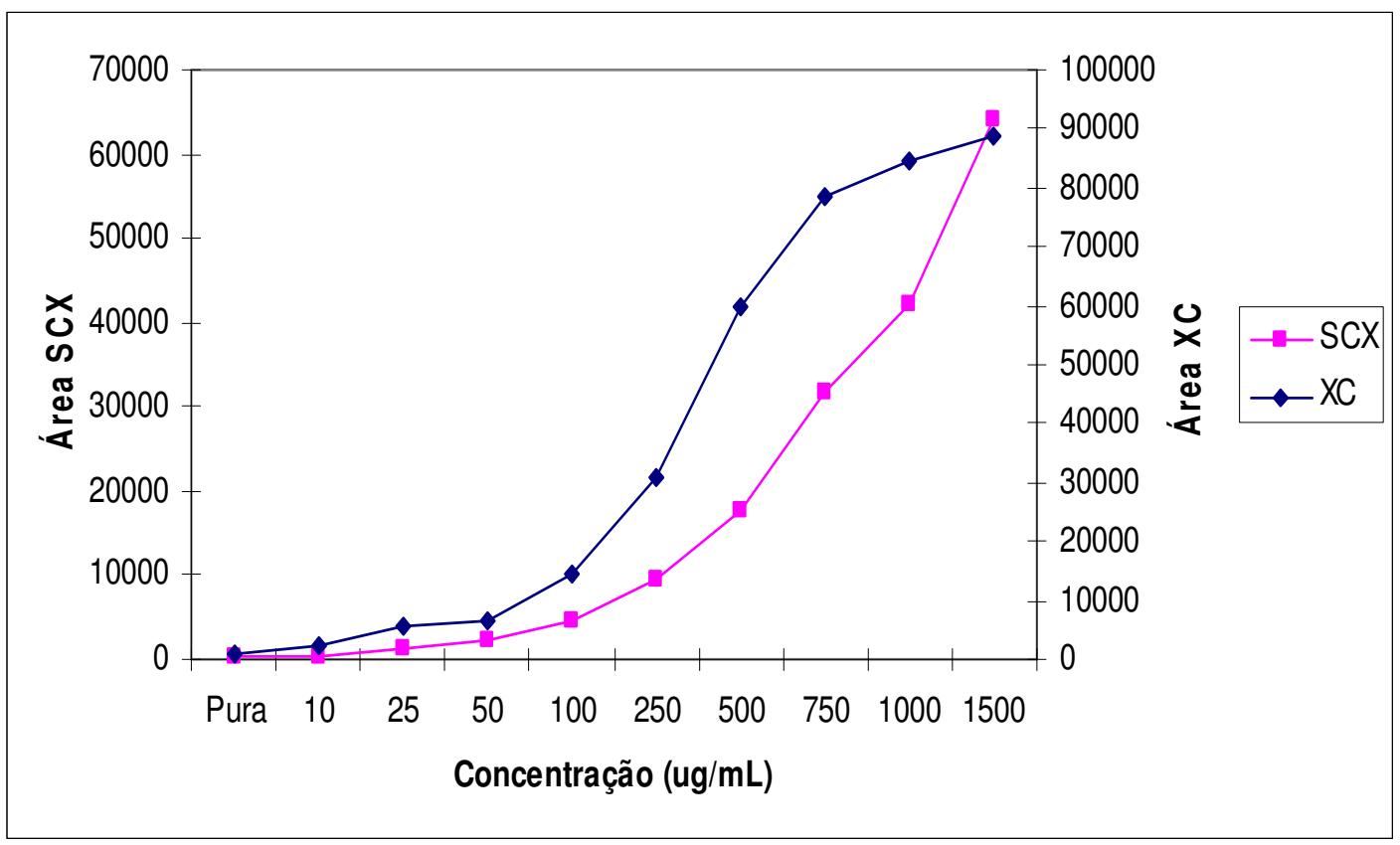

Figura 31. Comparação das respostas para GAA após extração em resinas SCX e $\mathrm{XC}$

Tanto para creatina quanto para GAA a recuperação é maior com a extração em resina polimérica (XC). No entanto, observa-se, nessa condição, um declínio relativo de sinal nas amostras de concentrações maiores para os compostos e seus análogos deuterados.

Esse achado poderia ser decorrente de saturação do espectrômetro de massas ou saturação dos sítios de ligação da resina de extração.

A primeira hipótese foi descartada pela injeção dos mesmos eluatos em duas diferentes condições, uma com redução dos volumes de injeção de amostra e outra em condições de aquisição fora dos valores ótimos (piorando as condições de detecção). Em ambos os casos o comportamento observado foi o mesmo: perda relativa de sinal para as concentrações altas.

Assim, considerou-se como determinante desse comportamento a possibilidade de saturação dos sítios de ligação da resina. Essa situação 
poderia ser corrigida de duas formas: pela utilização de uma quantidade maior de resina ou de um volume menor de amostra. Dentre essas possibilidades, a mais factível seria reduzir o volume de extração. Por isso foi necessário reavaliar o impacto do volume de extração padronizando-a para essa nova condição.

4.4.5. Avaliação do volume de extração na resina XC (polímero)

As respostas em termos de áreas de creatina e GAA obtidas pela extração de volumes de 5, 10 e $50 \mu \mathrm{L}$ das amostras preparadas segundo descrito no item 3.8.5 estão expressas nas Figuras 32 e 33.

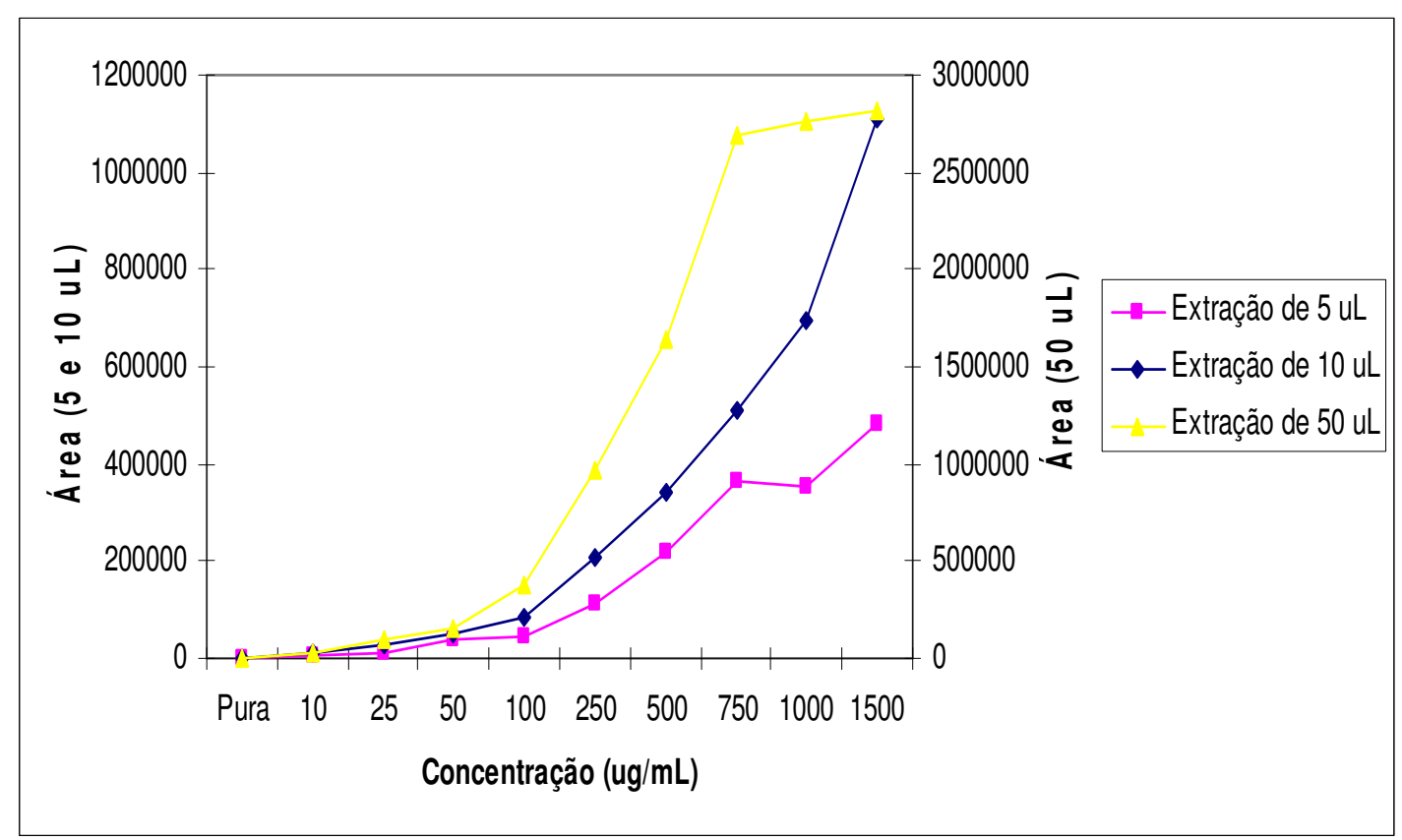

Figura 32. Comparação das respostas para creatina obtidas após extração de volumes de 5, 10 e $50 \mu \mathrm{L}$ de amostra em resina $\mathrm{XC}$. 


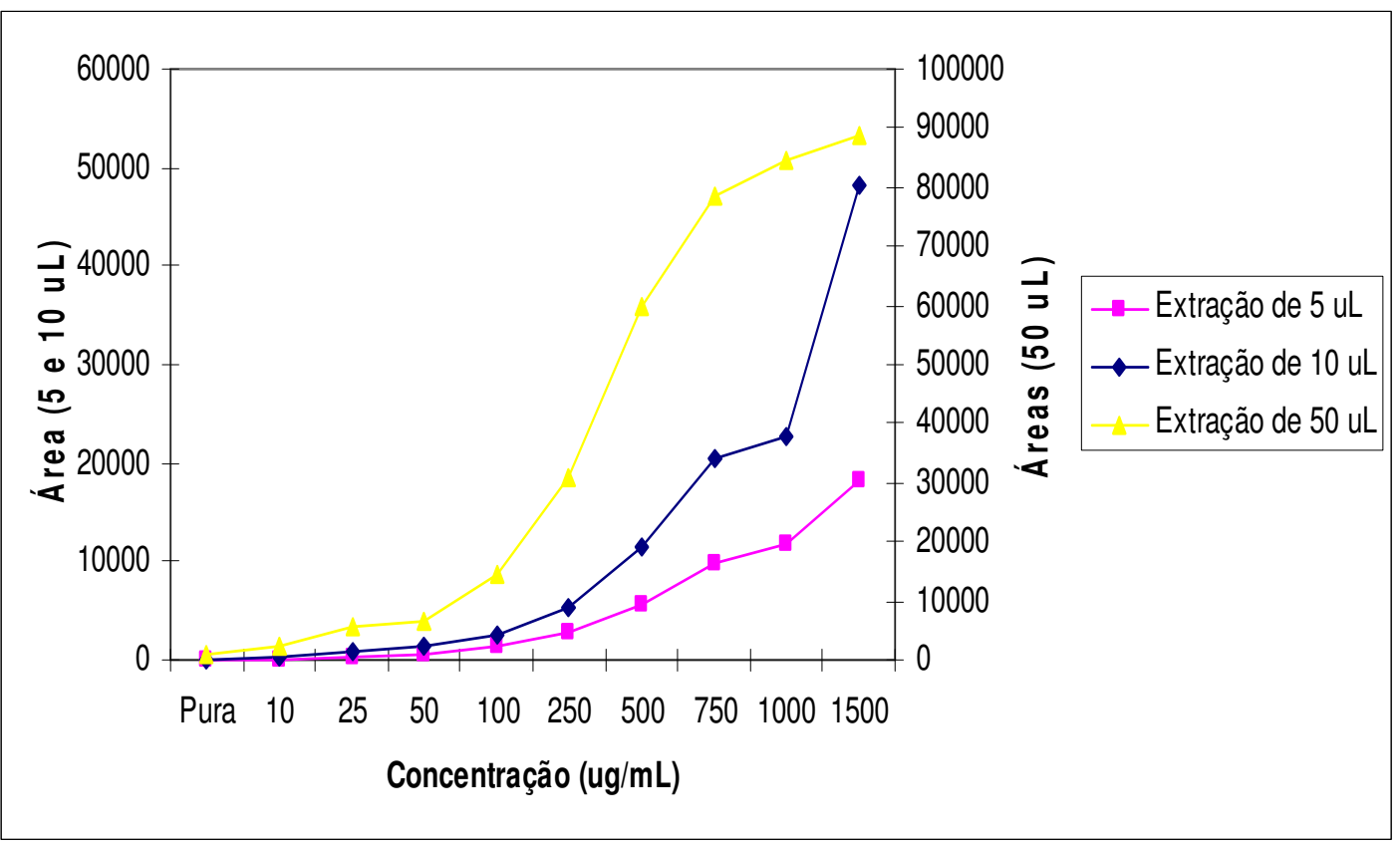

Figura 33. Comparação das respostas para GAA obtidas após extração de volumes de 5,10 e $50 \mu \mathrm{L}$ de amostra em resina $X C$.

Os dados obtidos indicam que a extração de $50 \mu \mathrm{L}$ de amostra resulta em áreas maiores para os dois compostos. No entanto, mesmo aplicando-se diferentes modos de ajuste de equação (linear, quadrático, cúbico) não foi possível alcançar uma condição adequada a valores baixos e altos. Em qualquer tipo de ajuste utilizado, há distorções nos dois extremos. Por outro lado, a extração de $10 \mu \mathrm{L}$ apresentou resultados com progressão de áreas mais regular para os dois compostos e uma boa resposta com a aplicação de ajuste polinomial de segunda ordem (quadrático) sendo por isso a condição selecionada.

\subsection{Extração em fase sólida com matriz de soro ou plasma}

As condições pré-definidas de condicionamento da coluna de 
extração, lavagens ácida e alcalina e eluição estabelecidas para as soluções-padrão em concentrações baixas e altas foram adotadas como padrão independentemente da matriz a que seriam aplicadas. $O$ ponto que necessitou ser tratado em particular, em função da natureza da matriz da amostra, foi a etapa de preparação para aplicação na coluna de extração. Nessa etapa, o conteúdo proteico e iônico das diferentes matrizes poderia requerer tratamentos diferenciados de modo que a remoção de interferentes específicos não ocasionasse uma recuperação ineficiente.

Assim, foram estudadas condições de preparo de amostras de soro levando em conta a sensibilidade necessária ao ensaio e tomando como ponto de partida os extremos de valores de referência expressos descritos na literatura e apresentados na Tabela 16.

Tabela 16. Extremos de valores de referência para creatina e guanidinoacetato encontrados na literatura expressos em $\mu \mathrm{g} / \mathrm{mL}$ e $\mu \mathrm{mol} / \mathrm{L}^{41,51-55}$.

\begin{tabular}{ccccc}
\hline \multirow{2}{*}{ Matriz } & \multicolumn{2}{c}{ Creatina } & \multicolumn{2}{c}{ Guanidinoacetato } \\
& $\boldsymbol{\mu m o l} / \mathbf{L}$ & $\mu \mathrm{g} / \mathrm{mL}$ & $\mu \mathrm{mol} / \mathbf{L}$ & $\boldsymbol{\mu g} / \mathbf{m L}$ \\
\hline Plasma & $3,81-114,41$ & $0,5-15$ & $0,35-3,59$ & $0,041-0,42$ \\
Urina & $6,86-10487,4$ & $0,9-1375$ & $8,54-1263,88$ & $1,0-148$ \\
\hline
\end{tabular}

\subsubsection{Tamponamento da amostra}

Para o preparo das amostras de soro foi considerado o fato de que essa matriz apresenta-se fisiologicamente tamponada a um $\mathrm{pH}$ em torno de 7, sendo, portanto, necessário um tratamento ácido mais agressivo do que aquele definido para urina. Assim, foi utilizado ácido orto-fosfórico para reduzir o pH do meio a valores próximos a 1,5. A proporção ácido/amostra 
necessária para alcançar esse $\mathrm{pH}$ foi de 2:100, ou seja, $2 \mu \mathrm{L}$ de ácido para $100 \mu \mathrm{L}$ de soro.

4.5.2. Contribuição da extração em SPE no sinal dos analitos em soro/plasma

A seguir foi realizado um experimento em que foram utilizados os volumes de $25,50,100$ e $200 \mu \mathrm{L}$ de soro dialisado adicionado de $50 \mu \mathrm{g} / \mathrm{mL}$ de creatina e GAA com e sem extração em SPE preparados segundo descrito no item 3.9.2 de Materiais e Métodos, com o objetivo de verificar a contribuição da extração na intensidade dos sinais obtidos e definir o volume de amostra necessário para obtenção de sinal de intensidade satisfatória.

Os resultados estão apresentados nas Figuras 34 e 35.

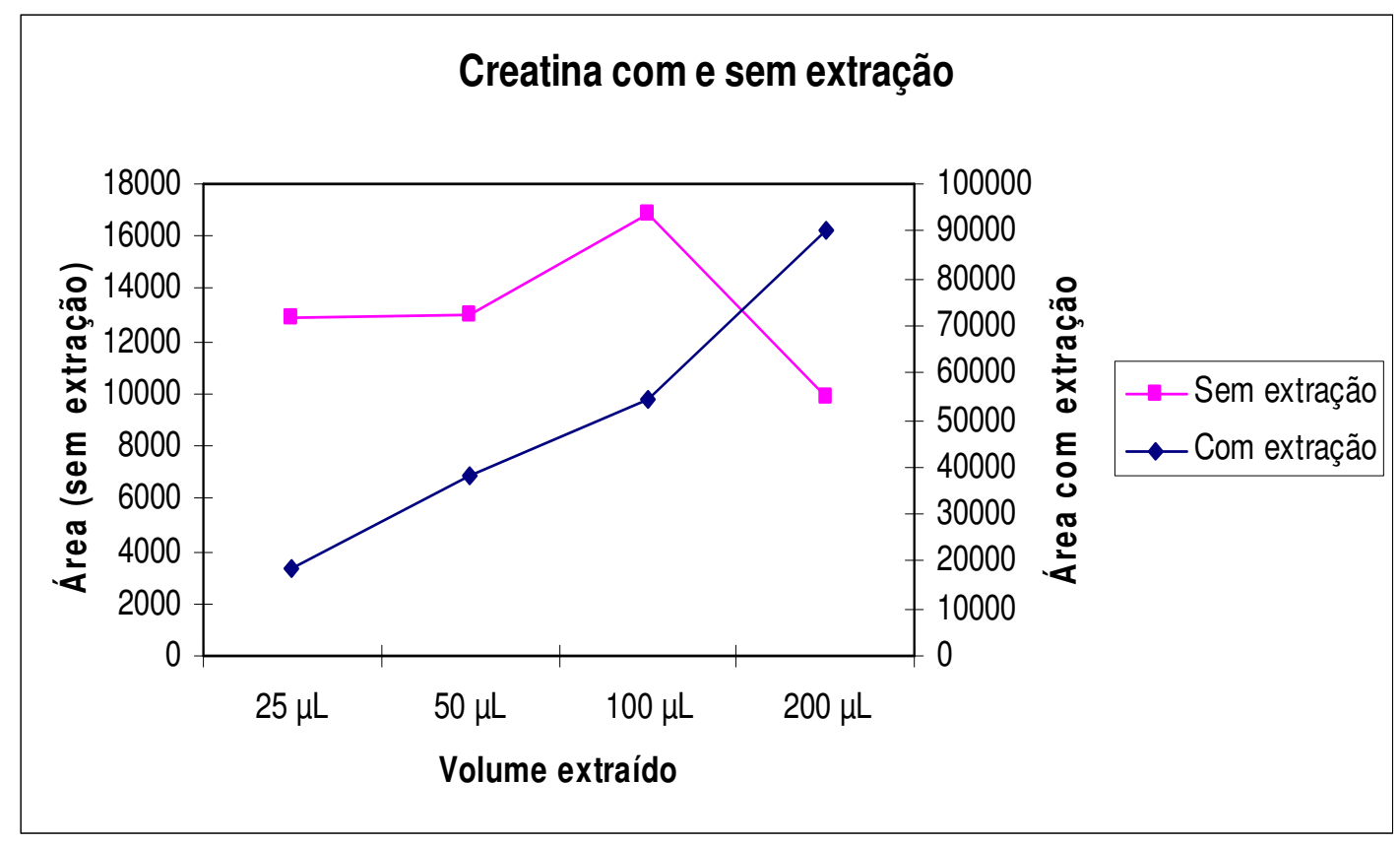

Figura 34. Áreas obtidas para creatina com e sem extração por SPE. 


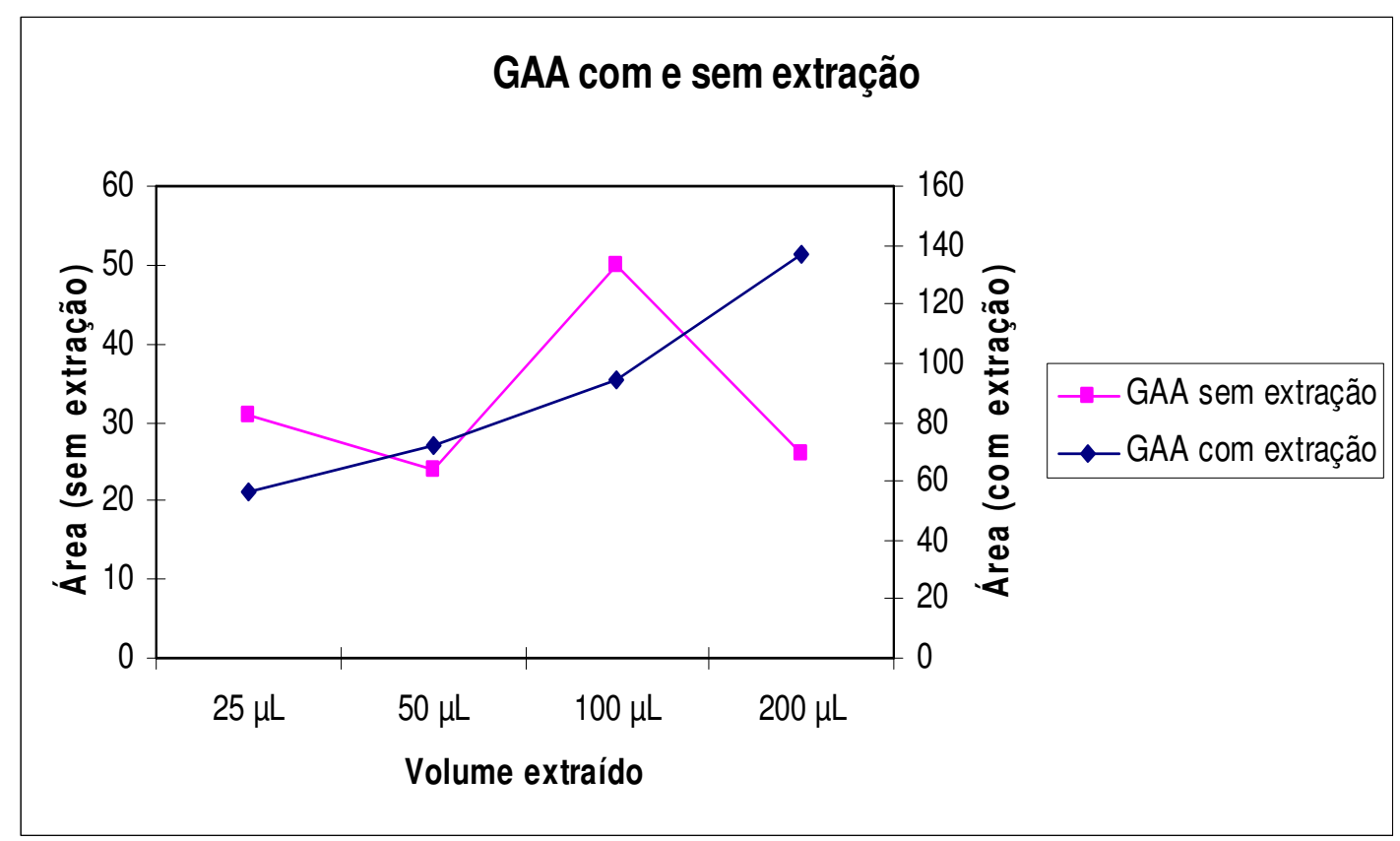

Figura 35. Áreas obtidas para GAA com e sem extração por SPE

A evolução do sinal para creatina e GAA em função do aumento de volume de amostra utilizado mostrou-se mais consistente naquelas em que foi aplicada da extração em SPE. Nestas, houve ganho na intensidade dos sinais tanto para creatina como para GAA em todos os volumes testados, o que reforça a importância da extração no enriquecimento do sinal. Aparentemente, sem a aplicação da extração em SPE, o aumento do volume de amostra acasiona iregularidade e até redução dos sinais possivelmente devido a supressão iônica por interferentes.

A julgar por esse experimento, poder-se-ia trabalhar com volumes maiores de amostra favorecendo uma melhora na sensibilidade do ensaio. Entretanto, esse teste aplica-se fundamentalmente à população pediátrica, sendo, portanto, necessário ponderar sobre a conveniência de ampliar ainda mais o volume utilizado. 
Assim, as condições de extração foram refinadas de forma a aumentar a sensibilidade sem ampliar o volume de amostra utilizado pela manipulação dos volumes de ressuspensão do eluato seco e de injeção. Foram então extraídos dois grupos de amostras nos volumes de 100, 150 e $200 \mu \mathrm{L}$ sendo que, após a etapa de secagem, um deles foi ressuspendido com $50 \mu \mathrm{L}$ e o outro com $100 \mu \mathrm{L}$ de $\mathrm{ACN}$ 88\% (consultar item 3.9.2 de Materiais e Métodos). Foram realizadas injeções de 10, 15 e $20 \mu \mathrm{L}$ de cada eluato.

A utilização de $150 \mu \mathrm{L}$ de soro, ressuspensão do extrato seco em 50 $\mu \mathrm{L}$ de $\mathrm{ACN} 88 \%$ (6 $\mu \mathrm{L}$ de água e $44 \mu \mathrm{L}$ de $\mathrm{ACN}$ ) e injeção de $20 \mu \mathrm{L}$ no sistema, resulta em uma boa sensibilidade sendo essa a condição definida para esta matriz.

A seguir foi avaliada a eficiência da remoção do conteúdo proteico da amostra pela análise de proteínas por vermelho de pirogalol em equipamento automatizado ADVIA 1200 do primeiro eluato resultante da aplicação da amostra na placa de SPE e da amostra sem pré-tratamento diluída na mesma proporção do eluato (ítem 3.9.3 de Materiais e Métodos). Nesse experimento foi obtido para a amostra pura o valor de 550,1 mg/dL de proteínas e para o $1^{\circ}$ eluato, o valor de $512,1 \mathrm{mg} / \mathrm{dL}$. Observou-se que quase todo o conteúdo proteico da amostra é removido apenas pela aplicação da amostra preparada na coluna de extração, ou seja, as proteínas não ficam retidas na coluna de extração, o que descarta a necessidade de inclusão de uma etapa de lavagem com água para sua remoção. 
Desta forma, o protocolo de preparo da amostra para aplicação na coluna de SPE foi definido como descrito a seguir: a $150 \mu \mathrm{L}$ de amostra são adicionados $3 \mu \mathrm{L}$ de ácido orto-fosfórico, $10 \mu \mathrm{L}$ de $\mathrm{PI}(\mathrm{a} 100 \mu \mathrm{g} / \mathrm{mL})$ e $750 \mu \mathrm{L}$ de água. Essa solução é homogeneizada e aplicada na coluna précondicionada. Os demais passos da extração são semelhantes àqueles estabelecidos para urina. Após a secagem, o extrato seco é ressuspendido em $6 \mu \mathrm{L}$ de água e $44 \mu \mathrm{L}$ de ACN. São injetados no sistema $20 \mu \mathrm{L}$.

Com os dados acumulados até aqui, foi iniciada a etapa final do desenvolvimento do método: a avaliação e comprovação de sua consistência e robustez pelos testes de validação.

Devido ao fato de terem sido definidos protocolos distintos de preparo de amostra em função da sua natureza, um para urina e outro para soro, foram realizadas validações independentes.

\subsection{Validação do método}

As validações dos métodos para urina e soro foram realizadas de forma independente segundo o preconizado pelo Clinical and Laboratory Standards Institute (CLSI). Foram avaliados: linearidade e recuperação (documento EP6-A) ${ }^{44}$, precisão (documento EP5-A2) ${ }^{45}$, limite de quantificação (documento EP17-A) ${ }^{46}$ e arraste segundo protocolo definido no software EP evaluator versão $4^{48}$.

As amostras foram preparadas a partir de pools de soro e urina segundo descrito nos itens 3.4.6.1 e 3.4.6.2 e analisadas de acordo com o descrito no item 3.10. 
A Tabela 17 apresenta os dados obtidos nessa validação. Os valores foram convertidos para $\mu \mathrm{mol} / \mathrm{L}$ para facilitar a comparação com os dados da literatura.

Tabela 17. Dados de validação nas matrizes de urina e soro.

\begin{tabular}{|c|c|c|c|c|c|}
\hline Matriz & \multicolumn{3}{|c|}{ Parâmetro } & Creatina & Guanidinoacetato \\
\hline \multirow{10}{*}{ Urina } & \multicolumn{3}{|c|}{ Linearidade } & 74 a $10363 \mu \mathrm{mol} / \mathrm{L}$ & 135 a $12987 \mu \mathrm{mol} / \mathrm{L}$ \\
\hline & \multirow{6}{*}{ Precisão } & \multirow{2}{*}{ LI } & Intraensaio & $10,9 \%$ & $8,6 \%$ \\
\hline & & & Interensaio & $7,4 \%$ & $16,1 \%$ \\
\hline & & \multirow{2}{*}{ LII } & Intraensaio & $3,3 \%$ & $5,0 \%$ \\
\hline & & & Interensaio & $3,9 \%$ & $5,5 \%$ \\
\hline & & \multirow{2}{*}{ LIII } & Intraensaio & $5,5 \%$ & $5,5 \%$ \\
\hline & & & Interensaio & $4,4 \%$ & $3,7 \%$ \\
\hline & \multicolumn{3}{|c|}{ LQ } & $5,9 \mu \mathrm{mol} / \mathrm{L}$ & $12,6 \mu \mathrm{mol} / \mathrm{L}$ \\
\hline & \multicolumn{3}{|c|}{ Arraste } & Não observado & Não observado \\
\hline & \multicolumn{3}{|c|}{ Recuperação } & 81,3 a $105,4 \%$ & 89,0 a $102,6 \%$ \\
\hline & & Linear & ade & $\mu \mathrm{mol} / \mathrm{L}$ & $\mu \mathrm{mol} / \mathrm{L}$ \\
\hline & & & $\mathrm{LI}$ & $3,7 \%$ & $17,1 \%$ \\
\hline & Precisão & & LII & $5,2 \%$ & $6,1 \%$ \\
\hline \multirow[t]{4}{*}{ Soro } & & & LIII & $6,5 \%$ & $6,6 \%$ \\
\hline & \multicolumn{3}{|c|}{ LQ } & $1,98 \mu \mathrm{mol} / \mathrm{L}$ & $0,13 \mu \mathrm{mol} / \mathrm{L}$ \\
\hline & \multicolumn{3}{|c|}{ Arraste } & Não observado & Não observado \\
\hline & \multicolumn{3}{|c|}{ Recuperação } & 98,1 a $101,4 \%$ & 89,7 a $100 \%$ \\
\hline
\end{tabular}

Legenda: LI, pool de valor baixo; LII, pool com valor médio; LIII, pool com valor alto; $L Q$, limite de quantificação.

A Tabela 18 apresenta dados de desempenho reportados na literatura com a utilização de metodologias baseadas em LC-MS/MS. 
Tabela 18. Dados de desempenho de métodos descritos na literatura.

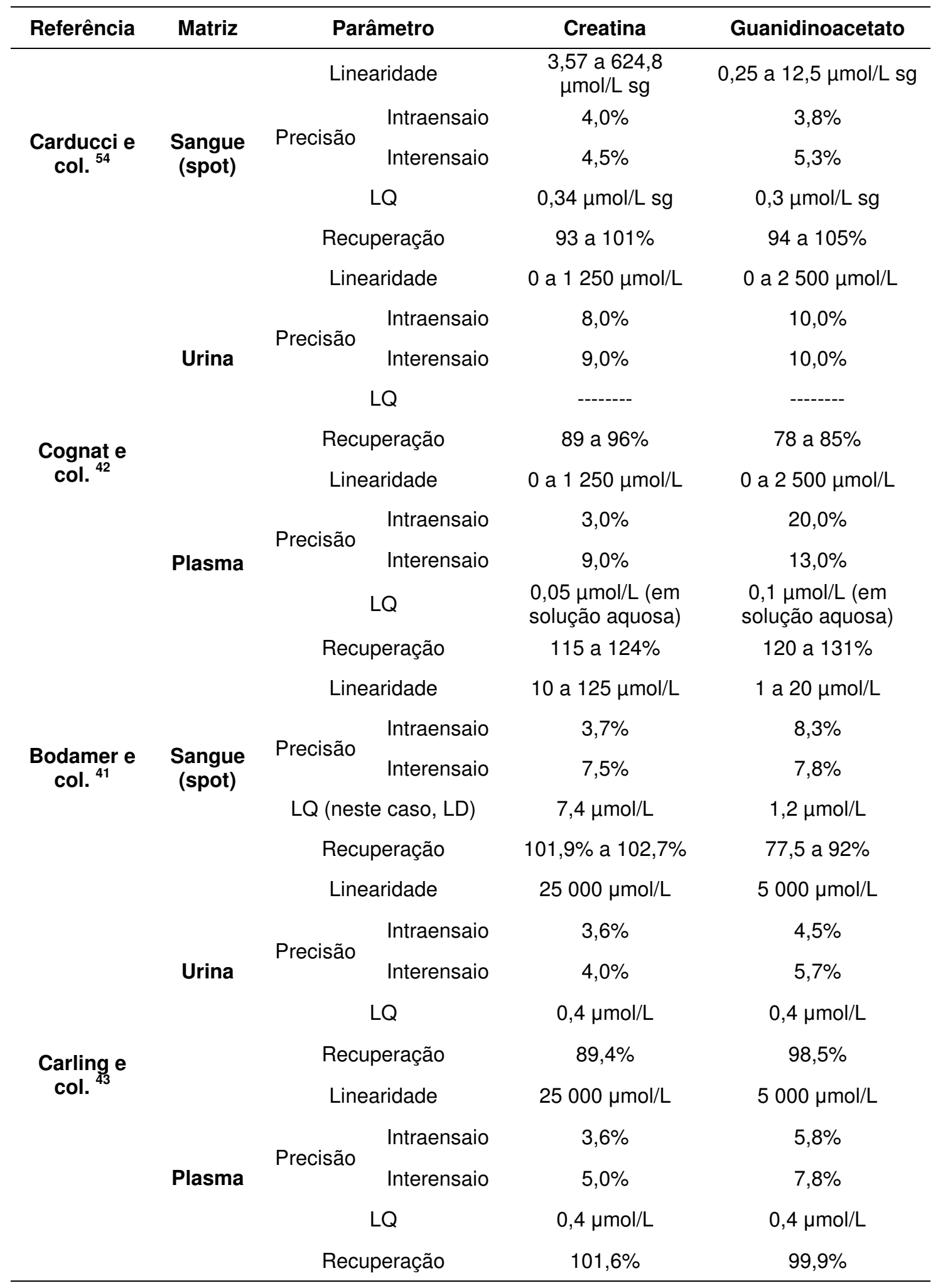

Legenda: sg, sangue; LQ, limite de quantificação; LD, limite de detecção. 
Os dados de validação do método proposto estão consistentes com a literatura em relação à precisão e recuperação. As linearidades alcançadas para urina e soro foram superiores às referidas pela maioria dos autores citados. Os limites de quantificação, embora discretamente acima daqueles publicados na literatura, estão adequados para aplicação em rotina.

A exatidão do método proposto foi avaliada pela análise de amostras de urina por diferentes métodos, segundo o recomendado pelo $\mathrm{CLSI}^{47}$. Em soro esse tipo de análise comparativa não foi possível devido à indiponibilidade de metodologias com desempenho comparável, tanto em laboratórios particulares, como em grupos de pesquisa com os quais tenha sido estabelecida colaboração.

Desta forma, foram analisadas vinte amostras de urina de pacientes portadores de alguma das formas de síndrome de deficiência de creatina cedidas pelo Instituto de Genética Médica Jacinto de Magalhães, IGMJM (Porto, Portugal), onde é utilizada a metodologia de GC-MS descrita por Valongo e colaboradores ${ }^{51}$ (amostras E1 a E20). Foram também avaliadas doze amostras de urina enviadas a Mayo Clinic (Rochester, USA) onde é utilizado o método por LC-MS/MS preconizado por Cognat e colaboradores ${ }^{42}$ (amostras E21 a E32).

Os valores de referência adotados em cada centro estão referidos na Tabela 19 e os resultados obtidos com suas interpretações estão apresentados nas Tabelas 20 e 21. Os resultados do IGMJM foram interpretados segundo a relação creatina/creatinina e 
guanidinoacetato/creatinina (dados disponibilizados por aquele centro), de acordo com as referências lá utilizadas de Valongo e colaboradores ${ }^{51}$.

Tabela 19. Valores de referência para creatina e GAA adotados no $\operatorname{IGMJM}^{51}$ e na Mayo Clinic ${ }^{55}$.

\begin{tabular}{|c|c|c|c|c|c|c|c|}
\hline \multirow[t]{2}{*}{ Fonte } & \multirow[t]{2}{*}{ Faixa etária } & \multicolumn{6}{|c|}{ Analito e unidade referida } \\
\hline & & \multicolumn{2}{|c|}{ Creatina $(\mu \mathrm{M})$} & \multicolumn{2}{|c|}{ GAA $(\mu \mathrm{M})$} & \multicolumn{2}{|c|}{ Creatina/Creatinina } \\
\hline \multirow{4}{*}{51} & $<4$ anos & $40-1510 \mu \mathrm{M} / \mathrm{mmol}$ & creatinina & \multicolumn{2}{|c|}{ creatinina } & \multicolumn{2}{|c|}{0,04 a 1,5} \\
\hline & 5 a 11 anos & \multicolumn{2}{|c|}{$\begin{array}{c}\text { 40-1070 } \mu \mathrm{M} / \mathrm{mmol} \\
\text { creatinina }\end{array}$} & \multicolumn{2}{|c|}{18 a $130 \mu \mathrm{M} / \mathrm{mmol}$} & \multicolumn{2}{|c|}{0,04 a 1,07} \\
\hline & 12 a 16 anos & $\begin{array}{r}40-560 \\
\text { crea }\end{array}$ & $\begin{array}{l}\mathrm{M} / \mathrm{mmol} \\
\text { nina }\end{array}$ & $\begin{array}{r}18 \text { a } 130 \\
\text { crea }\end{array}$ & $\begin{array}{l}\mathrm{AM} / \mathrm{mmol} \\
\text { nina }\end{array}$ & \multicolumn{2}{|c|}{0,04 a 0,56} \\
\hline & & $0^{\lambda}$ & q & $\hat{0}$ & q & $0^{\pi}$ & q \\
\hline \multirow{5}{*}{55} & 1 a 31 dias & $12-2930$ & $12-2930$ & $9-210$ & $9-210$ & $0,02-0,93$ & $0,02-0,93$ \\
\hline & $\begin{array}{c}32 \text { dias a } 23 \\
\text { meses }\end{array}$ & $\begin{array}{c}18- \\
10490\end{array}$ & $\begin{array}{c}18- \\
10490\end{array}$ & $16-860$ & $16-860$ & $0,02-2,49$ & $0,02-2,49$ \\
\hline & 2 a 4 anos & $\begin{array}{l}200- \\
9210\end{array}$ & $\begin{array}{l}200- \\
9210\end{array}$ & $90-1260$ & $90-1260$ & $0,04-1,75$ & $0,04-1,75$ \\
\hline & 5 a 18 anos & $60-9530$ & $60-9530$ & $40-1190$ & $40-1190$ & $0,01-0,96$ & $0,01-0,96$ \\
\hline & $>18$ anos & $7-470$ & $5-2810$ & $30-710$ & $30-760$ & $0,00-0,04$ & $0,00-0,46$ \\
\hline
\end{tabular}


Tabela 20. Valores de creatina e GAA obtidos no IGMJM e pelo método proposto (unidade: $\mu \mathrm{mol} / \mathrm{L}$ ).

\begin{tabular}{|c|c|c|c|c|c|}
\hline \multirow{3}{*}{ Amostra } & \multirow{3}{*}{$\begin{array}{l}\text { Sexo e } \\
\text { idade }\end{array}$} & \multirow{2}{*}{\multicolumn{2}{|c|}{$\begin{array}{c}\text { IGMJM } \\
\text { Valor }(\mu \mathrm{mol} / \mathrm{L})\end{array}$}} & \multirow{2}{*}{\multicolumn{2}{|c|}{$\begin{array}{l}\text { Novo método } \\
\text { Valor ( } \mu \mathrm{mol} / \mathrm{L})\end{array}$}} \\
\hline & & & & & \\
\hline & & Creatina & GAA & Creatina & GAA \\
\hline E1 & $\mathrm{M}, 12 \mathrm{a}$ & $9350(\uparrow)$ & $341(\mathrm{~N})$ & 3749 & 213 \\
\hline E2 & $\mathrm{M}, 17 \mathrm{a}$ & $27525(\uparrow)$ & $7705(\uparrow)$ & 17442 & 5857 \\
\hline E3 & $\mathrm{M}, 5 \mathrm{a}$ & $29005(\uparrow)$ & $618(\uparrow)$ & 10093 & 371 \\
\hline E4 & $\mathrm{F}, 12 \mathrm{a}$ & $129(\downarrow)$ & $4464(\uparrow)$ & 157 & 2740 \\
\hline E5 & $\mathrm{M}, 5 \mathrm{a}$ & $54113(\uparrow)$ & $1827(\uparrow)$ & 36835 & 391 \\
\hline E6 & $F, 10 a$ & $55307(\uparrow)$ & $3192(\uparrow)$ & 2847 & 3188 \\
\hline E7 & $\mathrm{F}, 12 \mathrm{a}$ & $273(N)$ & $5975(\uparrow)$ & 493 & 4371 \\
\hline E8 & $\mathrm{F}, 13 \mathrm{a}$ & $5926(\mathrm{~N})$ & $6248(\uparrow)$ & 5148 & 5099 \\
\hline E9 & M, 3 a & $8751(\uparrow)$ & $213(\mathrm{~N})$ & 4329 & 133 \\
\hline E10 & $\mathrm{F}, 10 \mathrm{a}$ & $32702(\uparrow)$ & $9625(\uparrow)$ & 19995 & 7272 \\
\hline E11 & $\mathrm{M}, 12 \mathrm{a}$ & $11889(\uparrow)$ & $340(\mathrm{~N})$ & 10477 & 340 \\
\hline E12 & $\mathrm{F}, 9 \mathrm{a}$ & $136(\downarrow)$ & $4949(\uparrow)$ & 396 & 3656 \\
\hline E13 & $\mathrm{M}, 16 \mathrm{a}$ & $15804(\uparrow)$ & $4427(\uparrow)$ & 11464 & 2605 \\
\hline E14 & $F, 9 a$ & $110(\mathrm{~N})$ & $2447(\uparrow)$ & 251 & 2587 \\
\hline E15 & $\mathrm{F}, 12 \mathrm{a}$ & $26850(\uparrow)$ & $1999(\uparrow)$ & 23509 & 1400 \\
\hline E16 & $\mathrm{M}, 21 \mathrm{a}$ & $7766(\uparrow)$ & $2338(\uparrow)$ & 18273 & 2005 \\
\hline E17 & $\mathrm{M}, 5 \mathrm{a}$ & $9395(\uparrow)$ & $227(\mathrm{~N})$ & 6286 & 413 \\
\hline E18 & $\mathrm{F}, 10 \mathrm{a}$ & $27248(\uparrow)$ & $3885(\uparrow)$ & 14482 & 3339 \\
\hline E19 & $\mathrm{M}, 13 \mathrm{a}$ & $14689(\uparrow)$ & $899(\uparrow)$ & 163 & 62 \\
\hline E20 & $\mathrm{M}, 5 \mathrm{a}$ & $7766(\uparrow)$ & $202(\mathrm{~N})$ & 6739 & 490 \\
\hline
\end{tabular}

Legenda: $M$, masculino; F, feminino; a, anos; $(\uparrow)$, acima dos valores de referência; $(\downarrow)$, abaixo dos valores de referência; $(N)$, dentro do intervalo de referência. 
Tabela 21. Valores de creatina e GAA obtidos na Mayo Clinic e pelo método proposto (unidade: $\mu \mathrm{mol} / \mathrm{L}$ ).

\begin{tabular}{cccccc}
\hline & & \multicolumn{2}{c}{ Mayo Clinic } & \multicolumn{2}{c}{ Novo método } \\
Amostra & $\begin{array}{c}\text { Sexo e } \\
\text { idade }\end{array}$ & \multicolumn{2}{c}{ Valor $(\mu \mathrm{mol} / \mathrm{L})$} & \multicolumn{2}{c}{ Valor $(\boldsymbol{\mu m o l} / \mathbf{L})$} \\
\hline E21 & M, 14 a & 49 & 163 & 29 & 110 \\
E22 & M, 16 a & 48 & 555 & 29 & 401 \\
E23 & M, 15 a & 10 & 60 & 8 & 45 \\
E24 & M, 15 a & 72 & 77 & 47 & 54 \\
E25 & F, 16 a & 74 & 282 & 37 & 182 \\
E26 & M, 38 a & 3368 & 629 & 2210 & 415 \\
E27 & M, 9 a & 165100 & 580 & 121633 & 474 \\
E28 & M, 6 a & 10159 & 963 & 6917 & 676 \\
E29 & M, 14 a & 1117 & 479 & 815 & 405 \\
E30 & M, 10 m & 1484 & 497 & 1175 & 472 \\
E31 & M, 4 a & 189 & 570 & 229 & 528 \\
E32 & M, 10 a & 2730 & 339 & 1857 & 346 \\
\hline
\end{tabular}

Legenda: $a$, anos; $M$, meses; $(N)$, dentro dos intervalos de referência para sexo e idade.

A comparação numérica dos valores do novo método perante aqueles referidos pelo IGMJM demonstrou uma baixa correlação entre os dados. $\mathrm{Na}$ comparação entre os resultados obtidos pelo novo método e pela Mayo Clinic foi verificado um desvio negativo, porém com um coeficiente de correlação de 0,99 para creatina e de 0,97 para guanidinoacetato, o que indica uma melhor correspondência entre os dados.

Essa discrepância numérica entre os resultados obtidos por diferentes métodos evidencia a necessidade de definição de valores de referência 
aplicáveis ao novo método possibilitando a comparação diagnóstica desses achados.

Assim, valores de referência foram definidos para o método com a análise de 150 amostras de urina e 197 amostras de soro provenientes de indivíduos de ambos os sexos e idades compreendidas entre 0 e 16 anos, atendidos no Hospital Universitário, após a aplicação do termo de consentimento livre e esclarecido (anexo D). Os materiais utilizados para esse fim eram excedentes de amostras rotineiramente coletadas para outras finalidades e cujos volumes o permitiram. A triagem foi realizada pelo valor de creatinina que deveria estar dentro das faixas de referência adotadas naquele serviço.

Foram definidos grupos etários em função de maturidade hormonal a exemplo do que é utilizado em pediatria e adotado por Valongo e colaboradores ${ }^{51}$.

Os dados obtidos foram tabulados e tratados no EP Evaluator versão 4, módulo ERI que toma como referência o recomentado pelo CLSI no documento C28-A2 ${ }^{48}$.

Foram realizadas análises separando-se cada grupo etário em função do sexo, com o intuito de verificar se haveria diferenças nos valores em função dessa variável, já que uma das formas da doença é ligada ao cromossomo X. Essa hipótese foi descartada uma vez que as diferenças obtidas não foram significativas. Por conseguinte, os valores foram estratificados apenas em função dos grupos etários definidos inicialmente (tabelas 22 e 23). 
Tabela 22. Valores de referência em urina definidos para o novo método (Crtnn $=$ creatinina).

\begin{tabular}{ccccc}
\hline Grupo etário & Creatina $(\mu \mathrm{M})$ & GAA $(\mu \mathrm{M})$ & Creatina/Crtnn & GAA/Crtnn \\
\hline <1 ano & $7,9-4106$ & $6,4-418,6$ & $0,008-1,218$ & $0,021-0,186$ \\
1 a 4 anos & $67,6-9055$ & $31,3-706,7$ & $0,020-1,869$ & $0,008-0,130$ \\
5 a 11 anos & $8,9-5645$ & $24,5-1167,0$ & $0,004-0,627$ & $0,009-0,098$ \\
12 a 16 anos & $10,8-1026$ & $17,4-911,0$ & $0,003-0,133$ & $0,005-0,131$ \\
\hline
\end{tabular}

Tabela 23. Valores de referência em soro definidos para o novo método.

\begin{tabular}{ccc}
\hline Grupo etário & Creatina $(\mu \mathrm{M})$ & GAA $(\mu \mathrm{M})$ \\
\hline$<1$ ano & $13,6-218,5$ & $0,26-2,65$ \\
1 a 4 anos & $37,0-196,2$ & $0,34-2,14$ \\
5 a 11 anos & $15,3-123,6$ & $0,51-2,65$ \\
12 a 16 anos & $8,2-210,6$ & $0,51-2,99$ \\
\hline
\end{tabular}

A Tabela 24 apresenta o diagnóstico firmado para os pacientes E1 a E20 do IGMJM, as relações creatina/creatinina e GAA/creatinina e a interpretação desses resultados diante dos valores de referência utilizados. Da mesma forma, expressa a interpretação dos valores obtidos pelo método proposto em relação aos valores-referência estabelecidos. 
Tabela 24. Diagnóstico referido para pacientes das amostras E1 a E20. Interpretação das relações creatina/creatinina e GAA/creatinina segundo valores de referência do IGMJM; Interpretação dos dados obtidos pela nova metodologia segundo a referência estabelecida.

\begin{tabular}{|c|c|c|c|c|c|}
\hline \multirow{2}{*}{ Amostra } & \multirow{2}{*}{ Deficiência } & \multicolumn{2}{|c|}{ IGMJM } & \multicolumn{2}{|c|}{ Novo método } \\
\hline & & Creatina/Crtnn & GAA/Crtnn & Creatina/Crtnn & GAA/Crtnn \\
\hline E1 & CRTR1 & $3,02(\uparrow)$ & $0,11(\mathrm{~N})$ & $1,50(\uparrow)$ & $0,10(\mathrm{~N})$ \\
\hline E2 & GAMT $(*)$ & $2,33(\uparrow)$ & $0,65(\uparrow)$ & $1,24(\uparrow)$ & $0,42(\uparrow)$ \\
\hline E3 & CRTR1 & $9,06(\uparrow)$ & $0,19(\uparrow)$ & $4,71(\uparrow)$ & $0,20(\uparrow)$ \\
\hline E4 & GAMT & $0,03(\downarrow)$ & $0,91(\uparrow)$ & $0,05(\mathrm{~N})$ & $0,57(\uparrow)$ \\
\hline E5 & CRTR1 & $8,59(\uparrow)$ & $0,29(\uparrow)$ & $4,87(\uparrow)$ & $0,05(\mathrm{~N})$ \\
\hline E6 & $\operatorname{GAMT}\left({ }^{*}\right)$ & $6,01(\uparrow)$ & $0,35(\uparrow)$ & $4,43(\uparrow)$ & $0,35(\uparrow)$ \\
\hline E7 & GAMT & $0,04(\mathrm{~N})$ & $0,87(\uparrow)$ & $0,08(N)$ & $0,77(\uparrow)$ \\
\hline E8 & GAMT & $0,36(\mathrm{~N})$ & $0,38(\uparrow)$ & $0,47(\uparrow)$ & $0,46(\uparrow)$ \\
\hline E9 & CRTR1 & $3,37(\uparrow)$ & $0,08(N)$ & $2,31(\uparrow)$ & $0,06(N)$ \\
\hline E10 & $\operatorname{GAMT}\left({ }^{*}\right)$ & $2,10(\uparrow)$ & $0,62(\uparrow)$ & $1,01(\uparrow)$ & $0,35(\uparrow)$ \\
\hline E11 & CRTR1 & $2,90(\uparrow)$ & $0,08(\mathrm{~N})$ & $2,53(\uparrow)$ & $0,07(\mathrm{~N})$ \\
\hline E12 & GAMT & $0,03(\downarrow)$ & $1,03(\uparrow)$ & $0,12(\mathrm{~N})$ & $1,03(\uparrow)$ \\
\hline E13 & $\operatorname{GAMT}\left({ }^{*}\right)$ & $1,7(\uparrow)$ & $0,48(\uparrow)$ & $1,48(\uparrow)$ & $0,45(\uparrow)$ \\
\hline E14 & GAMT & $0,05(\mathrm{~N})$ & $1,06(\uparrow)$ & $0,12(\mathrm{~N})$ & $0,96(\uparrow)$ \\
\hline E15 & GAMT $\left(^{*}\right)$ & $4,8(\uparrow)$ & $0,36(\uparrow)$ & $6,03(\uparrow)$ & $0,30(\uparrow)$ \\
\hline E16 & GAMT $\left(^{\star}\right)$ & $5,73(\uparrow)$ & $0,42(\uparrow)$ & $3,13(\uparrow)$ & $0,35(\uparrow)$ \\
\hline E17 & CRTR1 & $3,48(\uparrow)$ & $0,08(\mathrm{~N})$ & $2,81(\uparrow)$ & $0,17(\uparrow)$ \\
\hline E18 & GAMT $\left({ }^{*}\right)$ & $3,63(\uparrow)$ & $0,52(\uparrow)$ & $2,01(\uparrow)$ & $0,45(\uparrow)$ \\
\hline E19 & CRTR1 & $2,37(\uparrow)$ & $0,14(\uparrow)$ & $2,20(\uparrow)$ & $0,30(\uparrow)$ \\
\hline E20 & CRTR1 & $4,57(\uparrow)$ & $0,12(\mathrm{~N})$ & $2,69(\uparrow)$ & $0,16(\uparrow)$ \\
\hline
\end{tabular}

Legenda: CRTR1, transportador de creatina; Crtnn, creatinina; $(\uparrow)$, acima dos valores de referência; $(\downarrow)$, abaixo ddos valores de referência; $(N)$, dentro do intervalo de referência; $\left(^{*}\right)$ pacientes em tratamento. 
A análise dos dados em função da interpretação perante os respectivos valores de referência revela:

- Concordância absoluta, ou seja, creatina e GAA elevados ou normais em 14 casos (amostras E1, E2, E3, E6, E7, E9, E10, E11, E13, E14, E15, E16, E18 e E19),

- Concordância apenas para creatina em 3 casos (amostras E5, E17 e E20),

- Concordância apenas para GAA em 3 casos (amostras E4, E8 e E12).

É importante ressaltar que os casos em que a concordância foi apenas para os dados de creatina eram provenientes de pacientes portadores de deficiência de transportador de creatina, doença cujo marcador bioquímico principal é a elevação de creatina, o que foi apontado pelos dois centros.

Da mesma forma, nos casos em que a concordância se restringiu aos valores de GAA, as amostras eram provenientes de portadores de deficiência de GAMT cujo marcador central é a elevação de GAA, o que foi observado nos dois centros.

Considerando-se o fato de que as condições de conservação das amostras durante o transporte entre os centros não foram as mais adequadas (as amostras ficaram a temperatura ambiente por pelo menos quatro dias), esses resultados foram muito satisfatórios revelando uma concordância diagnóstica total. 
A mesma avaliação foi realizada em relação aos resultados das amostras encaminhadas à Mayo Clinic conforme demonstrado na Tabela 25.

Tabela 25. Resultados obtidos na Mayo Clinic e pelo novo método com a interpretação em relação aos respectivos valores de referência.

\begin{tabular}{|c|c|c|c|c|c|c|c|c|}
\hline \multirow{2}{*}{ Amostra } & \multicolumn{4}{|c|}{ Mayo Clinic } & \multicolumn{4}{|c|}{ Novo método } \\
\hline & Creatina & Cr/Crtnn & GAA & GAA/Crtnn & Creatina & Cr/Crtnn & GAA & GAA/Crtnn \\
\hline E21 & 49 & 0,01 & 163 & 0,05 & 29 & 0,01 & 110 & 0,04 \\
\hline E22 & 48 & 0,005 & 555 & 0,06 & 29 & 0,003 & 401 & 0,05 \\
\hline E23 & 10 & 0,01 & 60 & 0,03 & 8 & 0,01 & 45 & 0,03 \\
\hline E24 & 72 & 0,01 & 77 & 0,01 & 47 & 0,01 & 54 & 0,01 \\
\hline E25 & 74 & 0,01 & 282 & 0,03 & 37 & 0,01 & 182 & 0,03 \\
\hline E26 & $3368(\uparrow)$ & $0,21(\uparrow)$ & $629(\mathrm{~N})$ & 0,04 & $2210(\uparrow)$ & $0,17(\uparrow)$ & $415(\mathrm{~N})$ & $0,03(\mathrm{~N})$ \\
\hline E27 & $165100(\uparrow)$ & $17,73(\uparrow)$ & $580(\mathrm{~N})$ & 0,06 & $121634(\uparrow)$ & $11,27(\uparrow)$ & 474 & 0,04 \\
\hline E28 & 10159 & 0,85 & 963 & 0,08 & 6917 & 0,74 & 676 & 0,07 \\
\hline E29 & 1117 & 0,06 & 479 & 0,02 & 815 & 0,04 & 405 & 0,02 \\
\hline E30 & 1484 & 1,51 & 497 & 0,50 & 1175 & 1,24 & 472 & 0,50 \\
\hline E31 & 189 & 0,01 & 570 & 0,04 & 229 & 0,02 & 528 & 0,03 \\
\hline E32 & 2730 & 0,39 & 339 & 0,06 & 1857 & 0,25 & 346 & 0,05 \\
\hline
\end{tabular}

Legenda: $(\uparrow)$, acima dos valores de referência; $(\downarrow)$, abaixo dos valores de referência; $(\mathrm{N})$, dentro do intervalo de referência; $\mathrm{Cr}$, creatina; Crtnn, creatinina.

Embora alguns dos resultados se apresentem marginalmente alterados, apenas os das amostras E26 e E27 foram considerados francamente alterados e indicativos de deficiência de transportador de 
creatina tanto pela análise na Mayo Clinic quanto pela realizada com o novo método.

\subsection{Avaliação das amostras dos participantes do estudo}

Amostras de urina, soro e plasma de 54 pacientes que preenchiam os critérios para inclusão neste projeto foram analisadas com a aplicação dos protocolos definidos em função da matriz. Para as amostras de plasma foi utilizado o protocolo de soro.

Esses pacientes apresentavam idades entre 2 e 40 anos sendo a maioria do sexo masculino (45 em 54) sem história de consanguinidade dos pais. Os quadros clínicos eram variados (vide Tabela 7 e Anexo F).

Os resultados das análises em $\mu \mathrm{mol} / \mathrm{L}$ estão apresentados na Tabela 26. 
Tabela 26. Resultados de creatina e guanidinoacetato obtidos pelo novo método.

\begin{tabular}{|c|c|c|c|c|c|c|c|}
\hline \multirow{2}{*}{ Pac. } & \multirow{2}{*}{$\begin{array}{l}\text { Sexo e } \\
\text { idade }\end{array}$} & \multicolumn{3}{|c|}{ Creatina $(\mu \mathrm{mol} / \mathrm{L})$} & \multicolumn{3}{|c|}{ Guanidinoacetato ( $\mu \mathrm{mol} / \mathrm{L})$} \\
\hline & & Urina & Soro & Plasma & Urina & Soro & Plasma \\
\hline 1 & $\mathrm{M}, 3 \mathrm{a}$ & 2166 & 83,7 & 83,3 & 109 & 0,77 & 0,77 \\
\hline 2 & $F, 6 a$ & 3018 & 67,7 & 65,6 & 1021 & 1,79 & 1,62 \\
\hline 3 & $\mathrm{M}, 10 \mathrm{a}$ & 1159 & 47,3 & 45,7 & 632 & 1,37 & 1,71 \\
\hline 4 & $\mathrm{M}, 11 \mathrm{a}$ & 635 & 35,5 & 34,4 & 638 & 1,28 & 1,62 \\
\hline 5 & $\mathrm{~F}, 12 \mathrm{a}$ & 136 & 35,2 & ------ & 495 & 1,28 & ------ \\
\hline 6 & $\mathrm{~F}, 8 \mathrm{a}$ & 247 & 54,8 & ------ & 39 & 1,79 & ------ \\
\hline 7 & $\mathrm{M}, 6 \mathrm{a}$ & 4221 & ------ & 92,8 & 168 & ------ & 1,54 \\
\hline 8 & $\mathrm{M}, 7 \mathrm{a}$ & 6284 & 96,2 & 89,5 & 972 & 1,54 & 1,45 \\
\hline 9 & $\mathrm{M}, 14 \mathrm{a}$ & 1904 & 70,7 & 66,9 & 559 & 1,71 & 1,96 \\
\hline 10 & $\mathrm{M}, 14 \mathrm{a}$ & 78 & 30,9 & 30,3 & 283 & 2,39 & 2,48 \\
\hline 11 & $\mathrm{M}, 10 \mathrm{a}$ & 60 & 31,2 & 31,6 & 128 & 1,45 & 1,62 \\
\hline 12 & $\mathrm{M}, 16 \mathrm{a}$ & 135 & 31,4 & 31,2 & 415 & 1,96 & 1,79 \\
\hline 13 & $\mathrm{M}, 13 \mathrm{a}$ & 181 & 28,1 & 28,5 & 706 & 2,82 & 3,07 \\
\hline 14 & $\mathrm{M}, 13 \mathrm{a}$ & 29 & 27,8 & 20,8 & 110 & 2,48 & 2,22 \\
\hline 15 & $\mathrm{M}, 18 \mathrm{a}$ & 103 & 15,9 & 17,2 & 253 & 2,22 & 2,48 \\
\hline 16 & $\mathrm{M}, 2 \mathrm{a}$ & 1268 & 89,9 & ------ & 239 & 0,77 & ------ \\
\hline 17 & $\mathrm{M}, 8 \mathrm{a}$ & 4022 & 45,6 & 41,9 & 627 & 1,28 & 1,28 \\
\hline 18 & $\mathrm{M}, 8 \mathrm{a}$ & 716 & 73,8 & 74,9 & 304 & 1,20 & 1,37 \\
\hline 19 & $\mathrm{M}, 10 \mathrm{a}$ & 631 & 53,4 & 54,4 & 352 & 1,88 & 2,22 \\
\hline 20 & $\mathrm{M}, 7 \mathrm{a}$ & 67 & 10,5 & 10,7 & 401 & 2,65 & 2,56 \\
\hline 21 & $M$ & 39 & 11,4 & 11,8 & 77 & 2,73 & 2,65 \\
\hline 22 & $\mathrm{M}, 12 \mathrm{a}$ & 146 & 20,5 & 20,4 & 395 & 1,96 & 1,96 \\
\hline 23 & $\mathrm{M}, 12 \mathrm{a}$ & 82 & 26,2 & 25,6 & 285 & 2,90 & 3,07 \\
\hline 24 & $\mathrm{M}, 11 \mathrm{a}$ & 29 & ------- & ------ & 401 & ------- & ------- \\
\hline 25 & $\mathrm{M}, 15 \mathrm{a}$ & 27 & ------- & ------- & 108 & ------- & ------- \\
\hline 26 & $\mathrm{M}, 4 \mathrm{a}$ & 3260 & 66,1 & 63,1 & 664 & 1,96 & 2,05 \\
\hline 27 & $F, 9 a$ & 2240 & 69,6 & 63,0 & 404 & 1,96 & 1,88 \\
\hline 28 & $M, 6$ a & 3471 & 67,8 & 68,7 & 322 & 1,02 & 1,20 \\
\hline
\end{tabular}




\begin{tabular}{|c|c|c|c|c|c|c|c|}
\hline \multirow{2}{*}{ Pac. } & \multirow{2}{*}{$\begin{array}{l}\text { Sexo e } \\
\text { idade }\end{array}$} & \multicolumn{3}{|c|}{ Creatina $(\mu \mathrm{mol} / \mathrm{L})$} & \multicolumn{3}{|c|}{ Guanidinoacetato ( $\mu \mathrm{mol} / \mathrm{L})$} \\
\hline & & Urina & Soro & Plasma & Urina & Soro & Plasma \\
\hline 29 & $M$ & 583 & 43,6 & 42,8 & 659 & 1,79 & 1,79 \\
\hline 30 & $\mathrm{M}, 18 \mathrm{a}$ & 46 & 9,2 & 8,9 & 112 & 2,65 & 2,56 \\
\hline 31 & $\mathrm{M}, 14 \mathrm{a}$ & 8 & 37,1 & 37,1 & 45 & 2,13 & 2,22 \\
\hline 32 & $\mathrm{M}, 40 \mathrm{a}$ & 37 & 23,9 & 23,3 & 312 & 3,84 & 4,01 \\
\hline 33 & M, 5 a & 544 & 66,1 & 61,5 & 284 & 0,94 & 0,94 \\
\hline 34 & $F, 9$ a & ------ & 24,0 & 22,9 & ------- & 1,45 & 1,54 \\
\hline 35 & F, 19 a & 819 & 52,7 & 52,7 & 333 & 2,22 & 2,56 \\
\hline 36 & M, 7 a & 686 & 51,1 & 48,1 & 849 & 1,37 & 1,37 \\
\hline 37 & $\mathrm{M}, 14 \mathrm{a}$ & 90 & 24,6 & 23,0 & 316 & 2,82 & 2,99 \\
\hline 38 & $F, 16$ a & 37 & 51,7 & 49,6 & 182 & 2,56 & 2,65 \\
\hline 39 & $\mathrm{M}, 17 \mathrm{a}$ & 45 & 49,0 & 45,4 & 278 & 2,05 & 1,96 \\
\hline 40 & $\mathrm{~F}, 6 \mathrm{a}$ & 654 & 41,2 & 39,6 & 456 & 1,62 & 1,79 \\
\hline 41 & $\mathrm{M}, 37 \mathrm{a}$ & 2210 & 60,5 & 56,5 & 415 & 3,07 & 3,07 \\
\hline 42 & M, 9 a & 479 & ------- & ------- & 367 & ------- & ------- \\
\hline 43 & M & 121634 & 665,2 & 598,6 & 474 & 0,85 & 0,77 \\
\hline 44 & $\mathrm{M}, 6 \mathrm{a}$ & 1076 & 73,5 & 73,8 & 391 & 1,37 & 1,45 \\
\hline 45 & M, 5 a & 6917 & 68,7 & 64,9 & 676 & 1,28 & 1,45 \\
\hline 46 & $\mathrm{M}, 10 \mathrm{a}$ & 615 & 38,7 & 37,1 & 484 & 1,62 & 1,54 \\
\hline 47 & $F, 20 \mathrm{a}$ & 1828 & 27,5 & 25,5 & 666 & 1,71 & 1,79 \\
\hline 48 & $\mathrm{M}, 15 \mathrm{a}$ & 138 & 9,1 & 8,5 & 274 & 2,99 & 3,25 \\
\hline 49 & $\mathrm{M}, 14 \mathrm{a}$ & 37 & 32,3 & 28,3 & 215 & 4,53 & 4,27 \\
\hline 50 & $\mathrm{~F}, 6 \mathrm{a}$ & 815 & 56,1 & 55,1 & 372 & 1,45 & 1,37 \\
\hline 51 & M, 5 a & 1789 & 44,7 & 44,8 & 431 & 0,94 & 0,94 \\
\hline 52 & $\mathrm{M}, 17 \mathrm{a}$ & 31 & ------- & ------- & 202 & ------ & ------- \\
\hline 53 & $\mathrm{M}, 16 \mathrm{a}$ & ------- & 53,1 & 50,9 & ------- & 2,82 & 3,07 \\
\hline 54 & M, 5 a & 957 & 41,6 & 38,4 & 709 & 2,05 & 1,79 \\
\hline
\end{tabular}

Legenda: M, masculino; F, feminino; a, anos; Pac., paciente; material não colhido 
Os dados apresentados demonstram que, de maneira geral, há uma boa correspondência entre os valores de creatina e GAA obtidos pela análise de soro e plasma podendo-se, portanto, utilizar ambas as matrizes.

Analisando-se os valores de referência para creatina e guanidinoacetato em matriz urinária obtidos para o novo método, assim como aqueles referidos na literatura, observa-se que o intervalo dinâmico, particularmente para creatina, percorre várias ordens de grandeza, o que não ocorre para os valores em soro. Esse comportamento indica a conveniência de realizar a correção por creatinina para amostras de urina, prática referida na literatura e usual dentre os centros que realizam essa análise e reforça a hipótese de que a matriz sérica ou plasmática é mais adequada para a avaliação desses analitos.

Por esta razão, a análise de creatinina foi agregada ao método de forma a prescindir-se de sua análise pela metodologia colorimétrica de Jaffé $^{56}$ modificada. Embora, inicialmente, as amostras de urina (sempre que o volume disponível o permitiu) tenham sido avaliadas por esse método no equipamento automatizado $\operatorname{ADVIA}^{\circledR} 1200$ da Siemens (amostras 1 a 8), a partir da incorporação da creatinina no método, os valores passaram a ser determinados por LC-MS/MS.

Para que fosse possível uma comparação dos valores obtidos pelos dois métodos de forma a avalizar o desempenho do novo método, todas as amostras de urina utilizadas para a determinação dos valores de referência (150) e as amostras dos pacientes (1 a 54) foram avaliadas por Jaffé e LCMS/MS, revelando excelente correlação (acima de 0,99). 
Os resultados de creatina e GAA das amostras de urina expressos em função das relações com a creatinina, assim como a avaliação diante dos valores de referências estabelecidos estão apresentados na Tabela 27. 
Tabela 27. Resultados de creatina e GAA em urina expressos em função da creatinina e indicação de alterações tendo em vista os valores de referência estabelecidos.

\begin{tabular}{|c|c|c|c|c|c|}
\hline \multirow{2}{*}{ Pac. } & \multirow{2}{*}{$\begin{array}{l}\text { Sexo e } \\
\text { idade }\end{array}$} & \multicolumn{2}{|c|}{ Creatina } & \multicolumn{2}{|c|}{ Guanidinoacetato } \\
\hline & & $\mu \mathrm{mol} / \mathrm{L}$ & Creatina/Crtnn & $\mu \mathrm{mol} / \mathrm{L}$ & GAA/Crtnn \\
\hline 1 & M, 3 a & 2166 & 0,72 & 109 & 0,04 \\
\hline 2 & $\mathrm{~F}, 6 \mathrm{a}$ & 3018 & 0,17 & 1021 & 0,06 \\
\hline 3 & $\mathrm{M}, 10 \mathrm{a}$ & 1159 & 0,10 & 632 & 0,06 \\
\hline 4 & $\mathrm{M}, 11 \mathrm{a}$ & 635 & 0,03 & 638 & 0,03 \\
\hline 5 & $\mathrm{~F}, 12 \mathrm{a}$ & 136 & 0,01 & 495 & 0,03 \\
\hline 6 & $\mathrm{~F}, 8 \mathrm{a}$ & 247 & 0,56 & 39 & 0,09 \\
\hline 7 & $M, 6$ a & $4221(\mathrm{~N})$ & $0,65(\uparrow)$ & $168(\mathrm{~N})$ & $0,03(\mathrm{~N})$ \\
\hline 8 & M, 7 a & $6284(\uparrow)$ & $0,50(\mathrm{~N})$ & $972(\mathrm{~N})$ & $0,08(\mathrm{~N})$ \\
\hline 9 & $\mathrm{M}, 14 \mathrm{a}$ & $1904(\uparrow)$ & $0,23(\mathrm{~N})$ & $559(\mathrm{~N})$ & $0,07(\mathrm{~N})$ \\
\hline 10 & $\mathrm{M}, 14 \mathrm{a}$ & 78 & 0,01 & 283 & 0,03 \\
\hline 11 & $\mathrm{M}, 10 \mathrm{a}$ & 60 & 0,02 & 128 & 0,04 \\
\hline 12 & $\mathrm{M}, 16 \mathrm{a}$ & 135 & 0,01 & 415 & 0,03 \\
\hline 13 & $\mathrm{M}, 13 \mathrm{a}$ & 181 & 0,01 & 706 & 0,06 \\
\hline 14 & $M, 13 \mathrm{a}$ & 29 & 0,01 & 110 & 0,04 \\
\hline 15 & $\mathrm{M}, 18 \mathrm{a}$ & 103 & 0,01 & 253 & 0,01 \\
\hline 16 & $\mathrm{M}, 2 \mathrm{a}$ & 1268 & 0,28 & 239 & 0,05 \\
\hline 17 & M, 8 a & 4022 & 0,40 & 627 & 0,06 \\
\hline 18 & M, 8 a & 716 & 0,22 & 304 & 0,10 \\
\hline 19 & $\mathrm{M}, 10 \mathrm{a}$ & 631 & 0,12 & 352 & 0,07 \\
\hline 20 & $\mathrm{M}, 7 \mathrm{a}$ & 67 & 0,004 & 401 & 0,02 \\
\hline 21 & $\mathrm{M}, ?$ & 39 & 0,003 & 77 & 0,01 \\
\hline 22 & $\mathrm{M}, 12 \mathrm{a}$ & 146 & 0,01 & 395 & 0,03 \\
\hline 23 & $\mathrm{M}, 12 \mathrm{a}$ & 82 & 0,01 & 285 & 0,03 \\
\hline 24 & $\mathrm{M}, 11 \mathrm{a}$ & $29(N)$ & $0,003(\downarrow)$ & $401(\mathrm{~N})$ & $0,05(\mathrm{~N})$ \\
\hline 25 & $\mathrm{M}, 15 \mathrm{a}$ & 27 & 0,004 & 108 & 0,02 \\
\hline 26 & $\mathrm{M}, 4 \mathrm{a}$ & 3260 & 0,41 & 664 & 0,08 \\
\hline 27 & $\mathrm{~F}, 9 \mathrm{a}$ & 2240 & 0,55 & 404 & 0,10 \\
\hline
\end{tabular}




\begin{tabular}{|c|c|c|c|c|c|}
\hline \multirow{2}{*}{ Pac. } & \multirow{2}{*}{$\begin{array}{l}\text { Sexo e } \\
\text { idade }\end{array}$} & \multicolumn{2}{|c|}{ Creatina } & \multicolumn{2}{|c|}{ Guanidinoacetato } \\
\hline & & $\mu \mathrm{mol} / \mathrm{L}$ & Creatina/Crtnn & $\mu \mathrm{mol} / \mathrm{L}$ & GAA/Crtnn \\
\hline 28 & $\mathrm{M}, 6 \mathrm{a}$ & 3471 & 0,42 & 322 & 0,04 \\
\hline 29 & $\mathrm{M}, ?$ & 583 & 0,09 & 659 & 0,10 \\
\hline 30 & $\mathrm{M}, 18 \mathrm{a}$ & 46 & 0,005 & 112 & 0,01 \\
\hline 31 & $\mathrm{M}, 14 \mathrm{a}$ & $8(\downarrow)$ & $0,01(\mathrm{~N})$ & $45(N)$ & $0,03(\mathrm{~N})$ \\
\hline 32 & $\mathrm{M}, 40 \mathrm{a}$ & 37 & 0,004 & 312 & 0,04 \\
\hline 33 & $\mathrm{M}, 5 \mathrm{a}$ & 544 & 0,08 & 284 & 0,04 \\
\hline 34 & $F, 9 a$ & ------ & ------ & ------- & ------ \\
\hline 35 & $\mathrm{~F}, 19 \mathrm{a}$ & 819 & 0,11 & 333 & 0,05 \\
\hline 36 & $\mathrm{M}, 7 \mathrm{a}$ & 686 & 0,07 & 849 & 0,08 \\
\hline 37 & $\mathrm{M}, 14 \mathrm{a}$ & 90 & 0,01 & 316 & 0,03 \\
\hline 38 & $\mathrm{~F}, 16 \mathrm{a}$ & 37 & 0,01 & 182 & 0,03 \\
\hline 39 & $\mathrm{M}, 17 \mathrm{a}$ & 45 & 0,003 & 278 & 0,02 \\
\hline 40 & $\mathrm{~F}, 6 \mathrm{a}$ & 654 & 0,10 & 456 & 0,07 \\
\hline 41 & $\mathrm{M}, 37 \mathrm{a}$ & $2210(\uparrow)$ & $0,17(\uparrow)$ & $415(\mathrm{~N})$ & $0,03(\mathrm{~N})$ \\
\hline 42 & $\mathrm{M}, 9 \mathrm{a}$ & 479 & 0,08 & 367 & 0,06 \\
\hline 43 & $\mathrm{M}, ?$ & $121634(\uparrow)$ & $13,07(\uparrow)$ & $474(\mathrm{~N})$ & $0,05(\mathrm{~N})$ \\
\hline 44 & $M, 6$ a & 1076 & 0,15 & 391 & 0,05 \\
\hline 45 & $\mathrm{M}, 5 \mathrm{a}$ & $6917(\uparrow)$ & $0,66(\mathrm{~N})$ & $676(\mathrm{~N})$ & $0,06(\mathrm{~N})$ \\
\hline 46 & $\mathrm{M}, 10 \mathrm{a}$ & 615 & 0,07 & 484 & 0,06 \\
\hline 47 & $\mathrm{~F}, 20 \mathrm{a}$ & $1828(\uparrow)$ & $0,19(\uparrow)$ & $666(\mathrm{~N})$ & $0,07(\mathrm{~N})$ \\
\hline 48 & $\mathrm{M}, 15 \mathrm{a}$ & 138 & 0,01 & 274 & 0,01 \\
\hline 49 & $\mathrm{M}, 14 \mathrm{a}$ & 37 & 0,003 & 215 & 0,02 \\
\hline 50 & $\mathrm{~F}, 6 \mathrm{a}$ & 815 & 0,15 & 372 & 0,07 \\
\hline 51 & $\mathrm{M}, 5 \mathrm{a}$ & 1789 & 0,17 & 431 & 0,04 \\
\hline 52 & $\mathrm{M}, 17 \mathrm{a}$ & 31 & 0,005 & 202 & 0,03 \\
\hline 53 & $M, 16$ a & ------- & ------- & ------- & ------- \\
\hline 54 & $\mathrm{M}, 5 \mathrm{a}$ & 957 & 0,08 & 709 & 0,06 \\
\hline
\end{tabular}

Legenda: M, masculino; F, feminino; anos; pac., paciente; Crtnn, creatinina; material não enviado; $(\uparrow)$, acima da referência; $(\downarrow)$, abaixo da referência, ?, idade não informada . 
Pela análise dos dados expressos na Tabela 27, verificou-se que:

- Quatro casos $(8,9,31$ e 45$)$ apresentaram valores de creatina alterados, porém com a relação creatina/creatinina dentro das faixas de referência para as idades;

- Dois casos (7 e 24) apresentaram discreta alteração da relação creatina/ creatinina com valores de creatina dentro das faixas de referência;

- Dois casos caso tiveram as interpretações prejudicadas pela ausência da informação das idades dos pacientes (21 e 29);

- Três casos (41, 43 e 47) apresentaram aumento dos valores de creatina e da relação creatina/creatinina e valores GAA e da relação GAA/creatinina dentro das faixas de referência. Esses resultados são compatíveis com perfil bioquímico característico da deficiência de transportador de creatina.

Esses achados reforçam a importância da avaliação conjunta das informações. A valorização de resultados marginalmente alterados ou que não apresentem a consistência de dados observada nas amostras 41, 43 e 47, de forma a caracterizar todo o perfil bioquímico apontando para uma das formas da doença, deve ser ponderada tendo em vista a amplitude dos valores de referência, o que justifica sua interpretação como essencialmente normais.

Da mesma forma, os valores de algumas das amostras de soro e plasma apresentaram-se discretamente alterados. Destes, apenas o 
paciente 43 seria indiscutivelmente identificado como portador de deficiência de transportador. Esse paciente já havia sido submetido a RM com EIM, em que foi verificada a redução do pico de creatina. A avaliação conjunta destes dados com os achados bioquímicos na realidade corrobora a hipótese de tratar-se de uma das formas de síndrome de deficiência de creatina.

É importante notar, que as amostras de urina dos pacientes 41 e 43 estavam dentre as encaminhadas à Mayo Clinic para avaliação da exatidão do método (E26 e E27 respectivamente). A interpretação dos resultados pelos dois métodos, tendo em vista os devidos valores de referência e os critérios acima mencionados foi semelhante nos dois casos. 


\section{CONCLUSÕES E CONSIDERAÇÕES FINAIS}

Neste estudo foi desenvolvida uma metodologia para análise de creatina e guanidinoacetato por LC-MS/MS com a utilização de extração por troca catiônica forte e separação e detecção por cromatografia líquida de interação hidrofílica acoplada a espectrometria de massas em tandem aplicável a amostras de soro e urina. Os dados de validação atestaram sua seletividade, sensibilidade, linearidade e robustez. Resultados de amostras de urina obtidas pela aplicação deste e de outros métodos descritos na literatura foram comparados, com interpretações clínicas semelhantes.

Essa metodologia é inovadora ao associar as estratégias mencionadas para a análise desse grupo de biomoléculas, dispensando etapas de extração líquido-líquido e de derivatização, comuns a outros métodos, o que tornou o preparo das amostras mais simples.

Foram definidos valores de referência de creatina e guanidinoacetato em soro e urina específicos para esse método em população pediátrica.

Amostras de 54 pacientes com sintomas clínicos que poderiam ser atribuídos a síndrome de deficiência de creatina foram analisadas. Em três casos foram identificadas alterações bioquímicas compatíveis com esse diagnóstico.

Até o momento não há no país centros que ofereçam a possibilidade diagnóstica para as síndromes de deficiência de creatina com o uso de marcadores bioquímicos.

A transferência desta tecnologia para centros especializados de 
triagem neonatal poderá, no futuro, representar a possibilidade de diagnóstico precoce desta condição, o que é de particular importância visto que algumas de suas formas (deficiência de GAMT e AGAT) são passíveis de tratamento. Esse fato, aliado à questão da herança genética comum com Portugal, onde a prevalência dessa condição é relativamente alta, justifica a relevância da busca de novos métodos diagnósticos passíveis de serem incorporados ao perfil ampliado de triagem neonatal, a exemplo do que já ocorre em alguns países da Europa ${ }^{57}$.

O avanço das técnicas bioanalíticas tem elevado as possibilidades diagnósticas e prognósticas, seja propondo novas soluções para antigos problemas pelo aprimoramento ou modificação de abordagens metodológicas, seja expandindo seu alcance a territórios ainda desconhecidos. Certamente, nos próximos anos, estudos nas áreas de metabolômica e proteômica poderão oferecer novas perspectivas para o mapeamento de vias metabólicas, identificando novos marcadores ou perfis de apresentação de metabólitos relacionados a esta e a muitas outras condições clínicas. A espectrometria de massas está intimamente envolvida nesse cenário representando uma ferramenta fundamental para que essas novas possibilidades sejam exploradas. 


\section{ANEXOS}

Anexo A. Carta de aprovação do projeto pela Comissão de ética para análise de Projetos de Pesquisa (CAPPESQ) da Diretoria Clínica do Hospital das Clínicas e da Faculdade de Medicina da Universidade de São Paulo.

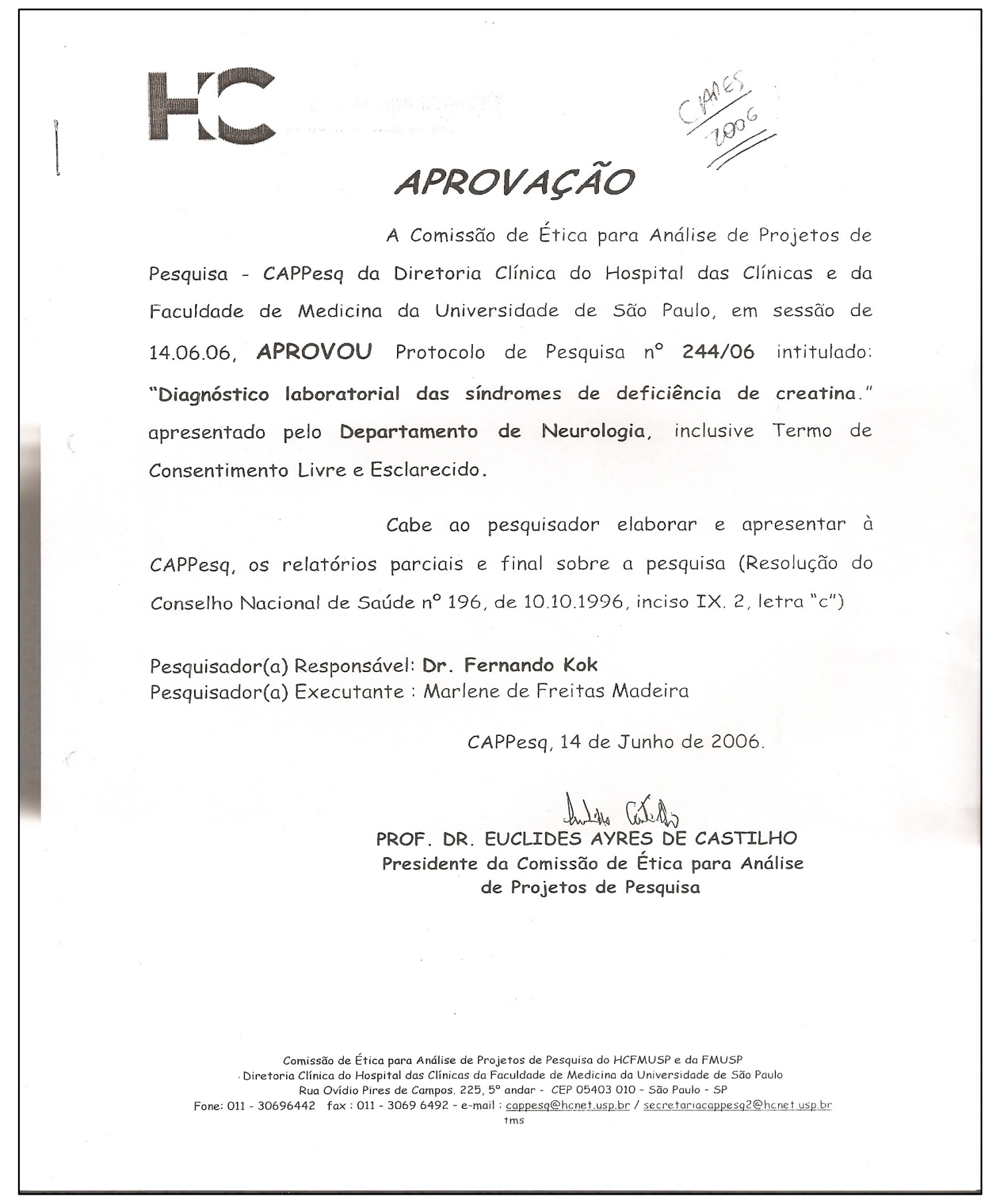


Anexo B. Carta de aprovação do projeto pelo Instituto Fleury.

\section{INSTITUTO FLEURY}

São Paulo, 3 de novembro de 2005.

IImo(s). Sr (s)

Fernando Kok, Marlene de F. Madeira e Valdemir M Carvalho

O projeto de pesquisa intitulado "Diagnóstico laboratorial das síndromes de deficiência de creatina" submetido ao Departamento de Pesquisa e Desenvolvimento Ceintífico e Tecnológico do Instituto Fleury e que visa a quantificaçăo de guanidinoacetato, creatina e creatinina por meio de cromatografia líquida associada a espectometria de massa em tandem, foi avaliado por dois relatores que recomendaram sua aprovaçăo. A contrapartida oferecida pelo Instituto será a realizaçăo dos testes de epsctometria de massa. Assim, o Departamento de PDCT considera que o projeto atende às caracteristicas de projeto em colaboração e o aprova.

Atenciosamente,

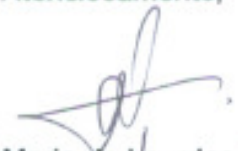

Maria de Lourdes Chauffaille

Departamento de PDCT

Instituto Peury

Rua Gal Waldomiro de Lima, 509,

Săo Paulo, SP

Tel 50147621 


\section{Anexo C. Aprovação do projeto pelo Comitê de Ética em Pesquisa do Hospital Universitário da Universidade de São Paulo.}

São Paulo, 30 de novembro de 2009.

$I l^{m o(a)} . S^{r(a)}$.

Dr. Fernando Kok

Hospital das Clínicas da Faculdade de Medicina UNIVERSIDADE DE SÃO PAULO

REFERENTE: Projeto de Pesquisa "Diagnóstico laboratorial das síndromes de deficiência de creatina" - Pesquisador(a) Responsávell: Dr. Fernando Kok - CoInvestigador(es): Marlene de Freitas Madeira - Registro CEP-HU/USP: 967/09 SISNEP CAAE: 0082.0.198.000-09

Prezado(a) Senhor(a)

O Comitê de Ética em Pesquisa do Hospital Universitário da Universidade de São Paulo, em reunião ordinária realizada no dia 27 de novembro de 2009, analisou o Projeto de Pesquisa acima citado, considerando-o como APROVADO, bem como o seu Termo de Consentimento Livre e Esclarecido.

Lembramos que cabe ao pesquisador elaborar e apresentar a este Comitê, relatórios anuais (parciais ou final, em função da duração da pesquisa), de acordo com a Resolução no 196/96 do Conselho Nacional de Saúde, inciso IX.2, letra "c".

O primeiro relatório está previsto para 27 de novembro de 2010.

Atenciosamente,

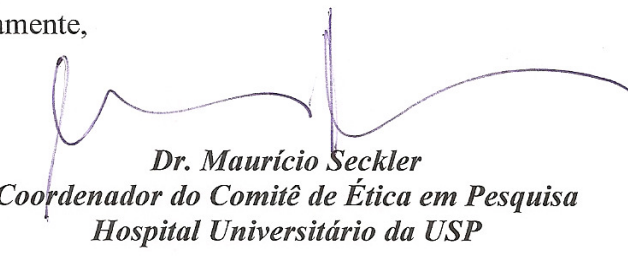

COMITÊ DE ÉTICA EM PESQUISA DO HOSPITAL UNIVERSITÁRIO DA USP Avenida Professor Lineu Prestes, 2565 - Cidade Universitária - 05508-000 São Paulo - SP Tels.: (11) 3091-9457 - Fax: (11) 3091-9452 - E-mail: cep@hu.usp.br 
Anexo D. Modelo de Termo de consentimento livre esclarecido para utilização de material biológico para definição dos valores de referência para os analitos estudados.

\author{
Termo de consentimento livre e esclarecido \\ Diagnóstico Laboratorial das Síndromes de Deficiência de Creatina
}

$\mathrm{O}$ (A) Sr(a). ou seu dependente está sendo convidado(a) a participar de um estudo que tem o objetivo de investigar os níveis normais de creatina, creatinina e guanidinoacetato em sangue e/ou urina. Esse estudo determinará os valores sanguíneos e/ou urinários dessas substâncias encontrados em pacientes não portadores de uma das formas do grupo de doenças denominado "Síndrome de Deficiência de Creatina". Será utilizada uma pequena parte da(s) amostra(s) colhida(s) a pedido do médico que o atendeu. Consequentemente não haverá qualquer procedimento adicional decorrente desse estudo. Esse material seria de qualquer forma descartado após a realização dos seus exames. As informações obtidas pelo estudo do seu sangue e/ou urina serão analisadas em conjunto com as informações de outros voluntários participantes. Essa etapa da pesquisa terá duração máxima de 1 ano. Após esse período o restante da(s) sua(s) amostra(s) será(ao) descartada(s). Seus dados serão tratados de forma anônima e confidencial sendo que as únicas informações que serão utilizadas no estudo são: idade, sexo e as concentrações obtidas pelas dosagens de creatina, creatinina e guanidinoacetato. A participação é voluntária e não implica em quaisquer vantagens. Da mesma forma, sua recusa em participar não trará qualquer prejuízo ao seu atendimento nesta instituição.

Caso decida não mais participar da pesquisa será garantida sua liberdade de retirada deste Termo de Consentimento a qualquer momento, sem que isso traga qualquer prejuízo à continuidade do seu tratamento. Durante qualquer etapa do estudo, você terá acesso aos profissionais responsáveis pela pesquisa para esclarecimentos de eventuais dúvidas sobre ela. O médico responsável pelo estudo é o $\mathrm{Dr}$. Fernando Kok que pode ser encontrado na Avenida General Valdomiro de Lima, 508, São Paulo, SP; fone (11) 5014-7636; e-mail mfmadeira@hu.usp.br. E a pesquisadora responsável nesta instituição é a farmacêutica bioquímica Marlene de Freitas Madeira (3091-9297). Se você tiver alguma consideração ou dúvida sobre os aspectos éticos do estudo poderá entrar em contato com o Comitê de Ética em Pesquisa do Hospital Universitário da Universidade de São Paulo situado na Avenida Professor Lineu Prestes, 2565, São Paulo, SP; fone (11) 3091-9457; e-mail: cep@hu.usp.br.

$\mathrm{Eu}$, (nome do sujeito de pesquisa ou responsável legal e nesse caso qual grau de parentesco, tutor, curador, etc.), portador do documento de identidade de $\mathrm{n}^{\circ} \_$do sexo _ data de nascimento ,residente a e telefone (

declaro que "Declaro que, após convenientemente esclarecido pelo pesquisador e ter entendido o que me foi explicado, consinto em participar do presente Projeto de Pesquisa.

São Paulo, de de

Assinatura do(a) paciente ou responsável (caso o paciente seja menor que 18 anos) 
Anexo E. Modelo de Termo de consentimento livre esclarecido para coleta de material biológico de pacientes com clínica compatível com SDC.

\section{Termo de consentimento livre e esclarecido}

Um dependente seu está sendo convidado(a) a participar do projeto de pesquisa denominado "Diagnóstico Laboratorial das Síndromes de Deficiência de Creatina”. Esse estudo pretende diagnosticar a falta da creatina, uma substância que serve como reserva de energia para o organismo. Quando ela está baixa, podem ocorrer diversos problemas, como retardo mental, dificuldade na movimentação, convulsões e problemas de comportamento. O diagnóstico da deficiência de creatina pode ser feito por meio da dosagem de certas substâncias na urina e no sangue.

Para participar deste estudo, será necessário colher uma amostra de $10 \mathrm{~mL}$ de urina e de $5 \mathrm{~mL}$ de sangue (o que equivale ao volume de uma colher de sobremesa). A coleta de urina será feita por meio da aplicação de um saco coletor apropriado ou diretamente no frasco. A coleta de sangue é feita por punção de uma veia do antebraço com agulha estéril e descartável, o que pode causar algum desconforto e levar ao aparecimento de mancha roxa no local da coleta.

O resultado do exame, mesmo quando normal, the será comunicado. Caso seja diagnosticada deficiência de creatina, poderão ser indicados outros exames para caracterizar melhor a condição e para orientar o tratamento. Serão também tomadas providências para que o tratamento seja feito de forma apropriada e o mais rápido possível. Os medicamentos para tratar a deficiência de creatina estão disponíveis no Brasil e são de fácil acesso.

Caso você prefira não participar dessa investigação, não haverá qualquer tipo de limitação ao seu tratamento ou ao atendimento que vem recebendo atualmente. Esse estudo foi aprovado pela comissão de ética do Hospital das Clínicas da FMUSP.

Nome do participante no estudo:

Nome do responsável pelo participante:

Local e data:

Assinatura do responsável:

Responsáveis pela pesquisa: Dr. Fernando Kok

Marlene de Freitas Madeira 
Anexo F. Dados clínicos dos pacientes participantes do projeto:

\section{Paciente 1}

Sexo: Masculino

Procedência: Hospital das Clínicas FMUSP SP

Data de nascimento: 31/07/2004

Data de coleta: 23/05/2007

Idade na data da coleta: 2 anos e 10 meses

Quadro clínico: Atraso no desenvolvimento neuromotor de etiologia indeterminada. Informações familiais: filho de primos em $1^{\circ} \mathrm{grau}$

Exames complementares realizados:

- Cariótipo: normal

- Audiometria: Normal

- Ressonância magnética: Normal

Observações: Avaliado no HC e encaminhado para médico externo.

\section{Paciente 2}

Sexo: Feminino

Procedência: Encaminhamento pela mãe (residentes em Araraquara)

Data de nascimento:

Data de coleta: 16/07/2007

Idade na data da coleta: 6 anos

Quadro clínico: Creatinina baixa, atraso do desenvolvimento.

Informações familiais: Sem informações.

\section{Paciente 3}

Sexo: Masculino

Procedência: Hospital das Clínicas FMUSP SP

Data de nascimento: 20/05/1997

Data de coleta: 25/07/2007

Idade na data da coleta: 10 anos e 2 meses

Quadro clínico: Atraso no desenvolvimento neuropsicomotor, microcefalia e diatonia de membros inferiores

Informações familiais: filho de primos em $1^{\circ} \mathrm{grau}$

Exames complementares realizados: 
- Ressonância magnética de crânio: moderada dilatação do sistema ventricular suprateutorial, leve alargamento das cisternas basais e sulcos corticais. Cistos aracnóides em região temporal bilateral. Má rotação dos hipocampos mais evidente à direita.

\section{Paciente 4}

Sexo: Masculino

Procedência: Hospital das Clínicas FMUSP SP

Data de nascimento: 10/03/1996

Data de coleta: 25/07/2007

Idade na data da coleta: 11 anos e 4 meses

Quadro clínico: Atraso no desenvolvimento neuromotor precoce que evoluiu com deficiência mental e síndrome extra piramidal (distonia apendicular, careteamento facial e coreoatetose)

Informações familiais: sem consangüinidade parental.

Exames complementares realizados:

- Ressonância magnética de encéfalo: Normal

\section{Paciente 5}

Sexo: Feminino

Procedência: Hospital das Clínicas FMUSP SP

Data de nascimento: 28/11/1995

Data de coleta: 19/12/2007

Idade na data da coleta: 12 anos

Quadro clínico: Retardo mental de provável herança autossômica recessiva.

Informações familiais: Pais primos em $2^{\circ}$ grau.

Exames complementares realizados:

- Tomografia de crânio: Normal

\section{Paciente 6}

Sexo: Feminino

Procedência: Hospital das Clínicas FMUSP SP

Data de nascimento: 29/07/1999

Data de coleta: 13/02/2008

Idade na data da coleta: 8 anos e 7 meses 
Quadro clínico: Hipotonia, coreoatetose, retardo mental. Sem crises epilépticas.

Informações familiais: Pais primos em $1^{\circ}$ grau. Avô paterno espanhol. Tronco comum brasileiro.

Exames complementares realizados:

- Ressonância de crânio: Normal

\section{Paciente 7}

Sexo: Masculino

Procedência: Hospital das Clínicas FMUSP SP

Data de nascimento: 03/04/2001

Data de coleta: 05/03/2008

Idade na data da coleta: 6 anos e 11 meses

Quadro clínico: Retardo mental e epilepsia de difícil controle

Informações familiais: Filho único de pais primos em $3^{\circ} \mathrm{grau}$.

Exames complementares realizados:

- Eletroencefalograma: paroxismos de ritmo rápido com projeção generalizada concomitante com crise axial. Paroxismos de espículas, AO e OS multifocal. Investigação para Síndrome de Angelman negativa.

- Ressonância magnética: discreto hipersinal T2 e região periventricular.

\section{Paciente 8}

Sexo: Masculino

Procedência: Genoma

Data de nascimento: 06/04/2001

Data de coleta: 10/06/2008

Idade na data da coleta: 7 anos e 2 meses

Quadro clínico: Espectro autista de comportamento com desempenho superior. Alterações percebidas no primeiro ano de vida.

Informações familiais: $3^{\circ}$ filho de pais não consangüíneos.

Exames complementares realizados:

- Tomografia: Normal.

- EEG: Normal

\section{Paciente 9}

Sexo: Masculino 
Procedência: Hospital das Clínicas de Ribeirão Preto

Data de nascimento: 29/06/1994

Data de coleta: $05 / 08 / 2008$

Idade na data da coleta: 14 anos e 1 mês

Quadro clínico: Suspeita de defeito de transportador de creatina

Informações familiais: $2^{\circ}$ filho de pais não consangüíneos.

Exames complementares realizados: Sem informações

\section{Paciente 10}

Sexo: Masculino

Procedência: Hospital das Clínicas de Ribeirão Preto

Data de nascimento: $23 / 11 / 1993$

Data de coleta: 11/09/2008

Idade na data da coleta: 14 anos e 10 meses

Quadro clínico: Retardo do desenvolvimento neuromotor ligado ao X com alteração comportamental e epilepsia.

Informações familiais: $1^{\circ}$ filho de pais não consangüíneos. Tio por parte de mãe apresentando atraso no desenvolvimento da fala. Mãe portadora certa (tem outros filhos dessa e de outra união afetados). Irmão por parte de pai e mãe do paciente 11 e por parte de mãe do paciente 12.

\section{Exames complementares realizados:}

- Tomografia de crânio: Normal.

- Teste molecular para X frágil e FRAXE: Normal

\section{Paciente 11}

Sexo: Masculino

Procedência: Hospital das Clínicas de Ribeirão Preto

Data de nascimento: $23 / 11 / 1998$

Data de coleta: 11/09/2008

Idade na data da coleta: 9 anos e 10 meses

Quadro clínico: Retardo do desenvolvimento neuromotor ligado ao $X$ com alteração comportamental e epilepsia.

Informações familiais: $2^{\circ}$ filho de pais não consangüíneos. Tio por parte de mãe apresentando atraso no desenvolvimento da fala. Mãe portadora certa (tem outros filhos dessa e de outra união afetados). Irmão por parte de pai e mãe do paciente 
10 e por parte de mãe do paciente 12.

\section{Exames complementares realizados:}

- Tomografia de crânio: Normal.

- Teste molecular para X frágil e FRAXE: Normal

\section{Paciente 12}

Sexo: Masculino

Procedência: Hospital das Clínicas de Ribeirão Preto

Data de nascimento: $23 / 11 / 1992$

Data de coleta: 11/09/2008

Idade na data da coleta: 15 anos e 10 meses

Quadro clínico: Retardo do desenvolvimento neuromotor ligado ao $X$ com alteração comportamental e epilepsia.

Informações familiais: Sem informação sobre consangüinidade. Tio por parte de mãe apresentando atraso no desenvolvimento da fala. Mãe portadora certa (tem outros filhos dessa e de outra união afetados). Irmão por parte de mãe dos pacientes 10 e 11 .

Exames complementares realizados: Sem informações.

\section{Paciente 13}

Sexo: Masculino

Procedência: Hospital das Clínicas de Ribeirão Preto

Data de nascimento: 16/11/1994

Data de coleta: 11/09/2008

Idade na data da coleta: 13 anos e 10 meses

Quadro clínico: Deficiência mental ligada ao X com alteração comportamental.

Informações familiais: Sem informação sobre consangüinidade parental. Dois primos em $2^{\circ}$ grau por parte da mãe são portadores de deficiência mental e epilepsia. Irmão do paciente 14. Dois de seus irmãos estudaram na APAE.

Exames complementares realizados:

- Teste molecular para X frágil e FRAXE: Normal

\section{Observações:}

No heredograma, mãe, avó e irmã da avó são apontadas como portadoras certas. 


\section{Paciente 14}

Sexo: Masculino

Procedência: Hospital das Clínicas de Ribeirão Preto

Data de nascimento: 16/11/1994

Data de coleta: 11/09/2008

Idade na data da coleta: 13 anos e 10 meses

Quadro clínico: Deficiência mental ligada ao X com alteração comportamental.

Informações familiais: Sem informação sobre consangüinidade parental. Dois primos em $2^{\circ}$ grau por parte da mãe são portadores de deficiência mental e epilepsia. Irmão do paciente 13. Dois de seus irmãos estudaram na APAE.

\section{Exames complementares realizados:}

- Teste molecular para X frágil e FRAXE: Normal

\section{Observações:}

No heredograma, mãe, avó e irmã da avó são apontadas como portadoras certas.

\section{Paciente 15}

Sexo: Masculino

Procedência: Hospital das Clínicas de Ribeirão Preto

Data de nascimento: 12/11/1989

Data de coleta: 11/09/2008

Idade na data da coleta: 19 anos e 10 meses

Quadro clínico: Retardo do desenvolvimento neuropsicomotor associado a epilepsia e a alterações comportamentais.

Informações familiais: Sem consangüinidade parental. Filho de $2^{\underline{a}}$ união da mãe que apresenta leve atraso cognitivo, distúrbios psiquiátricos com alterações comportamentais e epilepsia.

\section{Exames complementares realizados:}

- Teste molecular para $X$ frágil: Normal

\section{Paciente 16}

Sexo: Masculino

Procedência: Hospital das Clínicas de Ribeirão Preto

Data de nascimento: 02/06/2006

Data de coleta: 11/09/2008

Idade na data da coleta: 2 anos e 3 meses 
Quadro clínico: Deficiência mental associada a distúrbios da fala e crises convulsivas.

Informações familiais: Sem consangüinidade parental. Tios maternos apresentam MPS tipo II mas mãe não é portadora da mutação dessa doença.

\section{Exames complementares realizados:}

- Cariótipo: Normal

- Teste molecular para X frágil e FRAXE: Normal

- Cromatografia de aminoácidos (HPLC): Normal

- GAGS: Normal

- Screening para MPS: Normal

\section{Paciente 17}

Sexo: Masculino

Procedência: Hospital das Clínicas de Ribeirão Preto

Data de nascimento: 14/07/2000

Data de coleta: 11/09/2008

Idade na data da coleta: 8 anos e 1 mês

Quadro clínico: Deficiência mental associada a distúrbio comportamental e epilepsia.

Informações familiais: Sem consangüinidade parental. Irmão apresentando epilepsia e deficiência mental.

\section{Exames complementares realizados:}

- Cariótipo: Normal

- Teste molecular para $X$ frágil: Normal

\section{Paciente 18}

Sexo: Masculino

Procedência: Hospital das Clínicas de Ribeirão Preto

Data de nascimento: 25/06/2006

Data de coleta: 11/09/2008

Idade na data da coleta: 2 anos e 2 meses

Quadro clínico: Deficiência mental ligada ao X com alteração comportamental.

Informações familiais: Sem consangüinidade parental. Irmão representado no heredograma como afetado sem descrição do quadro. Mãe e tia por parte de mãe assinaladas como heterozigotas. 


\section{Exames complementares realizados:}

- Cariótipo: Normal

- Teste molecular para $X$ frágil: Normal

\section{Paciente 19}

Sexo: Masculino

Procedência: Hospital das Clínicas de Ribeirão Preto

Data de nascimento: 11/06/1998

Data de coleta: 11/09/2008

Idade na data da coleta: 10 anos e 3 meses

Quadro clínico: Deficiência mental com atraso marcante do desenvolvimento da fala.

Informações familiais: Sem consangüinidade parental. Irmão representado no heredograma como afetado sem descrição do quadro. Mãe e tia por parte de mãe assinaladas como heterozigotas.

Exames complementares realizados:

- Cariótipo: Normal

- Teste molecular para X frágil: Normal

\section{Paciente 20}

Sexo: Masculino

Procedência: Hospital das Clínicas de Ribeirão Preto

Data de nascimento: 16/02/1991

Data de coleta: 11/09/2008

Idade na data da coleta: 17 anos e 7 meses

Quadro clínico: Deficiência mental ligada ao X com alteração comportamental.

Informações familiais: Sem consangüinidade parental. Irmã e primo por parte de mãe também afetados (mãe e tia assinaladas como portadoras certas).

\section{Exames complementares realizados:}

- Cariótipo: Normal

- Teste molecular para X frágil: Normal

\section{Paciente 21}

Sexo: Masculino

Procedência: Hospital das Clínicas de Ribeirão Preto 


\section{Data de nascimento: ?}

Data de coleta: 11/09/2008

Idade na data da coleta:

Quadro clínico: Deficiência mental ligada ao X com alteração comportamental e epilepsia.

Informações familiais: Sem consangüinidade parental. Mãe, tia por parte de mãe e irmãs de outra união materna apresentam alterações psiquiátricas e déficit de aprendizado.

Exames complementares realizados:

- Cariótipo: Normal

- Teste molecular para X frágil: Normal

\section{Paciente 22}

Sexo: Masculino

Procedência: Hospital das Clínicas de Ribeirão Preto

Data de nascimento: 08/05/1996

Data de coleta: 11/09/2008

Idade na data da coleta: 12 anos e 4 meses

Quadro clínico: Deficiência mental possivelmente ligada ao X e epilepsia.

Informações familiais: Sem consangüinidade parental. Irmão gêmeo do paciente 23. Possui outro irmão e um primo por parte de mãe também afetados.

\section{Exames complementares realizados:}

- Cariótipo: Normal

- Teste molecular para X frágil: Normal

\section{Paciente 23}

Sexo: Masculino

Procedência: Hospital das Clínicas de Ribeirão Preto

Data de nascimento: 08/05/1996

Data de coleta: 11/09/2008

Idade na data da coleta: 12 anos e 4 meses

Quadro clínico: Deficiência mental possivelmente ligada ao X, alterações comportamentais e epilepsia.

Informações familiais: Sem consangüinidade parental. Irmão gêmeo do paciente 22. Possui outro irmão e um primo por parte de mãe também afetados. 


\section{Exames complementares realizados:}

- Cariótipo: Normal

- Teste molecular para $X$ frágil: Normal

\section{Paciente 24}

Sexo: Masculino

Procedência: Hospital das Clínicas de Ribeirão Preto

Data de nascimento: 26/03/1997

Data de coleta: 11/09/2008

Idade na data da coleta: 12 anos e 4 meses

Quadro clínico: Deficiência mental e alteração comportamental.

Informações familiais: Sem consangüinidade parental.

Exames complementares realizados:

- Cariótipo: Normal

- Teste molecular para $X$ frágil: Normal

\section{Paciente 25}

Sexo: Masculino

Procedência: Hospital das Clínicas de Ribeirão Preto

Data de nascimento: $14 / 07 / 1993$

Data de coleta: 11/09/2008

Idade na data da coleta: 15 anos e 1 mês

Quadro clínico: Deficiência mental associada a atraso marcante do desenvolvimento da fala e alteração comporetamental.

Informações familiais: Sem consangüinidade parental.

Exames complementares realizados:

- Cariótipo: Normal

- Teste molecular para $X$ frágil: Normal

\section{Paciente 26}

Sexo: Masculino

Procedência: Hospital das Clínicas da FMUSP

Data de nascimento: 05/04/2004

Data de coleta: 17/12/2008

Idade na data da coleta: 4 anos e 8 meses 
Quadro clínico: Atraso no desenvolvimento neuropsicomotor, movimentos involuntários e epilepsia.

Informações familiais: Sem consangüinidade parental. Pais oriundos de lugares diferentes.

Exames complementares realizados:

- Ressonância magnética: Atrofia cerebral

- EEG: Normal

Paciente 27

Sexo: Feminino

Procedência: Hospital das Clínicas da FMUSP

Data de nascimento: 11/06/1999

Data de coleta: 13/02/2009

Idade na data da coleta: 9 anos e 8 meses

Quadro clínico:

Informações familiais: Sem informações.

Exames complementares realizados: Sem informações.

\section{Paciente 28}

Sexo: Masculino

Procedência: Hospital das Clínicas da FMUSP

Data de nascimento: 05/11/2002

Data de coleta: 08/04/2009

Idade na data da coleta: 6 anos e 5 meses

Quadro clínico: Involução do desenvolvimento neuropsicomotor a partir do $6^{\circ}$ mês (síndrome cognitiva). Síndrome extrapiramidal.

Informações familiais: Sem consangüinidade parental. Irmão de outro relacionamento materno também afetado.

Exames complementares realizados: Sem informações.

\section{Paciente 29}

Sexo: Masculino

Procedência: APAE Limeira

Data de nascimento: ?

Data de coleta: 28/05/2009 
Idade na data da coleta:

Quadro clínico: Deficiência mental com importante atraso de fala e alterações comportamentais.

Informações familiais: Sem consangüinidade parental.

\section{Exames complementares realizados:}

- Cariótipo: Normal

- Teste molecular para FRAXA/FRAXE: Normal

- Tomografia de crânio: normal

- RNM de encéfalo: Normal

\section{Paciente 30}

Sexo: Masculino

Procedência: Hospital das Clínicas de Ribeirão Preto

Data de nascimento: 15/03/1990

Data de coleta: 28/05/2009

Idade na data da coleta: 19 anos e 2 meses

Quadro clínico: Deficiência mental grave ligada ao $X$ associada a epilepsia e distúrbios de comportamento.

Informações familiais: Sem consangüinidade parental. Primo por parte de mãe (filho de tia) afetado sugerindo serem portadoras certas (mãe e tia).

\section{Exames complementares realizados:}

- Cariótipo: Normal

- Teste molecular para FRAXA/FRAXE: Normal

- Tomografia de crânio: atrofia cortical

\section{Paciente 31}

Sexo: Masculino

Procedência: HCRP

Data de nascimento: 17/02/1994

Data de coleta: 28/05/2009

Idade na data da coleta: 15 a e 3 meses

Quadro clínico: Deficiência mental possivelmente ligada ao $\mathrm{X}$ associada a alterações comportamentais.

Informações familiais: Sem consangüinidade parental. Tias e prima por parte da mãe apresentaram dificuldades escolares assim como sua irmã. 


\section{Exames complementares realizados:}

- Cariótipo: Normal

- Teste molecular para X-frágil: Normal

\section{Paciente 32}

Sexo: Masculino

Procedência: APAE Limeira

Data de nascimento: 12/04/1969

Data de coleta: 28/05/2009

Idade na data da coleta: 40 anos e 1 mês

Quadro clínico: Deficiência mental moderada com graves alterações comportamentais e atraso de fala.

Informações familiais: Sem consangüinidade parental. Não há história de DM na família mas tem casos de alcoolismo, doença psiquiátrica (avó materna), natimortalidade.

\section{Exames complementares realizados:}

- Cariótipo: Normal

- Teste molecular para FRAXA/FRAXE: Normal

- Tomografia de crânio: normal

- RNM de encéfalo: Normal

\section{Paciente 33}

Sexo: Masculino

Procedência: APAE Limeira

Data de nascimento: 19/07/2004

Data de coleta: 28/05/2009

Idade na data da coleta: 4 anos e 10 meses

Quadro clínico: Deficiência mental ligada ao X com alteração comportamental e importante atraso de fala.

Informações familiais: Sem consangüinidade parental. Avó apresenta distúrbios psiquiátricos e irmão dificuldade escolar.

\section{Exames complementares realizados:}

- Cariótipo: Normal

- Teste molecular para FRAXA/FRAXE: Normal

- Tomografia de crânio: normal 


\section{Paciente 34}

Sexo: Feminino

Procedência: APAE Limeira

Data de nascimento: $18 / 05 / 2000$

Data de coleta: 28/05/2009

Idade na data da coleta: 9 anos

Quadro clínico: Deficiência mental associada a distúrbio comportamental.

Informações familiais: Sem consangüinidade parental. Irmão estudou algum tempo na APAE, tem hipertireoidismo, gagueja um pouco, é medroso.

Exames complementares realizados:

- Cariótipo: Normal

- Tomografia de crânio: normal

- Triagem para EIM na urina: Normal

\section{Paciente 35}

Sexo: Feminino

Procedência: APAE Limeira

Data de nascimento: 20/02/1990

Data de coleta: 28/05/2009

Idade na data da coleta: 19 anos e 3 anos.

Quadro clínico: Deficiência mental associada a epilepsia.

Informações familiais: Sem consangüinidade parental. História familial de prematuridade e depressão.

\section{Exames complementares realizados:}

- Cariótipo: Normal

- Tomografia de crânio: normal

- Triagem para EIM na urina: Normal

\section{Paciente 36}

Sexo: Masculino

Procedência: APAE Limeira

Data de nascimento: 03/10/2001

Data de coleta: 28/05/2009

Idade na data da coleta: 7 anos e 7 meses

Quadro clínico: Deficiência mental com distúrbio de fala importante. 
Informações familiais: Sem consangüinidade parental.

Exames complementares realizados:

- Cariótipo: Normal

- Teste molecular para FRAXA/FRAXE: Normal

- Tomografia de crânio: normal

\section{Paciente 37}

Sexo: Masculino

Procedência: APAE Limeira

Data de nascimento: $16 / 12 / 1994$

Data de coleta: 28/05/2009

Idade na data da coleta: 14 anos e 5 meses

Quadro clínico: Deficiência mental moderada com importante atraso de fala e alterações comportamentais.

Informações familiais: Sem consangüinidade parental. Irmão está em avaliação na APAE

\section{Exames complementares realizados:}

- Cariótipo: Normal

- Teste molecular para FRAXA/FRAXE: Normal

- Tomografia de crânio: normal

- RNM de encéfalo: Normal

\section{Paciente 38}

Sexo: Feminino

Procedência: APAE Limeira

Data de nascimento: 27/11/1992

Data de coleta: 28/05/2009

Idade na data da coleta: 9 anos

Quadro clínico: Deficiência mental associada a epilepsia

Informações familiais: Sem consangüinidade parental.

\section{Exames complementares realizados:}

- Cariótipo: Normal

- Tomografia de crânio: normal

- Triagem para EIM na urina: Normal 


\section{Paciente 39}

Sexo: Feminino

Procedência: APAE Limeira

Data de nascimento: 16/12/1991

Data de coleta: 28/05/2009

Idade na data da coleta: 17 anos e 5 meses

Quadro clínico: Deficiência mental ligada ao X. Apresenta características autísticas e crises convulsivas.

Informações familiais: Sem consangüinidade parental. Irmã apresenta deficiência mental leve e alterações psiquiátricas.

\section{Exames complementares realizados:}

- Cariótipo: Normal

- Teste molecular para FRAXA/FRAXE: Normal

- Tomografia de crânio: normal

\section{Paciente 40}

Sexo: Feminino

Procedência: APAE Limeira

Data de nascimento: 17/06/2002

Data de coleta: 28/05/2009

Idade na data da coleta: 7 anos e 11 meses

Quadro clínico: Deficiência mental associada a epilepsia e distúrbio comportamental.

Informações familiais: Sem consangüinidade parental.

\section{Exames complementares realizados:}

- Cariótipo: Normal

- Tomografia de crânio: normal

- Triagem para EIM na urina: Normal

\section{Paciente 41}

Sexo: Masculino

Procedência: APAE Limeira

Data de nascimento: 17/08/1971

Data de coleta: 28/05/2009

Idade na data da coleta: 37 anos e 9 meses 
Quadro clínico: Deficiência mental moderada associada importante atraso de fala e alterações comportamentais.

Informações familiais: Sem consangüinidade parental. Teve irmã que nasceu com hidrocefalia (falecida aos 42 dias).

\section{Exames complementares realizados:}

- Cariótipo: Normal

- Teste molecular para FRAXA/FRAXE: Normal

- Tomografia de crânio: normal

- RNM de encéfalo: Normal

\section{Paciente 42}

Sexo: Masculino

Procedência: APAE Limeira

Data de nascimento: 17/12/1999

Data de coleta: 28/05/2009

Idade na data da coleta: 19 anos e 5 meses

Quadro clínico: Deficiência mental com crises convulsivas e importante atraso de fala.

Informações familiais: Sem consangüinidade parental. Pai apresenta surdez condutiva. Tem irmã com retardo do desenvolvimento neuropsicomotor (não anda).

\section{Exames complementares realizados:}

- Cariótipo: Normal

- Teste molecular para FRAXA/FRAXE: Normal

- Tomografia de crânio: normal

\section{Paciente 43}

Sexo: Masculino

Procedência: Hospital de Clínicas de Porto Alegre

Data de nascimento: ?

Data de coleta: 08/2009

Idade na data da coleta: Sem informação

Quadro clínico: Atraso no desenvolvimento neuromotor e distonia de face, pescoço e tronco.

Informações familiais: Sem informação

Exames complementares realizados: 
- Espectroscopia por ressonância magnética com creatina baixa.

\section{Paciente 44}

Sexo: Masculino

Procedência: Genoma

Data de nascimento: 29/01/2003

Data de coleta: 29/09/2009

Idade na data da coleta: 6 anos e 8 meses

Quadro clínico: Atraso no desenvolvimento neuromotor e da fala. Retardo mental moderado, leve atetose e epilepsia.

Informações familiais: Pais primos em $1^{\circ}$ grau (ambos procedentes de Fortaleza).

\section{Exames complementares realizados:}

- EIM: Normal

- RNM sem espectroscopia: Normal

\section{Paciente 45}

Sexo: Masculino

Procedência: Hospital de Clínicas de Porto Alegre

Data de nascimento: 07/11/2003

Data de coleta: 30/09/2009

Idade na data da coleta: 5 anos e 10 meses

Quadro clínico: Distonia iniciada aos 4 meses de vida com regressão neurológica associada. Síndrome extrapiramidal (distonia) e piramidal.

Informações familiais: Pais não consangüíneos.

\section{Exames complementares realizados:}

- RNM: Hipersinal em globo pálido

- Excluídas doenças metabólicas que cursam com distonia (GM1, GM2, Krabbe, alterações das rotas das purinas, acidúrias orgânicas e deficiência de BH4, mutação de DYT1, teste terapêutico para DYT5 - LDOPA e doença de Wilson.

\section{Paciente 46}

Sexo: Masculino

Procedência: APAE Limeira

Data de nascimento: 25/02/1999 
Data de coleta: 07/10/2009

Idade na data da coleta: 10 anos e 7 meses

Quadro clínico: Deficiência mental ligada ao X com moderado atraso de fala.

Informações familiais: Sem consangüinidade parental.

Exames complementares realizados:

- Cariótipo: Normal

- Teste molecular para FRAXA/FRAXE: Normal

- Tomografia de crânio: normal

\section{Paciente 47}

Sexo: Feminino

Procedência: APAE Limeira

Data de nascimento: 10/04/1989

Data de coleta: 07/10/2009

Idade na data da coleta: 20 anos e 5 meses

Quadro clínico: Deficiência mental associada a alteração comportamental. Informações familiais: Pais consangüíneos (primos em $1^{\circ} \mathrm{grau}$ ). Tem primos que apresentaram déficit de aprendizado.

Exames complementares realizados:

- Cariótipo: Normal

- Tomografia de crânio: normal

- Triagem de EIM: Normal

\section{Paciente 48}

Sexo: Masculino

Procedência: APAE Limeira

Data de nascimento: 14/07/1993

Data de coleta: 07/10/2009

Idade na data da coleta: 15 anos e 9 meses

Quadro clínico: Deficiência mental associada a alteração comportamental. Informações familiais: Pais não consangüíneos. Primo por parte de mãe portador de Síndrome de Down.

Exames complementares realizados:

- Cariótipo: Normal

- Teste molecular para FRAXA/FRAXE: Normal 
- Tomografia de crânio: normal

- Triagem de EIM: Normal

\section{Paciente 49}

Sexo: Masculino

Procedência: APAE Limeira

Data de nascimento: 12/08/1995

Data de coleta: 07/10/2009

Idade na data da coleta: 14 anos e 1 mês

Quadro clínico: Deficiência mental ligada ao X com importante atraso de fala.

Informações familiais: Pais não consangüíneos. Histórico familial de esquizofrenia.

\section{Exames complementares realizados:}

- Cariótipo: Normal

- Teste molecular para FRAXA/FRAXE: Normal

- Tomografia de crânio: normal

\section{Paciente 50}

Sexo: Feminino

Procedência: APAE Limeira

Data de nascimento: 29/12/2003

Data de coleta: 07/10/2009

Idade na data da coleta: 6 anos e 2 meses

Quadro clínico: Deficiência mental associada a epilepsia e alteração comportamental.

Informações familiais: Pais não consangüíneos.

Exames complementares realizados:

- Cariótipo: Normal

- Teste molecular para FRAXA/FRAXE: Normal

- Triagem de EIM: Normal

\section{Paciente 51}

Sexo: Masculino

Procedência: APAE Limeira

Data de nascimento: 13/04/2004 
Data de coleta: 07/10/2009

Idade na data da coleta: 5 anos e 5 meses

Quadro clínico: Deficiência mental ligada ao X com atraso de fala importante.

Informações familiais: Pais não consangüíneos. Irmã afetada

Exames complementares realizados:

- Cariótipo: Normal

- Teste molecular para FRAXA/FRAXE: Normal

- Tomografia de crânio: normal

Paciente 52

Sexo: Masculino

Procedência: APAE Limeira

Data de nascimento: 09/09/1992

Data de coleta: 07/10/2009

Idade na data da coleta: 17 anos

Quadro clínico: Deficiência mental com atraso grave de fala.

Informações familiais: Pais primos em $2^{\circ}$ grau.

Exames complementares realizados:

- Cariótipo: Normal

- Teste molecular para FRAXA/FRAXE: Normal

- Tomografia de crânio: normal

- Triagem para EIM: Normal

\section{Paciente 53}

Sexo: Masculino

Procedência: APAE Limeira

Data de nascimento: 28/01/1993

Data de coleta: 07/10/2009

Idade na data da coleta: 16 anos e 9 meses

Quadro clínico: Deficiência mental ligada ao $X$ com atraso de fala e crises convulsivas.

Informações familiais: Pais não consangüíneos. Mãe com alterações psiquiátricas. Irmão hiperativo.

Exames complementares realizados:

- Cariótipo: Normal 
- Teste molecular para FRAXA/FRAXE: Normal

- Tomografia de crânio: normal

\section{Paciente 54}

Sexo: Masculino

Procedência: APAE Limeira

Data de nascimento: 10/01/2004

Data de coleta: 07/10/2009

Idade na data da coleta: 5 anos e 9 meses

Quadro clínico: Deficiência mental com distúrbio comportamental, atraso da fala e características autísticas.

Informações familiais: Sem informações.

Exames complementares realizados:

- Cariótipo: Normal

- Teste molecular para FRAXA/FRAXE: Normal

- Tomografia de crânio: normal

- Triagem para EIM: Normal 


\section{REFERÊNCIAS}

1. Wallimann T. Bioenergetics. Dissecting the role of creatine kinase. Curr Biol. 1994;4:42-6.

2. Verhoeven NM, Salomons GS, Jakobs C. Laboratory diagnosis of defects of creatine biosynthesis and transport. Clin Chim Acta. 2005;361:1-9.

3. Wallimann $\mathrm{T}$, Hemmer W. Creatine kinase in non-muscle tissues and cells. Mol Cell Biochem. 1994;133-134:193-220.

4. Schulze A. Creatine deficiency syndromes. Mol Cell Biochem. 2003;244:143-50.

5. Braissant O, Henry H. AGAT, GAMT and SLC6A8 distribution in the central nervous system, in relation to creatine deficiency syndromes: A review. J Inherit Metab Dis. 2008;31:230-9.

6. Wang YE, Esbensen P, Bentley D. Arginine kinase expression and localization in growth cone migration. J Neurosci. 1998;18:987-98.

7. Braissant $O$, Cagnon L, Monnet-Tschudi $F$, Speer $O$, Wallimann $T$, Honegger $\mathrm{P}$, et al. Ammonium alters creatine transport and synthesis in a 3D culture of developing brain cells, resulting in secondary cerebral creatine deficiency. Eur J Neurosci. 2008;27:1673-85. 
8. Klein AM, Ferrante RJ. The neuroprotective role of creatine. Subcell Biochem. 2007;46:205-43.

9. Sullivan PG, Geiger JD, Mattson MP, Scheff SW. Dietary supplement creatine protects against traumatic brain injury. Ann Neurol. 2000;48:723-9.

10. Ferrante RJ, Andreassen OA, Jenkins BG, Dedeoglu A, Kuemmerle S, Kubilus JK, et al. Neuroprotective effects of creatine in a transgenic mouse model of Huntington's disease. J Neurosci. 2000;20:4389-97.

11. Stromberger C, Bodamer OA, Stockler-Ipsiroglu S. Clinical characteristics and diagnostic clues in inborn errors of creatine metabolism. $J$ Inherit Metab Dis. 2003;26:299-308.

12. Wyss M, Kaddurah-Daouk R. Creatine and creatinine metabolism. Physiol Rev. 2000;80:1107-213.

13. Hoberman HD, Sims EA, Peters JH. Creatine and creatinine metabolism in the normal male adult studied with the aid of isotopic nitrogen. J Biol Chem. 1948;172:45-58.

14. Salomons GS, van Dooren SJ, Verhoeven NM, Marsden D, Schwartz C, Cecil KM, et al. X-linked creatine transporter defect: an overview. J Inherit Metab Dis. 2003;26:309-18. 
15. Stockler S, Holzbach U, Hanefeld F, Marquardt I, Helms G, Requart $M$, et al. Creatine deficiency in the brain: a new, treatable inborn error of metabolism. Pediatr Res. 1994;36:409-13.

16. Salomons GS, van Dooren SJ, Verhoeven NM, Cecil KM, Ball WS, Degrauw TJ, et al. X-linked creatine-transporter gene (SLC6A8) defect: a new creatine-deficiency syndrome. Am J Hum Genet. 2001;68:1497-500.

17. Item CB, Stockler-Ipsiroglu S, Stromberger C, Muhl A, Alessandri MG, Bianchi MC, et al. Arginine:glycine amidinotransferase deficiency: the third inborn error of creatine metabolism in humans. Am $J$ Hum Genet. $2001 ; 69: 1127-33$.

18. Item CB, Mercimek-Mahmutoglu S, Battini R, Edlinger-Horvat C, Stromberger C, Bodamer O, et al. Characterization of seven novel mutations in seven patients with GAMT deficiency. Hum Mutat. 2004;23:524.

19. Clark AJ, Rosenberg EH, Almeida LS, Wood TC, Jakobs C, Stevenson RE, et al. X-linked creatine transporter (SLC6A8) mutations in about $1 \%$ of males with mental retardation of unknown etiology. Hum Genet. 2006;119:604-10.

20. Ensenauer R, Thiel T, Schwab KO, Tacke U, Stockler-Ipsiroglu S, Schulze A, et al. Guanidinoacetate methyltransferase deficiency: differences of creatine uptake in human brain and muscle. Mol Genet Metab. 
2004;82:208-13.

21. Neu A, Neuhoff $H$, Trube G, Fehr S, Ullrich $K$, Roeper J, et al. Activation of $\mathrm{GABA}(\mathrm{A})$ receptors by guanidinoacetate: a novel pathophysiological mechanism. Neurobiol Dis. 2002;11:298-307.

22. Cupello A, Balestrino M, Gatta E, Pellistri F, Siano S, Robello M. Activation of cerebellar granule cells $\operatorname{GABA}(A)$ receptors by guanidinoacetate. Neuroscience. 2008;152:65-9.

23. Stockler S, Isbrandt D, Hanefeld F, Schmidt B, von Figura K. Guanidinoacetate methyltransferase deficiency: the first inborn error of creatine metabolism in man. Am J Hum Genet. 1996;58:914-22.

24. deGrauw TJ, Cecil KM, Byars AW, Salomons GS, Ball WS, Jakobs C. The clinical syndrome of creatine transporter deficiency. Mol Cell Biochem. 2003;244:45-8.

25. Leuzzi V. Inborn errors of creatine metabolism and epilepsy: clinical features, diagnosis, and treatment. J Child Neurol. 2002;17 Suppl 3:3S89-97; discussion 3S.

26. Schulze A, Ebinger F, Rating D, Mayatepek E. Improving treatment of guanidinoacetate methyltransferase deficiency: reduction of guanidinoacetic acid in body fluids by arginine restriction and ornithine supplementation. $\mathrm{Mol}$ 
Genet Metab. 2001;74:413-9.

27. Schulze A, Mayatepek E, Bachert P, Marescau B, De Deyn PP, Rating

D. Therapeutic trial of arginine restriction in creatine deficiency syndrome. Eur J Pediatr. 1998;157:606-7.

28. Bianchi MC, Tosetti M, Battini R, Leuzzi V, Alessandri MG, Carducci $\mathrm{C}$, et al. Treatment monitoring of brain creatine deficiency syndromes: a $1 \mathrm{H}-$ and 31P-MR spectroscopy study. AJNR Am J Neuroradiol. 2007;28:548-54.

29. Rosenberg EH, Almeida LS, Kleefstra T, deGrauw RS, Yntema HG, Bahi $\mathrm{N}$, et al. High prevalence of SLC6A8 deficiency in X-linked mental retardation. Am J Hum Genet. 2004;75:97-105.

30. Lion-Francois L, Cheillan D, Pitelet G, Acquaviva-Bourdain C, Bussy $G$, Cotton $F$, et al. High frequency of creatine deficiency syndromes in patients with unexplained mental retardation. Neurology. 2006;67:1713-4.

31. Almeida LS, Vilarinho L, Darmin PS, Rosenberg EH, Martinez-Munoz C, Jakobs C, et al. A prevalent pathogenic GAMT mutation (c.59G>C) in Portugal. Mol Genet Metab. 2007;91:1-6.

32. Cheillan D, Salomons GS, Acquaviva C, Boisson C, Roth P, Cordier MP, et al. Prenatal diagnosis of guanidinoacetate methyltransferase deficiency: increased guanidinoacetate concentrations in amniotic fluid. Clin 
Chem. 2006;52:775-7.

33. Ilas J, Muhl A, Stockler-lpsiroglu S. Guanidinoacetate methyltransferase (GAMT) deficiency: non-invasive enzymatic diagnosis of a newly recognized inborn error of metabolism. Clin Chim Acta. 2000;290:17988.

34. Grazia Alessandri M, Celati L, Battini R, Baldinotti F, Item C, Leuzzi V, et al. HPLC assay for guanidinoacetate methyltransferase. Anal Biochem. 2004;331:189-91.

35. Verhoeven NM, Schor DS, Roos B, Battini R, Stockler-Ipsiroglu S, Salomons GS, et al. Diagnostic enzyme assay that uses stable-isotopelabeled substrates to detect L-arginine:glycine amidinotransferase deficiency. Clin Chem. 2003;49:803-5.

36. Schulze A, Mayatepek E, Rating D, Bremer HJ. Sakaguchi reaction: a useful method for screening guanidinoacetate-methyltransferase deficiency. J Inherit Metab Dis. 1996;19:706.

37. Hunneman DH, Hanefeld F. GC-MS determination of guanidinoacetate in urine and plasma. $J$ Inherit Metab Dis. 1997;20:450-2.

38. Struys EA, Jansen EE, ten Brink HJ, Verhoeven NM, van der Knaap MS, Jakobs C. An accurate stable isotope dilution gas chromatographic- 
mass spectrometric approach to the diagnosis of guanidinoacetate methyltransferase deficiency. J Pharm Biomed Anal. 1998;18:659-65.

39. Carducci C, Birarelli M, Santagata P, Leuzzi V, Carducci C, Antonozzi I. Automated high-performance liquid chromatographic method for the determination of guanidinoacetic acid in dried blood spots: a tool for early diagnosis of guanidinoacetate methyltransferase deficiency. $J$ Chromatogr $B$ Biomed Sci Appl. 2001;755:343-8.

40. Carducci C, Birarelli M, Leuzzi V, Carducci C, Battini R, Cioni G, et al. Guanidinoacetate and creatine plus creatinine assessment in physiologic fluids: an effective diagnostic tool for the biochemical diagnosis of arginine:glycine amidinotransferase and guanidinoacetate methyltransferase deficiencies. Clin Chem. 2002;48:1772-8.

41. Bodamer OA, Bloesch SM, Gregg AR, Stockler-Ipsiroglu S, O'Brien WE. Analysis of guanidinoacetate and creatine by isotope dilution electrospray tandem mass spectrometry. Clin Chim Acta. 2001;308:173-8.

42. Cognat S, Cheillan D, Piraud M, Roos B, Jakobs C, Vianey-Saban C. Determination of guanidinoacetate and creatine in urine and plasma by liquid chromatography-tandem mass spectrometry. Clin Chem. 2004;50:1459-61.

43. Carling RS, Hogg SL, Wood TC, Calvin J. Simultaneous determination of guanidinoacetate, creatine and creatinine in urine and plasma by un- 
derivatized liquid chromatography-tandem mass spectrometry. Ann Clin Biochem. 2008;45:575-84.

44. CLSI. Evaluation of the linearity of quantitative measurement procedures: a statistical approach; approved guideline. CLSI document EP6A. Wayne, PA: Clinical and Laboratory Standads Institute 2003.

45. CLSI. Evaluation of precison performance of quantitative measurement methods; approved guideline. CLSI document EP5-A2. 2nd ed. Wayne, PA: Clinical and Laboratory Standards Institute 2004.

46. CLSI. Protocols for determination of limits of detection and limits of quantitation; approved guideline. CLSI document EP17-A. Wayne, PA: Clinical and Laboratory Standards Institute 2004.

47. CLSI. Method comparison and bias estimation using patient samples; approved guideline. CLSI document EP9-A2. 2nd ed. Wayne, PA: Clinical and Laboratory Standards Institute 2002.

48. Rhoads DG. EP Evaluator. 4 ed. Kennett Square, PA: David G. Rhoads Associates, Inc. Consultants 2002.

49. Cardozo KH, Carvalho VM, Pinto E, Colepicolo P. Fragmentation of mycosporine-like amino acids by hydrogen/deuterium exchange and electrospray ionisation tandem mass spectrometry. Rapid Commun Mass 
Spectrom. 2006;20:253-8.

50. Alpert AJ. Hydrophilic-interaction chromatography for the separation of peptides, nucleic acids and other polar compounds. I Chromatogr. 1990;499:177-96.

51. Valongo C, Cardoso ML, Domingues P, Almeida L, Verhoeven N, Salomons G, et al. Age related reference values for urine creatine and guanidinoacetic acid concentration in children and adolescents by gas chromatography-mass spectrometry. Clin Chim Acta. 2004;348:155-61.

52. Arias A, Ormazabal A, Moreno J, Gonzalez B, Vilaseca MA, GarciaVilloria J, et al. Methods for the diagnosis of creatine deficiency syndromes: a comparative study. J Neurosci Methods. 2006;156:305-9.

53. Almeida LS, Verhoeven NM, Roos B, Valongo C, Cardoso ML, Vilarinho L, et al. Creatine and guanidinoacetate: diagnostic markers for inborn errors in creatine biosynthesis and transport. Mol Genet Metab. 2004;82:214-9.

54. Carducci C, Santagata S, Leuzzi V, Carducci C, Artiola C, Giovanniello T, et al. Quantitative determination of guanidinoacetate and creatine in dried blood spot by flow injection analysis-electrospray tandem mass spectrometry. Clin Chim Acta. 2006;364:180-7. 
55. Mayo. 2007 test catalog. Rochester: Mayo Medical Laboratories; 2007 p. 188 Creatine disorders panel, urine.

56. Jaffe M. Ueber den Niederschlag, welchen Pikrinsaure in normalem Harn erzeugt and ueber eine Reaction des Kreatinins. Zeitschrift Fuer Physiologische Chemie. 1886;10:391-400.

57. Bodamer OA, Hoffmann GF, Lindner M. Expanded newborn screening in Europe 2007. J Inherit Metab Dis. 2007;30:439-44. 